


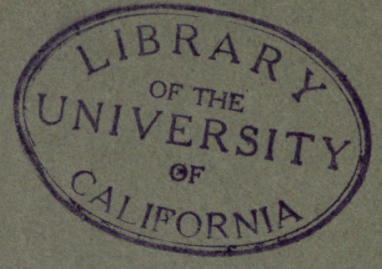




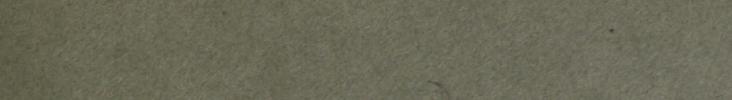

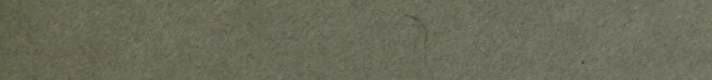

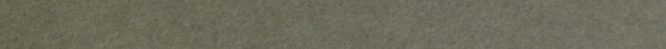

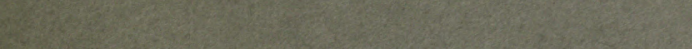
Wry \begin{tabular}{l}
45 \\
\hline
\end{tabular}

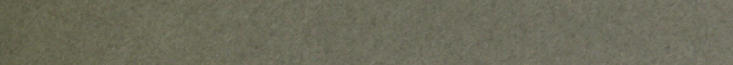

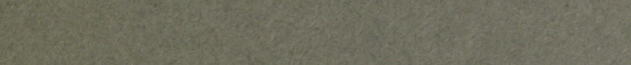

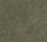

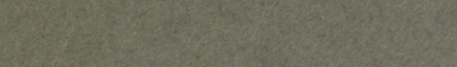

Pastion

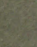

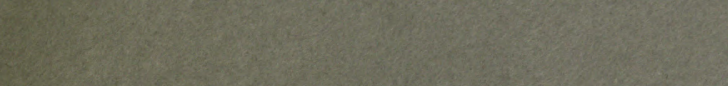
E.

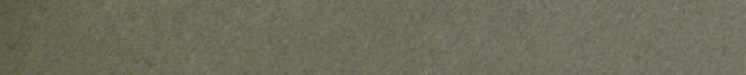

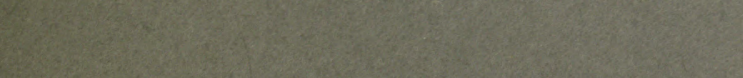
10.0 (3)

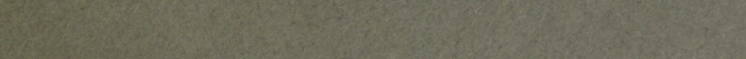

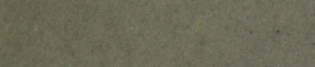

inge

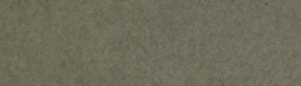
exiog 





\section{CONTENTS.}

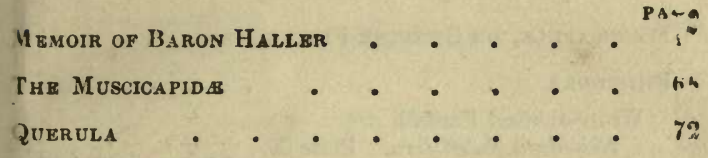

Red-Throated Piha.

Querula rubricollis. Plate I. . . . . it

LATHRIA

Grey Piha.

Lathria cinerea. Plate II. . . . . 78

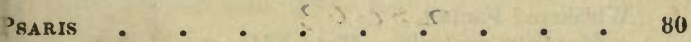

Rufous-eared Black-cap.

Psaris erythroyenys. Plate III. ․ . 83

PACHYRHYNCHUS • • • • • • 84

Cuvier's Thick-bill.

Puchyrhynchus Cuvierii. Plate IV. • • - 8.3

PLUVICOLINA, OR WATER-CHatS . • . . 87

YUBERNETES • • • • • • 90

Scissar-tail, or Swallow Black-cap.

Gulsernetes forficutus. Plate V. ․ . 93

I LFETVRA

Cock-tailed Water-chat.

Alecturu Azuriz. Plate Vil. . . . . I

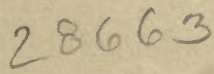




\section{CONTENTS.}

BLEChROpUS

Crested Black Water-chat.

Blechropus cristatus. Plate VII. . . . 99

Fu,uvicola

Mocking Water-chat.

Fluvicula nengeta. Plate VIII. . . . . 102

Perspicilla

Spectacle, or White-winged Water-chat. Perspicilla leucoptera. Plate IX.

Muscicapine, or Genuine Flycatchers

RHIPIDURA

White-shafted Fantail.

Rhipidura flabellifera. Plate X.

Leucocirca

Black Fantail.

Leucocirca laticauda. Plate XI.

Leucocica laticauda. Plate XI.

Myadestres

Whiskered Fantail.

Myadestes genibarbis. Plate XIII.

Szïsura

Dishwater Fantail.

Së̈sura volütans. Plate XII. . . . . 158

Movacha

Golden-hooded Flyeatcher.

Monucha chrysomela. Plate XIV. . . . 142

Mrgalophus

Royal Great-crest.

Megulophus regius. Plate XV. . . . . 145

Todus

Tosus 
Conopophaga .

Rufous-crowned Tody.

Conopophaga ruficeps. Plate XVI. . . - 155

Platyrhynchus

Yellow-crested Flat-bi'l.

Platyrhynchus cancromus. Plate XVII. . . 158

ToDus

Green Tody.

Tudus viridis. Vignette. . . . . . 173

Black-headed Tody.

Todus melanocephalus. Plate XVIII. . . 175

Great-headed Todv.

Todus megacephalus. Plate X1X. . . 177

L.BPTURUS

179

Rufous-crowned Tody.

Lepturus ruficeps. Plate XX. ․ . . 181

Platystera . . . . . . . 182

Long-tailed African Tody.

Platystera longipes. Plate XXI. @ . 185

Spectacle Tody.

Platystera lobata. Plate XXII. . . 187

Platystra . . . . . . . . 188

MUSCICAPA . . . . . . 193

Cryptolopha . . . . . . . 198

Grey-headed Flycatcher.

Cryptolopha poiocephala. Plate XXIII. . . 200

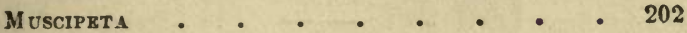

White-bellied Flycatcher

Muscipera ceucogaster. Plate XXIV. • • 205

Mrigra

Cærulean, or Long-tailed Flycatcher.

Myiagra longicauda. Plate XXV.

- 207 


\section{CONTLNTS.}

Muscicapa

White-collared Flycatcher.

Muscicapu allicollis. Plate XIVI. . . . 215

Robin Flycatcher.

Muscicapa rulsecola. Plate XXVII. . . . 221

HvLIOTA

Bıff-bodied Flycatcher.

Hyliota flavigaster. Plate XXVIII. . . . 228

Eurylamine, or Broad-BiLls. . . . . 231

Cymbirhynchus • • • • • • • 235

Black-billed Gaper.

Cymbirhynchus nasutus. Plate XXIX. . . 237

Eurylaimus . • . . . . . . 239

Horsfield's Gaper.

Eurylaimus Horsfieldii. Plate XXX. . . 240

SERILOPHUS . . . . . . . . $24 \%$

Psarisomus . . . . . . . 843

Platystomus . . . . . . . . 244

Fork-tailed Gaper.

Platystomus Blainvillii. Plate XXXI. . . 245

EURYlaimina, the Broad-bills . . . . 247

APPENDIX . $\quad . \quad+\quad . \quad . \quad 251$

Portrait of Baron HALLRR - . . . 2

Vignette Title-page . • • • . . .

In all Thirty-three Plates in this Voiume. 


\section{MEMOIR OF BARON HALLER.}


ate
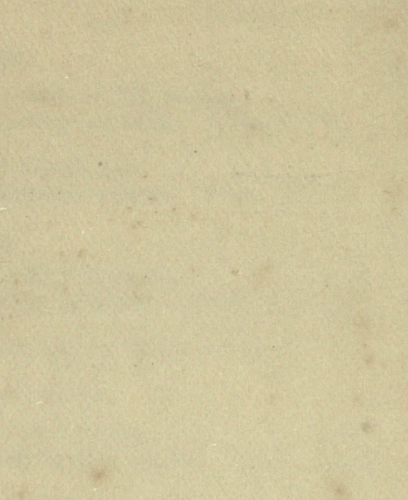

xy

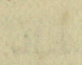

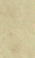




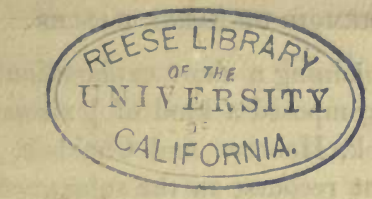

MEMOIR

OF

\section{BARON HALLER}

Albert Von Haller, the subject of this Memoir, was born at Berne on the 16th of October, 1708. He was the son of Nicolas Haller, an Adrocate of considerable eminence in his profession. His father had a numerous family, and Albert was the youngest of four sons. Though exceedingly delicate in infancy, yet, from his earliest years, he exhibited the greatest capacity for almost every species of literature. His education, as well as that of his brothers, was entrusted to the care of a preceptor named Baillodz, and such was the severity of discipline exercised by this individual, that the accidental sight of him, at any future period of life, never failed to excite in Haller great uneasiness, and to renew the terrors of his youth.

The early display of his talents was most extraordinary, and almost incredible; for no sooner was he taught to write, than he began to arrange in alphabetic order all the words he learned in different 
languages, subjoining a short explanation; so that he very early composed a kind of lexicon or vocabulary in Greek, Hebrew, and Chaldaic, to which he had frequent recourse in the subsequent periods of his life. When ten years of age, he wrote rerses in German and Latin, with a point which astonished his masters; and with this weapon he revenged himself for the severity of his tutor, by describing in Latin satires what was most ridiculous in his pedantry. At the age of twelve, he had extracted from the Dictionaries of Moreri and Bayle, literary notices of two thousand of the most distinguished characters there described, thus affording striking proof of his assiduity and industry. In his thirteenth year he lost his father, and was then sent to the public grammar school of his native city. Here he speedily distinguished himself among his fellows, of which the following has been narrated as one proof:-Soon after his attendance commenced, a translation into Latin was prescribed to him, which he not only speedily and ably executed, but also with equal success rendered it into pure and elegant Greek.

On leaving school, he devoted a large share of his attention to the cultivation of poetry; and his early essays in verse being published in the German language, immediately attracted the attention and admiration of the whole empire. His inclination to satire was strong, and his success might have tempted him to indulge his propensity, but an accident about this time occurred, which afforded him 
an opportunity of exercising his self-control, and manifesting his good sense and feeling. The house in which he resided having taken fire, he had scarcely time to make his escape, snatching along with him a few of those articles he esteemed the most precious. Among these were his poetical effusions; which taking occasion to examine, and finding that many of them were devoted to bitter criticism and sarcasm, he determined to commit them to the flames, and had the decision to execute his purpose. He reserved only such poems as have transmitted his character with credit to posterity.

It was now time that Haller should make choice of a profession; but he found the more difficulty in this, as his extensive acquirements, and the versatility of his powers, fitted him nearly alike for any. He had, however, some natural bias towards medicine, and a professional and respected friend having encouraged and cherished this predilection, he, at length, in 1723, came to the decision to resort to Tubingen for the prosecution of his studies. Here he was initiated into the first elements of the art by Camerarius and Duvernoi, then celebrated teachers in that city ; directing, at the same time, a considerable share of his attention to comparative anatomy.

During his stay at Tubingen, Haller took part in an adventure, which, though trifling in itself, yet as having established an epoque in his life, merits notice in this place. He formed one of a somewhat numerous meeting of his young associates, where, after the bottle had circulated somewhat ton 
freely, the parties tumultuously threw themselves into some scenes of pleasure which were very contrary to his tastes. At first, he himself took an active part in the sport, but being soon checked by an internal monitor, he continued only an unwilling spectator. He perceived with shame and grief, both in himself and his friends, that his senses were reeling, and his reason well nigh extinguished; and subsequent reflection only adding to his pain, he firom that time resolved never again to taste wine, to which resolution he scrupulously adhered till his dying day.

His master, Durernoi, making use of the Institutes of Boerhaave in his prelections, Haller was influenced by a vehement desire to profit by the instructions of this celebrated man; and he determined therefore to visit Leyden, that he might derive benefit from a master whose works had greatly astonished him, and whose reputation was second to none who had appeared since the revival of science.

Whilst Boerhaave taught medicine and botany at Leyden, Albinus was his associate in the school of anatomy; and both of these illustrious men conferred conspicuous marks of their favour on Haller, which excited in his breast the most earnest solicitude to merit their approbation. But there was another individual, a contemporary of these eminent men, whose influence was, if possible, greater than that of either of them. This was the celebrated Ruysch, who at this time used constantly to frequent his museum, working amidst the innumerable objects 
of organic life which his skill so admirably preserved, conferring on them all the semblance and freshness of life, without its inherent tendency to decay; whilst he himself, now a nonagenarian, shrivelled with years, yet always active and laborious, more remarkable than any of them, seemed to add to his secret of preserving them, the still more wonderful art of in more ways than one, immortalizing and preserving himself.

Animated by such examples as these, Haller laboured night and day with indefatigable zeal; so that he very soon deranged his health, which forced him for a time to quit his studies. On his return to Leyden, at the age of nineteen, he took his Doctor's degree, and speedily afterwards quitted Holland on a visit to England. Hans Sloane was now president of the Royal Society, and Douglas and Cheselden were amongst its most distinguished members. In London, it was the object of Haller rather to make the acquaintance of eminent men than to prosecute his studies; and in this design he succeeded to his entire satisfaction. Before leaving England he paid a visit to Oxford; and then passed over to France, where he became an inmate in the family of Ledran, and familiar with M. Geoffroy, the Jussius, J. L. Petit, and especially the celebrated Winslow, whose pupil he delighted to designate nimself.

Being again threatened with ill health, Haller eft Paris with the intention of visiting Italy; but the fatigues of the journey proving too much for 
him, he turned aside into Switzerland, and there passed some time in the society of the celebrated Bernouilli, Professor of Mathematics at Bâsle. Under his guidance he engaged in the study of geometry, and so entirely did he devote himself to this captirating study, that for a time medicine seemed almost forgotten, until some kind hints from his master again altered the current of his thoughts, and prompted him to return to his former and most favourite pursuit. The time which was thus spent in the exact sciences was far, however, from being mispent; and his acquaintance with them was ever afterwards useful to him, not only in the propounding of his own views, but more especially in pointing out those errors, which at that period were so prevalent from their abuse.

Haller returned to his native city in 1729 , and though still a very young man, he now seriously engaged in the labours and pursuits attendant upon his arduous profession. After some years, he sought the situation of physician to one of the public hospitals. On his first application, another candidate was preferred; but very saon afterwards the situation was offered to his acceptance, and he most creditably discharged its duties till the year 1736 . In 1734, the Republic of Berne established a school for anatomical demonstrations, and requested their accomplished countryman to superintend it. The same year, in a competition for the chair of Belles Lettres, he delivered a discourse on the superiority of the ancients over the moderns; and at the same 
time published a learned work, in German, on the dangers connected with the imagination.

At this period of his life, viz. from 1732 to 1736 , Haller found time afresh to devote a considerable share of his attention to poetry; and during it, he published anonymously a series of odes and epistles in German, which were at first attributed to Muralt, at that period very celebrated; and when, soon afterwards, the author became known, the general estimate was increased rather than diminished. These poems were speedily translated into many of the continental languages, and during his lifetime ran through upwards of twenty editions in various tongues. His poetry is distinguished by great sensibility, and by elevation and grandeur of thought: remarkably free from frivolous ornaments, it abounds in original touches of pathos and genius. Great variety of subjects became the burden of his song. He delighted to dwell on the beauties of the early dawn, which he was always solicitous to enjoy and inprove; he expatiated on the charms of nature; the love of one's country, and the pangs of separation and banishment; he descanted on the true value of glory and renown; and, in a poem of three cantos, on a still deeper subject, the origin of good and evil. His most finished performance, however, is "The Alps and its Inhabitants," a noble theme, which received ample justice at his hands.

To his high poetical talents, Haller conjoined a very extensive acquaintance with history and biography. This he had an opportunity of demonstrating 
in 1735 ; for being then appointed superintendent of the Public Library at Berne, he prepared a systematic catalogue of all the books in the collection; and, moreover, examined and arranged more than five thousand ancient coins and medals, of which he drew up a chronological list and account. During the summers of this period, he used, by way of relaxation, to prosecute his botanical pursuits in expeditions amongst the mountains and valleys of Switzerland; in the course of which, he at the same time applied himself assiduously to the cultivation of mineralogy and zoology.

In consequence of his ardent devotion to such objects, the reputation of Haller became widely extended; and in 1736, the Regency of Hanorer offered him the Chair of Botany, Anatomy, and Surgery, in the newly established school at Göttingen. No inducement was withheld, which could make the situation attractive and agreeable to him; and large funds were placed at his disposal for the prosecution of those schemes which formed the favourite objects of his life. He therefore gladly availed himself of the offer, and for seventeen years devoted his utmost energies to promote the celebrity of the school, with what success is universally known. Poetry was now entirely laid aside, and the graver subjects of pursuit henceforward engrossed his zealous exertions. Through his influence, the university was speedily enriched with a botanic garden and an anatomical theatre.

His application to botany may be styled enthu- 
siastic and his proximity to the Alps afforded him a wide and rich field over which to expatiate. Many were his excursions amidst their sublime scenery, which were not more agreeable than necessary to his health ; and for years he was employed in collecting a complete herbarium of the region. The fruit of his various excursions was published in two volumes folio, in 1742, under the title of Enumeratio Stirpium Helveticarum, and the work was adorned by a number of superb plates. In the preface of this work he gives a topographical description of the country; and remarks that, within a narrow compass, the region comprehends the plants and insects of Norway and of Italy. To make his treatise the more complete, he prefixed an historical exposition of all that had been previously written concerning the plants of the Alps, from the days of Brunfelzius to his own. Being at this time the youthful cotemporary of the still youthful Linnæus, it could not be expected that he would follow that system which ere long obtained so wide a celebrity. Indeed, in 1736, when Linnæus was not thirty, Haller published at Göttingen a plan for the prosecution of botany, in which he recommended the natural order. In his work on the Botany of the Alps, he chiefly employed as characters, the presence or absence of the stamens, of the corolla, and of the buds; the number of stamens when compared with the petals, and the number of the cotyledons, as well as that of the seeds, making fifteen classes in all. In the following year he pub- 
lished an account of the plants, and the arrangement of the Botanic Garden at Göttingen, which work was at later periods republished and greatly augmented by the addition of new plants. In 1749 he collected his isolated observations on the genera and species of plants, and on their fructification; and published them in a volume entitled Opuscula Botanica.

An interesting anecdote has been preserved respecting an incident which occurred in one of his journies in the Alps. He was on that occasion, as on many others, accompanied by his intimate friend Gesner. One day both being greatly fatigued by a laborious and protracted excursion, Gesner, overcome by fatigue, lay down and fell asleep on the snow, in the midst of an icy atmosphere. Haller, with the deepest distress, witnessed an occurrence, which, however, he in vain attempted to prevent, and which he apprehended might prove fatal. Goaded by the urgency of the occasion, he considered by what means the threatened danger might be averted, and speedily one method suggested itself to the warm sympathies of his heart. He stripped himself of his own garments and wrapped them round Gesner, and then with complacency set himself down, at no small risk, to contemplate a repose which he trusted would now be safe, as well as useful in recruiting his friend. The result fully realized his anticipations: Gesner in a short time awoke, not injured but refreshed, and they together in safety escaped the danger.

What most of all, perhaps, excites astonishment 
on the examination of Haller's very numerous and successive labours, is the rapid changes which he made from one subject to another. Most profoundly versed in some of them, he seems on all occasions on the level with the most advanced cultivators in each department, and frequently surpasses them all. However much then he may be the object of our admiration, on account of his classical attainments, his poetical powers, or his botanical knowledge, we now remark that he became still more eminent for his physiological researches. It is upon these that his highest celebrity is based, and in this view, therefore, we are now chiefly to regard him. On the death of his master, Boerhaave, in 1738, Haller published his prelections, with much original matter, in six volumes, which appeared successively from 1739 to 1745 . But his own discoveries and improvements soon tended to render this work obsolete; and in 1747 appeared the first edition of his " First Lines of Physiology," a synopsis of his own system of that branch of science. This is a truly valuable production which, long after the death of the author, was used as a text-book in the schools, and has only lately been superseded. During the subsequent years of his life, he continued to augment and perfect this production, and published it in eight volumes, quarto, between the years 1757 and 1766, under the titie of Elements of Physiology. Though referring chiefly to man, as usually exhibiting the utmost perfection of structure, yet it is by no means confined to him, and ranges widely orer 
the whole of comparative anatomy, and throughout the animal series down to the polypus. As comparative anatomy and physiology are two of the most interesting departments of zoology, Haller's claims to the attention of the naturalist are of a high order; and we shall stand excused for dwelling somewhat more in detail on this portion of his labours.

His work the "Elementa" astonished at the time, and still continues to astonish those learned men who peruse it, by the excellence of its arrangement -the precision of its style-the immense detail into which the author enters on the structure of the parts - the profound discussion of all the opinions previously delivered, as to their functions and uses - the exact and prodigiously numerous references to all those passages in authors, where allusion is made to the smallest matters connected with the science,- and the great improvement which it effected in physiology, by the substitution of induction for hypothesis. Any attempt to give the most curtailed account of this prodigious work, would within our limits be absurd, and we must therefore confine ourselves to a very few remarks.

It should not be forgotten that physiology was a very different science a hundred years ago from what it is at the present time, and that it was then much cumbered with scholastic learning and hypothetical disquisition, to the neglect of real observation and experimental inquiry. Haller was one of those who first and most powerfully contributed 
to effect a revolution in the character of the science, by appealing in all possible cases to direct experiment. At the period we now refer to, the doctrines of the circulation of the animal spirits, effected through the agency of the dura mater, which transmitted its prolongations to the very extremities of the frame, and there constituted the seat of the faculty of sensation, were prevalent and almost uncontroverted dogmata, utterly at variance with the truth. Haller impugned and overturned these doctrines; and thus merited the high commendation due to those who set aside false doctrine. Both Pacchioni and Baglivi maintained that the dura mater was muscular, and transmitted the vital fluid with a force not less than that which was exercised by the heart itself. Haller, on the contrary, demonstrated by experiment and otherwise, that the dura mater differs in no essential particular from the other cellular membranes of the body; that it was in no degree nuscular; that it did not supply a sheath to the nerves, which, on the contrary, had their own proper coverings wholly distinct from the dura mater: he demonstrated that this membrane had no apparent sensibility whatever, and therefore, from this consideration alone, could not be the seat of sensation and motion. In his own words - "I inquired if the dura mater were irritable; if it contracts, and so acts as a muscle. This enters essentially into Baglivi's system, and I plainly aver the contrary. In most animals the dura mater is closely attached to the bone, and if detached from it, it always is roid 
of motion. Comparative anatomy likewise informs us that this membrane is simply a true cover for the brain, for in some animals, as in the tortoise, it is found of a cartilaginous consistence."

There were other points of controversy in which Haller found himself early engaged. One of the most important of these regarded the respiration in man and the mammalia, and especially the instrumentality by which this vital function is effected. M. Hamberger, an eminent professor at Jena, had in 1727 published an account of the mechanism of respiration. According to his view, which was in unison with the prevailing and established notions, there was a permanent collection of air within the chest, between the ribs and lungs, as occurs in birds; and this air exerted an influence in compressing the lungs, which compression was, moreover, assisted by the action of the internal intercostal muscles. These opinions had, about the same time, been adrocated also by M. Bayle of Toulouse. In reference to them, we shall allow Haller to speak for himself:- " The commentaries which in $1739 \mathrm{I}$ commenced to give upon the Institutes of my illustrious master Boerhaave, led me to the subject of the mechanism of respiration, the thoracic air, and the use of the intercostal muscles. I cruld not agree with the views of M. Hamberger, with whom I was on terms of intimacy. Accordingly, I spoke of him with commendation, and endeavoured to treat him with politeness while commenting on his bypothesis; I cherished every feeling of delicacy 
which truth would permit in combating his opinions. But M. Hamberger's sensitiveness was extreme. At Jena, he had established a little empire, and the applause of his numerous students made him regard iny arguments as so many premeditated insults. He defended himself with asperity, and the more so, as Göttingen was enjoying a popularity which could not be shared by many of the German universities." This discussion led to a very keen and widely extended controversy, in which many of the eminent men of the day took a part. It led Haller, and his friends and pupils, into numerous and varied sets of observations, which have in a great measure formed the foundation of the opinions now universally received. We quote one passage on the point from his Physiology:- " Is air contained between the lungs and the thorax? Is this air rarefied in inspiration, and afterwards becoming condensed, and compressing the lungs, does it cause expiration? Is this opinion confirmed by the analogy of birds, of which it is strictly true? Every thing concurs to confute this opinion: behind the pleura in man and quadrupeds, living and dead, the naked lungs are visible, without any intermediate space betwixt them; and on perforating the pleura, the lungs retract towards the spine as soon as the air comes in contact with them. In birds, the lungs and their corerings being pervious, admit the air through large holes into the cavity of the thorax. But in these there is a manifest space betwixt the lungs and the pleura, which would be equally manifest in 
quadrupeds, if the lungs were not contiguous with the pleura."

But the views of Haller, which were the most original, and led to the keenest controversy at the time, and the greatest admiration afterwards, were those which he propounded on the subject of irritability. The numerous family of polypi presented to him the appearance of a high degree of irritability, without any ascertained brain or nerves. Worms also, often in the highest degree contractile, having very minute nerves, appeared by their structure to lead to a somewhat similar inference. He moreover remarked, that those parts of the frame which move the most frequently and powerfully, such as the heart, are very moderately sensible, and do not receive a large proportionate supply of nerves: and very numerous experiments taught him that contractions, whether natural or excited by artificial stimuli, and sensibility, are very unequally distributed, and their proportions are very different in organized bodies. The following are the terms in which, at an after period, he gave a somewhat chronological account of his discovery, for such he clearly considered it.* "In my Commentaries upon Boerhaave's Institutions, published in 1739, I have expressed myself as follows:-Wherefore the heart is moved by some unknown cause, which depends neither upon the brain nor the arteries, but lies concealed in

- Vis ab omni alià hactenus cognita proprietato corporum diversa et nova est : neque enim a pondere, neque ab attractione, neque ab elatere pendet.-Prim. Lin. Physiol. \$ 408. 
the very structure of the heart itself The nature of the thing obliged me to differ in opinion from my preceptor. Three years afterwards I published the following doctrine, viz. That all animal filres when they were irritated contracted themselves; that this character distinguislied them from those of vegetables, and that perpetual irritation alone was the cause of the continuance of motion in the vital organs, rohile the animal organs ceased to act. In the abridgement of my Physiology I have positively ascribed the motion of the heart to the force of a stimulus; and in the second edition, I have been more explicit on the irritability of muscular fibre, asserting that it was independent of the nerves, and of every other known property. If any person denies the truth of this assertion, I shall be glad to learn from him upon what property this motion depends. Since that time, numerous experiments have convinced me of the truth of the doctrine above advanced."

We shall in this place introduce a very succinct account of Haller's separate treatise on this interesting point. He divides all the parts of animals into those which are susceptible of irritability and sensibility, and those which are not. He designates irritable those parts which become shorter upon the application of a stimulus, and sensible, those which on being zouched transmit the impression to the sentient being; and, on the contrary, those are denominated insensible in which the most violent injuries occasion no pain or convulsive movement. These definitions are followed by a minute examination of tho 
sensibility of the several structures of the animal machine, and the degree of sensibility possessed by each. The skin is stated to be more sensible than any other; then the muscular fibre, both of which, however, derive this property from the nerves; and these being the source of the sensibility of the other parts, are themselves, of course, exceedingly sensible. Again the marrow, the bones, the internal viscera, \&c. to which this property had been generally very freely conceded, were found to be wholly destitute of it. So that all the facts on this point are summed up in the following sentence:- "The sensible parts of the body are the nerves themselves, and those parts to which they are distributed in the greatest abundance. In fact, the nerves alone are sensible of themselves, and their whole sensibility resides in their medullary part, which is a production of the internal substance of the brain, to which the piamater furnishes a covering."

The author next proceeds to the subject of irritalility, which he demonstrates to be so different from sensibility, that the most irritable parts are not at all sensible, and the most sensible are not irritable. He endeavours in detail to prove both of these propositions by facts, and then to demonstrate that irritability does not depend upon the nerves, but upon the inherent constitution of the parts in which it resides. After this, the whole variety of structures is in the same way examined as it respects their irritahility, begirning with the nerves, which are proved to be not at all irritable; no more is the 
skin, cellular membrane, fat, dura mater, \&c. Some other structures again appear to possess the property, but only to a limited extent, such as the veins, arteries, and other vessels. This point, though at first sight apparently very simple, is not free from difficulties. Haller remarks, that the principal artery of the silk-worm performs the office of a heart; and that in many animals, after the heart is removed, the motion of the fluids is continued, for a time, apparently solely by the arteries. "Upon examining," he says, "with the microscope, the blood in a fish and a frog, after they were deprived of their heart, it continued to move for some time in the vessels; and I have seen it pass up and down the ressels of smaller fish, which had no motion either in their heart or gills, and which did not show the least sign of sensibility. But still this does not quite prove the point." Haller could never witness contraction in the aorta or other great vessels of any of the larger animals; in living frogs, too, he had frequently irritated the arteries with a variety of stimuli, and could never discover any contraction occasioned thereby: and concerning the circulation of animals generally, he states, that upon examination with the microscope, he could never perceive any contraction in the blood-vessels. "I have viewed for hours the circulation in fishes and frogs, and during the whole time, the sides of the vessel remained as quiescent as those of the tubes with which I exanined tinem. If the beat of the artery had occasioned any motion in the neigh- 
bouring vein, I could not have failed to have discovered it."

Next in order come those parts in which irritability is unequivocally marked, and in which it appears to be naturally inherent. These are especially the flesh of animals, the muscular fibre wherever it can be traced, whether in the external coverings or internal viscera. The different structures, indeed, appear to be irritable in proportion as they are muscular; and hence we are not surprised to find that the heart, which is nothing more than a set of great hollow muscles, is especially endowed with this property; and that this is most remarkably true in regard to cold-blooded animals. In the eel, motion is conspicuous in the heart several hours after it has been removed from the body; in frogs, it is apparent from noon till almost midnight ; and in some other animals, it continues as long as twentyfour and thirty hours after death. Even after it has ceased to move spontaneously, its irritability again manifests itself on the application of a slight stimulus. On the whole, it appears that no part of the animal frame is irritable independent of the muscular fibre, and that the property is peculiar to this fibre; this remark, however, must not be extended to the insect world, which appears to have the singular quality of being both irritable and sensible all over. This property, which Haller denominated the vis insita, is distinct from all other known properties of bodies. Elasticity most nearly resembles it, but differs as it is peculiar to hard bodies, whilst irrita- 
bility is toosoft. Some polypi, though very soft, are so irritable as to be affected even by the light. Irritability then, is a property of animal fibre, in the same way as attraction and gravity are properties of matter in general; and all that can be done is to explain the phenomena presented by this quality of fibre, without entering into useless speculative inquiries.

We may add, that to Haller we apparently owe the discovery that the iris is not muscular. His words are, "You will be surprised to learn that the iris has no irritability, when the cause of irritation applied is mechanical. I have observed that its dilatation does not depend upon muscular force. After death it still remains dilated; and the phenomena presented in animals, whether cold-blooded or hot, harmonize with this view."

Such, then, is a very short analysis of one of Haller's treatises on this important subject; and instead of here expressing any opinion of our own concerning it, we shall subjoin a few sentences which embody the opinion of the celebrated Tissot; who took an early opportunity of introducing it to the notice of his countrymen in a French translation. "The great discovery of the present day is irritability, described in the accompanying treatise; in rraise of which I shall say nothing, seeing its celebrated author, for these twenty years past, has favoured the public with so many excellent performances, and now this subject is become the principal topic of all those who devote themselves to the important 
study of the animal economy. Irritability is a property entirely different from all those which were known before in the body; and being essential to all animals, as perhaps likewise to all regetables, it will henceforth be justly reckoned amongst the principal qualities of organized bodies. It must appear very surprising, and at the same time not a little mortifying to mankind, that a property which, as Zimmerman says, constitutes perhaps the very basis of life, should have escaped the eyes of all who imagined themselves to be observers, and some of whom were actually such. Perhaps it would not be impossible to assign the reason for this, but all that we shall say is, that it resembles other instances of a similar kind: attraction, and the weight and elasticity of the air, showed themselves to the senses every day, but it required a Toricelli and a Newton to illustrate them. As the whole animal economy revolves on this principle, it is easy to imagine what a change this discovery must produce. To England we owe philosophy, and to Switzerland physiology, the immovable basis of which is irritability."

Much praise is undoubtedly due to those, who, neglecting their own aggrandizement, endeavour to augment the popularity of others by introducing their works to notice, whether as translations from a foreign language, or by bestowing commendation and publicity on memoirs calculated to promote the progress of science, or in reviving discoveries which run a risk of being forgotten. This labour, less brilliant than useful, is one of those to which Haller 
assiduously devoted himself; and it would not be easy to state all that in this way he acomplished. During his residence at Göttingen he published an edition of a work of Rupp's, which he greatly eugmented, on the Flora of Jena ; and shortly afterwards, that of a German work, in which was collected every thing which related to the history of the representation and engraving of plants, and respecting those artists who had devoted themselves io this kind of work. In 1750, he became the editor of a German translation of Buffon's Natural distory, to which he prefixed an able dissertation; which was speedily translated into French; and aso of a work of Formey's entitled the Triumph of Ividence; likewise of a "Collection "of Voyages and Travels," the utility of which he demonstrated ir a lengthened preface. The only other works we siall add to this list are the Poems of Worlhof, a Dictionary of Natural History, by Messrs. Valmont and Bomare; a Comparison between the Temperature - Sroitzerland and Canada; and finally, a Treatise o the Baron de Lind upon The Veterinary Art.

During the period of his stay at Göttingen, Haller oten originated, and ever lent a ready and most sufficient help to such schemes as promised to subsrve the interests of science, and to promote the piblic weal. Thus, in 1751, he procured a charter for the surgeons of the town, and on their incorpor:tion was elected their first president. He did the same important service for the Royal Society of Sience; drew up its original constitution, and was. 
named its president. $\mathrm{He}$ also greatly promoted the establishment of various public hospitals, and also of a public museum to which he largely contributed; and finally, he established a school for artists, in which the study of delineating plants and animals might receive every facility. At the time the purpose and plan of this institution were altogether new; and the many which have since been established in almost every country upon the same model, have shown the usefulness of the scheme.

Labours so multiplied and important as these, were the sure means of insuring to Haller the highest possible celebrity. Almost every academ: in Europe hastened to enrol his name among its members. In 1748 he was elected a member o the Royal Society at Stockholm; and the king $d$ Sweden conferred on him an unsolicited honour, $b$ r raising him to the rank of knight of the order $c$ the Polar Star, the highest order in the kingdom conferred only on such scientific men as Linnæu and Haller. In I749 he was elected a fellow $a^{\circ}$ the Royal Society of London, and in $1754 \mathrm{~h}$ became one of the foreign associates of the Aca demie des Sciences at Paris. In 1745 his ow country likewise conferred an honour upon hin with which he was highly gratified; the republic $d$ Berne appointed him a seat in its Supreme Counci George II. of England, ever manifested the livelies interest in his welfare, and when at Göttinger always loaded him with kindness. In $1739 \mathrm{~h}$ named him his first physician in the electorate $c$ 
Hanover, and also made him a Privy Counsellor: he also requested for him from the Emperor, letters of nobility, which were transmitted in the most flattering manner in 1749; but notwithstanding, Haller would never assume the title of Baron, though frequently and properly applied to him. Many of the most celebrated universities made the attempt of enticing him to become their associate, but in vain. The celebrated Dillenius was anxious to procure him as his successor in the botanical chair at Dsford. The year after, he was urgently solicited to estaklish himself at Utrecht as chancellor of is uxivessity; and shortly afterwards, the king of Pratus mell known as the patron of letters and the friend of learned men, offered him, on the most liberal conditions, the presidency of the academy at Berlin. Marshal Keith wrote to him in the name of his sovereign, offering him the chancellorship of the university of Halle, and Count Orloff invited him to Russia, in the name of his mistress the empress, offering him a distinguished place at St. Petersburgh; but to all these solicitations he returned a negative reply.

There was only one country which Haller preferred to Hanover, and that was his native land. To it he returned in 1753 , on perceiving that his strength was no longer equal to the discharge of the numerous avocations in which he was engaged. Besides, he had now great scientific projects in view, and the engagements connected with the three chairs he filled at Göttingen very much interfered with the 
execution of them. His return to Berne spread the liveliest joy throughout the canton; and a short time after, being, as we have seen, a member of the sovereign council, he obtained, by lot, the situation of Governor of the Mansion House; so that on this occasion at least, the lot conspired with the wishes of the nation in recompensing a great man.

Any other man than Haller would now have sought retirement and coveted repose after such long continued and arduous labours. And, indeed, the abandonment of his professorship must have been a great relief; but the Government of Berne, overjoyed at having recovered her illustrious citizen, for several years furnished him with a variety of occupations, and induced him to undertake some journeys which were both useful to his health and to the public. In 1753 and 1754 , he traversed many of the cantons in search of salt-mines, which were much required, and afterwards he was sent to Kulm to examine some curious antiquities, of which an interesting account was subsequently given by M. Schmidt. The superintendence of the province of Roche was conferred upon him in 1758, and in 1762 he was appointed Governor of the canton of Aigle, to which he rendered important services. He drew up an account of the salt-mines of this district, and transmitted to the Royal Academy of Sciences, a memoir on the best mode of preparing salt by evaporation. He laboured hard to simplify its preparation, to increase its abundance and purity, and to reduce its price. He also drew up a code 
of laws for the regulation of this republic; and was often the commissioner of his own canton to those assemblies to which were remitted the general interests of the whole. He spent six years in the canton of Aigle, and there printed his great work on physiology.

But such employments as these could not long seduce the Baron from his literary occupations, and he speedily again applied himself to them with scarcely diminished energy. Within a few years of his return to Berne, he wrote an important work on Pathology, and also a treatise on Medical Electricity, on which we do not dwell. Removed, as he now was, from the botanical and anatomical theatre of Göttingen, we might be led to suppose that he would have renounced these two branches of study But he found plants in the country, and plenty of the amphibir and fishes in the lakes, as he did quadrupeds in the fields, and he thus amply supplied himself with objects of investigation. He continued his botanical pursuits, and with the help of the microscope, made many additional observations on the circulation of the blood in animals, on the growth of their bones, upon the brain and eyes of birds and fishes, several of which were published between the years 1756 and 1765, and some of which appeared at the time in the Memoirs of the Acad. Royal des Sciences.

Even after Haller's health began to decline, and he was a good deal confined to the house, he still discovered objects which excited his liveliest curi- 
osity, and which his extraordinary industry and ingenuity turned to account. It was under these circumstances that he began to direct a peculiar attention to the structure of the egg and the growth of the chick, and for three years bestowed upon this subject the most minute investigation which it has probably ever received. He made almost innumerable microscopic observations, and in a distinct work gave a detailed account of two hundred and eighty four of them. This treatise was subsequently incorporated into his great work on physiology, and as the subject in question is at once so interesting and important, we shall only be rendering a most acceptable service to our readers, by presenting them even with a very abridged account of his conclusions.

Before, however, doing so, we shall give, in a tabular form, the dates of the most striking phenomena which are observed during incubation. After the egg has been subjected to the process of incubation for

7 hours, the membrane of the yolk appears.

12 do. the peculiar envelope (the amnios) of the chick appears.

24 do. the envelope is perfect.

31 do. the venous figure appears.

45 do. this venous figure is completed.

48 do. the heart appears, and begins to pulsate.

55 do. first appearance of three cavities of the heart.

72 do. end of three days, the wings and legs appear.

96 do. four do. the two ventricles of the heart are seen; liver appears.

120 do. five do. ventricles of the heart completed.

144 do. six do. the bones appear.

240 do. ten do. first appearance of the feathers.

451 do. eighteen do. first cries of the chick.

528 do. twenty-one do. chick liberated from the shell. 
In the elements of physiology we find the following striking statement:- "The chick increases very quickly; its length on the twenty-second day is to its length on the first day, at least as $1,000,000$ to 1 ; and the whole increase of the bulk of the bird during the remainder of its life, does not relatively exceed the fifth part of its increase in the egg during the first day."

And now for his general conclusions.-I commence, says he, by remarking that the animal evidently undergoes changes solely by the evolution of its previously existing parts, without any addition of newly created ones. I at one time thought that I had found in the heart of the chick the proof of the creation of additional parts, and had persuaded myself that a curved tube had been converted into a muscle with four cavities, simply by the addition of new parts; but observation has shown me that the changes in this important organ are in truth only slight, and that they are effected in its primordial structure, by successive steps, which are the consequences of simple evolution.

In considering the different ways in which the animal which is to form can differ from the animal already formed, and how it can assume an appearance wholly different from what it had, I have found that the simple elongation of parts, which is naturally produced by the heart, may induce appearances which are altogether new. Such is the wmbilical membrane. It is first seen as a soft pulp, then traces of net-work appear in this pulp, pro- 
duced by the action of the heart: this net-work commences as it were by points; these points soon become threads, which ere long are coloured, and turn out to be arteries and veins, dividing at very small angles. These angles enlarge ; whitish coloured spaces appear between the vessels, which, with time, dilate exactly like the spaces betwixt the fibres of leaves. In retracing the successive changes of this membrane, it would evidently appear that it had always existed, as also its vessels; that it had expanded upon itself; that the impulse of blood had prolonged the arteries, or divided its folds ; that it had elongated the vessels from each other, and given to the membrane its length and breadth, its colourless spaces, and even its solidity. I regard this example as instructive, and calculated to exhibit the shades by which a soft and semi-fluid substance can pass into a state wholly different from its first condition, by simple evolution.

Regarding solidity, we have only to trace the successive increase of the lungs and other internal viscera, of the flesh, bones, \&c. to perceive the steps by which a true fluid may become viscid, may then harden by insensible degrees, and this without the mixture of any new parts. All these portions of the young animal are produced from a fluid, apparently organized, they then become consistent, and gradually acquire well defined limits. We need not here dwell on the causes of these changes. We may simply remark, that a simple diminution of the fluid parts, the effect of the dilatation of the 
ressel, is alone sufficient. Instead of water and other perfectly fluid elements, the enlarged ressels transmit particles which are viscid and albuminous, which mutually attract each other, and the nearer they approach the stronger they attract.

The manner in which the parts from being inrisible become visible, is truly simple ; it is effected by enlargement, and still more by opacity. The lungs become visible only on the sixth day. When first perceived, they are sixteen-hundredth parts of an inch long; they might have been visible when only four-hundredth parts long; but they are not when eight-hundredth parts, solely because they. were diaphenous, and of the same colour as the other parts. The liver is still larger on its first appearance; and if it does not appear earlier, it is not owing to its small size, but to its want of opacity. It is the same with other parts; so that we should be cautious in supposing that any portion of an animal is newly created, or that it had no previous existence: it may have been too small for observation, or may have been transparent.

The movement, and apparent repose of the parts of the body, depend also on the increase and opacity of the parts. The heart does not appear to have any movement previous to the lapse of forty-eight hours. Why, it may be inquired, does motion then appear? and is it not true that the heart has previously propelled the fluids with vigour, since the growth of the chick has been so rapid? If the heart has appeared in repose, it has been because it was 
transparent. We see not the wind. Too small and feeble to produce any effect upon the surrounding fluid, the heart has appeared motionless, as it previously had appeared to be wanting. This consideration should anticipate the conclusion we are prone to draw, that an animal lives, or does not live, or that it begins to live at this or that moment which we choose to fix: we recognize life only by motion, and motion is apparent only by a certain size and opacity.

But whence this opacity, and by what shades do colours appear? There is but one step between mucous transparency and whiteness : a little more liquid confers transparency on white bodies, and a little less deprives them of it. Paper is white, and so is pounded glass, yet both become transparent when soaked in water or oil : remove these liquids, and they again become white. Even the fat of living animals is transparent; a slight dissipation of its fluid parts, and its cooling by air, make it white.

White then is the first colour of the animal, as transparency is its first condition. This is true of all the quadrupeds upon whom I have made experiments, and these have been very numerous; the same is true respecting birds. The colours are produced by the power of the heart dilating the ressels, and so allowing them to transmit the coloured particles, which, according to the principles pointed out by Newton, are always larger than diaphanous particles. In the chick we find occurring the yellow, 
red, black, green, and blue, in the order just enumerated; and all produced by the heart, somewhat assisted by external heat. It is by the heart, because fish in the frozen seas of the north manifest almost every colour, and because heat without the aid of the heart will not do it. The chick is much retarded and dies, if the egg continues white. Heat again helps somewhat, since it is true that the most brilliant and beautiful colours of quadrupeds, birds, fishes, shells, and even flowers, are usually found in warm climates. In vegetables it is heat alone which confers the colour; at first they are white, and the sun effects all the subsequent changes.

Tastes and odours arise with the colours, or very shortly after them. The bile is green before it is bitter; but the bitterness is soon afterwards perceptible, and the colouring particles are apparently the same with those which excite the taste and the smell.

Pass we now to the mechanism which produces the various forms of the different parts. The most simple, and at the same time the most efficacious instrument is unequal increase. An animal no longer resembles itself when some of its organs diminish and become extinct, whilst the others increase and are developed, or when some increase to a great extent, whilst the rest make only a slow progress. It is thus the chick changes in relation to the yolk. During the early period of incubation the chick is small; the internal viscera are yet invisible, but an enormous appendage of these same 
viscera is placed exterior to the body of the chick, and is connected only by a canal of communication. During the latter stages of incubation, and especially in the hatched chicken, things are quite altered. The internal viscera now have become large and visible, the canal of communication and the yolk have faded and disappeared, and the chick has nothing pertaining to it external to itself. Again, the dorsal aorta of the chick, before it is hatched, appears to be a common trunk with three branches, two of which belong to the pulmonary artery, and the third to the left ventricle of the heart; but after it is hatched, the aorta is only a simple artery, proceeding from the left ventricle, and having no connexion with the pulmonary vessels. Once more, the chick of the first day is scarcely more than a head with a slender thread, which is the spinal column; when twenty-two days old, the extremities and viscera have been elaborated out of this almost invisible appendage, and the head in its turn has become an appendix.

Relative change of place is another instrument employed by nature. Of this we see an example in the yolk and intestines. Both these are external to the chick, almost to the termination of incubation, and the embryo being appears to have two bodies communicating together, the one consisting of the head, extremities, and internal cavities, and the other of the yolk, the umbilical membrane, and the intestines, all parts of the chick, and yet detached from it. The membrane fades and disap- 
pears, the yolk and intestines are included in the abdominal cavity by means of the acquired irritability of the muscles which cover that cavity, and this animal with a double body becomes a common chicken. So is it in another instance already noticed; the heart becomes that well defined organ, instead of being a half ring, separated widely from the spine and placed almost without the chest. It is the cellular membrane, passing from the fiuid state to a state of considerable solidity, which draws the separated portions of the heart towards each other, and approximates the whole to the back bone; and similar causes mould the chick, and bind it upon itself, till it attains that perfection in which we find it.

"I believe," continues the author, " enough has now been said to vindicate my opinion concerning the doctrine of gradual evolution. The probability appears to be, that all the essential parts of the chick exist throughout all time; not indeed such as they appear in the adult animal, but so disposed that certain and provided causes hastening the increase of some of these parts, hindering that of others, changing their relative places, making manifest organs which were formerly transparent, and giving consistence to fluids, in the end form an animal very different from the embryo, but in which no part exists which had not essentially existed before. This is my explanation of developement."

These observations lead to reflections not less 
important. It appears almost demonstrable that the embryo is found in the egg; and that the mother contains in her egg-vessel all that is essential to the chick. For the yolk is a prolongation of the intestinal canal of the chick; the internal membrane of the yolk is continuous with the internal membrane of that canal ; and this canal is continuous with the lining membrane of the stomach, mouth, and skin : the external membrane of the yolk again is the external membrane of the intestine expanded, and is continuous with the mysentery and peritoneum. The envelope which covers the yolk during the first days of incubation is a part of the skin of the chick ; and must always have covered it, though originally invisible, since the great size of the yolk, compared with the nascent chick, will not permit us to suppose that there could be found in the skin of this little being matter sufficient to supply an envelope, if this covering had not done it from all time. If the skin of the chick had been only proportionate to its own abdomen, it could never have covered the immense size of the yolk.

If the yolk be a continuation of the skin and intestine of the chick, the chick must always have existed in it; but the yolk has always existed within the hen; the chick then must have existed, though invisible, in its peculiar membrane the amnios, always apparently placed upon the yolk, though also invisible, on account of its minuteness and transparency.

"The venous figure," he concludes, "and the struc- 
ture of the yolk are exquisitely beautiful, though destined to endure but for twenty or rather ten days. What superabundance and prodigality of ornament for so momentary an existence! But time, all important to us, since it destroys us, is nothing to God, because he changes not. His creative wisdom alike adorns the grass which endures for a day, and the oak which lasts for ages. It would appear that God had thought fit that the world, as one theatre of his wisdom, should have as many parts in order and organization as the nature of things would admit, and that noise and confusion should have the least possible place. Upon the whole, it appears certain, that the beautiful structure of animals, however various, is always perfectly adapted to the proper and distinct habits, and functions, and manner of life of each ; calculated by rules more perfect than those of human geometry, and most evidently accommodated to foreseen purposes; in the eye, the ear, the hand, and finally, every where, and can be ascribed to no cause less than the infinite wisdom of the Great Creator."

In 1773, Haller published, in the Memoirs of the Economical Society of Berne, an able treatise on the nature of the "Epizootie," that dreadful disease among horned cattle, which for several years destroyed so many hundreds of thousands in so many countries of Europe. He there demonstrated. that though with great care they had overcome its violence and checked its progress on the side of Switzerland, 
yet the contagion was always afresh introduced from France, where no adequate means had hitherto been taken to arrest it; and he then exhibited the necessity of certain preventive methods, which soon afterwards being employed in concert by Hungary, Belgium, Switzerland, and France, were crowned with success.

By way of relaxation, and for his amusement, Haller, in 1772-4, committed to writing his thoughts upon the best form of the three different kinds of government. He published them as Romances in three volumes, which were severally entitled Usong, Alfred, and Fabius and Cato. The two former were immediately translated into French, and they all demonstrate the author's acquaintance at once with history and politics. If any one, misled by their popular appellation, were to expect only light reading and amusement, he would be surprised to discover in them deep views of the sagest administration, stern political truths, which were easily propounded under a slight disguise, and especially an elucidation of the omnipotence of morality and the laws. About this period he also contributed many articles to the supplement of Le Dictionaire Encyclopedique; and, as would appear from a review of the German journals, published, chiefly at Göttingen, as many as fifteen hundred communications*.

Haller's next important literary labours were the

* In the "Conversations Lexicon," the number is stated at twelve thousand, which we should think is an evident mistake. We follow Vicq d'Azyr. 
Bibliotheca. Being in possession of an immense collection of the choicest books in various departments of science, which he could not continue to use much longer, he wished to gratify himself by going over them once more; to render to these his farourite sciences a last service, and to learned men an additional favour, in pointing out to them those sources of information to which he had so successfully resorted. These great rolumes are chronological catalogues of works of every age, country, and language, relative to the subjects on which they treat, with concise analyses and notices of peculiar and important facts and opinions; and accordingly, they are very frequently consulted and quoted up to the present day. These libraries of professional knowledge, as they have been called, were published in the following order: Bibliotheca Botanica (1771, two vols. 4to); Bibliotheca Anatomica (1774, two rols. 4to); Bibliotheca Chirurgica (1774, two rols. 4to); Bibliotheca Medicince Practicae (1776-1788, four vols. 4 to, the last two volumes having appeared posthumously).

During Haller's declining years his health became most painfully infirm; thus probably paying the frequent and severe penalty of hard study and literary labour and eminence. We have already stated he was very delicate in infancy, and this state continued throughout his youthful years. At the age of twenty-one, however, he became stouter, though liable to frequent and violent attacks of indisposition. When about sixty he became a martyr 
to the gout, and this was soon followed by severe gravel complaints. But notwithstanding these most harassing ailments, the energy of his mind continued unabated, and in the midst of his pains he prosecuted his scientific pursuits. When much indisposed, he had the honour of being visited in his sick-chamber by the Emperor of Germany, who, in addition to this high compliment to his distinguished subject, was solicitous personally to express to him the deep interest he felt in his welfare and comfort: it was a visit alike of condescension and kindness. In a short time, Haller finding his strength become more and more exhausted, and perceiving he could not long survive his many troubles, solemnly inquired of his professional adviser and friend what he thought would be the term of his days, requiring at the same time a reply of sincerity and truth. Dr. Rosselet gave him a faithful and explicit answer, assigning a time but a few weeks distant. Haller with calmness expressed his obligation to his friend, and his gratitude for the speedy prospect, and continued to apply his time and powers to his literary occupations, and to pious offices, to which he had ever given a marked and devout attention. When the fatal moment approached, he was able to judge for himself; and putting his finger to his pulse, he remarked to Rosselet, "My pulse beats not." $\mathrm{He}$ thus himself indicated the moment when the vital spark was extinguished, and expired on the 12th December, 1777 , in his serentieth year.

Baron Haller had been thrice married; first, in 
1731, to Miss Marianne Wys, the daughter of the Seigneur of Mathod; of whom he was deprived in 1736, some months after his arrival in Göttingen. It is this lady who is so much celebrated in his poems under the names of Doris and Marianne. The love he felt for her was most ardent; and nothing can be more touching than his ode upon her death. In 1738 he again married, uniting himself to Miss E. Buiher, the daughter of M. Buiher, a counsellor of state and banneret of Berne, but she survived their union but a very short time. Finally, in 1741 he married Miss Teichmeyer, the daughter of a physician, who was privy counsellor and professor of medicine at Jena. He was also the father of a numerous family, leaving behind him eleven children and twenty grandchildren. to whom he consigned. with their patrimony, his fair name and good example.

Baron Haller was a Protestant, and very rigorously discharged the duties and obligations of his religion. He was decidedly pious, and like the great Robert Boyle, had a supreme veneration for the name of God. "A thousand incidents," says one of his panegyrists, " which passed unheeded by the vulgar eye, recalled to his mind the Deity : and when he recollected or heard that Great Name, he gave vent, in whatever company or circumstances he happened to be placed, to some pious ejaculation, with his eyes and hands uplifted towards heaven." He was also the champion of Protestantism, and published several treatises in its defence. That one 
which is best known in Britain, is his Letters to his Daughter on the Truth of the Christian Religion. We can find room but for a very short quotation, which, however, will illustrate the simplicity and power of his style. "Your father, who now addresses you, during the period of a long life, spent in continual labour and study, thought himself obliged to consecrate some of his leisure hours to inquiries on the subject of religion. The result of which has been, that those truths which have been called in question, always appeared to him the more evident and respectable, the more attentively he examined the reasons and proofs on which they were founded. Who are those sceptics and sneerers, who, in this our day so much abound? I have read the works of their most famous authors. Not one of them was capable of understanding the true and precise acceptation of the terms made use of in the sacred writings; not one of them had entered deep enough into the study of nature to trace Divinity in the various objects which surround us, notwithstanding those displays are so numerous and illustrious in every work of creation, whether we consider its design or disposition. Therefore, that which furnished Hobbes with a subject of infidelity, confirmed Newton in his faith; that which was to Ofray a matter of sport, was to Boerhaave an extensive theme for wonder and adoration."

The Baron both spoke and wrote the German language with much elegance and purity. $\mathrm{Dr}$ 
Hayne, the celebrated professor of eloquence at Göttingen, has stated that he did much to improve and simplify the language, and enriched it with many new and happy expressions. He was also master of French, English, Dutch, Italian, Danish, and Swedish, and communicated in all these languages with his foreign correspondents. These were numerous, as were his intimate acquaintances and friends, in which list may be enumerated the celebrated names of Worlhof, Bonnet, Gesner, and Tissot, Zimmermaun, Zin, Mecket, Hubert, and Sproegel. He was celebrated for the power of his memory, which scarcely allowed any thing which he had once heard or read to escape. On one occasion, being with Tissot in company with an officer who had served under the celebrated Charles XII. of Sweden, and who was giving a recital of his campaigns, thus fighting his battles o'er again, but who forgot the names of a great many places and positions, these were supplied so readily and accurately by Haller, that the old soldier could not be persuaded that the Baron had not visited and examined the country he seemed so well to know. We may add, that it was generally allowed at Berne, that no one was a sounder politician, or more intimately acquainted with the general politics of Europe, and still more with those of their own republic.

As the author of so many and great works, the habits of Haller could not fail to be most active, and his life much occupied and devoted to their 
execution. The reading of new books, which were sent to him from every part of the world, was the only relaxation which he allowed himself. It is remarkable that he even slept in his library, and sometimes did not leave it for months: he always took his repasts in it; and when his family were there collected round him, to partake of their common meal, he had under his eye all that was dearest to him in this world. His individual tastes and manner of living were the most simple and frugal possible. He ate but little and drank only water: and we find that in his poem on the Alps, far from condoling with the inhabitants of these mountains because the vine did not flourish in their soil, he regarded the privation as a benefit and a blessing. The following anecdote may give us some idea of his devoted activity. A short while after his return to Berne from Göttingen, in ascending a stair, he fell and broke his right arm. It was set by an able surgeon; and Haller instantly set to work as much as possible to provide a substitute for it. Nor was he long in procuring one; for the next morning the surgeon found him surrounded with his books, and writing with wonderful facility with his left hand; it was with some difficulty the surgeon could obtain time for the necessary dressing, and Haller seemed to view the affair chiefly as rendering useless one of his ordinary instruments of labour.

His excessive devotedness to study exerted an influence not only on his own character, but also on every thing which surrounded him; his mansion 
was a retreat for the sciences, and every thing within its walls was consecrated to their cultivation. His pupils, who, in great number, studied under his direction in his library and museum, his children, and even Madame Haller herself, who had learned to sketch and paint, that she might render herself useful to him, his friends, and even his fellow citizens made it their study to contribute to his labours. This impulse was communicated far and near; he himself collected all, laboured for all, and animated all. Thus placed in the centre, every thing again reacted upon him. His imagination usually presented to him every thing in fair and bright colours, and his sensibility, which was extreme, did not permit him to view any thing with indifference. Though habitually serious and reflecting, still the vivacity of his genius and the variety of his information did not allow the exhibition of his character to be always the same. He was sometimes the subject of rapid alternations of pleasure and of pain. This inequality was frequently manifested even in society, into which, however, he but seldom entered; his conversation, however, was at all times learned and pointed, and such was the constitution of his mind that he could always give even to minute objects the most acute and profound investigation. He had long been in the habit of making extracts of all that he read, which extracts were arranged according to their subjects, and he could thus readily use them when required. Those who laboured under him followed 
the same plan; and it was thus he acquired that almost incredible erudition of wbich his works are such striking proofs.

Upon the whole, the disposition of Haller was somewhat austere, and he long retained the impressions first made upon him, whether of favour or of injury. On some occasions he exhibited an arbitrary conduct, even towards his children, and frequently required considerable sacrifices at their hand. This trait became more conspicuous with his advancing years. Oppressed with infirmities, and also loaded with dignities and farours, not having the resource even of forming new desires, and abandoned solely to the passion of study, every thing which had no connexion with it had no charm for him. In fact, this in the long run very much altered his character, and no one could have discovered in him the affectionate friend of Gesner, and the fascinated and devoted admirer of his $\mathrm{Ma}$ rianne.

Haller was about the middle stature; he had much life in his eye, much expression and nobleness in his physiognomy, and he united great mental strength with a prodigious and unceasing activity. In a word, he was gifted with powers of which few men in a generation or an age are possessed, and he used them with almost unexampled assiduity. He was perhaps both the most voluminous and learned writer since the time of Galen. It has been alleged that his writings are somewhat obscure; but even his enigmas merit consideration. 
What especially proves the clearness and solidity of his doctrine is, that throughout all his numerous productions, there reigns the greatest harmony and consistency; and every where may be found the same power of generalization, and the same unity of aim and execution. 

THE

\section{U S I CA P I D E,}

Containing the Todies and Flycatchers, as is well known, form one of the great divisions of the insessorial or perching order, and are united on one side to the Ampelidice or chatterers, and on the other to the Liniadoe or shrikes. The food of the chatterers, however, is almost exclusively confined to fruits ; but one of the chief characteristics of the family now before us is that of feeding entirely upon insects; these are captured by the bill, during flight, in the same manner as that adopted by the swallows and all fissirostral birds. Their organization is consequently in strict conformity with this habit, and we shall see how beautifully nature has adapted it for such a life. The wings are not formed for such rapidity and celerity of movement as those of the swallows, since the flycatchers do not pursue their prey to any distance; but this deficiency is compensated by a very unusual breadth in the bill, the sides of which are furnished with long rigid bristles pointing forwards; thus provided, a flycatcher darts upon an insect with unerring certainty, since, if it fails to get a firm hold by its bill, the bristles standing out on each side confine the struggles of the viction, and 
at the same time prevent either the eyes or face being injured by the claws or wings of the insect. We have already seen their structure slightly developed among several groups of the warblers, and indeed the two families, as will subsequently appear, are so closely united, that the best ornithologists are perpetually confounding one with the other. A little attention, however, will show their true distinctions. Both are flycatching families, but with some remarkable differences; the warblers pursue the chase from tree to tree; they are perpetually wandering about and hunting up their game; whereas the true flycatchers are sedentary, they will choose some convenient station, generally near their nest, from which they watch for their prey, and where they will remain, with little variation, for hours; after every capture; they almost invariably return to the identical twig they before occupied. Now these totally opposite methods of procuring the same description of food, is marked by a difference equally striking in the conformation of the legs and feet. Those of the flycatching warblers (Sylviado), however broad may be their bill, or strongly bristled, are invariably longer, the toes larger and unconnected, and the whole structure adapted for that constant exercise and locomotion which belongs to the habits of the warblers; we see this in the Setophaga ruticilla, one of the broadest billed birds among the Sylviadoe. Now, as the true flycatchers, comparatively, have very little use for their feet, we consequently find that these members are formed in a very different 
manner; the leg is shorter, scarcely indeed exceeding the length of the hind-toe; the toes are particularly small, and (as an additional support to the bird in its sedentary mode of life) the two outer are more or less united, so as to give a breadth and a support to the sole of the foot which it would not otherwise possess. Nothing will illustrate their distinction better than taking an example. Let the student, therefore, compare the feet of the American Red-start (Setophaga rutcilla, Sw.), which is a flycatching warbler, with the feet of the common American Tyrannula rapax or wood-pierce flycatcher, and he will at once comprehend the force of the above distinction.

In regard to the name by which this family should be designated, we have been sadly perplexed, and this has chiefly originated from what we conceive to be the mistaken notions that have been entertained regarding the Todius viridis. Strictly speaking, the name of a group should always be derived from the typical genus; now if this rule was followed in the present instance, Eurylaimus (which is evidently the type of the whole family) should preserve the generic name of Todus, by which indeed it was known to all the Linnæan writers; the Todus viridis should have received another generic name, and the whole family might then be correctly termed the Todidoe; but these alterations would lead to so much confusion, that we have not rentured upon, much less do we recommend, their adoption. Again, as the whole of these birds are flycatchers, we might 
give that name to the family with great propriety, but if this idea is followed up, and the nomenclature of the genera and sub-families also changed, greater changes still more numerous and still more objectionable would follow. Eurylaimus must be changed for Muscicapa, and Muscicapa, as it now stands, should have a new name! Todus would thus be retained only as a genus, and no group would bear such a well known designation as would immediately remind us of birds with syndactyle feet; an idea, which, from long habit, we always associate with words modified from T'odus. Under all these disadvantages to applying a strictly correct and uniform nomenclature, we hope that the generality of ornithologists will approve of the middle course we have now chosen : that is, of naming the family after tha: typical group which is the largest and best known in the family, and sinking Todus to its proper level. T'his plan, after all, is certainly not without objections. but it is attended with fewer alterations of received names than any other we could devise, and it therefore may be thought the best. On a former occasion, some years ago, we designated this family by the name of Todidce, but it has been represented to us and perhaps with justice, that as the great majority of the birds are the Muscicapidoe of all modern systems, whether artificial or natural, it would save much misapprehension if that name was preserved on the present occasion, and this we have accordingly done.

The great majority of the flycatchers belong to 
the typical groups, which are so dissimilar from any of the chatterers, that they are in no danger of being confounded, even by the student; but in such as appear to be aberrant divisions, or, in other words, which connect the two families, the leading characters of both are in a greater or less degree united. The birds which occupy this intervenng station have an organization which proves them to feed upon fruit as well as upon insects, and the proportion in which these two different regimens are combined is manifested by the structure of the mouth; the presence or absence of rigid bristles at the rictus or gape, is decisive of the bird being frugivorous or insectivorous; and when, as in the Piauhou or red-throated chatterer of authors, the gape and general form of the bill assimilates to the Ampelida, yet that the rictus has stiff bristles, we infer that such a bird, although habitually a fruit-eater, is likewise a devourer of insects. And this accordingly turns out to be the fact. In this and all the other types which shew a tendency towards the family we have just left, the feet are much the same as those of the genus Casmorhynchus: that is, the toes are more or less united at their base, the soles broar, and the lateral scales of the tarsi are very small and numerous; the gape also continues to be very wide and the bill strong, often thick, and although depressed, is never so completely flattened as in the typical Muscicapidx; the few birds placed in the genera Psaris, Pachrynchus, and Querula, are precisely of this description, and but for the stiff 
bristles round the mouth, and their obvious affinity to other genera truly insectivorous, might be placed at once with the true fruit-eaters (Ampelidoe), was there any hiatus wherein they could be introduced. According to our views, however, such an hiatus does not exist, the passage from the Leiotrichinos to the Ampelidoe, although many links to render it perfect are wanting, is yet sufficiently well marked out, and we therefore decide on placing these fruit and insect eaters within the confines of the Muscicapidoe.

One of the chief peculiarities of the flycatchers is certainly found in their short and weak feet, a structure beautifully adapted for their perching habits, but quite incompatible with the power of walking. Yet it must be remembered that this, as well as every other, natural group, must have a rasorial type, and we therefore find that one of the aberrant divisions of the Muscicapidoe is distinguished by the length and strength of the legs. In all other respects, however, these walking flycatchers preserve the characteristics of their family, and although the bills of some are less flattened than usual, the stiff bristles of the mouth sufficiently indicate their true relationship. It may be proper in this place to observe, that no typical Muscicapidoe, as here defined, have yet been discovered in that part of America which lies north of Mexico: The flycatching tribe, which formerly bore that name, having been removed out of this circle to the confines of the next, where they now form part of the Tyranninae or Tyrants. 
This timely hint may save the student much trouble; and when we come to treat of the family in question, the peculiarities which separate the Old from the New World flycatchers, will be fully explained.

The geographic range of this family in their preeminent typical examples, is almost confined to intertropical regions; to those countries, in fact, where insects which constitute their principal, if not their only food, are the most abundant. During the heat of summer, three, or perhaps four species migrate into northern and central Europe, build their nests and rear their young, but on the first approach of autumn they disappear and return to the more genial coasts of Asia Minor or Southern Africa. The aberrant divisions, with the solitary exception of one genus, are all peculiar to South America. The greatbilled Eurylaimi are exclusively Indian, while the true Muscicapidoe, which comprise a greater number of species than are to be found in all the other divisions collectively, are distributed in nearly equal proportions over the hot latitudes of Africa, India, and New Holland; some few of very particular forms are found in Brazil, and others equally remarkable are restricted to the Australian province, but none, as we have already intimated, occur in North America.

From these preliminary remarks, the reader will be better prepared to understand the nature of the family which will now be investigated. As a whole, it is not what we should call a perfect group, because several of the connecting types are wanting; 
and this will always militate against every circular arrangement. On the other hand, these gaps are by no means wide; and although some of the primary divisions contain very few species, one of the most typical (Muscicapinoe) is remarkably perfect; this is peculiarly fortunate, in as much as it enables us to test the accuracy of the remainder, and almost to demonstrate, that however poor they may be in regard to their contents, the sub-families themselves are natural : these will now be explained under the names of, 1. Querulince; 2. Psariance; 3. Fluvicolina:; 4. Muscicapino; 5. Eurylaminae: the three first constitute the aberrant group; the fourth, the sub-typical; and the fifth, the typical.

Of the QUERULIN we know but of two species, and even these differ so much, that we are obliged to consider them for the present as distinct types. One, the most remarkable, is the Piauhau chatterer of Le Vaillant, and it now forms the type of the genus

\section{QUERULA.}

Linnæus and Brisson considered it as a flycatcher, on account of the stiff bristles of the mouth, but in all other respects this bird gives us the idea of a large strong billed chatterer. It is near twice the size of a thrush, measuring eleven inches ; entirely black, except under the throat of the male, where the feathers are deep red and glossy ; the bill is large, very strong, but considerably depressed, while the bristles, 
although short, are very stiff; the feet are remarkably short, small, and weak. It is not surprising that writers who are led to decide by outward and general similitudes, should have placed this singular bird in the same genus as its prototype, the Coracina scutata (Tem.), seeing that the colours of both are nearly the same. The Coracina, however, is merely the representative, among the crows, of Querula; its bill is high, compressed instead of depressed; and the feet, although very short, are remarkably strong; the lateral toes are likewise equal, while those of Querula are unequal : the bill, in short, of each bird, at once proclaims its family. Did the Piahau stand alone in the station we have assigned to it, we should have had much hesitation in removing it beyond the circle of the Ampelida, although quite ignorant what precise station it would hold in that circle. But fortunately there is another bird which is so clearly connected to Querula, yet is nevertheless such a decided flycatcher that our confidence in the arrangement we are now pursuing is greatly increased. We shall here insert the only species yet known of this genus. 


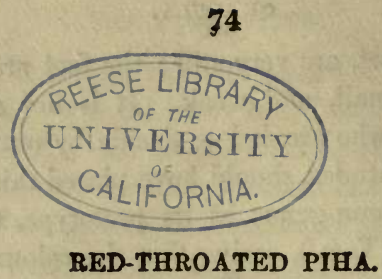

Querula rubricollis, VIEILLOT.

\section{PLATE I.}

Deep black ; the male with feathers of the throat rigid, nar. row, and deep crimson.

Le grand Gobe-mouche de Cayenne, Bris. Orn. ii. 386, Pl. Enl. 381. - Le Piauhau, Le Vaill. Ois. de l'Ameriq. PI. 47, 48.-Muscicapa rubricollis, Liren. Auct.-Querula rubricollis, Vieillot Gal. P1. 115.

Although by no means scarce, this singular bird appears confined to those limited portions of tropical America which constitute the colonies of Demerara, Surinam, and their immediate neighbourhood. In size, and in the general structure of its bill, wings, and feet, it bears a stronger resemblance to the chatterers than to the flycatchers; and Le Vaillant, who was also acquainted with its habits, makes no scruple of placing it in the genus Ampelis. Brisson, on the contrary, as well as all the writers of the Linnæan school, regarded it as a flycatcher, influenced, no doubt, by a consideration of the short but strong bristles at the gape, which plainly indicates that the bird is insectivorous. Le Vaillant is evi. 



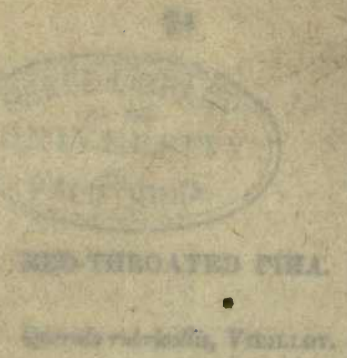

wathes.

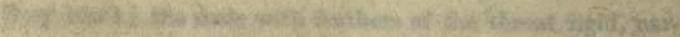

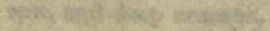

So

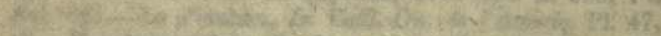

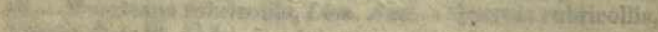

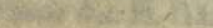

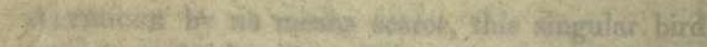

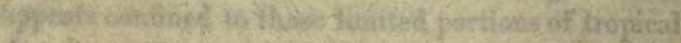

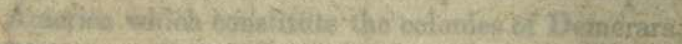

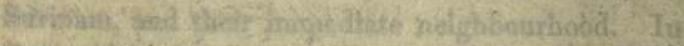

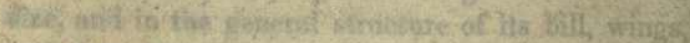

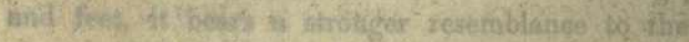

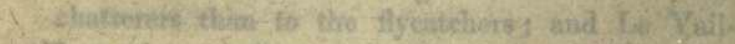
Wh:

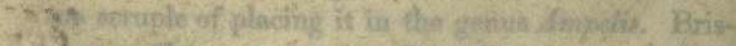

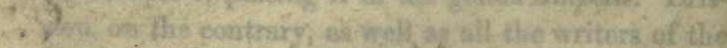

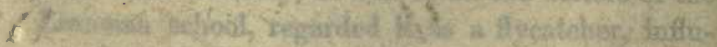

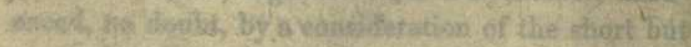

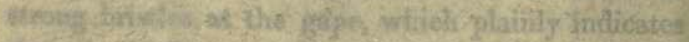
210 the Nis. 


\section{CALIFORNIA.}


dently prejudiced, however, in his determination to regard this as a perfectly true chatterer; and, to support his opinion, he asserts that it takes no other nourishment but fruits, an assertion which the above peculiarity in its structure absolutely demonstrates to be false; for there cannot be the least doubt that nature has given to this bird an organization in the stiff bristles of its bill, which, did it live on fruits only, would be perfectly useless.

The Piha, according to Le Vaillant, lives only in the forests, where it builds, on the highest branches, a large nest, in which the female deposits four eggs. It seems to have no other note than that which resembles the words pi-hau-hau, uttered rather in an agreeable than a harsh tone. The plumage of both sexes is of a deep and uniform black, with little or no gloss on the feathers, and equally dark on every part of the plumage. The male is distinguished by having the feathers of the throat of a very deep crimson, resembling, both in colour and rigidity, those which belong to the Ampilis pompadoura; but all the other feathers are of the ordinary softness : the tip of the chin is black. The female and young male are entirely without this ornamental patch, the throat being wholly black, like the rest of the plumage.

Total length, 11 inches; bill, from the gape, $l_{\frac{1}{1} \frac{4}{0}}$; from the front, 1 ; wings, 7 ; tail beyond, $1 \frac{1}{2}$; from the base, 5 ; tarsus, $\frac{8}{70}$.

The bird just before alluded to forms the genus 


\section{LATHRIA.}

Ir is about the size of a thrush, entirely of a dull brownish olive, and having every appearance, at first, of being a tyrant flycatcher (Tyrannus). On examining it, however, more attentively, we detect some of the peculiar characteristics of the Piauhau, blended with the more strongly bristled rictus and front, the flatter and weaker bill, and the diminished stature of the tyrants. The structure of this bird, indeed, is peculiarly interesting, because it not only shows a decided affinity to Querula, but opens an obvious passage to the next sub-family by means of a second species, rather smaller, which has recently come into our possession, as if to confirm the locality in the series we had previously assigned to its congener. But the relations of nature are so intricate and ramified, that the more we investigate them, the more do they seem to multiply; and no sooner do we get over one difficulty with " toil and trouble," hut another comes to light; and this we find in the present instance; there is a curious dull coloured bird, about the size of a very small thrush, which we described some years ago under the name of Tyrannus calcaratus, on account of its having a series of little spines at its knees. Now this bird has so 
much the general aspect and colour of $C$. cinerea, that it might pass for the young, or a smaller race of the same species, but that the legs are rather longer, and the claws instead of being short and broad are,-like all those of the genuine tyrants, slender, lengthened, and very much curved. The $T$ yrannus calcaratus differs also very materially from the $L$. cinerea and the Querula by having the commissure of the bill, as in Tyrannus, perfectly straight, except of course at the tip, where it suddenly bends down with the hook. Now, in all the typical Ampelide, and in the two birds just mentioned, the commissure is invariably arched. It seems, therefore, that this resemblance between $T$. calcarata and Lathria cinerea must be looked upon as only analogical, seeing that the former bird, however disguised, has all the essential characters of the true tyrants, the strong and clasping scales of the tarsi alone excepting; we are more disposed to take this view of its affinities, because the passage from $L a$ thria to $P_{\text {saris }}$ seems to be sufficiently made out without the intervention of the bird in question. 


\section{GREY PIHA.}

Lathria cinerea, SwaINs.

PLATE II.

Entirely cinereous; belly' and vent paler, and tinged with fulvous.

Le Cotinga cendré, Le Vaill. Ois. de l'Ameriq. Pl. 44, p. 135.

THe general aspect of this singular, although plain coloured bird, is so like that of the American tyrant flycatchers, that it is only upon looking to the more minute parts of its structure that our first opinion is shaken; and we feel disposed to place it much nearer the chatterers than it would be, if retained among the tyrants (Tyranninoe). In referring it to the station now proposed, we are strengthened both by the opinion of Le Vaillant, and by certain characters it presents, indicative of an affinity with the Querula rubricollis. Of its manners nothing whatever has been published, for Le Vaillant, who lived some years in Surinam, seems only to have become acquainted with this species by inspecting a preserved specimen in Paris; and although it was sometimes shot by my hunters in different parts of Southern Brazil, I could never learn any thing further than that it was found only near the thick forests. 


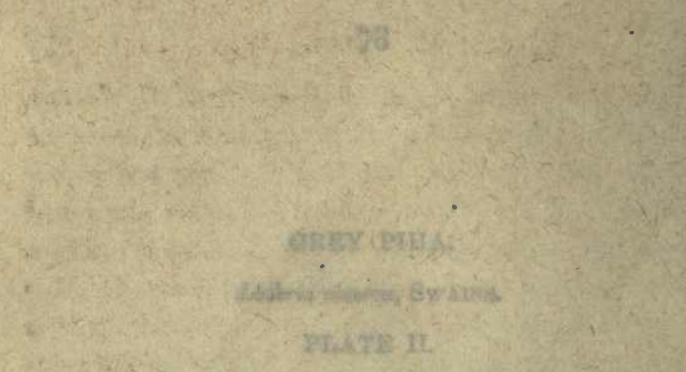

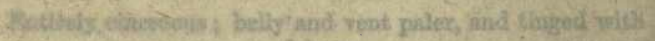
fodrutus,

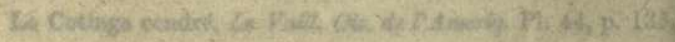

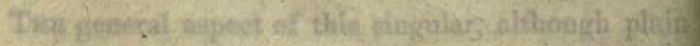

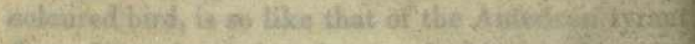

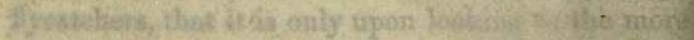

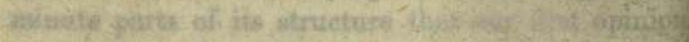

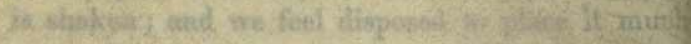

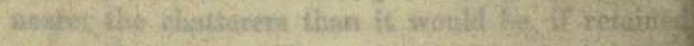

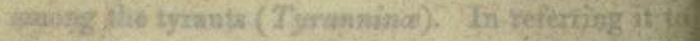

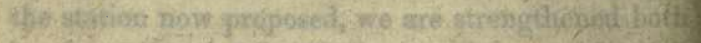

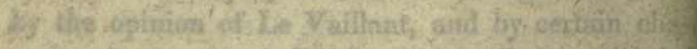

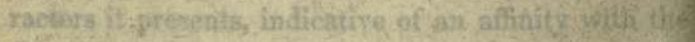
Querula hubrioullis. Of ics mannars nothitug whath

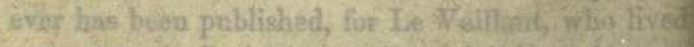

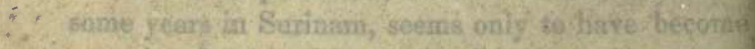
acguainted with this species by inipeeting a prect

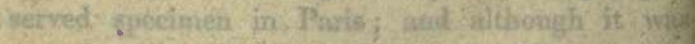
nometimen shos by my hutiters in different parst

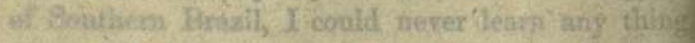

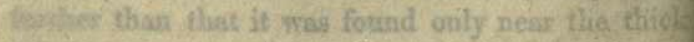
hisesh 


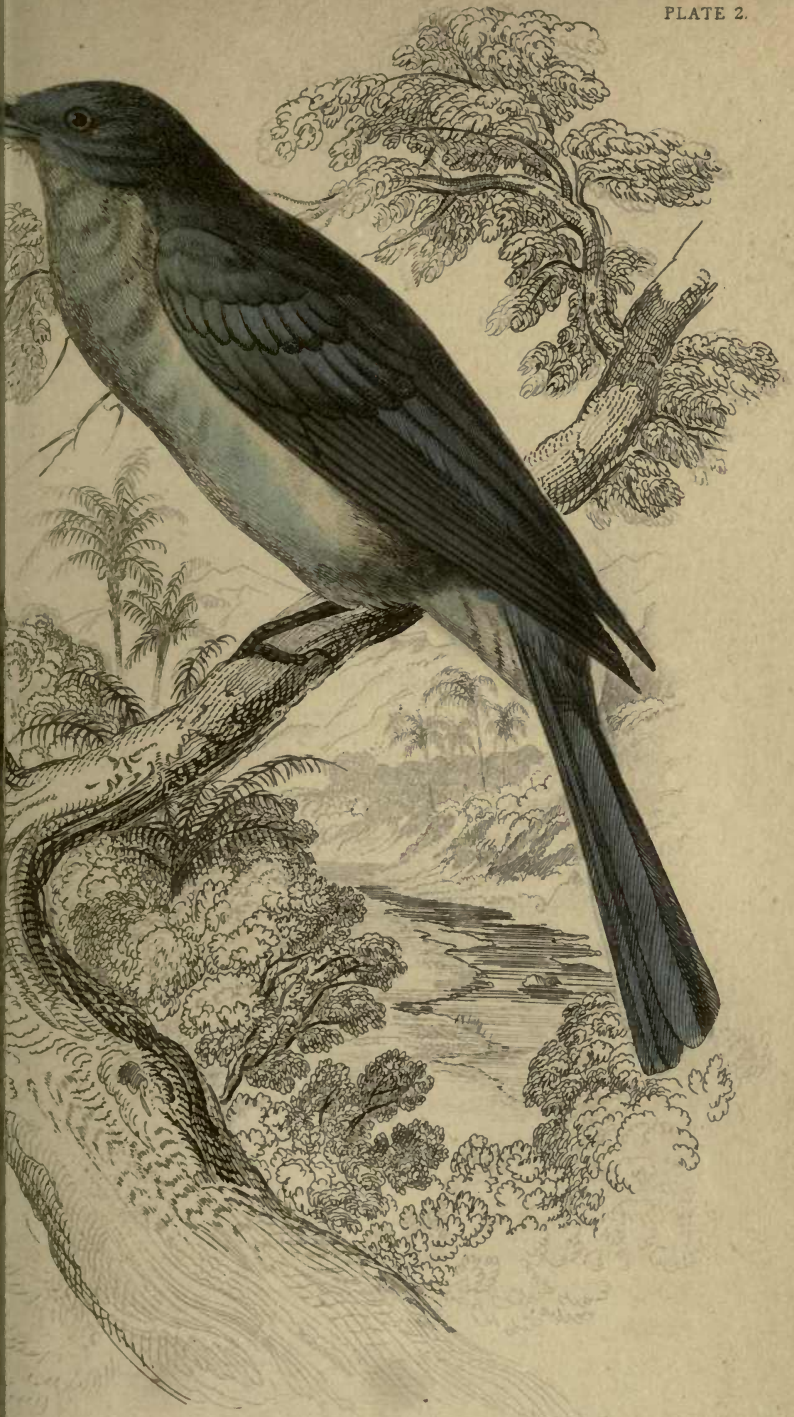

GRPY PIHA

Native of 3razil 


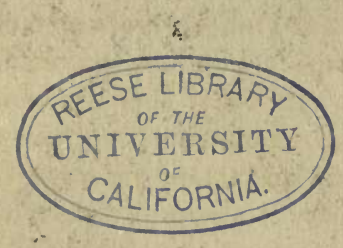


In respect to its affinity with the red-throated piha, it has already been observed, that although the bill is shaped like that of several of the tyrants, and is even as much bristled at its base, yet that the commissure, as in Querula, is arched, and not, as in the Tyrannula, perfectly straight; the distinction is of much importance, for it indicates that the bird has nothing of the shrike-like habits or structure of the true tyrants, and that it probably feeds as much upon fruits as upon insects. It is this peculiarity also which leads me to the belief that Tyrannus calcaratus is merely a representative of our present bird, although its colours are almost precisely the same. The second affinity it shows to Querula is in its feet and claws; the first are remarkably feeble. and covered with minute posterior tarsal scales while the claws are broad, and not gradually taper ing to an acute point, like those of the tyrants.

The plumage is sufficiently described in the specific character; the inner wing-covers and the vent are nearly white, and the tail is perfectly even. Although a common bird in South America, it has been so confounded with others by the old writers, that I can give no other synonyme with safety than that of Le Vaillant.

Total length, $9 \frac{1}{2}$ inches; bill, from the gape, $1_{1} \frac{1}{10}$ front, $\frac{7}{10}$; wings, $4 \frac{7}{10}$; tail beyond, $2 \frac{1}{2}$; base, $4 \frac{7}{1} \frac{7}{0}$ tarsus, $\frac{3}{4}$.

We are now brought to the Psarinas or blackcaps, represented by the genus 


\section{0}

\section{PSARIS,}

A more decided group than the preceding, and which makes a further step towards the typical characters of the genuine flycatchers. The general size of these birds is between that of a small thrush and a robin; and all the typical species are inhabitants of tropical America. They are conspicuous to ordinary observers, by their great heads and their thick depressed bill, the upper mandible of which has the very unusual character of being quite convex above, so that there is no culmen or ridge. The feet still retain the structure of the Ampelidor, being weak, and protected on the sides of the tarsi by minute lateral scales; the wings also are long and ample. Of their manners, in a state of nature, very little is known. It would seem, however, from the observations of Azara, that the typical species, like many of the chatterers, are to be seen sitting on the tops of lofty forest trees, and the structure of their wings show that they are quick fliers. In those larger species which form the genus Psaris, the bill seems very powerful, and is so abruptly hooked at the tip, that it is not surprising that the Linnæan writers, and some of the moderns, placed the only species then known, Psaris cayana, with 
the tyrant shrikes (Tyrannino). We suspect these birds to feed both upon insects and fruits, for several have rictal bristles, and their gape is very wide. There is a peculiarity in their colouring which deserves attention; four or five,-which from other circumstances we know to be distinct species, -are nevertheless coloured precisely alike; they are of that delicate light grey, so universally seen among the gulls, but with black heads and wings. Now, we explain this remarkable analogy by pointing to the part of the circle of Muscicapidoe where this group enters, and we shall then find that this station is precisely analogous to that which the Laridoe or true gulls appear to hold in the circle of the Natatores; the Natatores being itself represented among the Dentirostres by the family of Muscisapidce. The large head, again, of all the Psariance reminds us at once of the Pachycephala among the chatterers, and on comparing the two family circles, those particular groups stand opposite to each other. It is right however to mention, that no such analogy can be traced between Querula and the swallow chatterers (Bombycillidos), but then it may be as fairly supposed this want of conformity originates in ignorance of undiscovered birds, as in erroneous views. Time, however, will clear up such nice points which now lay open to controversy, and in the mean time we must endeavour to dispose the contents of imperfect groups, like the present, as near as we can to the course which nature has purued in her more perfect groups. 


\title{
BUFOUS-EARED BLACK-CAP
}

\author{
Psaris erythrogenys, SELBY.
}

\section{PLATE III.}

Cinereous-grey above; whitish beneath; front and sides of the head rufous; wings and tail black.

Psaris erythrogenys, Selby, Zool. Journal, ii. 483.-Illust. of Orn. i. under pl. 10.

Tre first intimation of this species was given by Mr. Selby, who observed it in the museum at Paris, where we subsequently drew and described it. Latterly, however, a specimen has come into our possession, but it must still be considered a very rare species, since we have not yet met with it in any of our public collections. It has been thought, indeed, to be the young of the Lanius inquisitor of Olfers; but I am by no means inclined to adopt this opinion, not only because there is no analogous instance of rufous changing into black merely upon one part of the head, but because a specimen of the adult male of the true inquisitor, forwarded to me from Berlin by Professor Lichtenstein, differs materially in its dimensions from our erythrogenys. That 

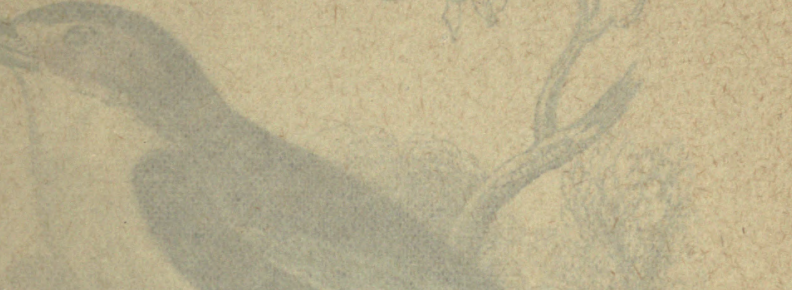

(2)

ying

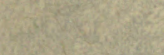
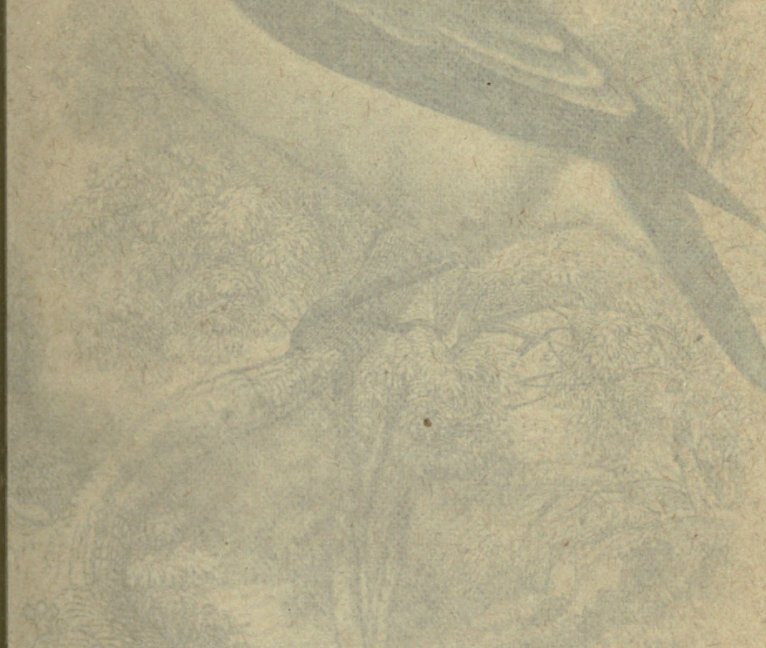

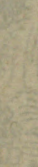

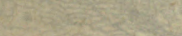

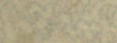

Misig)

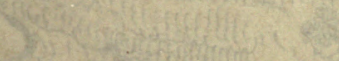

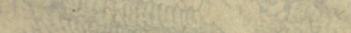




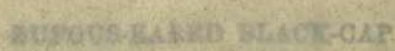

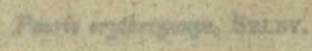

Fharas in:

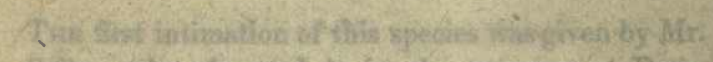

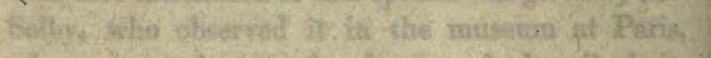

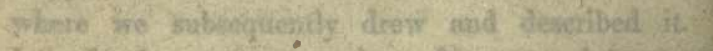

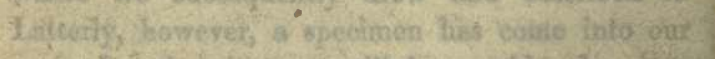

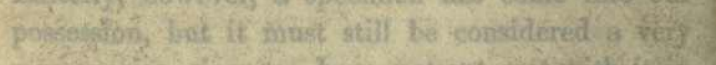

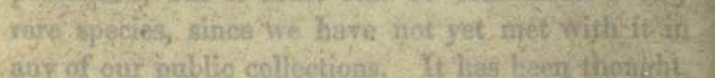

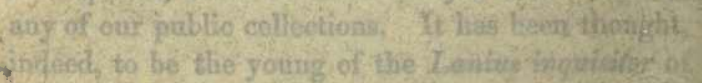

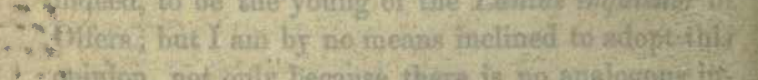

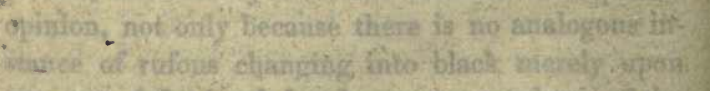

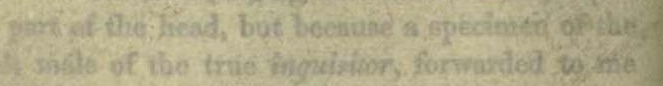

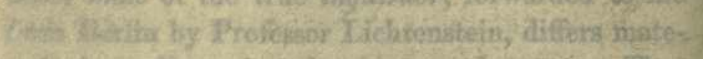

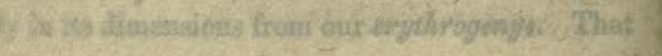




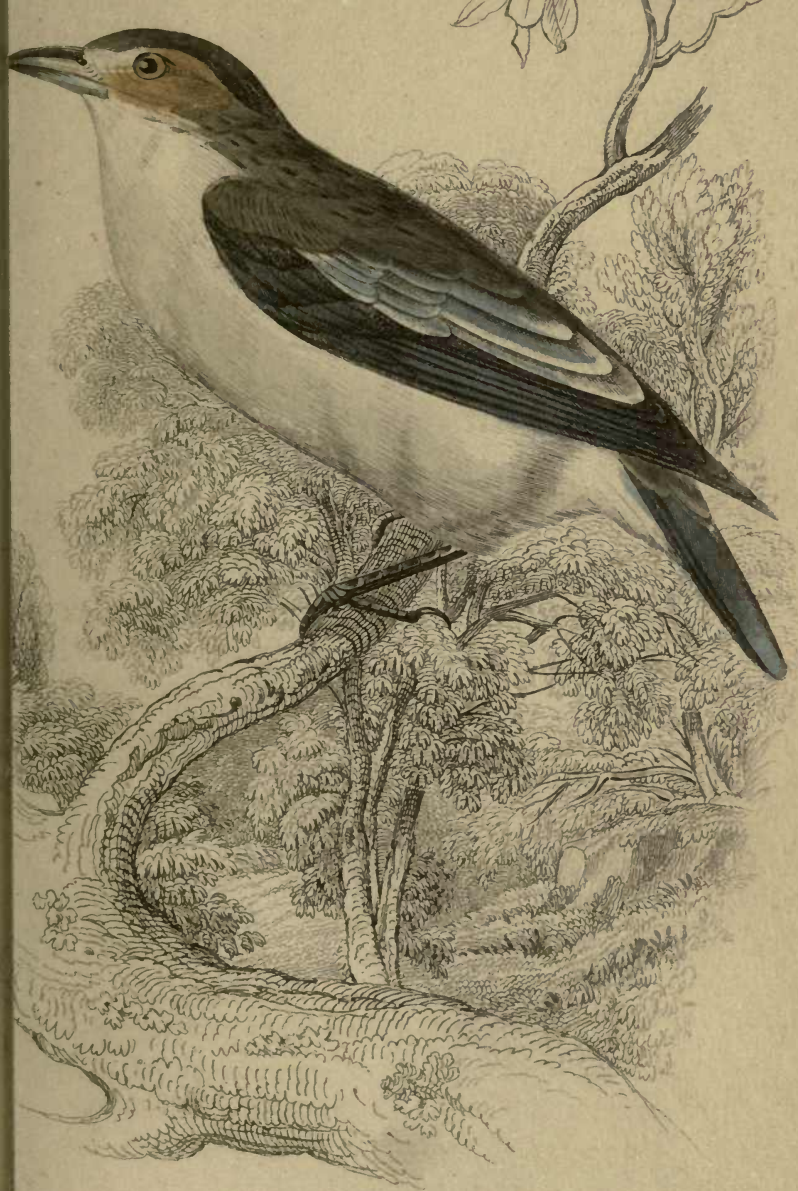




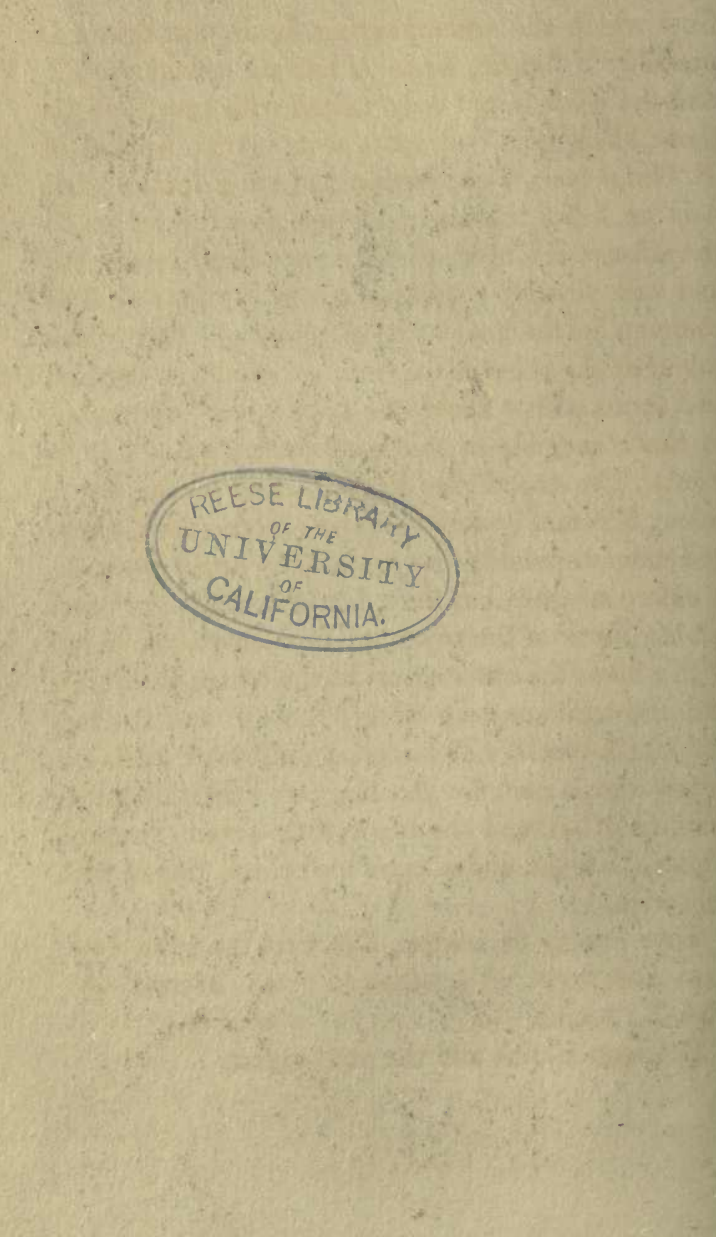


from which the accompanying figure was drawn is probably a female, since it has no spurious quill, and the back is not only mixed with grey, but has those black detached spots seen in the females of P. Guianensis, Braziliensis, and other species; but it is our belief that the male possesses the rufous on the sides of the head even brighter than the female, and will possibly exhibit also the spurious quill so common in the more typical species. The rufous colour of the sides of the head spreads over the ears and forms a line above the eyes, where it is united to the other side of the head by a narrow line in front. The top of the head is deep black, which colour becomes broken into spots on the nape, neck, and interscapulars; the remaining upper plumage is cinereous-grey, but those feathers which are nearest the blank of the wings are pure cinereous, edged with white; the outer covers of the wings, the quills, and the tail, are deep black; the bill and the feet are bluish-black. The second and third quills are nearly equal, and are the longest; while the inner margins of all, and the inner wing-covers, are pure white. All the under parts are white, tinged with yellowish.

Total length, $7 \frac{1}{4}$ inches; bill, from the gape, $1 \frac{1}{10}$; from the front, $I^{\circ}$; wings, 4 ; tail beyond, $\frac{8}{10}$; base, 3 ; tarsus, Io. $^{7}$.

Between Psaris and the next genus, 


\section{PACHYRHYNCHUS,}

(A name which some erroneously have applied to both), there is such a beautiful series of connecting species, as to render it quite impossible to decide where one group ends and the other begins; although, if we look only to their typical examples, the difference is very striking. Several of the large $P$ sari have a singular spurious quill, short and very slender, the use of which is altogether unknown, while in others the orbits and sides of the face are bare of feathers ; it is by these nice but certain characteristics of species that we are able to distinguish the different sorts, which are all coloured alike. There are two or three birds even larger, which may possibly come in the range of this sub-family; they are from New Holland, and form the genus Sphecotheres of Vielllot; the size is larger than a thrush, and the bill is equally large and broad at the base with Psaris, yet it is much more compressed on the sides; the under mandible is strong, and there is a large naked space round the eyes; the wings, in general, are not unlike those of Psaris, but the tail is much longer; the feet are short and remarkably strong, the nostrils quite bare, and the rictus smooth. We confess, however, our belief, that the true affinities of this genus are not to be 



\section{4}

\section{wiris}

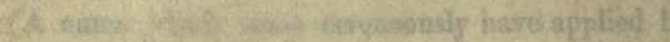

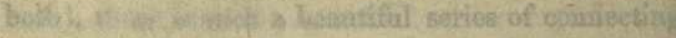

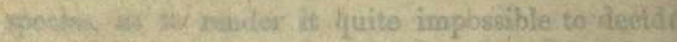
whore sigh sroup ends and the other pegingst al

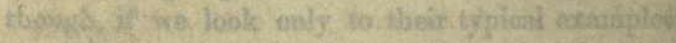

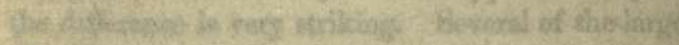

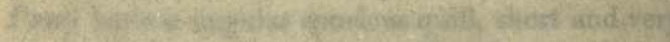

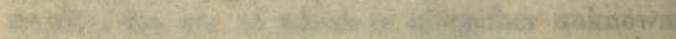

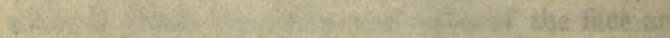

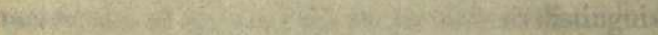

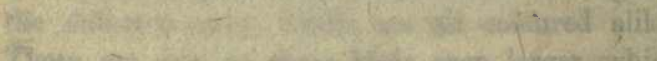

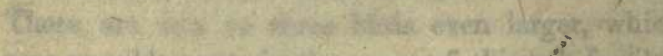

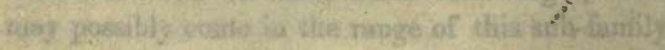

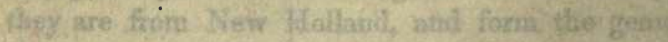

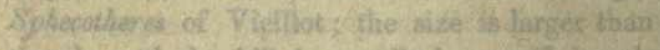

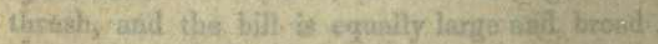

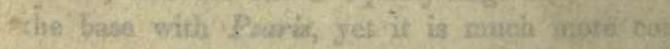

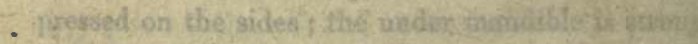

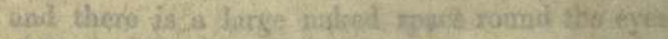

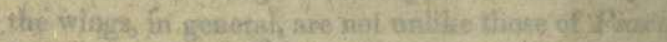

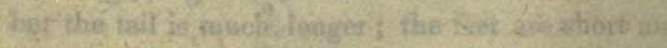

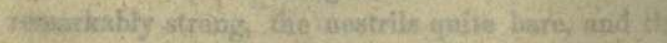

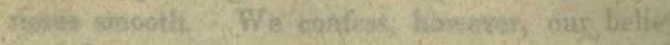

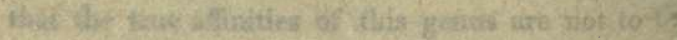




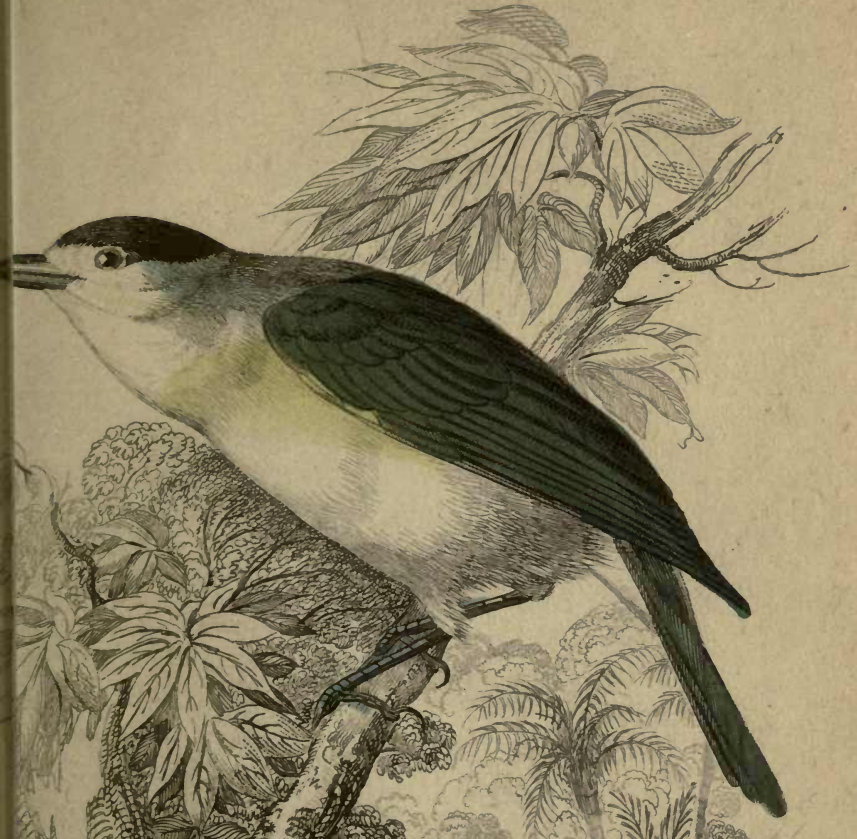

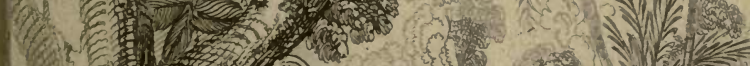

2. (C)

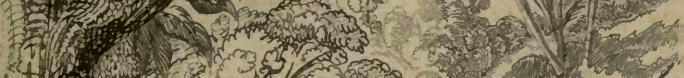
int

4 (1)

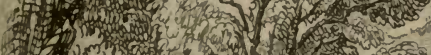




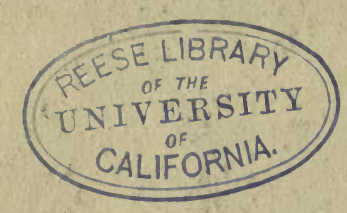


found in the present circle; that it has some relation, strictly so termed, to Psaris, is unquestionable, but we think that it is one of analogy rather than of affinity, and that Sphecotheres is the most aberrant type of the orioles, Oriolince, representing in that group, the genus Psaris. We incline the more to this view of the subject, because its position in this group seems to disturb the progression of forms between this and the sub-family we shall now enter upon.

\section{CUVIER'S THICK-BILL.}

Pachyrynchus Cuvierii, SpIx.

PLATE IV.

Above green; beneath white, with a bright yellow band across the breast; ears and neck above cinereous; the male with a black crown; the female with the wing-covers rufous.

Psaris Cuvierii, Zool. Illust. i. P1. 32, the male.-Tityra Vieillotii, Jardine and Selby, Illust. of Orn. i. Pl. 10, fig. 1, the female.

Trie most elegant species of this division, and the only one yet discovered that is ornamented with bright colours, is the $P$. Cuvierii, first figured in the Zoological Illustrations, and subsequently placed 
in the sub-genus Pachyrynchus, which name M. Spix very improperly applies also to the genuine Psari. I had long entertained the suspicion that the female was the $T$. Vieillotii of the Illustrations of Ornithology; but I was only confirmed in this belief by M. Natterer, who assured me, when inspecting my collection, that such was truly the fact.

In size, both sexes in our specimens are equal, and they do not exceed that of a sparrow. In the male the crown is of a deep and glossy black, which is separated from the bill by a narrow frontal line of white, which passes over the lores to the eyes. The upper part of the neck is of a clear and delicate cinereous, which tinges the ears, and advances towards the sides of the throat. The rest of the upper plumage is of a bright olive, or rather yellowishgreen, the quills alone being blackish beyond their outer edges; the tail is much rounded; the feathers olive-green, margined at their tips with yellowishwhite; the under plumage is white, with a broad and bright band (undefined at the edges) across the breast, the under wing-covers being of the same colour.

The female is in all respects like the male, except in the following particulars:-The crown of the head, instead of being black, is of the same green as the back; the eyes are surrounded with a yellow ring; while all those wing-covers which are nearest to the carpus, or outer edge, are covered by a spot of bright rufous. Between the first and second primaries of the male is a spurious quill, 
half the length of the second, which the female has not. The bill and feet in both sexes are blue-black.

Total length, 6 inches; bill, gape, $\frac{3}{4}$; front, $\frac{1}{2}$; wings, $2 \frac{3}{4}$; tail beyond, $2 \frac{1}{2}$; tarsus, I $^{7}$.

The

\section{FLUVICOLINA OR WATER-CHATS}

constitute the last of these aberrant divisions of this family. As it not only forms the passage to the shrikes but also to the Sylviadoe (as the other side of the dentirostral circle), it consequently presents in its contents a considerable deviation from the general characteristics of its own family. The birds, in fact, are terrestrial flycatchers, preserving all the characters of their tribe except in the legs, - these members being large, high, and stout, adapted for constant exercise upon the ground, where these birds are almost invariably seen. We have no examples of this group in England, but we may gather some idea of their forms and habits by looking to the stonechats of Europe. Along the Brazilian rivers and in all the flat and humid savannahs, these birds are seen running with great celerity in pursuit of insects, and moving their tail in the manner of our wheatear, which bird they further resemble in the black 
and white colour of their plumage. Such are the general habits of the whole group, but it comprises several genera, differing in the formation of the tail, the bill, and the wings. Of these the most curious is Alectura, first noticed by Azara under the name of Le Petit Coq. (Voy. iii. p. 447); its tail is broad, and, like that of our domestic fowl, it is laterally compressed and carried erect; in one species these feathers end in long naked filaments, and in another it is greatly forked. Near to these may be placed the long-tailed shrike-like flycatcher, another bird equally remarkable for the developement of the tail; it is called Yiperu by Azara, and is the type of the sub-genus Gubernetes. The fly-catchers, in general, are by no means a social family, yet nearly all of this division appear to live in small societies, frequenting, in little troops, the low marshy grounds of South America, where they keep up a loud discordant and disagreeable babbling; they are no less distinguished by these peculiarities than by their plumage, which is universally varied only with different shades of black and white. The whole group, as here characterised, is confined to tropical America. There are more birds referable to this group than to either of the two preceding, but it has been so completely overlooked by all systematic writers, with the exception of Azara, that it is very difficult at present to form a just idea of its contents.

In the foregoing remarks, the reader will perceive some peculiarities of the aquatic type, mingled, as 
it were, with those of the rasorial; nor is this the only instance where such an approximation is discovered. Great bulk, feeble and imperfect feet, and a fondness for water, are the three great indications of such vertebrated animals as belong to the first of these types; while strong and powerful feet, short but broad wings, and a harsh discordant voice, are chiefly to be found in those groups which represent the Rasores or fowls. Now each of these latter characters are possessed by the birds before us, to which they have superadded one, and but one, of the characters of the Natatores, namely, aquatic habits. Some highly interesting speculations arise out of this, too abstruse, however, for our present discussion. Certain, however, it is, that there is always one division of a large group like the present, which either directly or indirectly manifests an attachment to water; and as this is not seen, so far as we yet know, in the Querulinoe, it would naturally be expected in that aberrant division which stood on the opposite side of the circle. And accordingly we find it to be so. Querula has three of the natatorial characters, namely, great size (it is the largest bird in the whole family), a very broad and strong bill, and yet remarkably small and weak feet; but a fourth, the love of nater, it seems not to have, so far as our imperfect knowledge of its manners extends. It must be remembered, also, that no animals which are merely analogical representations of a type, represent all the characters of that type; a moment's reflection will show this to be a necessary law of 
nature; because, were it otherwise, such animals would no longer be representations, but actual examples of the type itself, in its full developement. Besides, we must not allow every little difficulty to turn us aside from what is evidently the path of nature. Of all the birds in this family, Querula obviously makes the nearest approach to the chatterers, and it is equally certain that the water-chats (Fluvicolino) make the nearest approach to the genuine flycatchers and to the tyrants. These two points, therefore, being incontestable, our business is to trace, as far as can be, the intervening series, and then to see how far the results accord with the general laws of nature.

The passage from the Black-caps to the Waterchats is effected, as usual, by a representation of the rasorial type. Of all known birds the Scissor-tail*, forming the genus

\section{GUBERNETES,}

comes nearest to Psaris cayana in the general character of its structure ; it has, however, a very long forked tail, and a more perfect fissirostral bill,-that is, shorter, broader, and more triangular. On the other hand, its legs are large and strong, perfectly adapted for walking,- the lateral toes being even,

- This bird, only known in England of late years, is accurately described by Azara, under the name of Yiperu. See Sonn. ed. 3. 196. 
and the claws, although sharp, very slightly curved ; this structure of foot, in short, is exactly what we find in all the water-chats, but Gubernetes is the only type which still retains a small row of those minute lateral scales on the tarsi, which are so constant in all the groups we have yet mentioned; the stiff rictal bristles of the insectivorous birds are now fully developed, and we have obviously quitted all those groups which feed in some degree upon fruits. Azara is the only writer who says any thing of the habits of this remarkable bird, which we shall call the Swallow Black-cap*. During flight, it seems to open and close its forked tail ; it frequents humid situations, associated in small flocks, and seeks upon the ground for worms and insects. Hence we see the use of its possessing strong feet and somewhat straight claws; thus combining the leading characters of the Psariance and the Fluricolina.

* No names in our vernacular nomenclature can be more valuable or expressive than those which express both the analogy and affinity of the object. It is evident that Gubernetes has analogy to the Hirundinida or Swallows, while it nevertheless truly belongs to the Psariance or Black-caps. 


\section{2}

SCISSAR-TAIL, OR SWALLOW BLACK-CAP,

Gubernetes forficatus, SwaINs.

\section{PLATE V.}

Cinereous; wings and tail brown; chin and throat whìie, bordered by a chestnut collar; primary quills fulvous-jellow at their base.

L'Yiperu, Azara ed Sonnini, iii. p. 196._Gubernetes Cunninghamii, Vigors, Zool. Journal, ii. Pl. 4, (fig. med.)

Azara was the first to record this remarkable bird, but, by a singular infelicity of arrangement, he has placed it among the Icterinoe, or hang-nests, with which it has obviously no connexion. This is the more unaccountable, as the account he gives of its manners are perfectly in unison with those of his Pepoazas, or water-chats, in which we include this and the last genus. Like these birds, it frequents, in small troops, the neighbourhood of swamps and rivers, sometimes perched upon the reeds and rushes, but more generally frequenting the ground in search of worms and other insects. During its flight it has the habit of expanding and opening its very long and forked tail, upon which account the natives of Para- 



\section{Plitis:}

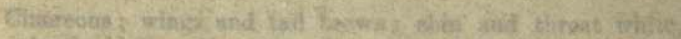

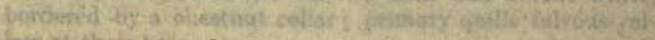
lowist there tase, -

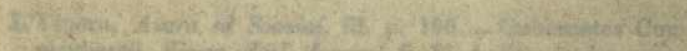

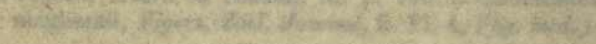

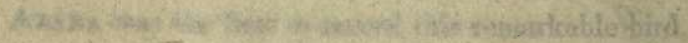

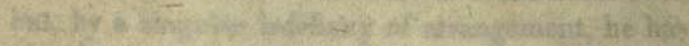

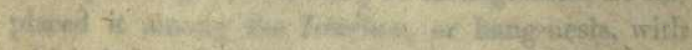

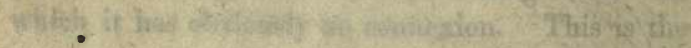

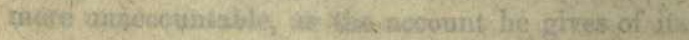

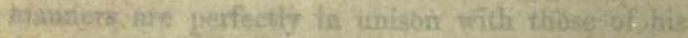

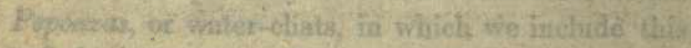

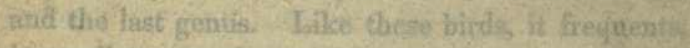

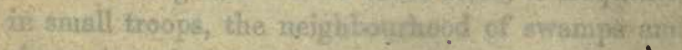

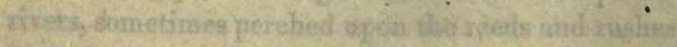

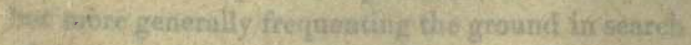

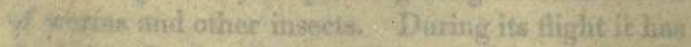

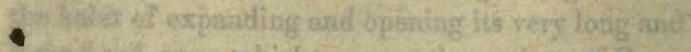
-2: 
REESE LIBRA TY

UNIVERSITY

CALIFORNIA. 
guay have given it the name of Yetapa, or the Scissar-tail. When perched, it has the distinguishing habit of the flycatchers, of darting upon such insects as pass within its range of wing, without, as it would seem, pursuing them. It is common in Paraguay, and not unfrequent in Southern Brazil.

The general colour of the upper plumage, excepting the wings and tail, is light cinereous, tinged with grey; this latter tint is chiefly caused by the shaft of each feather being brown. The under plumage, from the bottom of the neck downwards, is of the same colour as the back, but towards the belly and vent it gradually changes to a dull white. From the chin to the bottom of the nesk, which is very short, the feathers are pure white, this part being confined by a crescent of the deepest chestnut, which commences on the ears and crosses the upper part of the breast. Above the eye is a whitish stripe, but the lores are grey; the inner wing-covers, and the margins of the wings, are white; the wingcovers, scapulars, spurious wings, and most of the lesser quills, are dark sepia-brown; but the primaries, excepting the two outermost, are of an orangebuff colour, tipt only with brown; the tail is brown towards the base, but black beyond.

Total length, 15 inches; bill, gape, 1 ; front, $\frac{6}{1} \overline{0}$; wings, $4 \frac{9}{10}$; tail beyond, 8 ; base, $10 \frac{1}{2}$; tarsus, 1 .

From Gubernetes we are immediately led into the circle of the Fluvicolina by 


\section{ALECTURA,}

which is a no less remarkable type; three species only are as yet known, and these are very singular little birds ; their size is not bigger than that of a robin, but their head is enormous from the quantity of feathers upon the crown, while the tail, as already remarked, is erect and compressed, very much like that of the cock. The bill and feet are both large in proportion, and give us such a miniature resemblance of those members in Gubernetes, that no doubt can exist on the close affinity of the two genera; for although, if our views are correct, they do not stand in the same circle, yet, as they form a union between both, their separation is only nominal. These " little cocks," as Azara calls them, seem in their habits to be true water-chats, frequenting the open and humid sides of savannahs, where they search upon the ground for insects; occasionally, however, they exhibit a slight indication of the habits of the true flycatchers, by perching upon reeds or very low shrubs (never on trees), and catching insects as they fly near its station. It deserves to be noticed, that Azara, a decided opponent of technical systems, was yet too well versed in natural groups to confound these birds with the 
ordinary flycatchers; he consequently formed them into a distinct genus, without giving any other than a vernacular name. M. Vieillot, in the first instance, adopted Azara's views, and termed the group Alecturus; but the prejudices of system and its technicalities made him subsequently abandon the name and the distinction, and he incorporated them with a confused assemblage of birds now passing under the general designation of Muscicapa. We must, therefore, cite M. Vieillot's name to this genus, in contradiction even to himself; for had he paid due attention to the observations of Azara, or had given nore than a hasty glance at the structure of the jirds themselves, he would never have differed from is master and from himself. The Alecturi seem to je common in some parts of the southern provinces if Tropical America, but they are not met with in ing other localities. 
COCK-TAILED WATER-CHAT.

Alectura Azarii, Swains.

\section{PLATE VI.}

A bove blackish, edged with grey ; ears, shoulder-covers, margins of the quills, and under plumage, white; breast and sides of the neck with a black collar, almost obsolete in front.

Le Petit coq., Azarii ed. Sonnini, iii. 447.-Muscicapa alem tor, $\mathrm{Pl}$. Col. 155 ; fig. 1, male ; 2, female.-Muscicapa alectura, Vieill. Gal. PI. 132.

Ir is but justice to the memory of the great Spanish naturalist Azara, who first made known to us this extraordinary group of birds, that one of the species should be recorded by his name, especially since that of Alector is but a repetition of Alectura; and it is quite impossible to determine whether M. Vieillot's short description of his Alectura tricolor (which, in another part of the same work*, he calls Galiits tricolor) is intended for this or some other species.

In its manners, as detailed by Azara, may be recognized all the prominent characteristics of the true water-chats. It prefers open tracts in the immediate vicinity of water, but never enters into

* Analyse d'une Nour. Orn. p. 39 and 68. 


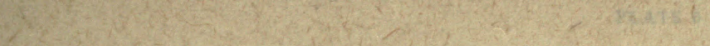

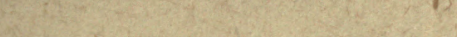

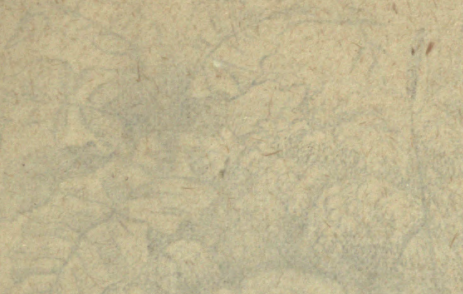

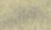

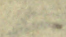

N.

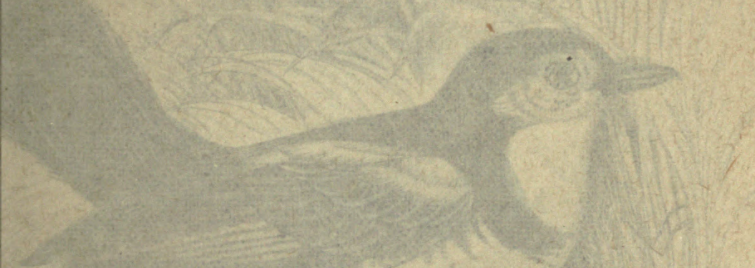

(2)
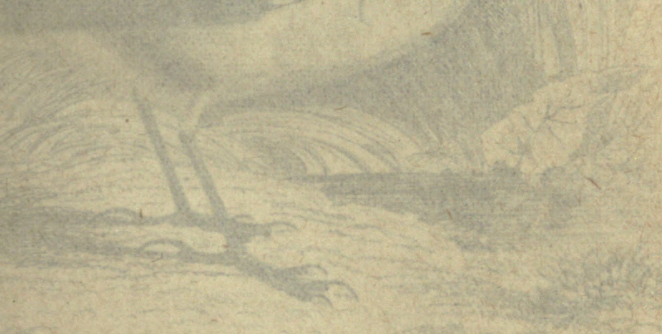

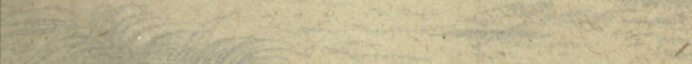

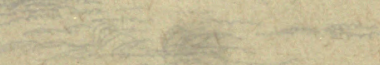




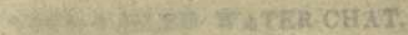

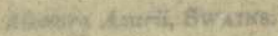

\section{PIIVIB Y.}

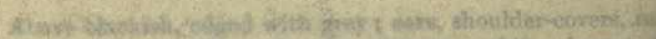

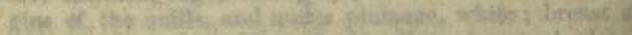

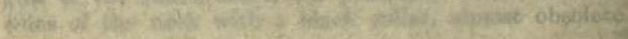
seost

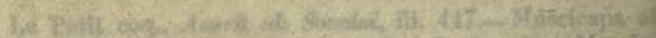

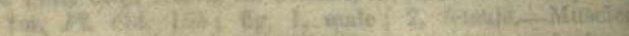

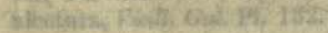

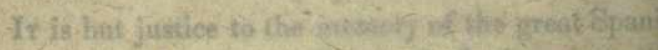

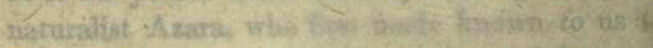

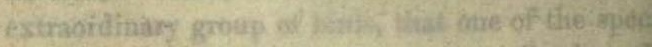

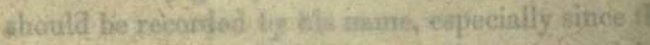

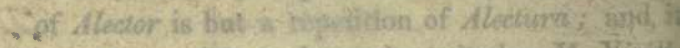
Guike impossitile to determine whether M. Yictls

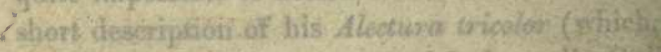
abother plust of the same workty be calls Gat

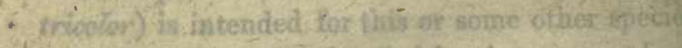
In its waninexs; as detalled by A zarti, may" be ocigaissd oll the prowizen? characteristics of Yme watex-chats. It prefers open facts, in.

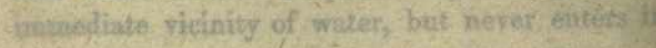

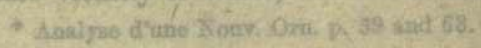




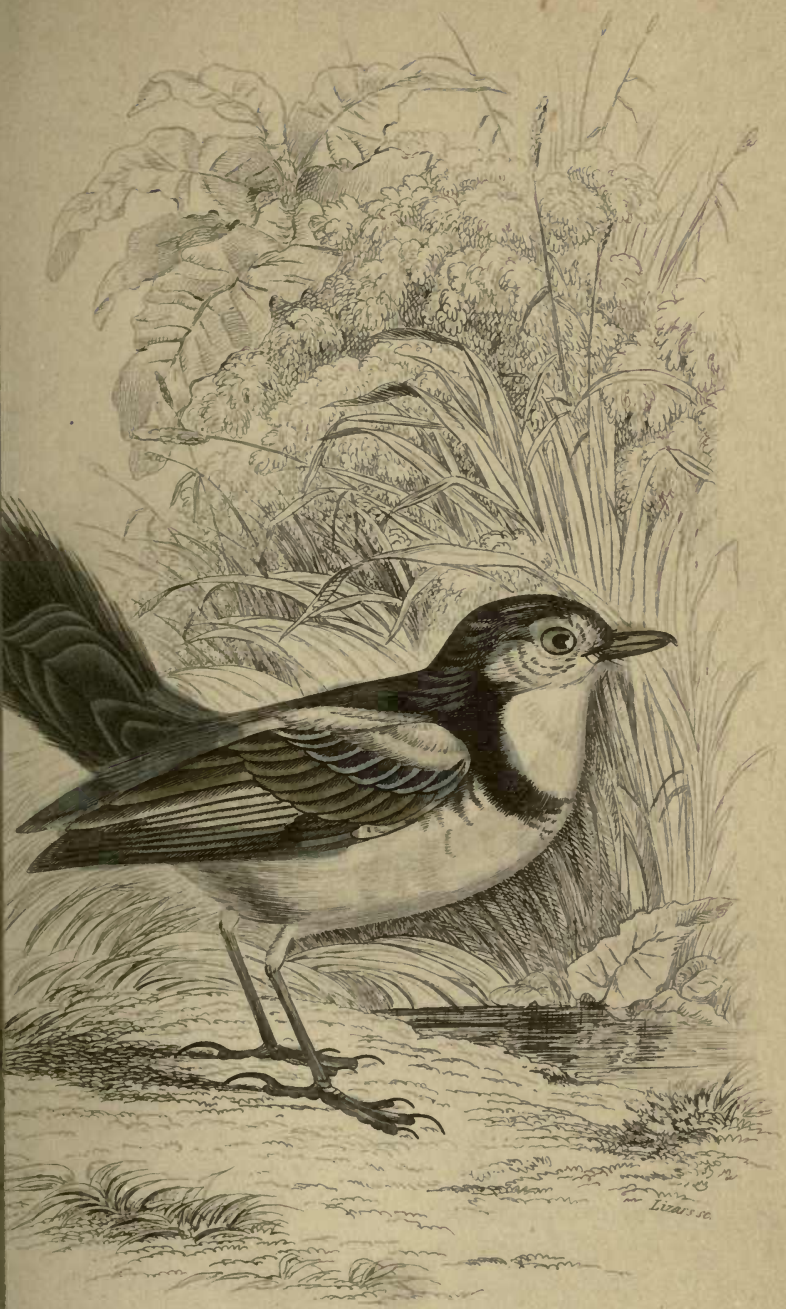




\section{REESE LIBRAPY
OF THE SITY
UNIV ERSIT CALIFORNIA.}

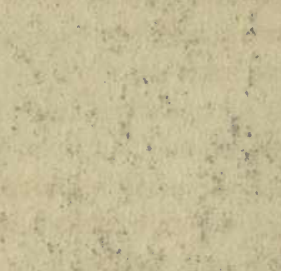

is 
the woods. Its food, in fact, appears to be semiaquatic insects, which it chiefly pursues on the ground, although it sometimes perches upon the reeds and aquatic shrubs, and darts upon insects as they pass within reach. The males are solitary, but it is not uncommon to find from two to six females together, living, as it would seem, in little troops. The males often take a flight almost vertical, and then, before they alight, turning themselves over something like a tumbler-pigeon.

The male has the upper plumage, for the most part, black, the feathers being edged with grey. Across the breast is a black collar, springing from behind the ears, and almost obliterated in front ; the shoulder-covers, and the edges of the quills, together with some spots on the front, are all white; the edges of the wing-covers, and the lower part of the back, are cinereous; the ears, stripe above the eye, lores, and all the under plumage, is pure white. The singular form of the tail is best understood by the figure. Its colour is deep black, excepting the grey tips of the lateral feathers. The female I have not yet seen. This species is found both in Paraguay and in Southern Brazil.

Total length, $5 \frac{1}{2}$ inches; bill, gape, $\frac{6}{10}$; front, $1^{4}$; wings, $2 \frac{3}{4}$; tail, from the base, $2 \frac{1}{4}$; tarsus, $\frac{3}{4}$.

The passage from Alecturus to the common tailed water-chats is not yet rendered unquestionable by a series of intervening forms; but there are some with long wing and short triangular bills, to which we shall retun the name of 


\section{8}

\section{BLECHROPUS,}

viewing them for the present as distinct from $F l u$ vicolina. Of these we know four or five species, and although they do not exhibit very decided peculiarities as to structure, still it seems desirable to keep them distinct; they differ from Fluvicola and agree with Alectura in their large heads ; their plumage is more or less deep black, with a concealed spot of white on the inner web of the quills, which only becomes suddenly conspicuous when the wing is expanded; the feet being smaller, and the toes rather shorter than in Fluvicola, would seem to indicate even more of the perching habits than are possessed by Alectura, while their singularity $\mathrm{O}_{2}$ plumage leads us to believe they must have also some peculiarity of manners. One of these we shall now figure. 


\section{8}

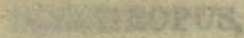

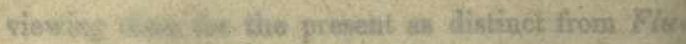

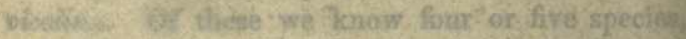

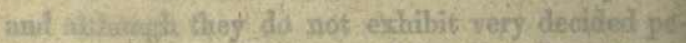

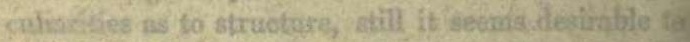

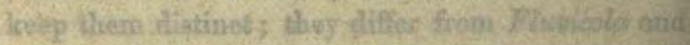

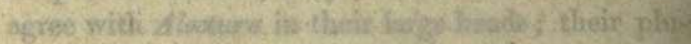

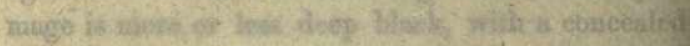

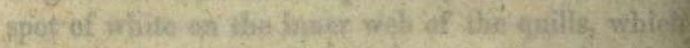

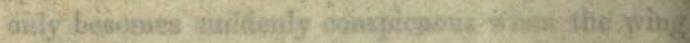

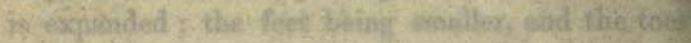

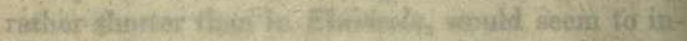

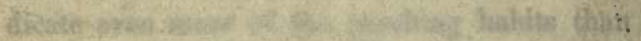

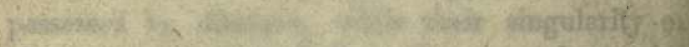

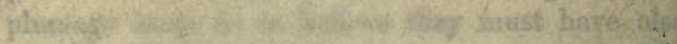

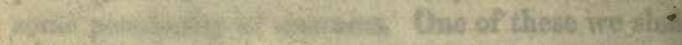
$\operatorname{lin}_{\rightarrow \infty}$

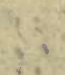




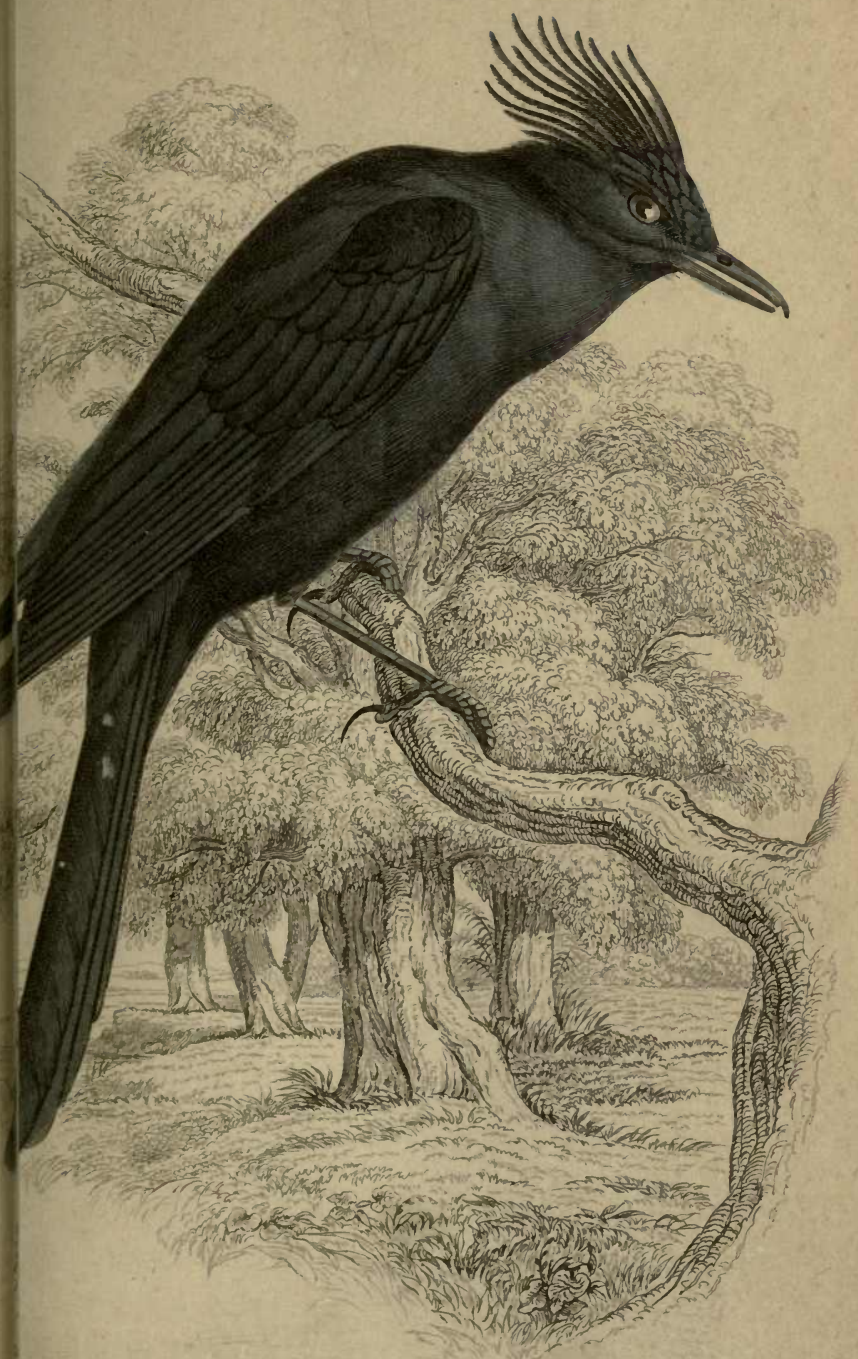

CRESTED BIACK WATER CHAT

Native of $S$. Amersca. 


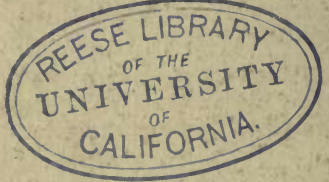




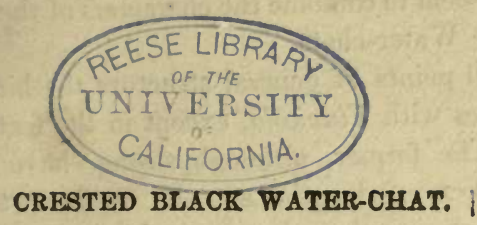

Blechropus cristatus, SwaINs.

PLATE VII.

Entirely black, with a large spot of white on the base of the inner web of the primary quills; head with a conspicuous crest of slender lengthened feathers.

Musicapa comata, Lich. in leteris.

THE bird we have here selected as an example of the genus Blechropus, will serve to show in what respect this group differs from that of Fluvicolina, although we candidly confess we do not as yet sufficiently understand the typical characters, or are we prepared to say whether this is a typical or an aberrant species. It is clear, however, from the strength and length of the legs, that it belongs to the Water-chats, and not to the Tyrants, while it differs so much from the typical examples of all those genera which compose the Fluvicolino, that we can only choose between viewing it as an aberrant species of Fluvicola, or separating it as a subgenus. I have adopted the latter view, at least for the present ; and until we know more of those birds, called by Azara Pepoaxas, and of certain others, 
which seem to combine the characters of the Tyrants and the Water-chats.

In all points of general structure the bird before us agrees with Fluvicola, except in the feet and the tail. The former, although strong, have not the tarsus so much lengthened, and the inner toe is obviously shorter than the outer; this latter character, indeed, is seen in the Fluvicola nengeta; but the toes of this bird are much shorter, and seem adapted as much for perching as for walking: the tail is lengthened, and so much rounded as to appear fanshaped, every feather being graduated; and it is this circumstance, more than any other, which induces me to look upon Blechropus as that type which passes into the Rhipidurae or fantails. The whole plumage is black, glossed with bluish, excepting the base of the inner webs of the primaries, which are pure white: the crest is very elegant, the feathers being long, narrow, and slightly recurved towards their tips; bill and legs black.

Total length 9 inches; bill, gape, $\frac{9}{10}$; wings, 5 ; tail beyond, $2 \frac{1}{4}$; from the base, $4 \frac{1}{2}$; tarsus, $\frac{9}{10}$; middle toe and claw, $\frac{8}{10}$.

It is evident that the bird last figured and described is very closely connected to the true waterchats, forming the genus 


\section{FLUVICOLA,}

the chief type of this sub-family. A great uniformity of plumage runs through all the species we have seen of this group, so that very many, we doubt not, have been overlooked or disregarded as varieties; the predominant colour is pure white, with deep black wings and tail; sometimes the whole or a part of the back and head is grey; the largest species is the Fluvicola nengeta, which is clothed in the same coloured plumage as the American mock-bird, while the smallest* is so like the European Muscicapa atricapella, that it is not surprising the old ornithologists in their systems placed it immediately after that bird. The aspect of all these birds, in short, will remind every one of the stone-chats and wheat-ears, and thus will do away with the necessity of proving that they represent each other. One of the most remarkable species is the Fluvicola cursoriat, because in this we see the tail, although not unusually long, is so much graduated as to assume something of the same shape and appearance as that of the next genus Rhipidura; another of the most typical species is the

* Fluvicola bicolor, Sw.; Muscicapa bicolor, Gm., Latham, \&c. Pl. Enl. 675. f..1.

+ Zool. Illustrations. 


\section{2}

\section{MOCKING WATER-CHAT.}

Fluvicola nengeta, Swanvs.

PLATE VIII.

Upper plumage, breast, and tip of the tail, cinereous ; wings and tail black; primary quills with a band of pure white at their base ; ears and maxillary stripe varied with grey and black ; throat and body beneath, white.

Lanius nengeta, Linn. Auct.-Muscicapa polyglotta, Spix, ii. P1. 24.

I BELIEVE that this common bird is one out $\alpha$ three species, of three different genera, that compose the Lanius nengeta of Dr. Latham and his followers. One of these appears to be the Grey Pie of Edwards, Plate 318, which is unquestionably a mocking thrush of the genus Orpheus; the second is some species of true Shrike (Lanius) found in Russia; and the third is the present bird. Dr. Latham has still further generalized his ideas of his Lanius nengeta, by actually placing with it, as varieties, two other species of true Lanius, one of which we have elsewhere shown to be nominal To unravel such a complication of errors is next to an impossibility; they meet us in every page of our 
(2)

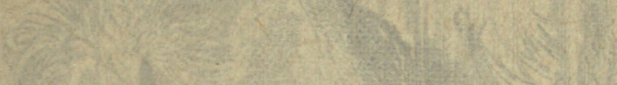

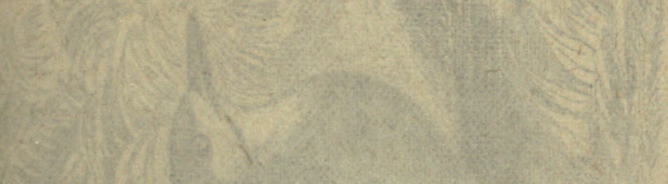

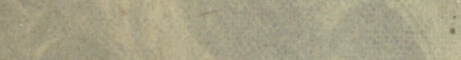

sites

has

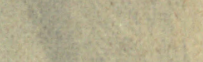

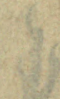

(7)

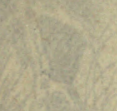

69:
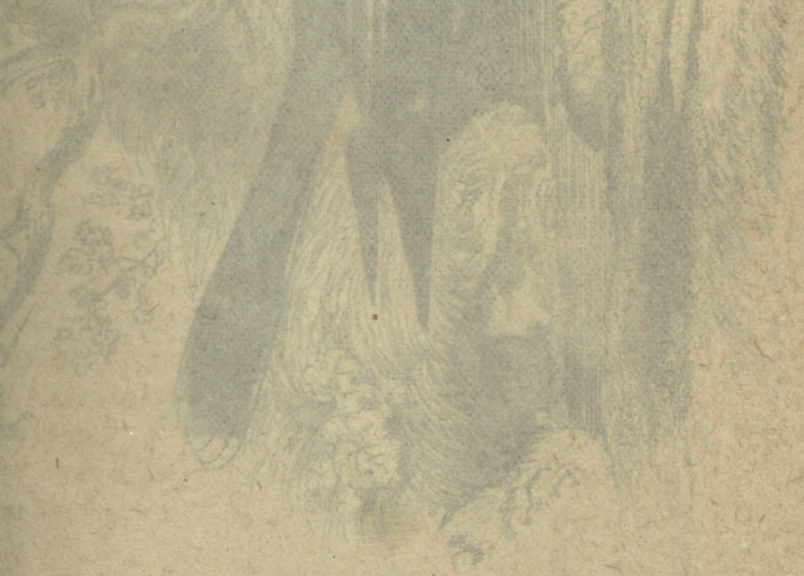


\section{ivis}

\section{$\lambda$

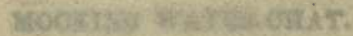

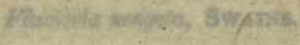

\section{- Plitre vir:}

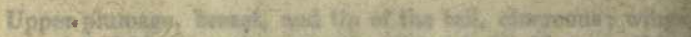

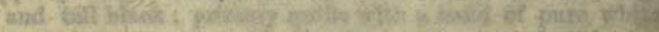

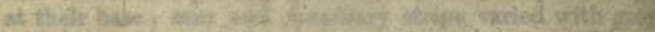

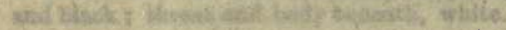

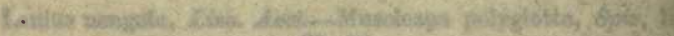
W. 21 .

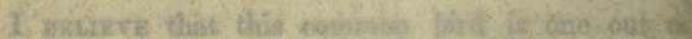

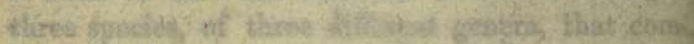

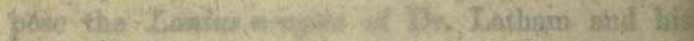

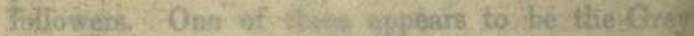

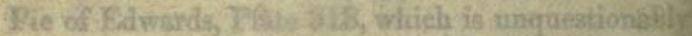

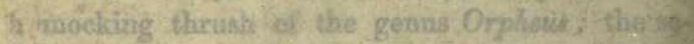

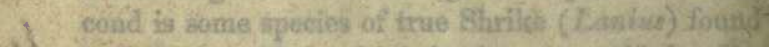

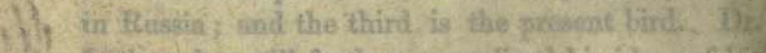

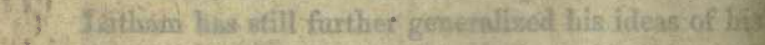

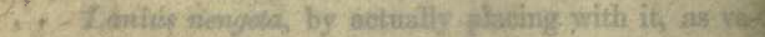

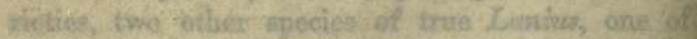

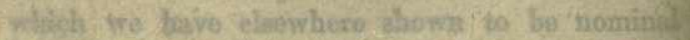
7. comared such a complication of eners is naxt to an ingegsibility ; they meet vi in every gage of ow 


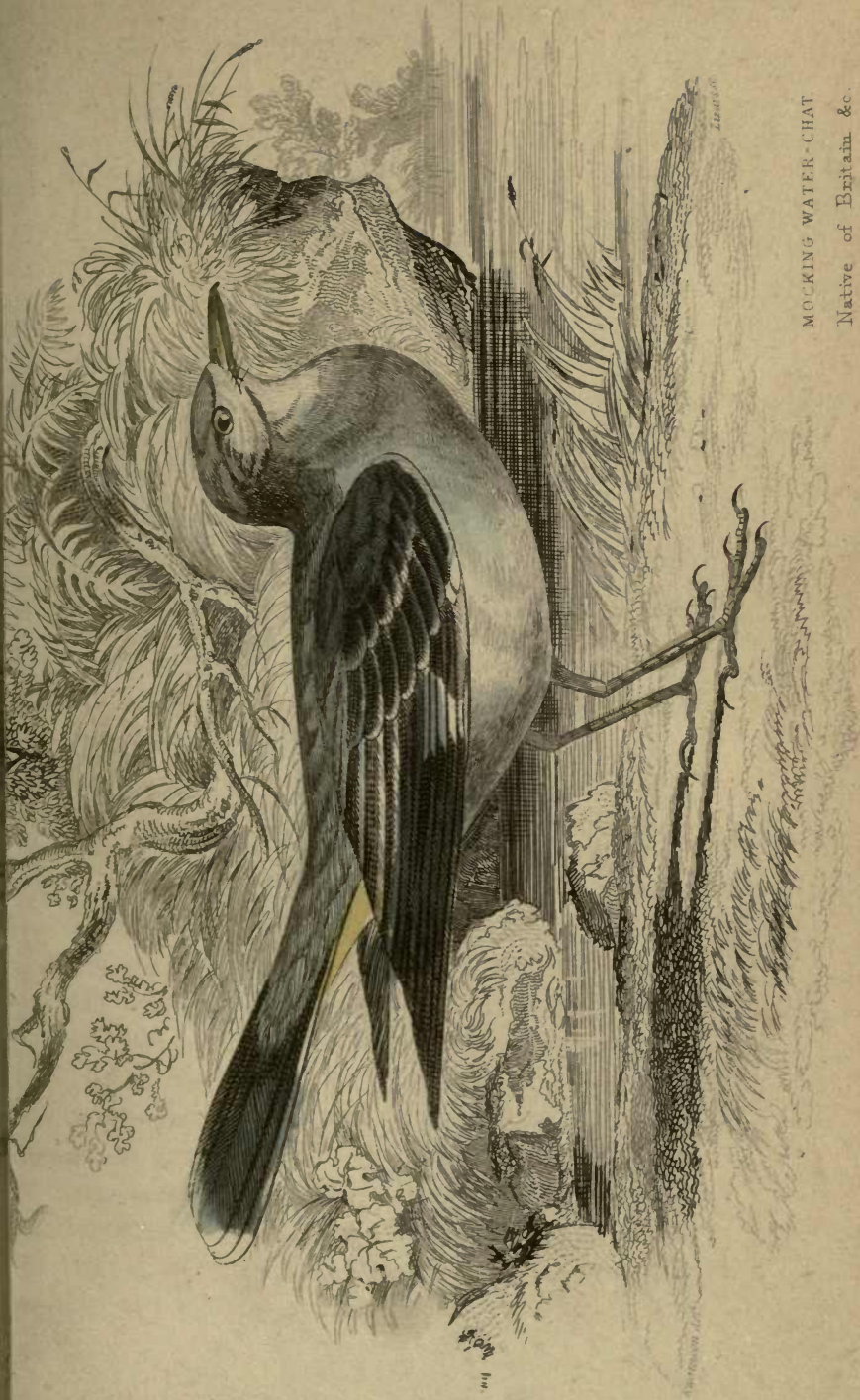



general systems, and to rectify them all would be the labour of a life. Hence arises the necessity or imposing new names upon species which, although long known, still remain so confounded with others, that if we aim at precision, we can hardly quote their former names even as synonymes.

In general structure the bird before us perfectly agrees with the typical Fivvicolinoe. The third and fourth quills are equal and longest, the two first being a little graduated, and slightly narrowed at their tips, especially the outermost; the general colour above is cinereous grey, which tips all the black tail-feathers, and margins those of the wingcovers and tertials, although these two latter are blackish-brown in the middle: the primaries, secondaries, and spurious wings are deep black, but the ninth and tenth quills are entirely pure white, which colour also forms a band at the base of the other primaries, narrowest on the longest and broadest on the shortest of these quills; the secondaries are merely tipt with white: the lores and maxillary stripe are black, but above the former is a white line, and the latter is varied with grey; under plumage white, but grey on the breast and flanks; tail black, tipt with greyish-white, the edge of the outer tail-feather being white.

Total length, 9 inches; bill, gape, 1 ; front, $\frac{3}{4}$; wings, $5 \frac{2}{10}$; tail beyond, $1 \frac{1}{2}$; base, 4 ; tarsus, $1 \frac{1}{1}$.

We have now traced the greatest part of the circle of the Fluvicolinoe, yet there still remains two types undetermined; and one of these is the tenuirostral 
or grallatorial. This latter we consider to be represented by the Sylvia perspicillata of the old authors, a bird which was even known to Buffon, but which has hitherto been very imperfectly described, and never figured. It forms the type of our genus

\section{PERSPICILLA,}

and we now annex a description of both sexes, procured in the southern parts of Brazil, where it is by no means common. Its relation to the water-chats is indisputable, for its entire organization bespeaks it a terrestrial bird, possessing something of the structure both of Fluvicola and of Alectura, yet exhibiting a strength of foot and a form of bill which separates it from both ; the whole appearance of this bird, in fact, is very striking, as will be seen by the annexed figure.

It is rather larger than Alectura, and is more truly characteristic of a grallatorial form, from the excessive developement of those quill-feathers which lay over the others. Setting aside the universality of this fact among the typical waders, we see it in their representatives the larks (Alaudince), pepits ( $A n$ thus), wagtails (Motacilla), and numerous others. The structure of Perspicilla, therefore, although singular and unique in its own circle, is in the most perfect harmony with those groups it represents in other circles. The nakedness of its face and the weakness of the bristles round the mouth, reminds 



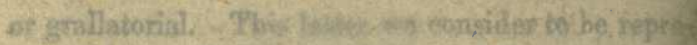

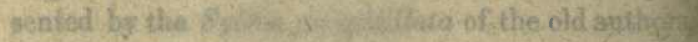

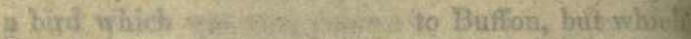
Whas hithestren

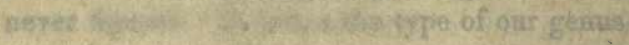

\section{DERSTXCHLA}

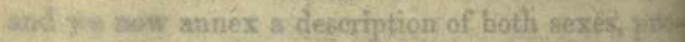
chared ir the southern parts of Brasil, where it is 0

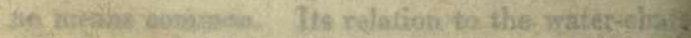

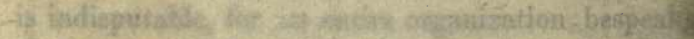

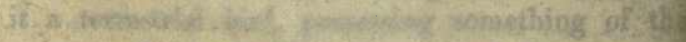

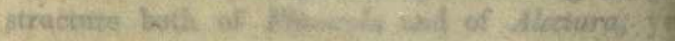

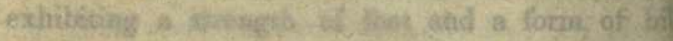

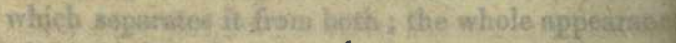

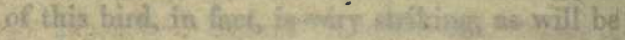

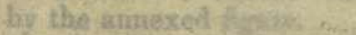

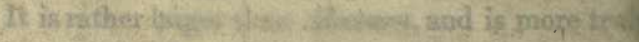

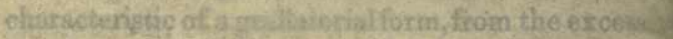
Aevelapentens of those guill-fenthers which laz on the cthers. Befting aside the univereality of 10 fres mong the typicen waders, we see it in; it

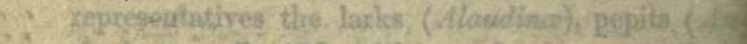
*. thive, wagtails (Motacilla), snd mimerous ofluct.

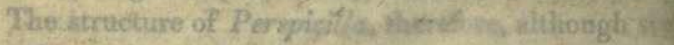

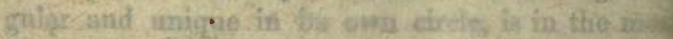

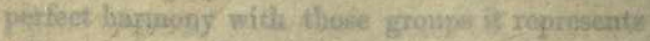
other cixcles. Tho nathedress of its feee and Wretherss af the bristlesc round the mouth, remi 

us of the typical Ampelidoe or chatterers, among which we have the only insessorial birds possessing white quill-feathers; we see its long legs, yellow bill, and fleshy orbits again repeated among the plovers (Charadriadoe), and similar naked appendages to the eyes occur among the caterpillar-catchers (Ceblepyrince), and certain todies. Now each and all of these are grallatorial types in their own circles, so that four at least of the leading types of the Fluvicolino may be considered determined; and we have only to wait for better information respecting that between Alectura and Fluvicolinoe, to pronounce this family so far to be complete.

SPECTACLE, OR WHITE-WINGED WATER-CHAT.

Perspicilla leucoptera, SwaINs.

PLATE IX.

Male, entirely black, excepting the primaries, which are white, tipt and edged with brown; round the eye a naked prominent fleshy ring. Female, brown, paler and striped beneath ; the primaries edged with rufuus; bill yellowishwhite.

Motocilla perspicillata, Linn. Auct.

THe habits of this very singular bird can only be guessed at from its construction: for although it seems a species well known to the older ornithologists, we are still in ignorance of its natural history, 
nor has the female, until now, ever been described Sonnini, indeed, in his translation of Azara, supposes that this is the Bec argente of the Spanish naturalist; but there seems to be no good foundation for this opinion. Such an accurate observer of nature as Azara was, would never have passed over in silence the extraordinary fleshy lobe which, like a pair of spectacles, encircles the eye of the male, and no mention whatever is made of this peculiarity in the description of the bird alluded to. (See Azara, iii. 453.)

The male, as already intimated, is entirely of a deep sooty black colour, uniform over the whole of the plumage excepting the quills; the first six of these are pure white, having the base, tips, and part of the outer web black, so that when the wings are closed these quills appear only to have an oblique band of white across their outer webs. The naked skin round the eye is loose, and, in the dea bird, plaited; perfectly similar, in fact, to that of the Prionops plumatus.

The female is so differently coloured that it might easily be mistaken for another species. The upper parts are brown, varied with lighter stripes, and pale edgings to the wing-covers ; but the basal margins of all the quills are clear and bright rufous; the inner wing-covers are of the same colour, but much paler. The under plumage is dingy white, striped with brown upon the breast and flanks. The bill of the male, even in the dead bird, is straw-coloured yellow, but that of the female has 
SPECTACLE, OR WHITE-WINGED WATER-CHAT. 107

the upper part brown; in both sexes the legs are deep black.

Total length, 6 inches; bill, gape, ${ }_{18}^{8}$; wings, $3 \frac{6}{10}$; tail beyond, 1 ; base, $2 \frac{3}{4}$; tarsus, 1 .

We now enter upon the sub-family of the

\title{
MUSCICAPINÆ,
}

\begin{abstract}
OR
GENUINE FLY-CATCHERS,
\end{abstract}

by far the most extensive and consequently varied group of this family. It is composed of those broad billed insectivorous little birds which dart upon their prey as it were from an ambush; they fix their station on the end of a branch or a projecting spray, from whence they suddenly dart upon such flying insects as come within a certain range, seldom making any attempt to pursue them, or to repeat another swoop if the first has been unsuccessful; sedentary habits, such as these, are not likely to call the feet of such birds into exercise, we consequently find that these members are always short and remarkably feeble in every part of their construction; the length of the tarsus, in fact, is very seldom more 
than that of the hind-toe and claw*, and in those very few types where this proportion is not observed, the tarsi, although lengthened, are remarkably slender and the claws syndactyle, that is, more or less united together at their base. There is another peculiarity which seems very characteristic of all the types we have hitherto seen of the Muscicapidee, where, notwithstanding the many variations in the form of the tail, no one instance can be cited of this member being forked. Attention also to the claws will enable the ornithologist to distinguish the genuine fly-catchers from the tyrant fly-catchers of America; in the latter they are invariably long, acute, and slender; so much so, indeed, as to make one believe they were intended to seize the prey of the bird; but this is not the case, although we are quite ignorant of the use of such a peculiar formation. The true fly-catchers, on the other hand, afford us not one recorded example of this structure, their claws are shorter, broader and much less acute; this difference, however, is not sufficient to distinguish all the tyrant fly-catchers, as some of the very small species, whose true affinities, in fact, are somewhat doubtful, possess the claws of the Muscicapidae, but these latter never exhibit those of the $T y$ rannince.

No circumstance is more remarkable, and cer-

* This distinction will much assist the ornithologist in descriminating the flycatching warblers, as Saxicola, Culicivora, Setophaga, and a few other groups, in all which the tarsi are lengthened; and the toes, although rather small, are always deeply cleft. 
tainly none more inexplicable, than that certain groups of birds, having a limited geographic distribution, should be distinguished from others of the same family (but inhabiting another continent), by a slight but invariable deviation in the form of their wings. This difference might be accounted for, if, upon further investigation, we had found that it was accompanied by a difference in the mode of flying or of capturing the food. But hitherto not the slightest variation has been detected, on these points, between the fly-catchers (Muscicapa) of the Old World and those of America. Nevertheless, so decidedly different is the structure of the wing in these two great geographic groups, that we may at once decide from this circumstance alone, whether a species we see for the first time is a New or an Old World fly-catcher. We drew the attention of ornithologists to this remarkable fact some years ago , and subsequent experience has not furnished us with a single exception to the rule. The common grey fly-catcher of Britain catches its prey in precisely the same manner, so far as 1 can discover, as do the little tyrants (Tyrannula) of Brazil, both sit upon a twig, dart at passing insects, and return to the same station; but the European species has the first quill-feather so small as to be spurious, or as it were elementary, while that of the other is three times as long, and the proportions of

* Northern Zoology. 
the remainder differing entirely from those of its congener. Now this spurious quill is the great and universal character of all the genuine flycatchers of Europe, Asia, Africa, and New Holland, while among those of America not a single instance of such a structure has yet fallen under our observation*. The student, therefore, if all other distinctions fail, has but to examine the wing of a flycatching bird, to know at once whether it is a native of the New or the Old World; whether in fact it belongs to the genera hereafter-mentioned, Todus or Muscicapa; the first, with one exception t, being an American, while the latter is an $0: d$ World group. But that the ornithologist may m re clearly comprehend these distinctions, we shati take this opportunity of explaining them more fully.

The wings of the paradise fly-catcher, a most beautiful though common bird, will give us a perfect idea of that structure, which, with very slight variations, runs through all the Old World Muscicapince. The general form of this member, although by no means short, is nevertheless rounded ; that is, the outermost feathers, instead of being the longest, as in the swallows, are much shorter than those which are nearest to the body, and, from being of different engths, they are termed graduated. The first quill

* The sub-genus Ptiliogenys is more a Ceblepyris than a syrant Fly-catcher (Tyrannınce).

+ The sub-genus Platystera, (J. and S.) peculiar to Western Africa, being the nearest point of that continent to Americe 
is small and spurious, being hardly half as long as the next; the second is half an inch shorter than the third; and this latter, again, is about three-tenths of an inch shorter than the fourth; the fourth, fifth, and sixth, being all of the same length, and longer than any of the others. This sort of wing, without any variation, is alike common to Muscicapa, Rhipidura, Seisura, Myagra, Monacha, and Platystera; in Hyliota there is a slight deviation; the second quill is longer, and the third almost reaches the end of the fourth; this departure from the typical structure prepares us for a second modification, as seen in the Muscicapa atricapilla of Europe and its allies; the first quill becomes smaller and is not one-third the length of the second, while the third is the longest of all. This structure of wing is much more pointed than that of the first we described: it has evidently greater power, and we consequently find it has been given to a group of birds which are known, like our grey flycatcher, to migrate. Were it not for the bristled and depressed bill of some of those latter, their feet are so unusually strong in comparison to those of their congeners, and their wings so very similar to those of the Stone-chats, that we should be almost tempted to place them with the Saxicolinos; and, indeed, in respect to some, we are by no means satisfied to which group they naturally belong; the characters by which we propose to denominate them will be subsequently stated. In the mean time, it deserves marked atention, that this close approximation leaves us in 
no doubt that the three aberrant families of the Dentirostres unite into a circle of their own, independent of their connexion to the shrikes (Laniada) and the thrushes (Merulidoe).

With these preliminary observations on the leading characters of this extensive assemblage of birds, we shall now proceed to the names and definitions of the genera composing it. These appear to he as follows:-1. Rhipidura, the Fan-tailed Flycatchers; 2. Monacha, the Oriole, or Hooded Fly-catchers; and, 3. Megalophus, or Greatcrested Fly-catchers. These three appear to form the aberrant group, as representing the rasorial, the grallatorial, and the fissirostral types. The fourth genus is ToDus, composed of the well known Todies, or South American Flycatchers. And the fifth is Muscicapa, consisting entirely of those, pre-eminently typical, which are restricted to the Old World.

Our proposition is, that these genera form a circular group. But before we enter into those details by which we hope to substantiate this assertion, let us, in the first instance, briefly state the prominent or typical distinctions of each, and then compare them, in our usual manner, with some other well known and authenticated groups, whose internal relations have stood the test of experience and rigid analysis. And, first, they may be compared with the Orders of Perchers in the following manner :- 
Analogies of the Muscicapidae and the Insessores.

Muscicapa... $\left\{\begin{array}{r}\text { Pre-eminently typical of their } \\ \text { respective circles........................ }\end{array}\right\}$ Conirostres. Tidus..............General structure less perfect.........Dentirostres. Megulophus.. $\left\{\begin{array}{r}\text { Feet short, weak ; toes syndac- } \\ \text { tyle; head large..................... }\end{array}\right\}$ Fissirostres.

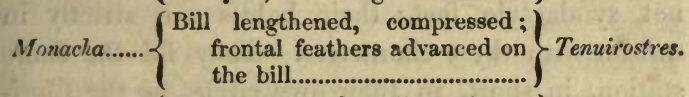
Rhipidura.... $\left\{\begin{array}{r}\text { Feet lengthened ; tail very large, } \\ \text { broad; habits familiar.......... }\end{array}\right\}$ Rasores.

The experienced ornithologist need hardly be reminded, that when two groups are compared whose rank and situation are either remote or very dissimilar, the analogical resemblances between them will partake of the same remoteness; hence it sometimes happens, that although they agree sufficiently strong in some parts to make us feel sufficiently confident that the analogies are just, yet others will be so obscure that their correctness can only be established by a line of inductive reasoning, and their mutual relations come to light through the instrumentality of other groups. Applying this undoubted fact to the foregoing table, we shall find some of the analogies more apparent than others; and we are therefore to inquire, how far those which seem the most remote can be placed on the same degree of probability with the others. There can be no doubt, for instance, that the true flyfatchers, forming the genus Muscicnpa, are the 
most perfectly organized group,-in reference to the true distinctions of that circle to which they belong, -in the whole sub-family. These typical distinctions are seen in the length of their wings, giving a power of flight not possessed by the Todies ; their strongly hooked bill, the long and stiff bristles round the mouth, and their remarkably short, but not syndactyle feet; their habits are strictly in unison with these characters. They fill the same station, in short, in their own circle, as the Conirostres do among the Perchers, and we hence conclude that they are analogous. If this position is true, it necessarily follows that the Todies and the Dentirostres are also analogous; because the affinity between Muscicapa and Todus is just as perfect and unquestionable as that between the Conirostres and the Dentirostres. Whether this analogy is shown in a more direct manner by certain habits possessed by both, of which we are at present ignorant, is a question to be determined hereafter; but we can discover no tangible analogy in their structure which would lead us immediately to conclude that they mutually represented each other. Passing to the two next groups brought under comparison, namely, Megalophus and the Fissirostres, we have one point of strong resemblance in the feet. The toes of the only species of Megapodius yet discovered, are much more united than in the typical examples of the two preceding genera, although its crest would seem to give this bird an equal claim to be considered a rasorial type. In determining, 
however, between these two opposite analogies, we have invariably found that great strength of foot, and disconnection of the toes, is a much more prevalent, and therefore a more certain indication of rasorial types, than the mere possession of a crest. This opinion is fully confirmed upon looking to the rasorial order itself, where we see that strength and perfection of foot is the universal character, while crests are not possessed by more than one-tenth of the whole. Or, if we reverse the comparison, and look to the Fissirostres and the Natatores, we observe that imperfection of foot is their predominant characteristic. Megalophus, therefore, may be considered a true fissirostral type ; possessing, however, in its remarkable crest, one of the characters of the genus into which it blends, at the opposite point of the circle, namely, Rhipidura. On the analogy of Monacha to the Tenuirostres there can be but little doubt; both are the most aberrant in their own circles, and both are remarkable for their cylindrical bills and the advancement of the frontal feathers over the nostrils. The last analogy to be traced, is that between the fantailed flycatchers (Rhipidura) and the rasorial birds (Rasores). Adverting to what we have just remarked on one of the primary characters of rasorial types, we find that this group of flycatchers have the longest and the strongest feet of any in the whole circle; when to this we see added a remarkably broad fan-shaped tail, and several peculiarities of economy which will be subsequently detailed, the analogy becomes 
more than probable-it is all but certain. Rhipidura, in fact, possesses the whole of the rasorial characters excepting one, which seems transferred, as it were, to Megalophus, in the form of a crest; at least no species has yet been discovered, among the fan-tailed flycatchers, which possesses this ornament.

Let us now institute another comparison, by which, probably, what we have just advanced on the analogies of this family will in some degree be confirmed. Every ornithologist must be struck with the resemblance between the Babbling Thrushes (Crateropus) and the Fan-tailed Flycatchers (Rhipidura). We will therefore bring the circles in which these two groups occur into comparison, and by placing them opposite one another, ascertain whether a resemblance may be traced in all the other groups of which these two circles are composed.

Circle of the

Flycatchers.

aNALOGICAL CHARACTERs. Circle of the Thrushes.

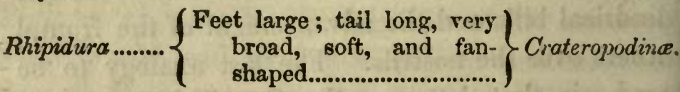

Monacha.......... $\left\{\begin{array}{r}\text { Bill cylindrical, the sides } \\ \text { compressed...................... }\end{array}\right\}$ Oriolince.

Megalophus...........Feet small, short, weak...........Brachypodince.

Todus............... $\left\{\begin{array}{l}\text { Wings and tail very short, } \\ \text { and rounded; legs long. } \\ \text { slender; toes often united }\end{array}\right\}$ Myotherina.

Muscicapa........ $\left\{\begin{array}{r}\text { Wings long; feet moderate; } \\ \text { the toes free..................... }\end{array}\right\}$ Merulina.

Here the analogies of the flycatchers become much more definite, imply because they are compared 
with a group more in accordance with their own; or, in other words, the resemblances loose that remoteness which was the inevitable consequence of our last comparison. Thus, we find, that not only the analogy between the fan-tailed flycatchers (Rhipidura) and the babbling thrushes is perfect, but that other unexpected points of analogy come to light in the remaining groups. The orioles (Oriolince) and the hooded flycatchers, for instance, not only are the most aberrant in all their characters, but they have a peculiarity of colouring in the black hood which envelopes the head and neck of nearly all the species, which is very striking. The bill of Monacha carinata is much more like that of an oriole than of a flycatcher, while the plumage, again, of Monacha chrysomela, is almost a counterpart of that of its prototypes,the Oriolus paradiscus and the Sericulus chrysocephalus, - not only as to its colour, but in that peculiar rich velvetty texture which is found in no other birds of these two families. The analogy between Megalophus and Brachypus is not so strong as among the others, but both have very short and peculiarly feeble feet; the weakness, however, of our comparison between these two last groups is amply made up by the strong resemblance of the todies to the Myotherina, as sufficiently expressed in the table, while the same observation is applicable regarding those points in which the typical flycatchers (Muscicapa) so perfectly represent the typical thrushes (Merulidae). 
One of the many inferences that may be drawn from the above exposition, is that which renders the genera of the Muscicapince representations, equally perfect, of the divisions of the Laniadoe or shrikes. The only point upon which further evidence seems to be necessary regards Megalophus; and, on this account, it will be as well if the two groups are examined more accurately. We shall therefore now state the analogies of the

\section{MUSCICAPIN Æ AND LANIADE.}

Genera of the Muscicapince. Muscicapa........ \{ ANALOGICAL CHARACTERS. Typical Genera of the Laniada.

Wings long; tail graduated; ) $\left.\begin{array}{l}\text { sit and watch for their } \\ \text { prey................................... Lanius. }\end{array}\right\}$ Todus............... $\left\{\begin{array}{c}\text { Wings short, rounded; tail } \\ \text { slender, weak; legs } \\ \text { lengthened; toes syndac- } \\ \text { tyle; seek for their prey } \\ \text { among trees..................... }\end{array}\right\}$ Thamnophilus. Megalophus...... $\left\{\begin{array}{r}\text { Feet short; head with fron- } \\ \text { tal crests........................ }\end{array}\right\}$ Dicrurus. Monacha.......... $\left\{\begin{array}{r}\text { The most aberrant in their } \\ \text { respective circles............. }\end{array}\right\}$ Ceblepyris.

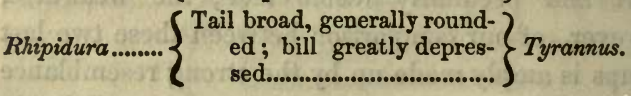

The two first of these analogies are so remarkably strong that they require no additional evidence to support them. The third, or that between Megalophus and Dicrurus, tends very much to confirm 
what we have advanced respecting Megalophus, for the crests, so common among the Drongo shrikes (Dicrurus), are certainly more like that of Megalophus, in point of structure, than are those of the Tyrannince; all the latter being concealed, and the feathers not lengthened.

We have already seen how completely the orioles are represented by Monacha; and we shall now find that both these are only prototypes of the Ceblepyrina. The colouring of Monacha carinata is that of a Ceblepyris; while the C. lobata has exactly the same sort of naked wattles so conspicuous in Monacha telascopthalmus. Lastly, the Tyrannulae represent Rhipidura in being the only shrikes which have the perfectly depressed bill of the flycatchers, and in the typical species having broad rounded tails. This analogy, however, is as weak as the last and the two first are the reverse : so that we have another proof, that in these sort of comparisons some resemblances will be much more strong, or rather better known, than others. Our inability, however, to discover other analogies than those we have just mentioned, between Rhipidura and Tyrannula, is of little consequence to our present purpose; for as we think it indisputable, after what has been said, that Rhipidura is a rasorial type, our only desire is to throw some additional light upon the analogies of Megalophus. This will be effected by looking to three of the genera composing the circle of the Thamnophilina, or Bush-shrikes, and comparing them with the 
three corresponding ones among the Muscicapida, thus,-

LANIADE. ANALOGICAL CHARACTERS. MUSCICAPIDE.

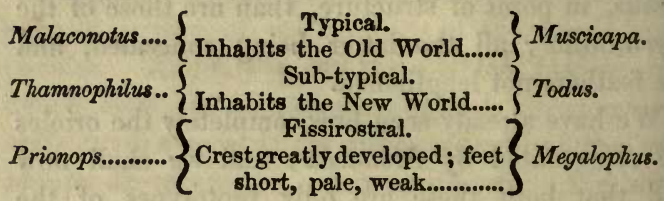

This we consider the best and the final test by which our proposition that Megalophus,-notwithstanding its crest, -is a fissirostral type, can be tried. The crest of the Prionops plumatus, although of a different sort, is more analogous, in its extraordinary size, to that of Megalophus, than that of any other known bird ; and both further coincide in having very pale and delicate feet, upon which the scales are so thin that they can scarcely be perceived. If we continued the comparison by enumerating the other two genera in the above circles, we should find that Colluricincla is no obscure representation of Monacha; but the remaining genus in the first series (the Thamnophilinoe) being unknown, we of course are entirely ignorant of the prototype of Rhipidura.

Having thus endeavoured to substantiate our views of the primary divisions of the family of Flycatchers, we shall now enter upon the details of each.

By commencing with the genus 


\section{1}

\section{RHIPIUURA (Hors. AND VIG.),}

we hegin with that group which shows the nearest affinity to the Fluvicolince, or Water-chats. It will be remembered, that on a former occasion* we placed the Australian genus Seisura, conditionally, within the confines of the Fluvicolince, though with very considerable doubt; expressing, at the same time, a strong suspicion that it truly belonged to the present division. This opinion has been fully confirmed by subsequent investigations; and we shall here attempt to refer it to its true rank and station among its congeners. The typical characters of the fan-tailed flycatchers may be gathered from what has already been intimated in our attempt to make out their analogies : their chief distinction, as their name implies, is exhibited in a very broad and rounded tail, which the bird is constantly in the habit of opening or expanding in the shape of a fan; next to this, in importance, is the general strength of their feet, as seen more particularly in three of the typical sub-genera, the tarsus of which is much larger than in any genuine flycaicher yet discovered. The bill exhibits nothing very peculiar or strikingly different from the typical flycatchers, except, indeed, that the sides, towards the end,

* Class. of Birds, vol. ii. p. 89. 
are rather compressed; thus indicating, on the one hand, an affinity to Muscicapa, and, on the other, to Monacha. The recent acquisition of some interesting birds from India, which prove to belong to this group, has thrown a new light upon others which have long baffled our further analysis of this group; so that now possessing, as we consider, four out of the five leading forms, we shall no longer refrain from characterizing them as so many subgenera; submitting to the reader, as we go on, those reasons which have influenced this determination. These types we shall distinguish by the names of Rhipidura (proper), Leucocirca, Myadestes, and Seisura; the first and the last having been already proposed by Messrs. Horsfield and Vigors. Rhipidura, in this restricted sense, contains those species only which have the bill remarkably small, and compressed for half its length; the rictal bristles extend to its tip, and are very stiff; the tail is particularly broad and fan-shaped, all the feathers being slightly graduated; but the feet are not more developed than in the typical flycatchers. The great-headed titmouse of Latham, not now existing in any of the London collections, is, in all probability, the most typical species; while the fan-tailed flycatcher of the same author, and several others, called by him "varieties," exhibit the same characters. The geographic range of these birds appear to be restricted to Australia and the smaller islands of the Pacific Ocean. Forster, in his voyage round the world, met with one species, 
of which, he says, "it is exceedingly familiar, constantly hunting after insects and flies, always with the tail spread like a fan; it is easily tamed, and will then sit on a person's shoulder and pick off the flies : it has a chirping note, but not to be called a song *." Lewin, again, speaking of another species, gives us, in a few words, the most essential character, in regard to habits, of the genus; he calls his orange-rumped flycatcher, - which (from a specimen now before us) is evidently a typical Rhipidura,_- a chattering noisy species, constantly in motion, jerking and spreading its fan-like tail as it passes from bush to bush, catching its food in its flightt." The American Redstart (Setophaga ruticilla) is well known to possess the same habits; yet the two genera differ so much, that it would be preposterous to class them together. Here, then, we have another instance of that beautiful series of analogies which nature preserves between the contents of all her groups, whether large or small ; and thus we find, that by comparing the circle of the Pariance with that of the Muscicapince, the genera Rhipidura and Setophaga will stand opposite, or are parallel to, each other.

* Lath. Synopsis, iii. pl. 49.

+ Lewin's Birds of New Holland, pl. 15. 


\section{4}

\section{WHITE-SHAFTED FANTATR.}

Rhipidura flabellifera, Hors. \& Vigors.

\section{PLATE $X$.}

Above, sooty brown, beneath fulvous; chin, eye-stripe, and tips of the wing-covers, whitish ; tail black, the lateras feathers with the shafts white.

Rhipidura flabellifera, Horsfield \& Vigors. Linn. Tr. xv. p. 247.

Thrs is the best known, and seems to be the most common species of Fantail hitherto received from Australia; for there can be no doubt that several others are included by Dr. Latham under the general name of Fantailed Flycatcher. According to Mr. Caley, a naturalist long resident in New South Wales, its manners are very peculiar. "It frequents small trees and bushes, from whence it suddenly darts on its prey, spreading out its tail like a fan, and to appearance turning over like a tumbler pigeon; it then immediately returns to the same twig or bough from whence it sprang. These actions it continues constantly to repeat. The skin is so very tender, that it is difficult, after having taken it off the body, to restore it again to its proper shape. The species is very common about $\mathrm{Pa}$ ramatta, and I do not recollect having missed it at 

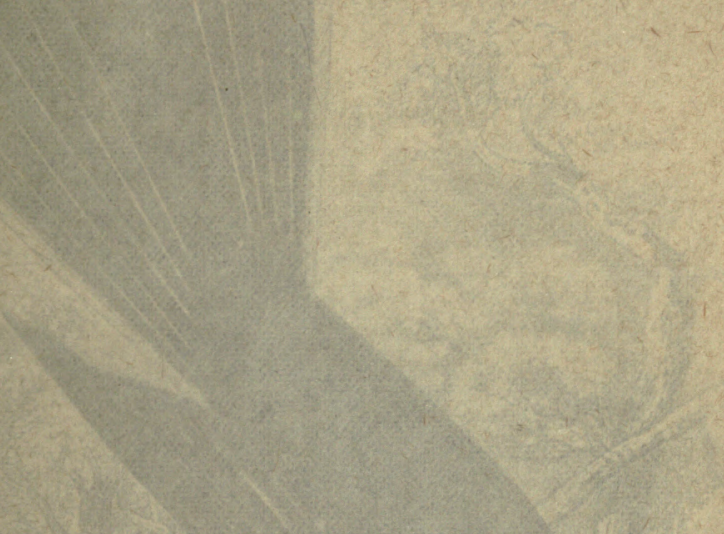

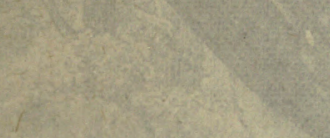
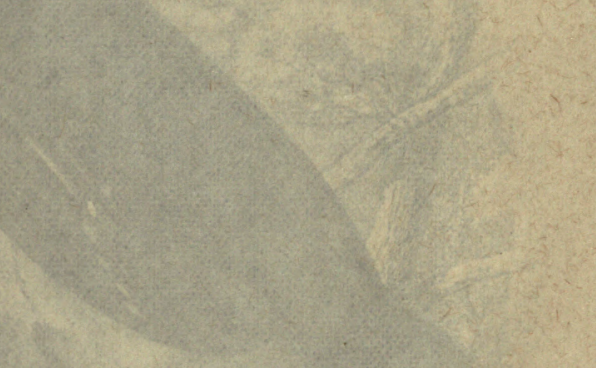

A)
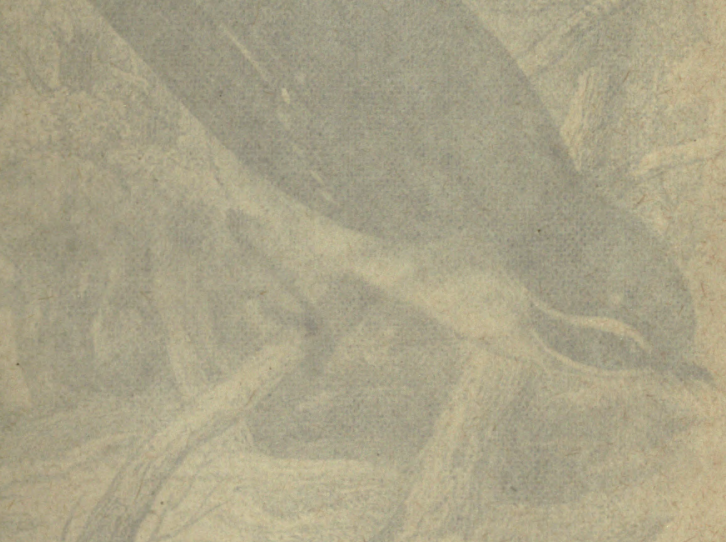

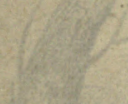
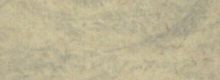


\section{WM}

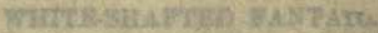

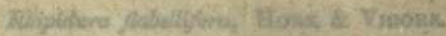

\section{Phate}

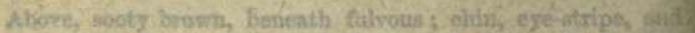

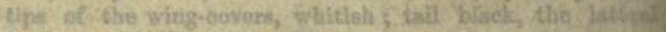

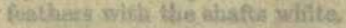

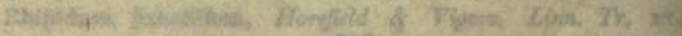
7):

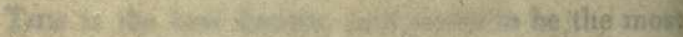

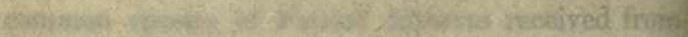

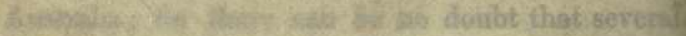

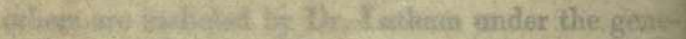

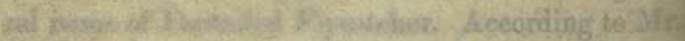

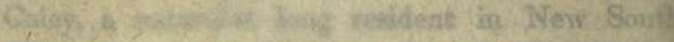

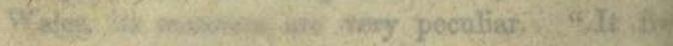

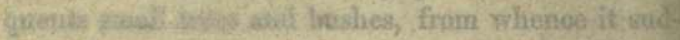
dehly datio cat its prey, spreading out its tril hise a

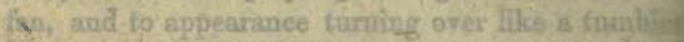
No Nony it then immediately returns to the zan. bulg or bough from whence it sprang. These are

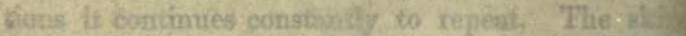
is se very tender, that it is difflculh after havib

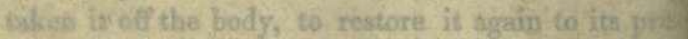
per uthage. The specteb is very common abont Hil

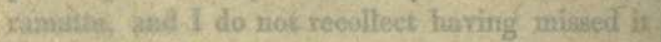




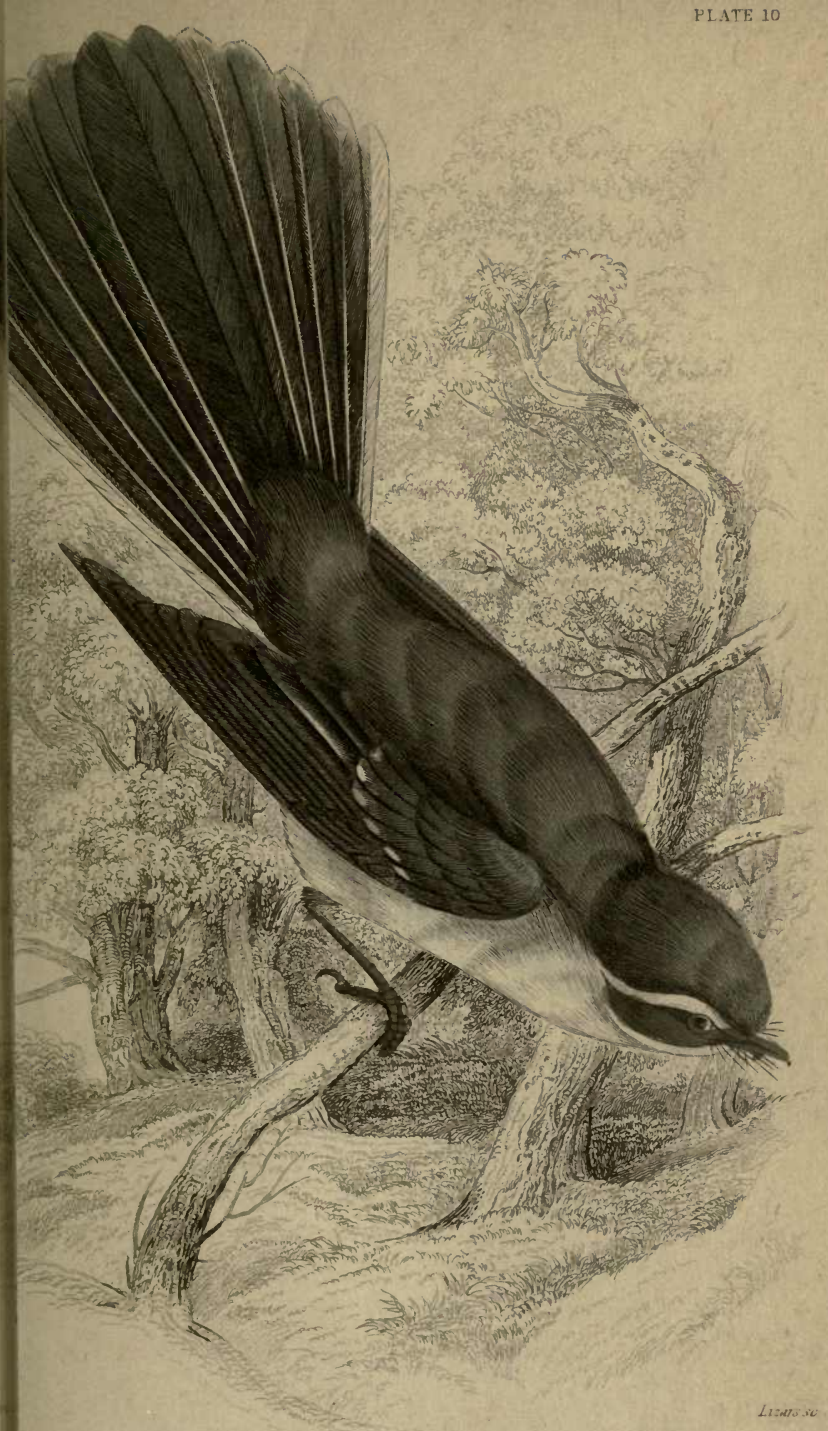


REESE LIBRARY UNIVERSITY

\section{CALIFORNIA.}


any period of the year*" The pure white shafts, contrasted with the blackish colour of the tail, when expanded, gives to this bird an elegance of appearance which it would not otherwise possess.

The bill is remarkably short, so that the bristles, which are thickly set, reach as far as the tip; the feathers of the head and throat are very full, resembling, in this respect, those of a Parus, or Titmouse; which group it represents in the circle of Muscicapinoe. The general colour of the upper parts is dark sepia brown, approaching to black; the edges of the tertials, and the tips of the greater and lesser wing-covers, are dull white, the spots upon the lesser covers being very small. In young birds, or in the females, these spots and borders are tinged with ferrugineous; the chin, and a stripe over the eye and ear, are white; so also are the shafts and tips of the tail-feathers; just below the chin is a narrow collar of brown, beyond which the rest of the under plumage is light buff colour; tail, and the upper covers, black.

Total length 6 inches; bill, gape, $\frac{1}{10}$; front, $\frac{1}{4}$; wings, $2 \frac{3}{4}$; tail beyond, $1 \frac{3}{4}$; base, $3 \frac{1}{2}$; tarsus, $\frac{6}{10}$.

The next modification of form, or sub-genus, we have nameả 


\section{LEUCOCIRCA,}

from the circumstance of several of the species having more white about their tails than any other fly-catching birds yet discovered. It is, in truth, now become a matter of no small difficulty in ornithology to frame generic names,-expressing a peculiarity of structure or of habit,-sufficiently different from those at present in use, to answer the object proposed. Names taken from the various constructions of the bill, wings, tail, and other members, are completely exhausted; while the comparative ignorance in which we remain regarding the habits of foreign birds, is an effectual bar to our compounding names founded upon such circumstances. We have hardly any other resource, therefore, left to us, but to employ designations derived from other peculiarities; and as we find that many natural groups are nearly as much distinguished by colour as by structure, there appears no valid objection to deriving our names occasionally from this source, as well as from structure or from hahits. But to return. The sub-genus Leucocirca, as far as we yet know, is restricted to the tropical latitudes of the Old World, but more especially to India and its islands, where it represents the last division. That it immediately follows Rhipidura, not a doubt 
can be entertained; the only difficulty seems to be, where we are to draw our imaginary line of demarcation. Considering, however, the remarkably small and universally compressed bill of Rhipidura, as seen in $R$. Alabellifera, as the most obvious, if not the real typical, character of that division, we place under Leucocirca all others which have the bill more lengthened, broader at the base, and less compressed towards the tip; the bristles at the corners of the mouth, although very rigid and often much lengthened, are not so long as the bill; the tail, in both, is the same, but in this the feet are more developed; and in one species (L. laticauda), which is probably the type, particularly long and stout. We can hardly suppose that none of these species have been described; but as they do not appear to be figured, excepting, indeed, the $M$. Javannica by Sparman (Mus. Carl. pl. 75), a specimen of this species, obligingly communicated to me by Dr. Horsfield, perfectly agrees with Le Vaillant's account and figure of his Gole-mouches a lunettes*. This circumstance is of more importance than the mere correction of synonymes ; for it establishes the fact, on the evidence of Le Vaillant, that this bird has the same habit of spreading out its tail, in the shape of a fan, as is possessed by Rhipidurat; a habit which no doubt extends to all the other species having the same structure. These latter, indeed, we have been compelled to

- Mus. Stellaris of suhsequent writers.

+ See Ois. $d^{\prime} A f$. iv. pl. 152. 
designate as new ; for not being figured, it is totally impossible to identify them with the loose and vague descriptions drawn up at a time when ornithology comparatively was in its infancy.

We have not, as yet, been able to determine whether Rhipidura or Leucocirca should be viewed as the pre-eminent type of this genus. If we considered that this station should be assigned to that division which, from what we yet know, shows the greatest developement of the tail, joined to a superior length and strength of foot, then Leucocirca must have the preference; but if we regard the greatest difference in the form of the bill from that so common among the typical flycatchers (Muscicapa), then we must place Rhipidura at the head of this genus. This point, however, is not of great moment to our present object, seeing that we have only just began to understand something of the whole group, which will probably be enriched, in a few years, with double the number of species now known. There can be no doubt, however, that the two sub-genera now described are the typical and sub-typical forms; a conclusion which may be drawn, not merely from their following each other in absolute affinity, but from the nature of the others, to which we now proceed.

It will be perceived, by a reference to the table already given, that the genus Rhipidura, as a rohole, is succeeded by that of Muscicapa; it follows, therefore, that the type which comes next - ohould resemble a Muscicapa more than does 
Leucocirca, because it must form the connecting link between the two primary groups. We have had in our Museum, for the last thirteen years, a most singular sort of flycatcher, whose natural relations, until the last week, had completely baffled us; so much so, indeed, as to cast a doubt over our arrangement both of the Saxicoloe and the Muscicapidac. The first impression, upon seeing this bird, is that of its being a robin (Erythaica); n glance at its bill and its feet destroys this idea, and we should then pronounce it a flycatcher. But its tail is so totally unlike that of the restricted genus Muscicapa, where alone it might le supposed to enter, that we were altogether perplexed as to its precise station: and although we were convinced it was either a most aberrant species, or the type of a new sub-genus, we did not venture to charac. terize it, even in our latest arrangement*. The recent acquisition, however, of the birds before alluded to, have solved all our doubts upon this subject; and under the sub-generic name of

- Class, of Birds, rul if 


\section{BI,ACK FANTAIL.}

Lencucirca laticauda, SWAINS.

\section{PLATE XI.}

Plumage above, and half way down the throat, deep black; stripe over the eye, spots on the wing-covers, and under plumage white; quills brown.

Tuis species, remarkable for its broad and perfectly black tail, makes a very near approach to the $R h i$ pidura motacilloides*; but it cannot possibly be the same, for the length of the wing, in that species, is stated to be only three inches and one-fifth, whereas the wing of this measures almost four inches. Neither has this any appearance of an interrupted pectorai band of black, while the wnite spots, on the wing-covers, seen in our present specres, are not noticed in the account given of the other.

Although this species does not exhibit the character so prevalent in this sub-genus of a white tipped tail, it nevertheless possesses all the others, namely, a bill of ordinary length, stout legs, and broad tail-feathers. I possess two specimens; but baving purchased them with other birds, I know

* Horsf. \& Vigors. Linn. Tr. xv. 248. 

130

\section{BHACX DAFTAIR.}

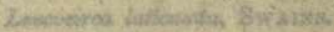

PLAXB XI.

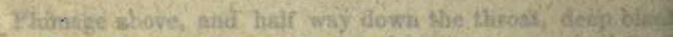

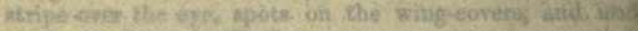

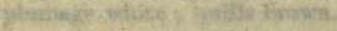

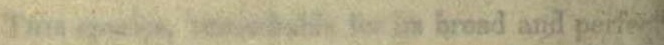

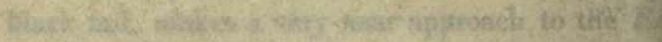

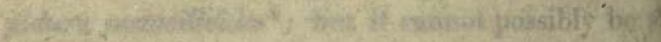

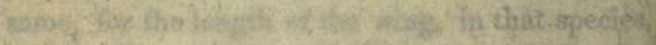

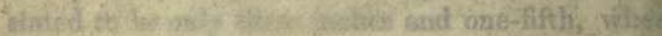

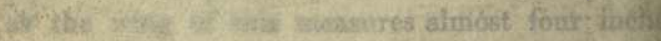

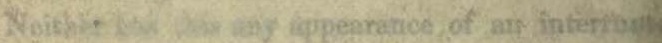

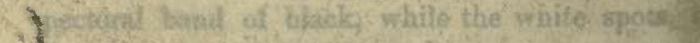

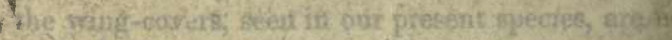
Watic d in the acoumt given of the other.

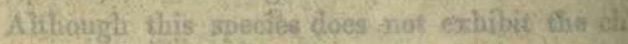
rancer so provalent in this sub-rents of a whe

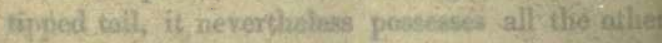

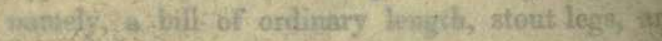

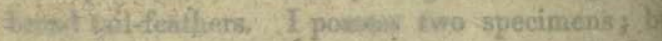

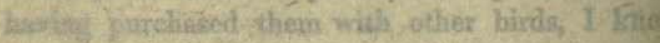

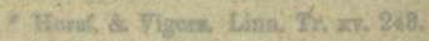


PLATE H
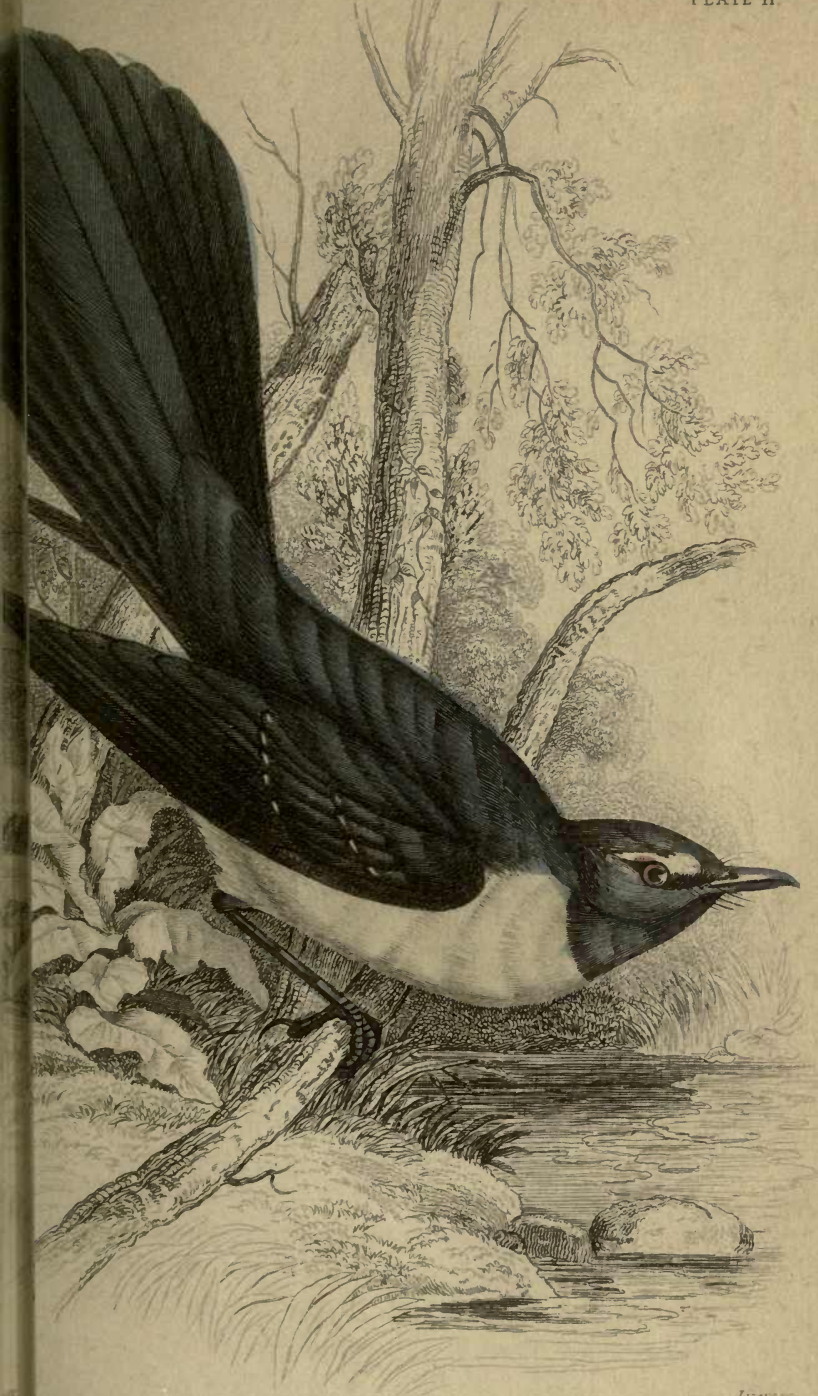

BL ACK FAN-TAIL

Native of Australia. 
REESE LIBRAPY UNIVERSITY CALIFORNIA. 
not whether they came from Australia or the East Indies.

The size, for a Flycatcher, is rather large; the total length being eight inches and a half. Nearly the whole of the upper plumage is of a deep and uniform black, which envelopes the head, chin, and half of the neck beneath, the quills alone are brown; a pure white line commences above the lores and passes over the eye, and all those wing. covers which are nearest to the carpus have a round white terminal spot; the sides of the neck, breast, and flanks, are of the same deep black as the upper part, but we cannot trace any indication of this colour advancing so far on the breast as to form an obsolete or interrupted pectoral band. The under plumage, from the lower part of the neck, is entirely white; inner wing-covers black, with a few white specks.

Total length, $8 \frac{1}{2}$ inches; bill, gape, $\frac{3}{4}$; front, $\frac{9}{80}$; wings, $3 \frac{9}{10}$; tail beyond, $2 \frac{1}{4}$; from the base, $4 \frac{1}{2}$; arsus, nearly 1.

As the fourth type in the circle, and following be last, we place the sub-genus 


\section{MYADESTES;}

we shall not only characterize this form, but endeavour to demonstrate it as the rasorial type of Rhipidura. The bill is small, angular, and much depressed towards the base; but the culmen is slightly and gradually bent, and the gonys ascends, in the same degree, towards the point: the rictal bristles are few and short, and do not extend to one-half the length of the bill : the wings are moderate, not reaching beyond the tail-covers; their structure is the same as in all the Old World flycatchers, but the first and second are suddenly narrowed at their tips; a character we have not met with in any other of this family. The legs, for a flycatcher, are strong, the tarsus moderately lengthened, and the toes considerably developed, much longer, in fact, than either in Rhipidura or Leucscirca. The middle toe is as long as the tarsus; the inner toe much shorter than the outer, but both are cleft to their base; the hinder and inner toes are equal; the legs are very pale, and the tarsal scale is in one entire piece ; the breadth and curvature of the claws, joined to the relative length of the toes, renders it highly probable that this bird does not habitually frequent the ground. But its great peculiarity lies in the tail, which is moderately 
lengthened and slightly graduated, having something of the size and form of Leucocirca, excepting that the feathers, instead of being broad, are rather narrow, with the tips acuminated.

Such are the characters of the bird before us. It is at once distinguished from our sub-genus Muscicapa (as subsequently defined) by its long toes and lengthened graduated bill; and from Leucocirca, by its small slightly bristled bill, and those other indications which unite it to the genuine flycatchers: the whole structure of the bird, particularly in the head, which is thick like that of the robin, is quite opposed to that slenderness of shape so general among its congeners. . Lastly, although not one of the least of its characteristic marks, is the pure white which ornaments the ends of the three pair of lateral tail-feathers. Laying all these particulars together, we view this bird as the rasorial representative of the fan-tailed flycatchers: its unusually long toes, its attenuated tail and quill-feathers, and its almost smooth rictus, are all so many indications of the type it represents, setting aside the developement of the tail, because that is the characteristic of the entire group of which this type forms but a part. 
WHISKERED FANTAII.

Myidestes genibarbis, SWAINs.

PLATE XIII.

Cinereous above and beneath ; throat, vent, and under tailcovers rufous; maxillary stripe and ears black, streaked with white; lateral tail-feathers black, the three outermost varied with white.

$W_{E}$ have already so fully described the structure of this remarkable bird, that nothing more is necessary than to glance at its analogies and describe its colours. We are entirely unacquainted with the country it inhabits, and, of course, are equally so regarding its manners. Judging from the formation of its wings, however, we should conclude it was from some part of the warm latitudes of Africa or India; while, from the structure of its feet, and more especially the length of its toes, there is every reason to believe it frequents the ground much more than any of the more typical Fantails.

A glance at the annexed figure will preclude all necessity for our pointing out the intimate resemblance which this flycatcher bears to the common Robin, not merely in the red colour of the throat, 


\section{$3 \times 4$}

\section{WHLSKLRED PHNTAIS}

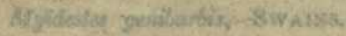

\section{- PuATE XaII}

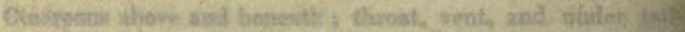

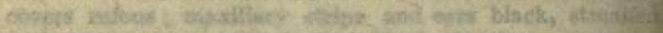

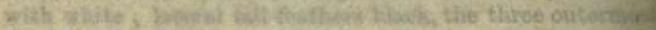
maded with ingates

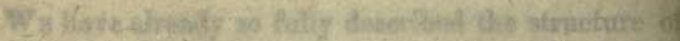

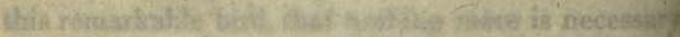

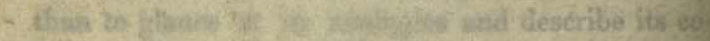

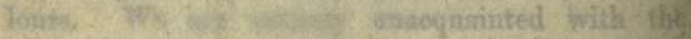

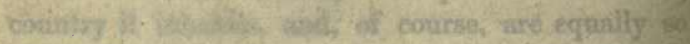

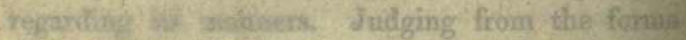
that of ith wings however, we should couclodo he wian ficoms somo part of the warm latitudea of Affic or Jndia ; while, from the atructure of its feuk, axt mono especially the length of ifs toieg; there lis erer

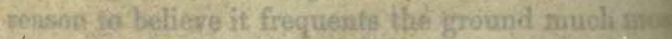

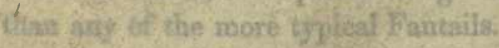

A glasige af the annoted figure will preclude

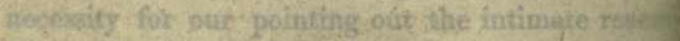
Whace which strib Alycatchet beans to the connuets Scobin, bot mierely in the red colour of the theo 


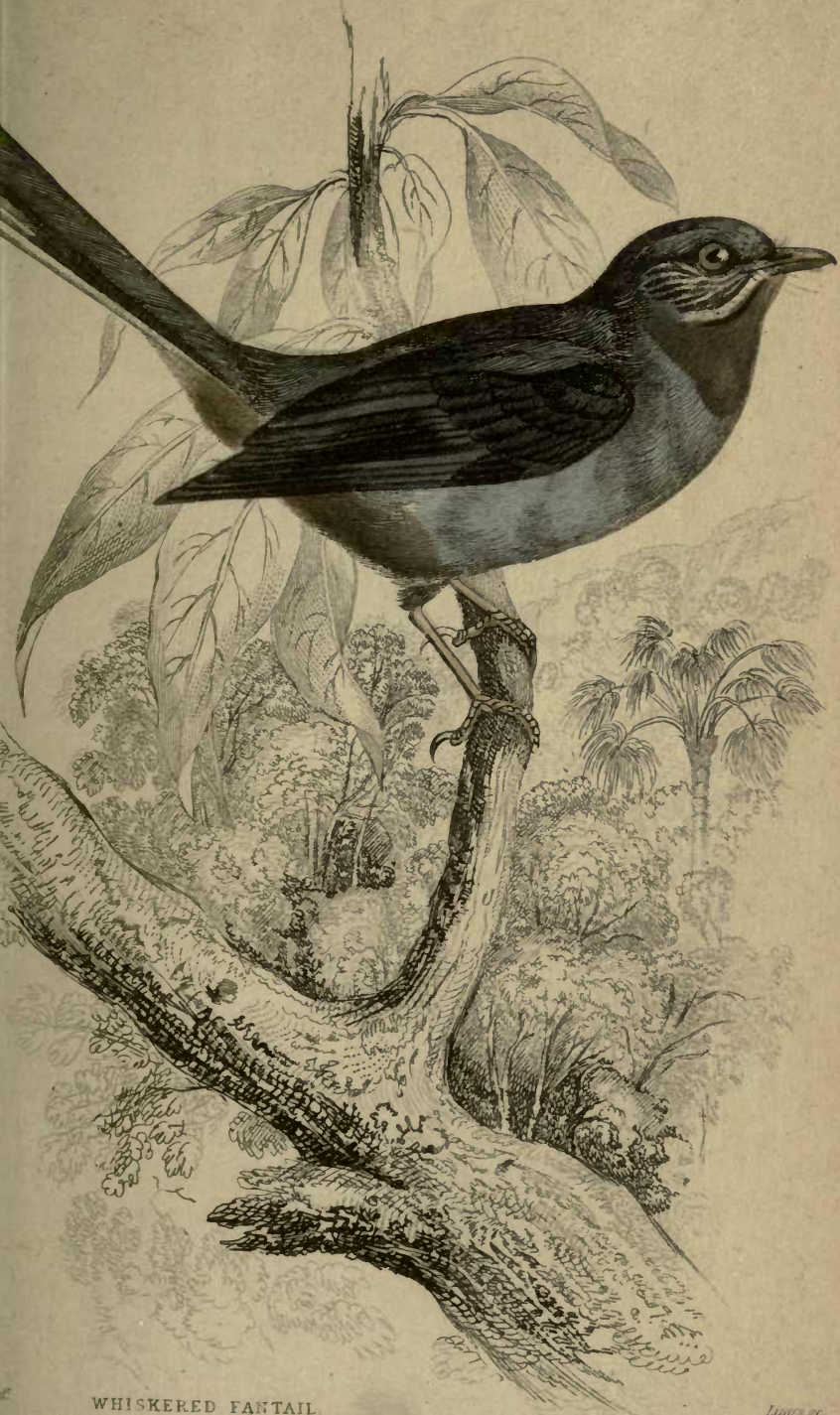




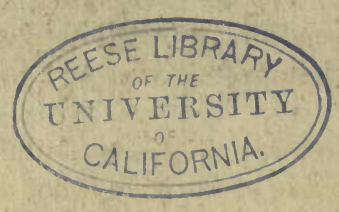


but in its thick head, plump body, and lengthened feet; it bears upon its face a flycatcher disguised as a robin. That it is not a robin, however, is quite evident from its bill, and from those other characters, already detailed, by which it becomes truly connected by structure with the Fantails, and with the true flycatchers. Anotner or its representatives, in this family, is the Conopophaga, previously figured; and in this manner we might trace its corresponding types through nearly every one of the numerous groups in the feathered creation.

With the exception of the tail, which is more lengthened, the size of the body is not much larger than that of the robin. The colour above, excepting the wings and the lateral tail-feathers, is clear cinereous, and all the under parts, not red, are the same, although much paler: there is a whitish maxillary stripe bordered by a black line, and the ears are black, striped with white lines. The external edges of the wing-feathers are grey, except the terminal half of the primaries, and a black band at the basal half of the secondaries; the lateral tail-feathers are black, having the end of the inner webs more or less white; the outermost is almost entirely white, with the outer edge of that and the next grey; the middle pair are wholly cinereous. The under plumage, from the chin to the throat, is bright rufous; which colour descends a little upon the breast, and is bordered on each side the chin by the black maxillary stripe, resembling 
a whisker, already mentioned; the breast and its sides are cinereous, nearly of as dark a tint as the back; as this colour descends, howerer, it becomes paler, and blends into the rufous on the belly, vent, and under tail-covers; the bill is deep black, and the legs very pale.

Total length, about 7 inches; bill, gape, $\frac{7}{10}$; front, $\frac{4}{10}$; wings, $3 \frac{4}{10}$; tail beyond, 2 ; base, 3 ; tarsus, $\frac{8}{10}$.

What the fifth and last type of Rhipidura may be, we know not; and we shall therefore at once proceed to the genus

\section{SEÏSURA,}

whose characters it is not necessary here to detail, further than to show its real affinities. Seïsura, in short, resembles an Old World flycatcher of M. Cuvier's division, Muscipeta, except that its bill is unusually long, its tail nearly even, and its tarsus rather more lengthened; although the toes are so small, that no one would suspect they were ever used to stand for more than an instant upon the ground, or upon any flat surface. The tail of $S$. volitans, the best known species, although not so broad or rounded as in the preceding types, has yet a sufficient length and breadth about it to justify a suspicion that it 
was occasionally spread out in the same manner; a fact confirmed by what has been published of its manners. It is a mistake, however, to suppose that this bird has no bristles at the gape; for although they do not reach to half the length of the bill, which is uncommonly long, they are nevertheless very stiff, and there are several others, slightly recurved, over the nostrils. We have already remarked how intimately this form appeared connected to the American water-chats, although we strongly suspected that future analysis would show that it belonged to the circle of Rhipidura. This opinion has been so strongly confirmed by a subsequent investigation, that we now place it at once as the tenuirostral sub-genus, a station which at once reconciles all the opinions that have been formed of it, and all that is known of its very peculiar manners. Occupying the most aberrant situation in the present genus, it is consequently that which unites Rhipidura to the Fluvicolina: as the tenuirostral type, it represents, in a most remarkable manner, its prototypes among the todies and the flycatchers, namely, the sub-genera Platystera and Hyliota, both of which have very long bills, - the primary character of all tenuirostral types. Mr. Caley, who seems to have possessed much tact in observing the habits of the Australian birds, observes of this:- "I have often considered it, when I witnessed its manners, to be the wagtail of the colony*." And such it truly is. The wagtails,

* Linn. Trans. xv. 250. 
as every ornithologist knows, form the tenuirostral type of the warblers; and Seisura holds exactly the same station in the genus Rhipidura. Such notes, made by mere observers of the facts they communicate, are often of the first importance, because they are framed without any reference to theories or general laws, and thus become the best possible evidence in support of a natural classification.

\section{DISHW ASHER FANTAIL.}

Seïsura volitans, Horsf. \& VranRs.

\section{PLATE XII.}

Above glossy blue-black; beneath pure white, or tinged on the breast with fulvous.

Turdus volitans, Latham, Ind. Ornith. Suppl. xli. No. 10.-

Volatile Thrush, Il. Gen. Hist. Birds, v. 122. - Seïsura volitans, Linn. Trans. xv. 250.

According to Mr. Caley, the colonists of New South Wales call this bird the Dishwasher, but for what precise reason does not appear. It is, observes the same writer, "very curious in its actions. In alighting on the stump of a tree it makes several semicircular motions, spreading out its tail at the same time, and making a loud noise, somewhat 
The
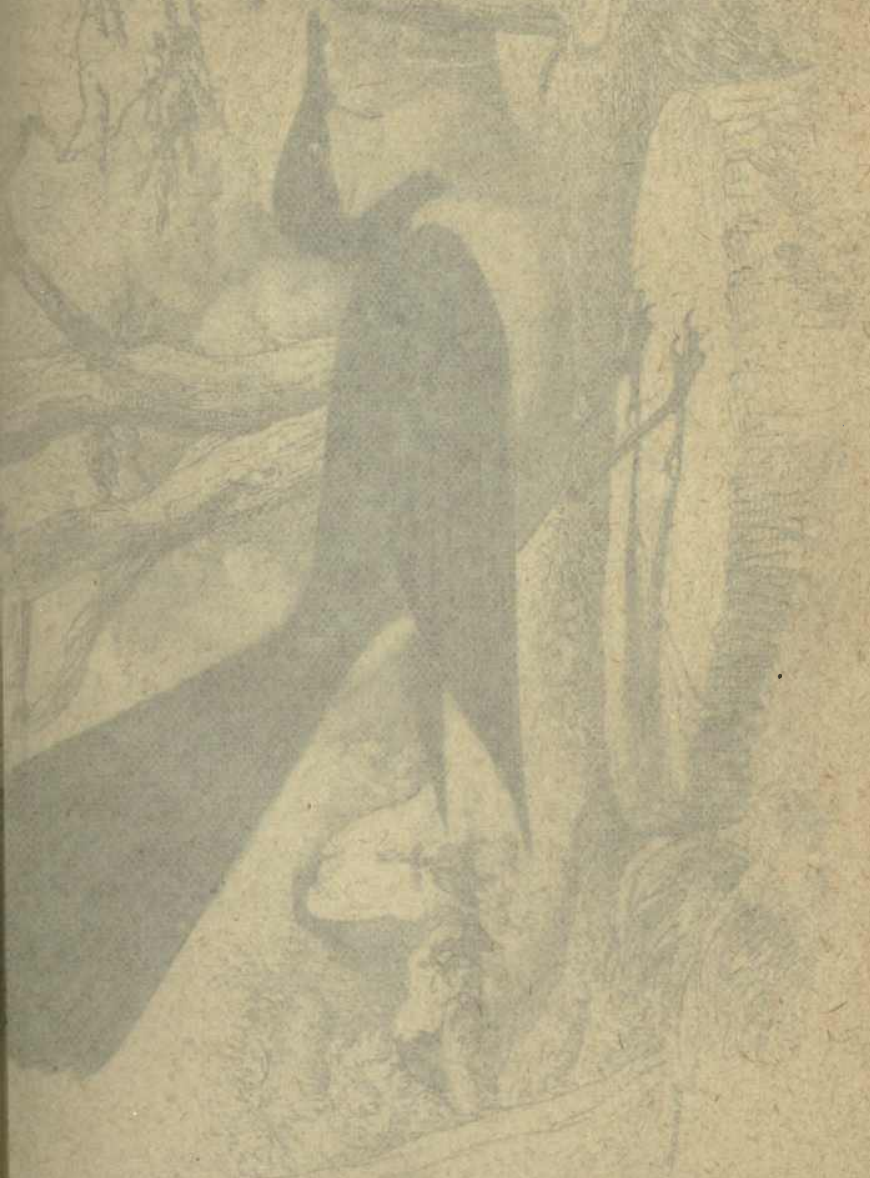
H.3.

axasuph.

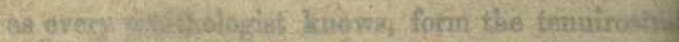

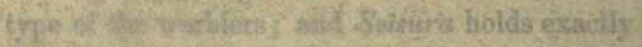

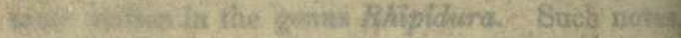

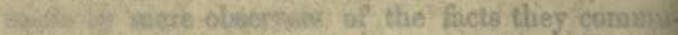

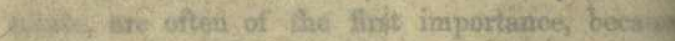
Acyace framed without any teqference to theoric ve general laws, and thuis become the best posilible sridence in oupport of a raghrar clasiffication.

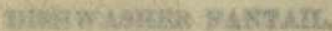

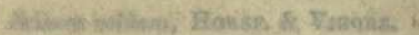

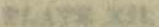

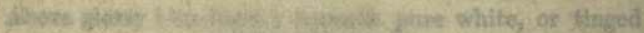

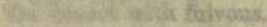

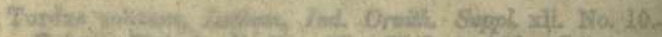

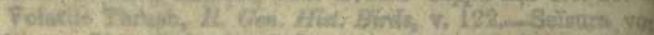

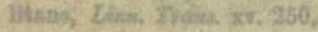

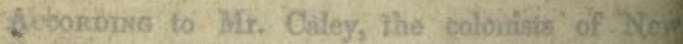
Gith Waileb call this bird the Dishmasber, but for

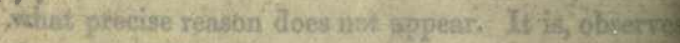
the wame writer, st very carives in its actionso: It

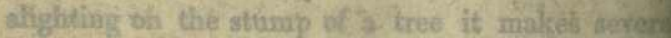

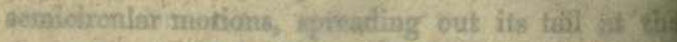

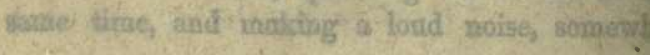





\section{CALIFORNIA.}


like that caused by a razor-grinder when at work. I have frequently seen it alight on the ridge of $\mathbf{m y}$ house and perform the same evolutions. I have often considered it, when I witnessed these manners, to be the Wagtail of the colony. The stumps of trees on which it alights are those which have been left standing where the ground has been cleared, the trees themselves having been cut down about a yard from the ground." So far we have the testimony of an eye-witness, corroborating all those analogical inferences to be drawn from its general structure, illustrating its relation to other tribes. It is truly, as Mr. Caley observes, the representation of the Motacilloe or Wagtails, not only in the colony, but in that natural circle into which it enters.

The colouring is very simple, being unbroken by any spots or markings. The upper plumage, excepting the quills, which are brown, is of a uniform glossy blue-black, darkest upon the head, where the feathers are somewhat scale-shaped; this colour advances so far on the sides of the head as to include the lores, eyes, and ears; the inner wing-covers are also black. The whole of the under plumage, from the chin to the tail-covers, is white, in one specimen I possess, and tinged with buff on the breast of another; this difference is probably sexual. The bill and feet are black.

Total length, $7 \frac{1}{2}$ inches; bill, gape, $I^{2}$; front, Io ; wings, $33_{10}^{8}$; tail beyond, $1_{10}^{8} ;$ base, 4 ; tarsus, $I^{7}$. 
MONACHA, HoRsf. \& Vigors.,

contains the Oriole, or Hooded-flycatchers. We give them this familiar name from the black and golden yellow colour of the typical species ( $M$. chrysomela), here figured, which immediately reminds the observer of an oriole: the two groups, in fact, are perfectly analogous, being the most aberrant (or the tenuirostral) type of their own circle. The French naturalists discovered two of the most beautiful species in the islands near New Guinea, to which, and the neighbouring continent of New Holland, the group is confined. The bill is particularly strong; and from being as much compressed as depressed, we immediately perceive how distinct they are from ordinary flycatchers. As representing the Tenurrostres, the gayest of all birds in their plumage, the oriole flycatchers present us with the most lovely bird in the whole family, the Monacha chyrsomela (Sw.). It is clothed in the same sort of brilliant velvet-like feathers-black and orange - of the regent oriole (Sericulus chrysocephalus); while another species, Monacha telescopthalima, (Sw.) likewise an inhabitant of New Guinea, has naked erect wattles over the eyes. Under the name of Musicapa carinata, of our Zool. Ill. i. pl. 147, we first brought this 
group to the notice of ornithologists; and, it is proper also to mention, that several others, erroneously placed by M. Temminck under our genus Drymophila, strictly belong to Monacha. The analogous representations of this beautiful group are so palpable that they hardly require pointing out. It reminds us immediately of Psaris by its bill,of Sericulus by its velvetty feathers, - of Oriolus by its colour, and, through them, of the paradise birds (Paradisidoe). The carinated species, again, puts on the exact colours of a Ceblepyris; while, in M. telescopthalma, we have the spectacle-like wattles of Perspicilla, Ceblepyrus lobatus, and the sub-genus Platystera; not to mention the numerous species of naked-eyed and wattled plovers, and many of the honey-suckers (Meliphagida), all rhich are grallatorial types. How surprising is this uniformity in the midst of the greatest possible variety! We know not which excites the greatest surprise-the fact itself, or the new lustre thus discovered in the works of OMNIPOTENCE. 


\section{GOLDEN-HOODED FLYCATCHER.}

Monacha chrysomela, SWAINs.

\section{PLATE XIV.}

Golden-orange ; chin, throat, interscapulars, wings, thighs, and tail, velvet-black, glossed on the throat with blue ; beneath the eye a snowy spot.

Muscicapa chrysomela, Garnot \& Less. Zool. de la Cog. Pl. 18, fa.

THE only specimen yet known of this superb Flycatcher, by far the most beautiful that has yet been discovered, was procured by the French naturalists who accompanied the discovery ship, Coquille, in the thick woods of New Ireland. It is now deposited in the Royal Museum at Paris, where the accompanying figure was made some years ago. As nothing is known of its manners, we have only, in this place, to describe its plumage.

The ground colour of the whole bird is of the brightest orange, or golden-yellow ; the feathers of the head being compact, and forming an obsolete crest, as in the typical species of Muscipeta. This brilliant colour is relieved by a large patch of the deepest black, glossed with blue, in front of the 


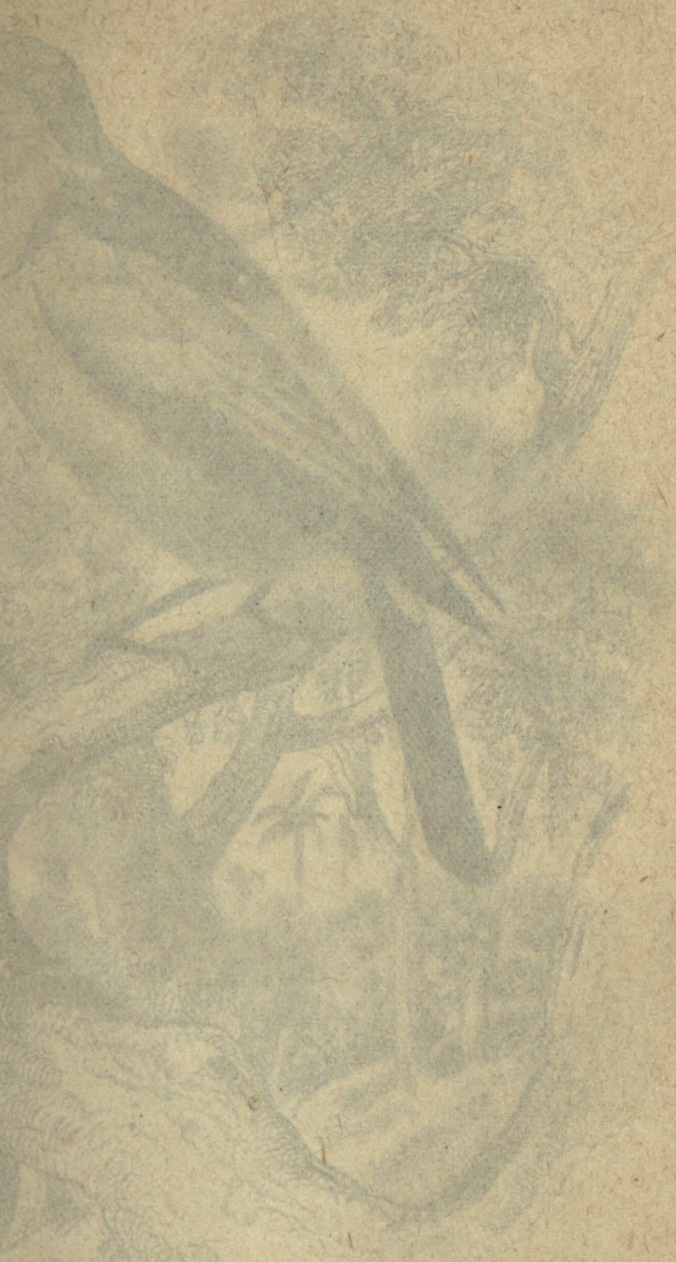




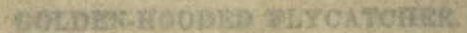

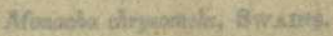

\section{PE:ATES XPY.}

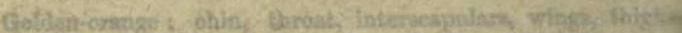

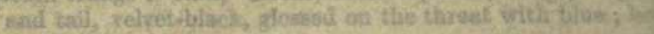

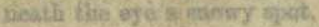

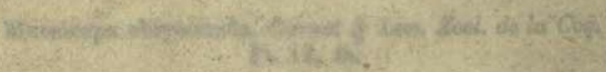

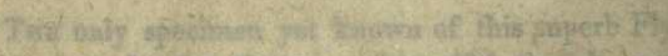

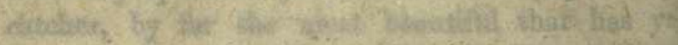

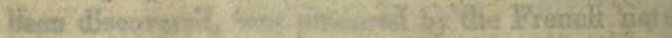

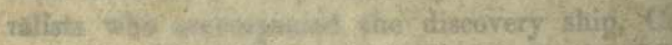

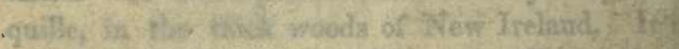

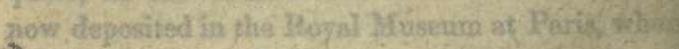

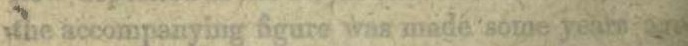

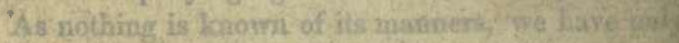
in this places to deseribo its planoegè

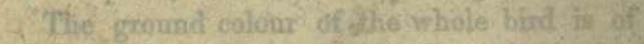

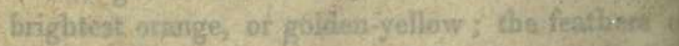

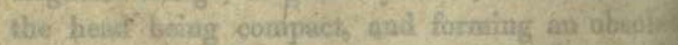

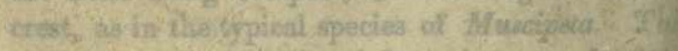

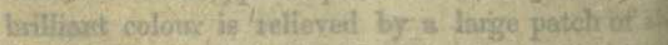

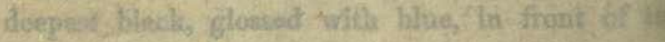




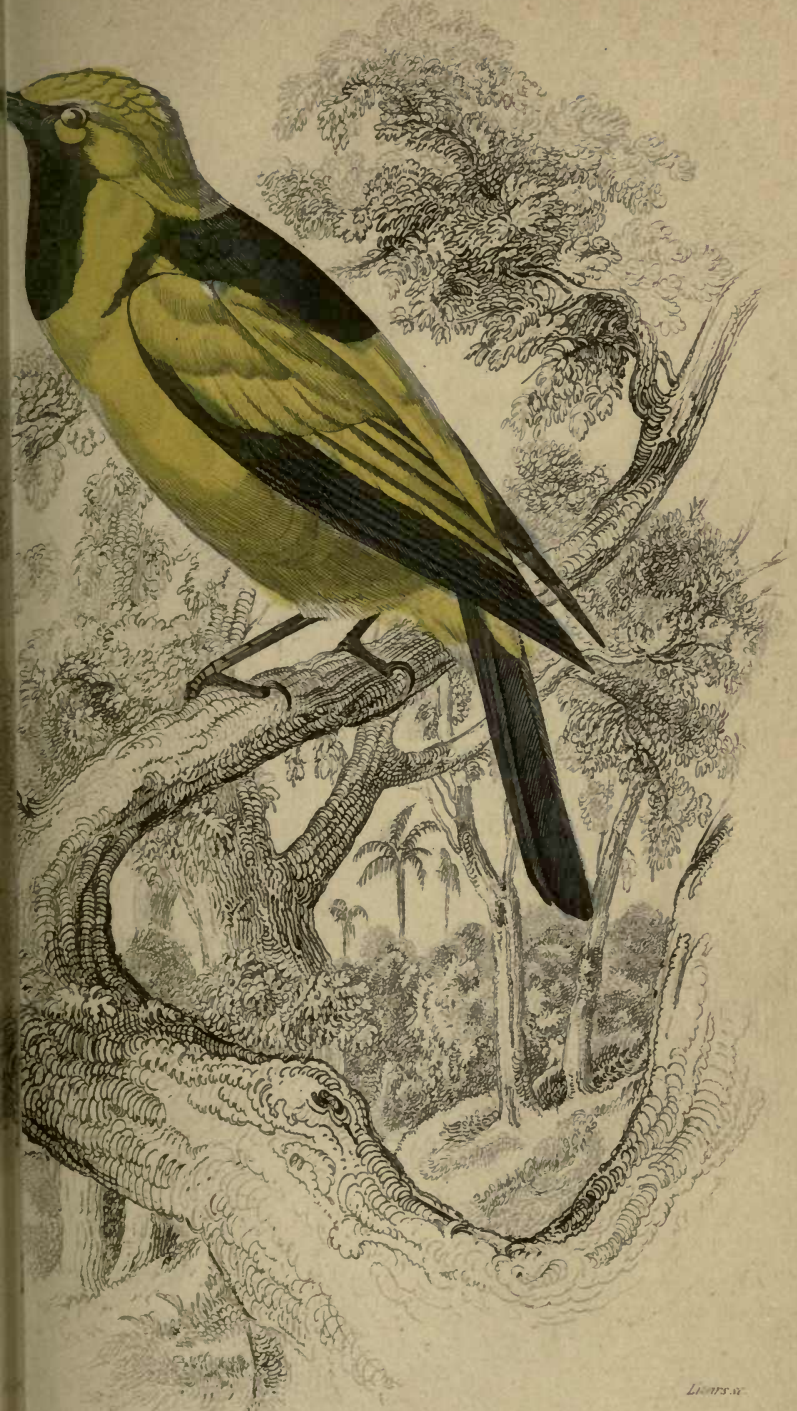


REESE LIBRARY

UNIVERSITY

CALIFORNIA. 
throat and one half of the ears, and by another, of a crescent shape, across the interscapulars; the outer margin of the wing, the whole of the primaries and secondaries, and the inner web of the tertials, together with the tail and thighs, are deep black; the bill is blue-black; the feet deep black. The tail is even, but the under feather is the shortest; the feathers in front of the throat are small, compact, and scale like.

Total length, about 6 inches; bill, front, $\frac{1}{2}$; wings, nearly 3 ; tail beyond, 1 ; base, $2 \frac{1}{4}$; tarsus, $\frac{1}{8}$.

The third division of this family is the genus

\section{MEGALOPHUS,}

at present represented by a single bird, whose structure is as remarkable as its appearance is beautiful. We have already attempted to show its natural station in this family and with its congeners. This extraordinary bird is not much bigger than a obin, and has nothing to recommend it in the yeneral colour of its plumage, which is brown on he wings and back, and deep buff on the tail and inder parts. Its crest, however, is perhaps the argest and most beautiful of any perching bird yet liscovered: no adequate idea of this splendid orna- 
ment can be given by words. When in a recumbent state, it is so long as to hang down upon the back and on each side the head; but when erect, it forms a large semicircle round the crown, very much in the manner of the half of a full blown plant of the syngenesius order; its colour is bright reddish cinnamon, each feather being tipt with glossy blue-black, and enlarged at the end. The bill, for the size of the bird, is enormous, its shape being like that of Muscipeta; although somewhat dilated towards the base, it is very flat, and rather lengthened, and so strongly protected, that the bristles at its base reach nearly to the tip. The wings and tail are moderately long; and their structure comes much nearer to those of the Muscipeta than to the flycatchers of the ew World Finally, the feet are very short, and nearly white the toes rather long in proportion, and the claws very slightly curved. The ornithologist will readily trace in these particulars many strong indications of the characters of Eurylaimus, to which group, as we believe, this bird constitutes the passage. Its great rarity is no doubt to be attributed to its very local dispersion. 



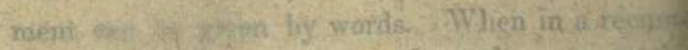

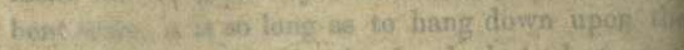

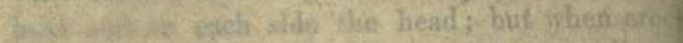

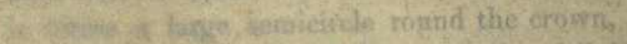

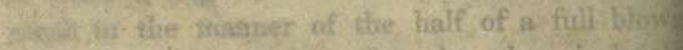

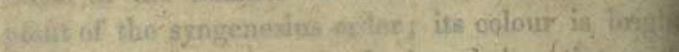

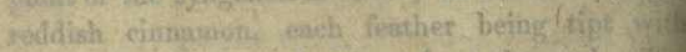
glopsy blue-theck, and enlarged at the end.

- Mly for the size of the bird, is enomous, its shapt

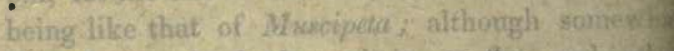
diflated towards the base, it is very flat, and inclyfor lengthenied, and so:strongly protected, thath brigetos of its two rovela mearly to the tip.

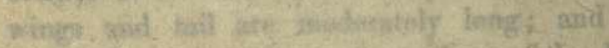

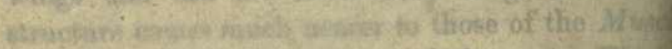

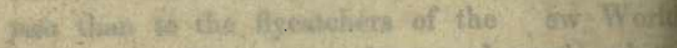

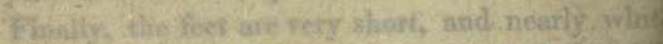

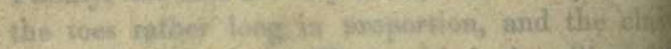

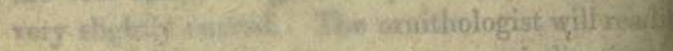

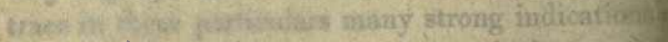

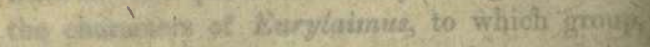
- wes believe, this bird constitutes the passagen to

4 great raxity is no doubt to be athibuted to its is focal dispersion. 


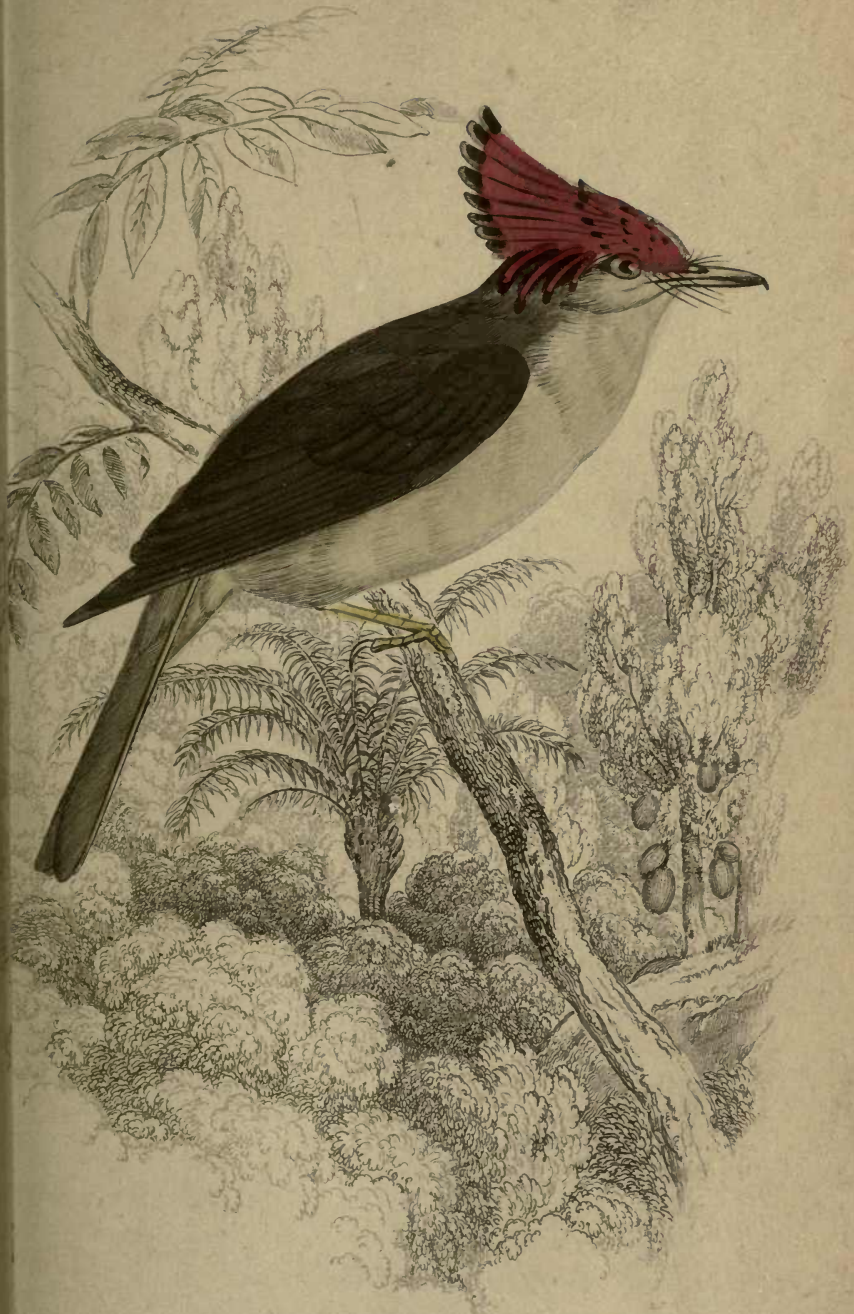

ROYAI, GREAT CREST

Native of Caynne. 


\section{\&}

REESE LIBP

UNIVTRSITI
CALIFORNIA. 
ROY AL GREAT-CREST.

Megalophus regius, SWAINs.

PLA TE XV.

Crest very large fan-shaped, bright rufous-red, with black tips; bridy above brown; tail and under plumage fulvous or ferrugineous ; chin paler.

Todus regius, Aut.-Le Roi des Grohe-mouches, Buffon, Pl. Enl. 289.-Megalophus regius, Birds of Brazil, PI. 51, 52.

UNTIL very lately, this rare and remarkable bird was only known to the ornithologists of the present day by the figure and description of Buffon, who mentions it as being found, although very rarely, in Cayenne. Dr. Shaw, indeed, alludes to another account, of what he considers to be the same bird, in a little known German work, entitled Naturforscher; but this we have never seen. Three or four, years ago, however, several specimens of this species came to England, through the hands, as we were informed, of the French dealers, but from what precise locality appears uncertain. One of these, obligingly lent to us by Mr. Gould of the Zoological Society, enabled us to delineate the species in two different attitudes in the Birds of Brazil, and the annexed figure was drawn from the same specimen. 
It would be difficult to convey, by words alone, a just idea of the peculiar form and colouring of the crest of this bird, which, in proportion to the size of the bird, is the largest example of this ornament in the whole of the perchers. The shape of the feathers is linear in their length, and almost spatulate, or spoon-shaped, at their extremity : they are disposed transversely across the head in various lengths, so that the last are by far the longest; their extremities are' somewhat incurved, but those ad.joining the ears are narrower, and are pendant on the sides of the head, something like ear-drops. When erected, the feathers form a semicircle, or crescent, across the back of the crown, and have a most splendid appearance. The ground colour of all these feathers is of the richest chesnut-red, resembling brick-dust; but each has a terminal spot of velvet-black, encircled by a margin of steel-blue, the effect of all which is heightened by a rich orange shade, intervening between the black spot and the deep red which succeeds. The rest of the plumage is comparatively plain; the upper parts are dark hair-brown, approaching to chestnut; the under parts light fulvous, or ferrugineous, rather brighter and deeper on the tail, which is slightly rounded. The other parts of its structure enters into the generic character.

Total lengtb, $6 \frac{1}{2}$ inches; bill, gape, 1; front, Io ; wings, $3 \frac{1}{2}$; tail beyond, $1 \frac{1}{2}$; ditto, base, 3 ; tarsus, $\frac{11}{8} \frac{1}{0}$. 


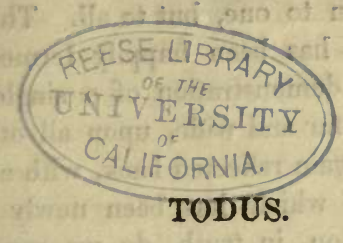

The genus Todus evidently succeeds the last. As it is one of them which are typical of this subfamily, we should expect to find it more numerous in species and more diversified in forms; and such we discovered to be the case. Unlike the three aberrant divisions we have just quitted, the one before us presents us, for the first time in this family, with a complete and perfect circle, where scarcely a link is missing; and where we have, in consequence, the five types of nature fully and perfectly demonstrated. Hitherto we have been barely able, with much difficulty, and some latent doubts, to make out the prominent types of the divisions just gone through; not so much from the absolute relations which they bear to each other by intervening species, as by comparing our distribution of the order of their succession with that of other and more perfect circles, whose validity has been long established. But in the todies we can proceed with more confidence; for if, amidst so much variation, we can yet establish the same uniformity, and add another instance in corroboration of those general laws elsewhere promulgated, additional confidence 
is not only given to one, but to all. The "flood of light", as it has been happily termed, which results from the demonstration of a single natural group, radiates, far and wide, upon all other such groups, and is again reflected back, with additional force, upon that which has been newly evolved. Of this description, in truth, do we consider the group we are about to illustrate. The views, now submitted to the scientific world, on the natural arrangement of this intricate family, have been "slowly and painfully" elaborating for near eleven years, in which period, as may be supposed, they have undergone numerous alterations and revisions ; for so long as a single modification of form could not be explained and accounted for, we hara studiously refrained from viewing our arrangement otherwise than as provisional. That it may not be found, hereafter, without errors, no one can suppose; and yet we may be allowed the satisfaction of saying, that there is no one bird, belonging to this genus, which has yet fallen under our inspection, but what may well find its place in the series, and furnish additional evidence that that series is in union with all those already established in other departments of nature. We venture to make these preliminary observations upon two grounds: 1 . the scientific importance of the group before us; and, 2. as the reasons of our entering so fuily into its detail.

The types of the genus 


\section{TODUS,}

as now defined, with but one exception, are exclusively restricted to the tropical latitudes of America ; they are all very small birds, the largest not being equal to a robin, while the smallest is more diminutive than the gold-crest. The whole group is remarkable for three peculiarities: 1 . the excessive shortness of the wings and tail ; 2 . the great comparative length and feebleness of the tarsi; and, lastly, the elongated boat-shaped form of the bill. Of these the first is the most universal; and when we compare these characters with those belonging to the same members in the birds of the genus Muscicapa, we can have no doubt of their being employed in a very different manner. This brings with it the inference, that the todies do not seize their prey in the same manner as the flycatchers. Upon this point, in the absence of better information, we can say something from personal knowledge. Whenever we observed the black-capped tody in the woods of Brazil, where it is by no means scarce, we always found it hopping among the branches and the foliage of trees, pursuing its search to the extreme twig. much in the same way as our tom-tits. If its ap- 
pearance gave warning to some hapless insect which could fly, and the attempt was made, the tody would then make a little saltus, or jumping flutter, two or three inches from the branch, and peradventure seize the insect; but if not, it would still continue its search for others, as if its wings were too feeble to sustain that sudden and vigorous flight which the true flycatchers can employ when so engaged. Now, as the species above alluded to is a typical example of the whole group, we may fairly and justly suppose that such are the typical habits; nor will this at all interfere with the fact that has been stated (but on somewhat questionable authority) regarding the green tody, which is said to frequent the ground in search of food as well as to frequent trees. Whether such a union exists in one and the same species may well be questioned; but the group, however small, would not be a natural one, did it not contain one which was to give us the rasorial or the grallatorial habit of walking on the ground, no less than another, which had the tail more developed than usual. The todies,-we are still speaking of the most typical species,-bave the rictus or gape very slightly bristled*; and, in some species, these bristles are nearly obsolete. We infer from this, that the food of these birds consists of small weak insects, probably larvæ, rather than of such as are able to make vigorous struggles in their attempts, when caught, to escape ;

* Platyrhynchus, as will presently appear, is the sub-typical form. 
for it is to counteract such effects that the bristles of the true flycatchers, which are altogether more powerful birds, are so strong. In a country like tropical America, where insect population is so dense and so varied, it is essential to the balance of creation that suitable checks should be provided for each tribe, after its kind. Now these flying tribes become the prey, according to their respective sizes and habits, of the tyrants (Tyrannina), the swallows, the water-chats (Fluvicolino), the tyrant warblers (Dumecola), and the todies; for the true flycatchers, we must remember, are excluded from the range of the NewW orld, their place being supplied by the tyrants. Consider, then, what a multitude of minute apterous insects, living among foliage, would have no equivalent check upon their increase, did all the Muscicapidoe live only upon such as could fly. Now the todies appear especially adapted to fill this office: they are fly-catchers, it is true, but very partially so; for they exert the power only upon particular occasions, and then very feebly. Nay, it may even be questioned, whether, - in accordance with what we so often find in typical forms, - the genuine todies do not occasionally eat soft fruits. When nothing, however, is absolutely known of the natural history of a group, it would be carrying analogy too far were we to attempt any explanation which could not be supported, in some manner, by ascertained facts. We must consequently remain in ignorance why the legs of the todies, although equally feeble with those of the flycatchers, are 
nevertheless so much longer. We know, however, that a syndactyle foot, from its giving greater breadth to the sole, is much more adapted for grasping than one in which all the toes are cleft to their origin; and as this power is called more into exertion among the todies than in the flycatchers, strictly so termed, we see that their toes are accordingly more united. Now the pre-eminent type of the whole group seems to be the Todus viridis. And it is consequently this very bird which has the most syndactyle foot; while the strong curvature and breadth of its claws would seem to disprove at once the assertion that it feeds upon the ground*. No bird, out of thousands which we know of, having the peculiar sort of claw possessed by the Todus viridis, has hitherto proved to be in any way terrestrial. On the contrary, their habits, whenever they come to light, turn out to be strictly arboreal. Now, in proportion as we recede from a type, its distinctions become less marked; and hence it is that in the black-capped tody the feet are less syndactyle, and the claws more like those of a raptorial type. The preceding observations on the natural history, properly so called, of the todies, chiefly relate to the typical examples; for as to the manners of Platyrynchus, and of the aberrant sub-genera, we know absolutely nothing. Let us now, therefore, consider the group more in detail ; for which purpose we shall designate the sub-genera as follows :1. Conopophaya, or short-tailed todies; 2. Platy* Vieillot, Ois. d'Amerique. 
rynchus, or flat-billed todies; 3. Todus; or the typical todies ; 4. Lepturus, or tyrant todies; and, 5. Platystera, or African todies. The first, fourth, and fifth of these sub-genera form the aberrant group; the second we regard as the sub-typical; and the third as strictly typical of the whole circle.

We commence with the sub-genus

\section{CONOPOPHAGA,}

because it evidently connects Todus with Megalophus; while a glance at its broad, although gradually narrowing bill, shows it to be of an intermediate. structure between Platyrhynchus and Megalophus. The birds belonging to this group, although the largest in size of all the todies, are not bigger than a robin, yet, from the excessive shortness of their tails, they seem to be much smaller; the tail, in fact, on a superficial glance, would seem as if it had been cut off, for it scarcely projects more than half an inch beyond the long and lax feathers which cover the back and rump. The wings, however, although much rounded, are by no means proportionably short; while the legs and toes are remarkably large, but somewhat slender. We might, from this structure, infer, that these were purely terrestrial birds; but we are not inclined implicitly to adopt this belief. The claws are very broad and fully curved, the lateral toes unequal, and the outer connected to 
the middle toe as far as the first joint; the same reasons, therefore, which have been urged against Todus viridis being a terrestrial bird, are equally applicable in the present case. Whatever may be the real economy of these birds, certain it is that they are of a thicker and stronger structure than any other of the todies. The head is particularly large, the body plump, and the feet comparatively strong; there is a strength, also, in the bill, which is not found in any of the other sub-genera: when viewed in profile only, it precisely resembles that of an antthrush (Myothera), occasioned by the thickness of the under mandible, the gonyx or ridge of which curves upward, while the tip is distinctly notched: this is an important and peculiar character. The Conopophago, in all probability, feed upon soft apterous insects; for they have no bristles, properly so called, on the sides of their bill, where there are merely a few straggling setaceous feathers; the front of the head is protected in the same way, as well as the nostrils; these latter being very large, beset with only a small oval aperture at the end, and which is placed nearly in the middle of the bill. The rough and bristly appearance of the front of these birds reminds us of Dasycephala, to which, both in this and in their brown plumage, they are analogous. Of their manners we are totally unacquainted, further than that our hunters reported they were only to be met with in thick woods; and they are at all times scarce. We possess two species from Brazil. 


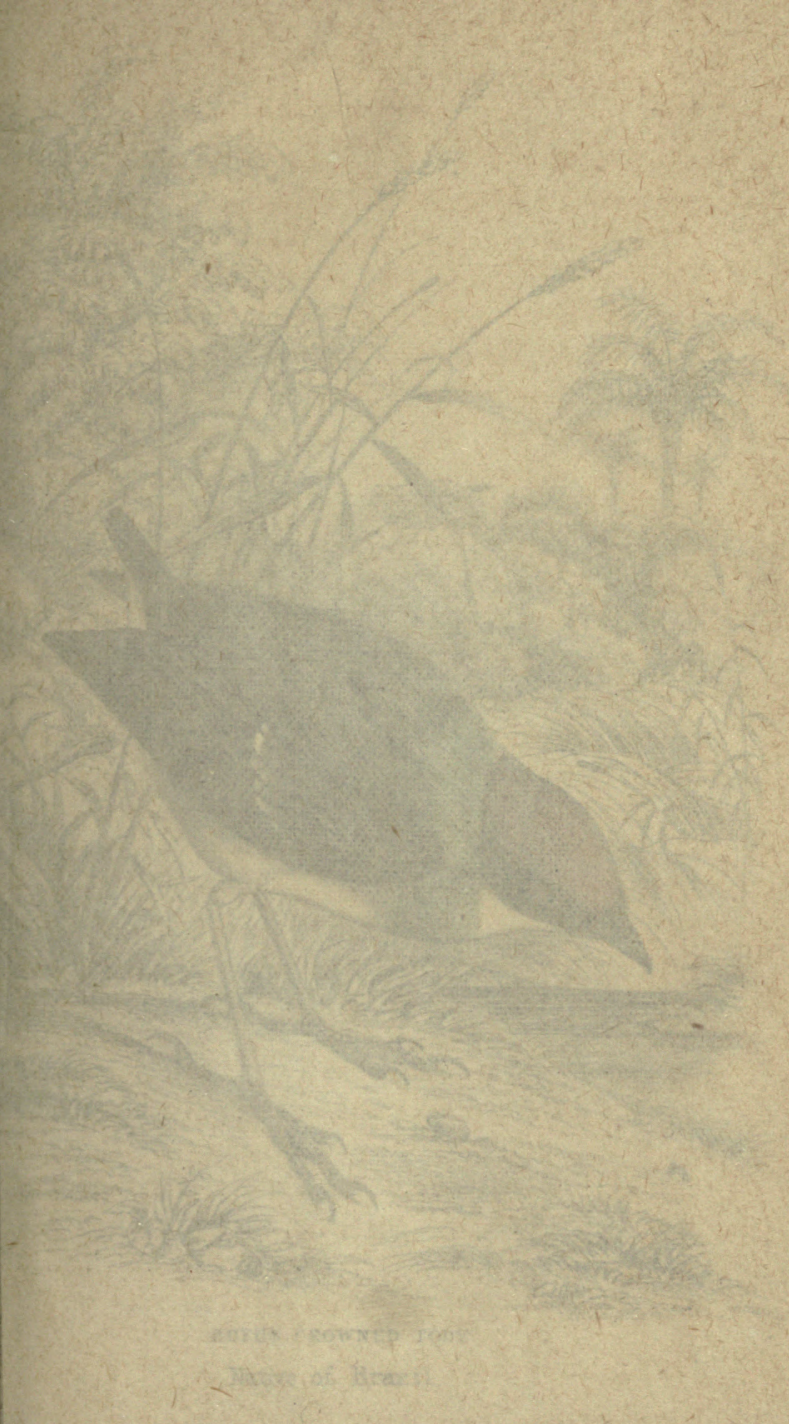




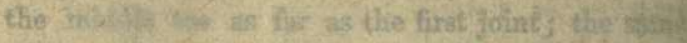

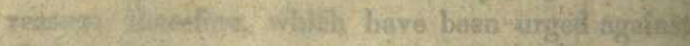

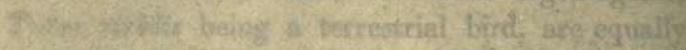

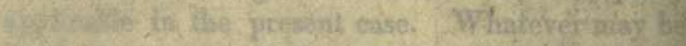

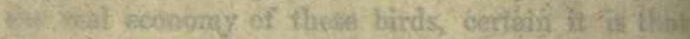

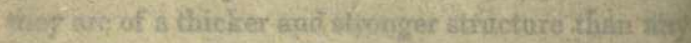

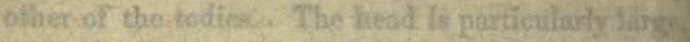
the body plimen, and the feet comparstirely strots? there is a strength, also, in the bill, which is kit found in any of this other sub-genera: when yieved It profile only, it precisely resembles that of ans salt

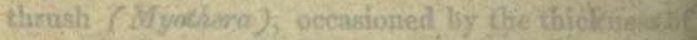

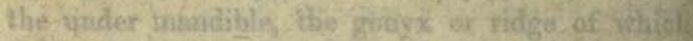

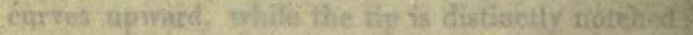

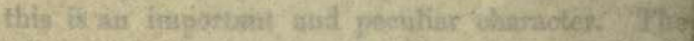

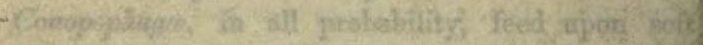

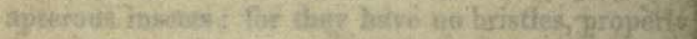

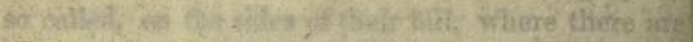

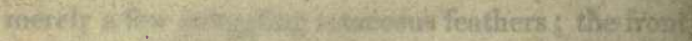

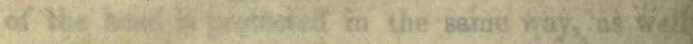

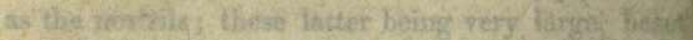

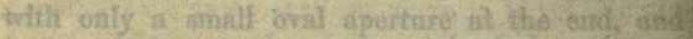
Which is placed mestity int the miacdle of ghe. Thill The rotgls and bnstly uppearance of thes froni ce

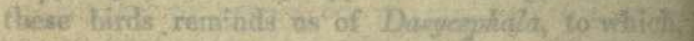

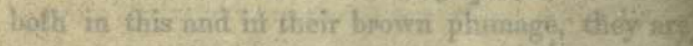

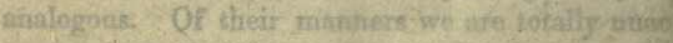

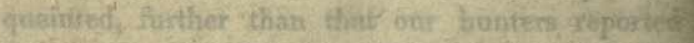

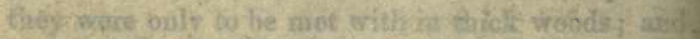

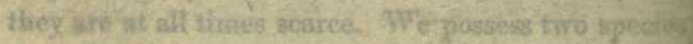
trom Dlomit. 


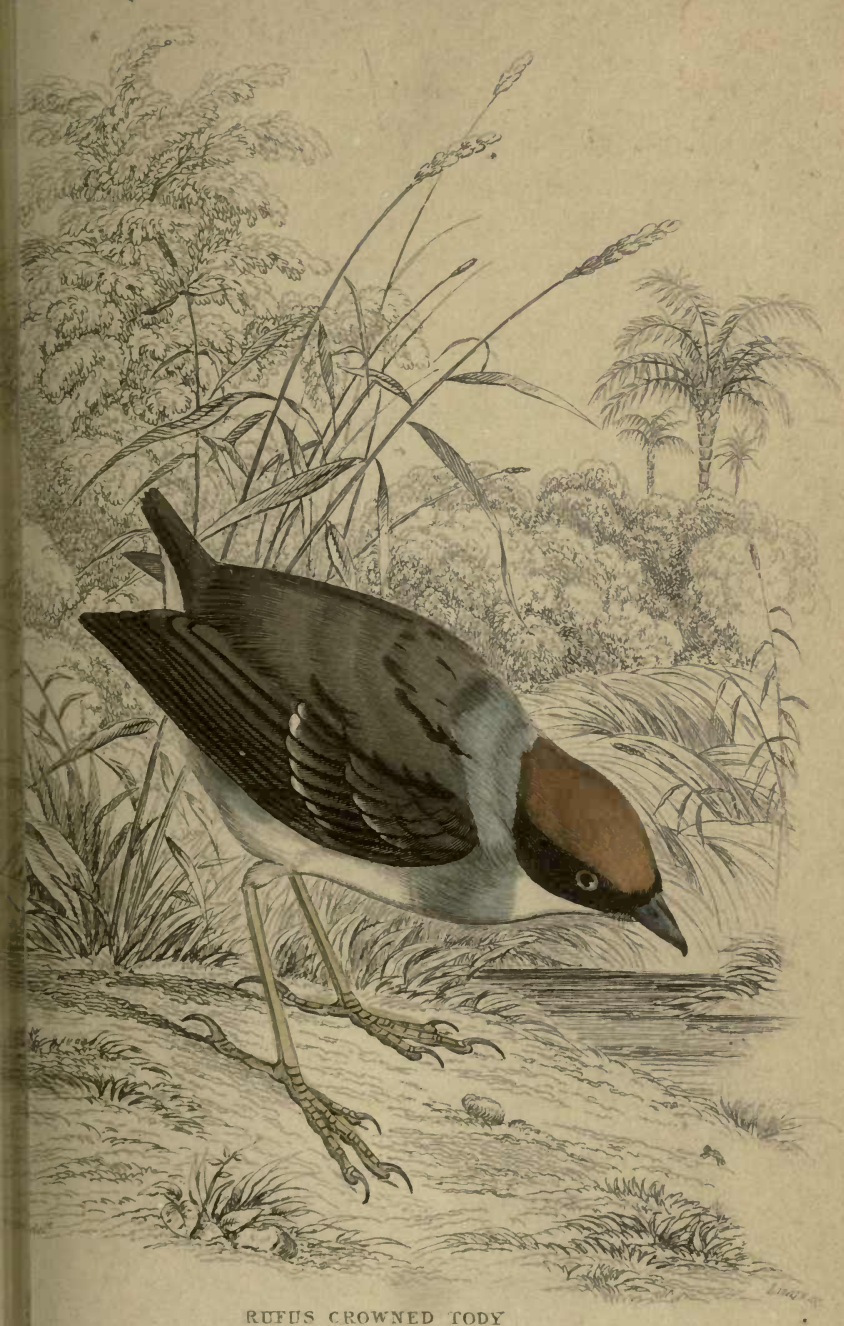

REFIS CROWNED TODY

Native of Brazil 


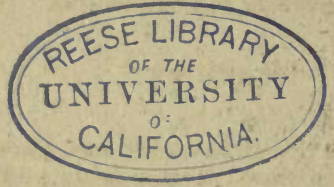




\section{5}

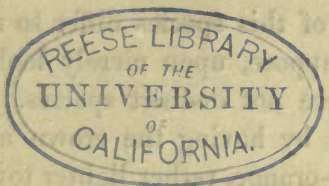

ROFOUS-CROWNED TODY.

Conopophaga ruficeps, SWATN8.

\section{PLATE XVI.}

Crown orange-rufous ; front, lores, and ears, black; chin andmiddle of the body white ; interscapulars with dark external edges.-Male.

Above brown ; beneath ferrugineous-orange; chin and middle of the body whitish; front and band over the eye and ear white.-Fenale.

Myothera perspicillata, Lich. Berlin cat? the male.-Conopophaga ruficeps, Birds of Brazil, ii. P1. 72, 73.

Althodgh one species of this singular genus was known to Buffon, who figured it at No. 822 of the Pl. Enl.,* nothing worth recording is mentioned of its habits, nor were we more successful in regard to this and another species, procured during our travels in Brazil. Its long legs, however, leads to the conjecture that it occasionally frequents the bround, although the inequality of its toes, and the :omplete union of the first joint of the middle one o the outer, show that its natural habits are more wborial than terrestrial.

* The Conopophagus leucatis of Vieill. Gall. PI. 127. 
The sexes of this species differ so much, that no one would suppose, upon merely looking at them, that they were not distinct species. The male is distinguished by having the crown and nape of a bright rufous-orange, rather lighter towards the bill, and darkest behind : the front of the head is crossed by a band of deep black, which widens on the sides of the head, and includes the lores, eyes, maxillary region, and the ears ; the rest of the upper plumage is light brown, tinged with rufous on the scapulars; the feathers of the back are bordered externally by a well-defined blackish line, or by a roundish spot; the lesser wing-covers are cinereous, and the greater have each a pale terminal spot; the external parts of the quills, and also the tail, are like the back, but the spurious wings are blackish-brown. The under plumage is cinereous, but the throat and middle of the body are pure white; the legs are pale, and the bill deep black. The female differs in the following particulars:-The crown, ears, and sides of the head, are of the same colour as the back; except a long white line which begins on the front and extends over the eye and ear; the lesser and greater wing-covers are both brown, tipt with pale fulvous; and all the under parts are bright ferrugineous where they are cinereous in the male.

Total length, $4 \frac{1}{2}$ inches; the tail not exceeding beyond the wings; bill, gape, $\frac{3}{4}$; front, $\frac{1}{2}$; wings, $2 \frac{1}{2}$; tarsus, 1 ; middle toe and claw, $\frac{8}{10}$.

The sub-genus 


\section{PLATYRHYNCHUS}

obviously follows the last sub-genus; for although we are unacquainted with those aberrant species which would have made the transition still more gradual, the approximation of the two is quite sufficient to render the series perfect. Platyrhynchus cancromus, in short, might at first be mistaken for a small Conopophaga, so exactly do the two forms agree in their general aspect. We enter not here into the technical distinctions; but Platyrhynchus is immediately known by its short and widely dilated bill, the under mandible of which is very thin, and the base of both defended by strong thickset bristles, pointing obliquely forwards; the feet are those of Conopophaga in miniature, the proportions being the same, but very greatly diminished; the claws, moreover, are slender, sharp, and but slightly curved, so that if either of these two groups might be supposed to frequent the ground, the probability would lie with Platyrlynchus. But here, again, we have not the slightest authenticated fact whereupon to ground a conjecture. The two species already known, we believe, are confined to Tropical America, where they are very scarce. It is probablo 
that the males, like that of $P$. cancromus, are distinguished by a concealed crest, an ornament so common among the fly-catching groups of America; but of which we do not know of more than one example in the flycatchers of the Old World.

\section{YELLOW-CRESTED FLAT-BILL.}

Platyrhynehus cancromus, TEMaINCK.

\section{PLATE XVII.}

Above light brown; beneath fulvous-yellow; throat white; crown with a conçealed crest of pure yellow.

Todus platyrhynchus, Auct.-Platyrhynchus cancromus, Temm., Pl. Col. 12, fig. 1.

Hitherto we have only seen one bird out of all those broad-billed flycatchers which have been called Platyrhynchi, which really belongs to this subgenus, as at present defined. There is, nevertheless, what appears to be a second, having a white crest, figured by Desmarest and Vieillot, and by the latter stated as a native of Senegal, a locality which we feel assured must be erroneous, since there has not been one land bird yet discovered which is a native both of tropical Africa and tropical America. In the 



\title{
158
}

\section{Tramporincams}

that the sales like that of $D$. eanctomue, ere dis-

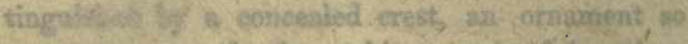

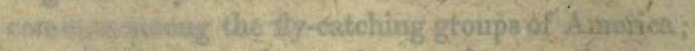

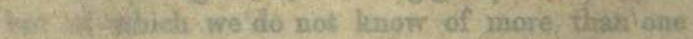

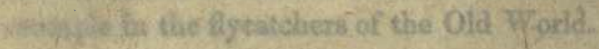

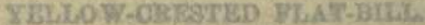

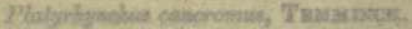

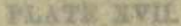

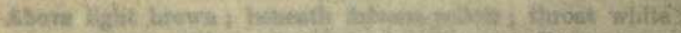

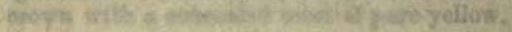

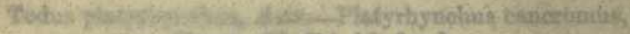

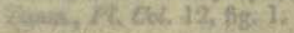

Karsagrto we have only seen one bixd out of all those twoad-billed fycatchers vihich have been galler. Pfurynguch which really belongs to this subgenu: us st present deftnod. There is, neverthelese what Appunirz to be a second, harivg, a whíte crist, figure

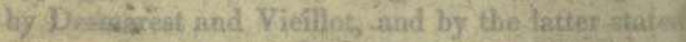

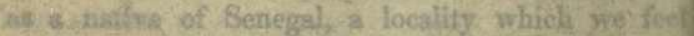
sustersd mast be erroneous, ainee thute has not bes. one buid bind yot, discoreted which is a native botyly of aropied Africs atd tropieal America. In the 


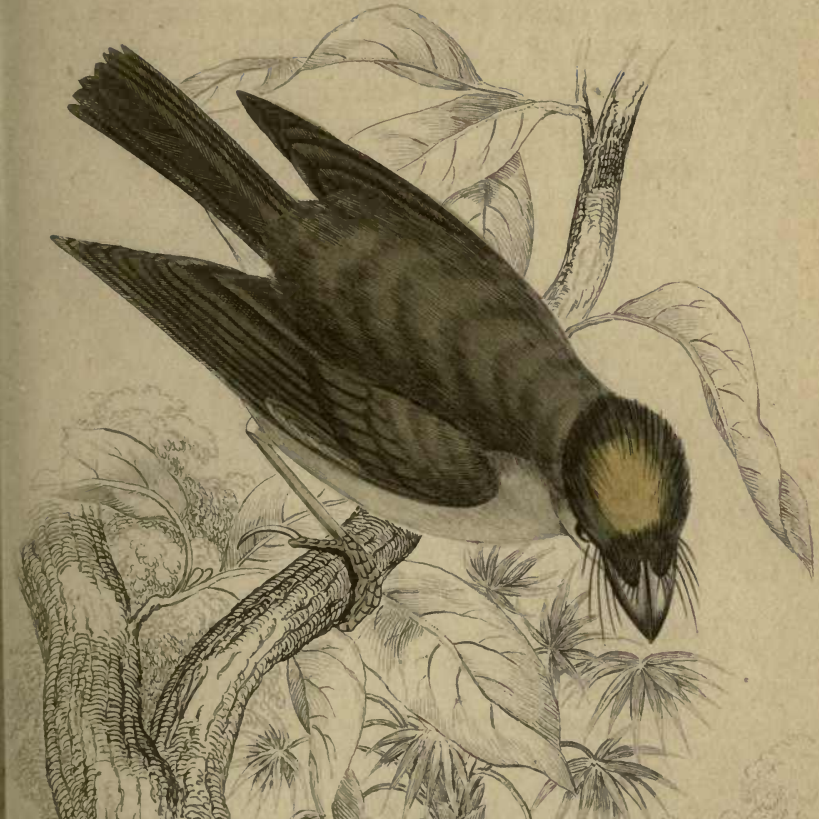

160 का

14. Wi

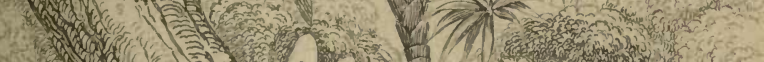
310. W. M. Q4)

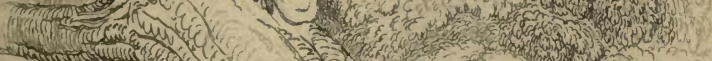

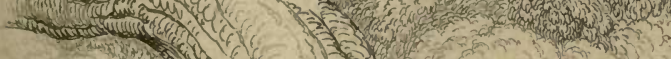
2. Eve 


\section{CALIFORNIA.}


young and female of the present species the yellow crest is not developed.

The upper plumage, when the crest is concealed, is entirely of a rich and full drab-brown, having a strong fulvous tinge on the back, which becomes almost ferrugineous on the margins of the wingcovers and the quills, both which, with the tail, are light brownish-black. The sides of the head are singularly varied; the lores have a fulvous-white line, but the lower half of the eyelids are black: another similar line begins behind the eye and passes over the ears, which are black; the ear is bordered below by another pale line, beneath which is another of black, which commences at the base of the lores, passes immediately under the eye, and is separated from the black of the ears by the pale line already noticed. The under plumage is of a fulvous-yellow, except the chin and throat, which are white; but the sides are tinged with yellow; the inner wing-covers are like the breast, but the thigh-feathers, except those close to the joint, are almost black. The yellow spot on the crown is very pure, but the tips of the feathers are of the same brown as the rest of the plumage, so that, unless they are raised, the crest would not be discovered; the under mandible of the bill and the legs are so very pale as to be almost white.

Total length, $3 \frac{1}{2}$ inches; bill, gape, $\frac{6}{10}$; front, ${ }_{10}^{3}$; wings, $1_{\frac{1}{1} \sigma}$; tail, base, $1_{\frac{1}{1} 0}$; tarsus $\frac{6}{10}$.

The last little group brings us at once to the sulgenus 


\section{TODUS,}

the pre-eminent type of the whole group, and which, although but a portion, retains, par excellence, the patronymic name. We have frequently called the attention of ornithologists to that peculiar property possessed by groups pre-eminently typical,whether those groups be large or small, - of exhibiting a greater number of modifications, in the subordinate forms, than are to be found in the other divisions of their own circle. Lawrance, our eminent physiologist, long ago announced this fact in reference to the Caucasian race of MAN, the most favoured and highly endowed of all that have ever lived. And it might be established beyond doubt, that this fact, first stated as an isolated and disconnected remark, might be traced throughout the class of animals now before us ; sufficient, at least, to establish it as one of the laws of nature. There are more genera and sub-genera,-in other words, mere variations of form,-among the order Insessores, or perchers, than in all the other orders put together, and more in the genus Corvus, the type of all birds, than in any other yet ascertained. The sub-genus before us, like the groups just 
named, is pre-eminently typical ; and we shall find, upon close analysis, that the variation of its species, as in the sub-genus Bos*, turns out to be regulated by the very same law; they actually become types of form. And we shall find these types almost as distinctly marked as if they belonged to a family, instead of merely representing the succession of species in a sub-genus.

The most universal character of the typical todies is their flat elongated bill, in opposition to that of Platyrhynchus, which, although equally flattened, is remarkably short; the sides are bristled, but these bristles are short and weak, and in some species are almost obsolete. The wings and tail are short, but the latter is much more conspicuous than in Platy.hyuchus, while the form of its termination indicates the variation of the species and the position they occupy in the series. Thus, in the Todus viridis the tail is even, in melanocephalus + it is gritduated, in megacephalus $\ddagger$ it is shortest, and the el: $d$ is rounded; while in platycircus it is longest, with the feathers broad, but terminating in points. The other species yet discovered fill up the intervals, and arrange themselves close to one or other of those just named. The variation in the length and structure of the feet is no less remarkable. These members are always sufficiently long to point out the sub-genus; their variation is consequently corn-

* Classif. of Quadrupeds, p. 281.

+ Spix Av. Nov. ii. pl. 9, f. 2.

‡ Ornitl. Drawings, pl. 
parative. In Todus platycircus their iength is the greatest; while in viridis and megaceplialus they are shorter than in melanocephalus. These variations are accompanied by differences in the formation of the claws and toes; so that without a competent knowledge of the group as a whole, "good genera," as such artificial divisions are sometimes called, might actually be made out of several of the species, to the no small confusion of all that is true in nature or useful in science. It has entirely originated, in fact, from such limited views, that the Todus viridis has been pronounced "the unique example of its genus ;" and all the other species detached from it, and thrown into the common receptacle of flat-bellied birds, - "the great genus" Muscicapa. It is needless, however, to criticise artificial systems; and therefore let us now see what results will be obtained ly arrangirg the species above named, and comparing them with the types they represent. 
Spacies of Todus.
Specific Distinctions of Structure.
Primary

Typee.

zodus viridis................ $\left\{\begin{array}{c}\text { Toes very syndactyle } \\ \text { or. prehensile; bill } \\ \text { long, notchnearly ob- } \\ \text { solete; claws broad, } \\ \text { obtuse....................... }\end{array}\right\}$ Insessonzs.

- melanocephalus.. $\left\{\begin{array}{c}\text { Bill shorter, the tip } \\ \text { more hooked; claws } \\ \text { slender, acute........... }\end{array}\right\}$ RAPTOREs.

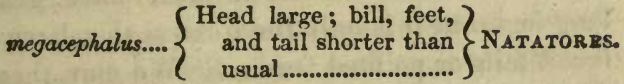
usual ...........................

[Legs very long; tail

platycircus........ $\{$ fully developed, the RAsones.

feathers rather broad,

the tips pointed........

'I hus. if we discriminated these birds as species, not bv their colour, but by the different shades or modincations of their structure, we might almost use the very words which would at the same time concisely express the leading distinctions of tne primary types of birds. The Todus viridis has the most perfect shaped foot, merely for grasping, in this little group ; and the prehensile power of these members constitutes the chief distinction of the order Insessores among birds, and Quadrumana among quadrupeds. The acute claws, and the more sudden deflection of the tip of the bill in Melanocephalus, and two or three others, are also characteristic of the falcons and the shrikes, the Raptores and the Dentirostres. The great size of the head, coupled with unusual brevity in the tail 
and the tarsi, are three of the primary distinctions of the Fissirostres and the Natatores. While the remarkably long legs of $T$. Platycircus* might lead us to believe it was the representation of the grallatorial birds, but for its tail. which is twice the ordinary length, and although unusually broad, yet the ends are pointed. The formation, therefore, of this member, stamps the bird at once as a rasorial type; both these orders, in fact, have generally long legs, but it is only the Rasores that have either 7rcad tails or pointed feathers. We may, therefore, fairly conclude, that the species of Todus which represents the Grallatores has not yet been discovered, or rather that it has not yet fallen under our observation.

The law of representation, although universal, is yet so simple, that if it is successfully demonstrated in any one group, it becomes equally established in all; because all must be referred to one general test, that is,-to the primary types of nature. This has been so frequently exemplified in our treatise upon birds, and in that upon quadrupeds, that it hecomes unnecessary to compare our present group with all others of the class or order to which it belongs; unless, indeed, there are some points of structure to be elicited which cannot be explained hy a single analogical comparison. Nevertheless, the views here taken of the particular group before

- The only specimen of this species I have yet seen is in the Paris Museum. 
us are so completely at variance with those of our best ornithologists, that it is due to them, no less than to ourselves, to strengthen our position as much as possible, that it may be seen we have given the subject that attention it deserved before we ventured to promulgate a theory so much at variance with all that has hitherto been received. It is with this intention that we shall now lay before the ornithologist two other tables in further illustration of the series of the typical species of Todus; the first of these will make good their analogy, in the following manner, with the sub-divisions of the genus.

Specific types of Todus.

ANALOGICAL CHARACTERS.

Sub-genera of Todus.

Tmlus viridis............. $\left\{\begin{array}{l}\text { Bill very long, } \\ \text { the tip scarce- } \\ \text { ly bent, and } \\ \text { nearly entire.. }\end{array}\right\}$ PLATYRHynchus.

melanoceplualus. $\left\{\begin{array}{c}\text { Bill shorter, the } \\ \text { tip abruptly } \\ \text { bent; tail short }\end{array}\right\}$ Todus.

- megacephalus.... $\left\{\begin{array}{ll}\text { Bill more trian- } \\ \text { gular; } & \text { head } \\ \text { large, front } & \text { bristly; tail } \\ \text { very short....... }\end{array}\right\}$ ConopopHAG..

- Flatysteria.

_ platycircus........ $\left\{\begin{array}{r}\text { Tail lengthened, } \\ \text { graduated, the } \\ \text { ends pointed... }\end{array}\right\}$ Lepturus.

The species here named Megacephalus, and which will be subsequently described and figured, is very 
diminutive, not more than three inches and a quarter long, of which the head and bill actually occupies one inch and a tenth, or nearly one-third the length of the entire bird. It differs also from all the other species in having the bill more gradually attenuated in its breadth as it approaches the end ; just, in short, as that of Conopophaga, of which it becomes, by its very short tail, large head, and bristled front, the complete prototype. Nevertheless, the sides of the mouth are strongly bristled, and the tarsi are considerably shorter than those of its congeners. Now, all these variations from the typical species are absolutely necessary to the harmony of nature. They indicate, as plainly as possible, that this bird is an aberrant species, and that it is of the fissirostral or aquatic type. Nor can it possibly be removed from this position among the todies, since there are now before me three other species which establishes the gradation between melanocephalus and megacephalus in the most decisire manner. And yet, if the bills of these two kindred species are viewed separately, one might be tempted to place them in different genera. The situation, also, of Todus megacephalus in the series of species, is further confirmed by the structure of $\boldsymbol{T}$. platycircus, which, from being clearly a representation of the Rasores, will stand at the opposite side of the circle to that of Megacephalus; the grallatorial, or intervening type, as before observed, being wanting. We thus find, that even in a subgenus the variations are sufficiently marked to give 
us the indications of a circular group; in which. although there is an apparent hiatus*, the remainder of the series is so perfect that no reasonable doubt can be entertained of its being natural. The species which will represent the grallatorial form may probably be found also in Brazil; but as the most aberrant types of this family, namely, Monacha and Platystera, are of the Old World, we should feel no surprise if this also turned out to be an inhabitant of the same region.

Considering the great variation of structure in so small a group as this, and which we merely term a sub-genus, it may be fairly asked,-even by those who take it for granted, or who cannot controvert the affinities here stated,-whether this group does not in reality hold a higher rank than what we have assigned to it? or, in other words, is it not a genus rather than a sub-genus? This question we have more than once investigated; and the result has been what we have stated. A desire of solving it as far as possible, led us, in fact, to undertake the analysis of the whole family. So far as we have yet laid the result of this labour before the reader,

* Since writing the above, we have procured a species of Todus very much resembling the $T$. plumbeus of Cayenne, but with the throat and breast marked with short black stripes like those on the larks, which family represents the Grallatores. But its chief peculiarity, and in which it differs from all other species, is in having the outer and inner toes almost free, and of nearly equal length. It is more than probable, therefore, that this bird may really be the type we are now reeking. 
he will perceive that the entire genus Todus is too distinct and peculiar to be incorporated with either Rhipirlura, Monacha, or Megalophus; while its relation to this latter, and to the genus Muscicapa, is so very nearly equal, that we can only conclude its station to be intermediate. This point being settled, we are next to ascertain whether Todus, -as a whole,-constitutes a natural group; or, in other words, whether this group is circular and representative. This question, as will presently appear, can also be answered in the affirmative. Hence it follows, that if its sub-genera differ more among themselves than do the species which we have been illustrating, our inevitable conclusion is, that these latter are variations of the sub-genus, and not of the genus, - that they are specific modifications, and not, like Conopophaga, \&c., types of sub-genera. We shall arrive at a similar conclusion if we argue the question in another way. We have stated, in another place, as one of the primary laws of natural classification, that the number of circular groups, in point of rank, are NINE; and that those which form the ninth are sub-genera. Let us then take one of the examples that have been quoted in support of this theory, and see how far the group, which we here term a sub-genus, will agree therewith. We have stated that Parus biarmicus holds precisely the same rank in the typical division, or sub-genus of Parus, as does Todus platycircus in our sub-genus Todus; the two birds, in fact, representing each other. We will therefore now see how 
many circles are to he traversed before we arrive at the two which contains the birds.

\author{
Rank of the \\ Parus Biarmices, $L$.
}

1. Kin!rdom, Animalia.

2. Sul-kingdom, Vertebrata.

3. Cluss, Avis.

4. Oider, Insessores.

5. Trille. Dentirnstres.

6. Fumily, Sylviadæ.

7. Sub-funtily, Parianæ.

8. Genus, Parus.

9. Sub-genus, Parus proper.

Type of form, Parns biarmicus. Type of form, Todus platycircus.

We thus perceive that the genus Todus is precisely of the same rank as that of Parus, and that the pre-eminent typical division, or sub-genus, of each, contains suhordinate types of variation or of form, as well marked as those of all the higher divisions; so that a sub-genus, when perfect, becomes just as much a circular group as any of the eight which precedes it in the list. There is not a whit greater difference between Todus viridis and Todus platycircus, than there is between Parus biarmicus and Parus corruleus. And if Todus megacephalus deserves to be ranked as a sub-genes, so must its representative Parus caudatus; far the cre is a prototype of the other-both being at cace distinguished by their great disproportionate heads. All these arguments, indeed, may be admitted; and 
yet it may be urged that this determinate number of nine, in the different ranks of circular groups, is a theory too important to be taken on the testimony of one naturalist only, interested in strengthening a theory of his own, and, therefore, with every wish to be accurate, still peculiarly liable to error. Now we shall at once annul this objection, although it rests on no demonstrative evidence, by producing the unpremeditated evidence of one who had no idea of the law in question, but merely drew up his ohservations to illustrate a particular group of animals in a totally different class. Mr. Macleay's views on the number of circular groups which exist, before he arrived at that of the genus Scaraboeus, has thus been stated by himself; and we shall now compare them with those of the genus Todus.

Rank of the

SCarabeus SACER, according to Mr. Macleay.
Rank of the

Todus Megacrphalus, Swains.

1. Kingdom, Animalia.

1. Kingdom, Animalia.

2. Sub-kingdom, Annulosa.

2. Sub-kingdom, Vertebrata.

3. Class, Ptilata, Arist. (Man- 3. Class, Aves. dibulata, Macl.)

4. Order, Coleoptera, Lin.Macl. 4. Order, Insessores.

5. Tribe, Chilognathiform, Macl. 5. Tribe, Dentirostres.

6. Family,Petalocera Sapropha- 6. Fumily, Muscicapidæ. ga, Macl.

7. Sub-fumily,Scarabæidæ,Macl. 7. Sub-family, Muscicapinæ.

8. Genus, Scarabæus, Mucl.

8. Genus, Todus.

9. Sub-genus, Scarabæus proper, 9. Sul-genus, Todus proper. Macl.

Type of form, Scarabæus Sacer. Type of form, Todus Megaco. phalus. 
To these nine circular groups, one within the other, indicated in the Hor. Ent., we have only given those names indicatory of their relative ranks, which have already been elsewhere explained*, and uniformly employed in our former works. The groups themselves are Mr. Macleay's, not ours; and we are assured they are the result of close analysis. So likewise are those in the opposite series, the result of an analysis undertaken to ascertain the rank of one animal in the scale of nature; and as the results of both inquiries perfectly accord, we know not how the question regarding the fank of Todus viridis, megacephalus, or of ąny other of the species here mentioned, can be further prosecuted. Far from thinking it necessary to apologise for these details, we consider it fortunate to be possessed of those materials necessary for the investigation. Ornithologists need not be told how highly important it has become to have some definite notions on the affinities of the Todus viridis. One of our best systematists places it between the Australian manakins (Pardalotus) and the flycatchers. Another, between the kingfishers (Halcyonidoe) and the motmots (Prionites). A third (M. Cuvier), between the kingfishers and the hornbills! While a fourth makes it the point of connexion between the wide-mouthed rollers (Eurystomus) and $A l$ cedo. In respect to the latter arrangenuent, which professes to be quinary and circular, we may renture to observe, that there is an evident relation

- Geography and Classitication of Anim p. 268. 
between Eurystomus, Todus, and one of the types of Alcedo, as well as with Eurylaimus and Muscicapa, all flat-billed groups. But there is as much difference, in other respects, between Eurystomus and Todus, as there is between Platyrlynchus cancromus and Eurylaimus. They are all, in fact, either directly or indirectly, fissirostral types, whatever may be their local rank in relation to other groups : and if the form of the bill was to decide the location of a bird, all these, nay, the whole of the fissirostral types throughout ornithology, might, on such a principle, be placed by themselves in a distinct division. But before proceeding further. we shall annex the figures and descriptions of three of the most remarkable birds just mentioned. 


\section{GREEN TOOY.}

Todus viridis, LINNAUS.

VIGNETTE.

Above parrot-green; beneath yellowish-white; under taitcovers yellow; chin and throat with a lengthened $I$ utch of bright scarlet; sides of the breast rusy.

Todus viridis, Linn., Auct.; Edwards, Pl. 121 ; Pl. Enl. 58.5 (fig. pess.); Desmarest, N. H. Tunag. et Tod. Pl. of (tig. op.); Zool. 1ll. ii. Pl. 66.

Turs is the most beautiful of all the Todies, and, among the whole of this family, only yields in richness of colouring to the Monacha chrysomela. The natural history of this bird, differing so remarkably in colour from all its congeners, must possess great peculiarities; but, unfortunately, the meagre notices that we yet possess on its habits and economy are very slight, and in some respects contradictory. It is said to build its nest on the ground, either on a tuft of grass or in the open fissures; a statement we do not credit, seeing that such situations are never chosen by birds which have not their feet constructed for walking. The remark, that, when at rest, it always sits with the head and bill pointing 
upwards, is in exact accordance with what, from theory, we should suppose; for we believe that the bright red spot on its throat, in such situations, acts as a snare to attract insects (just as a candle attracts moths), that they only discover their danger when too late to escape tne sudden dart of the bird. This species, as yet, has never been found on the continent of South Ámerica, although it appears common in several of the West India islands. We have long been expecting an account of the habits of this bird from Mr. M'Leay, but, although announced, it has never yet been published*.

The predominant colour of the upper parts is a rich parrot-green, the wings above being blackish in such parts as are concealed when they are folded; the tail is the same, the external edges being alone green. The under plumage is more varied: the whole extent of the chin is occupied by a patch of the richest scarlet, bordered on each side by a maxillary stripe of white; while the side-feathers of the breast are of a delicate rose colour. The remainder of the throat is whitish, which gradually becomes of a full yellow on the vent and under tail-covers; under mandible nearly white; feet pale brown.

Total length about $3 \frac{3}{4}$ inches; bill, $x^{2}$; wings, $1 \frac{8}{10}$; tail, base, $1 \frac{1}{2}$; tarsus, $\frac{1}{2}$.

* See Zool. Ill, ol. 66. 



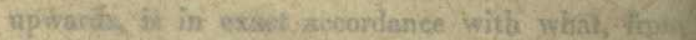

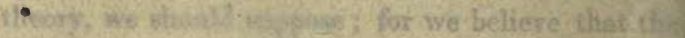

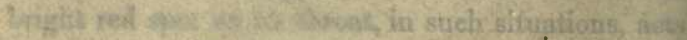

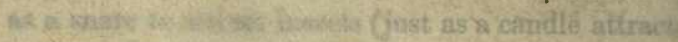

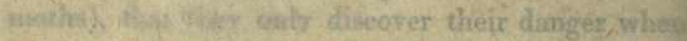

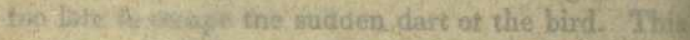
spocios, we givh has never been found on the conti nent if souch America, although it appears comaing in severat of the Weat India islandis, We have long been expecting en account of the habits of this bird from Nfr. MYLeay, but, although ammonced, bas never yet been priblished".

The predominant solour of the upper parts is $x$

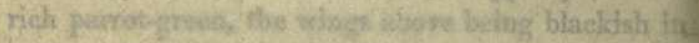

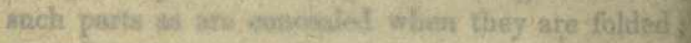
the val in the samey, the externat edges being alond

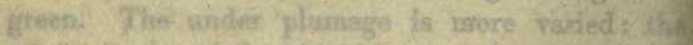

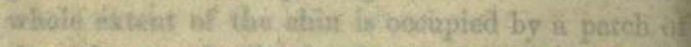

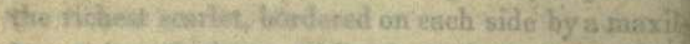

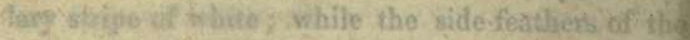

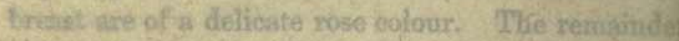
Whe the throat fs whitikh, wioh gradually becones of is full yellow on the vent nd under taill-covare uader mandible nearly white; feet pate brown.

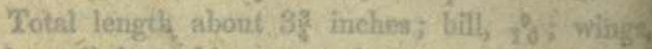
It 2 i tai, base 1 ; ; tarrus, $\frac{1}{2}$.

4 Sor Zool. 31. n2. 66, 


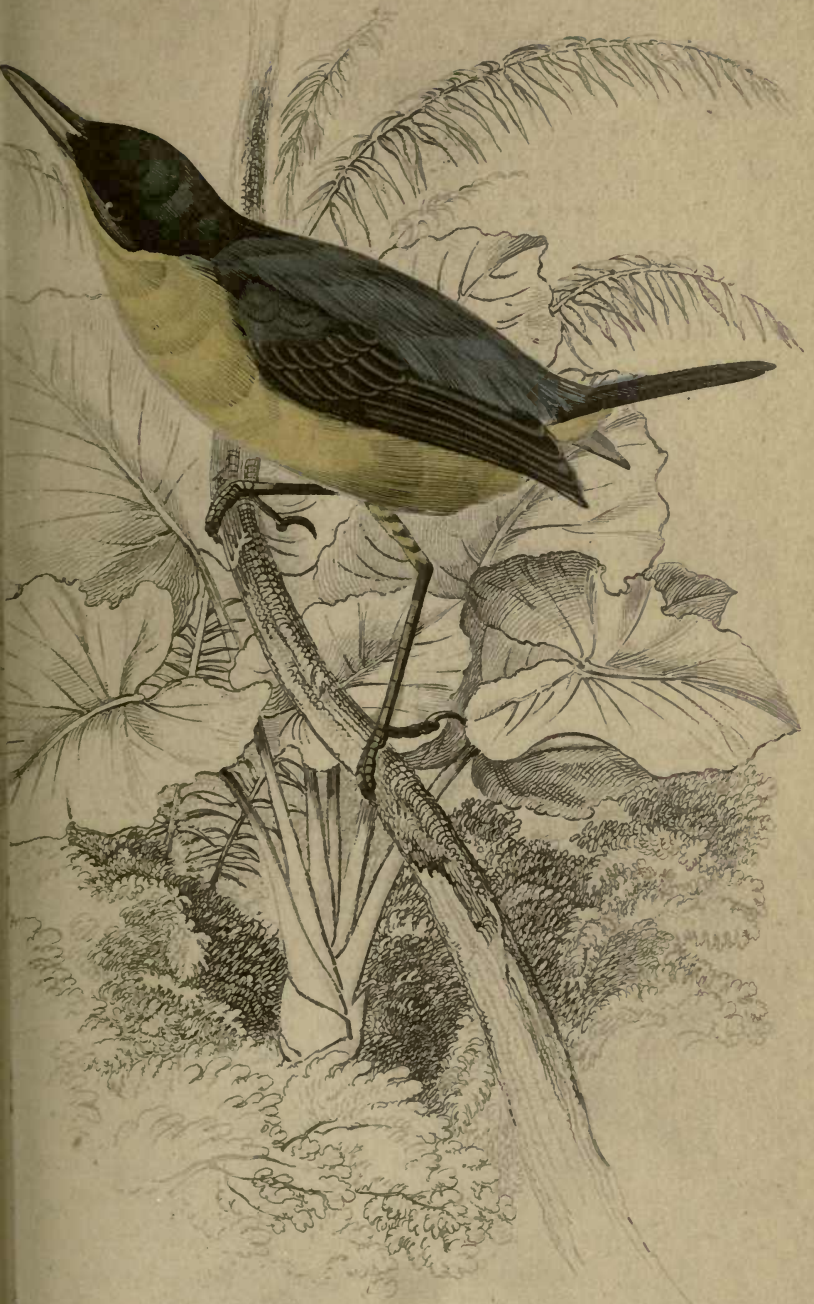


REESE LIBRAN UNIVERSITY CALIFORNIA. 


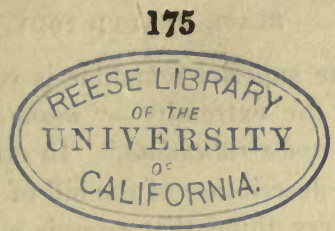

BLACK·HELDED TUDY.

Todus melanosephalus, SpIx.

PLATE XVIII.

A :ure cinereous, tinged with olive; fore part of the head black ; under plumage yellow; wings black; the feathers with yellowish margins; bill distinctly notched; the tip abruptly hooked.

Todus melanocephalus, Spix, ii. Pl. 9, fig. 2.

THE admirable precision with which the celebrated M. Desmarest (the best ornithologist that France has produced since the days of Brisson) has characterized his Todus cinereus, enables us not only to determine this as a different species, but, what is of still more importance, to point to that bird as supplying an indisputable and a very beautiful link between this and Todus viridis, thus placing, beyond all doubt, this latter bird in the same series of species which includes the notched-bill todies: those, in fact, which Temminck and others would remove to a totally different part of the system. M. Desmarest expressly states as a specific character of his Todier Tic-Tic, figured on the sixty-eighth plate of his beautiful volume on the Tanagers, Todies, 
\&c., that the superior mandible is very entire, and rounded at the extremity- " mandibula superiore integerrima apice rotundata." In other words, this is the exact description of the bill of Todus viridis; while, in every thing that regards size and colour, M. Desmarest's description is perfectly applicable to the bird now before us. Thus we have, in his Todus cinereus, a species with the colours of melinocephalus and the bill of viridis. Our present species carries us one remove farther from the type, and exhibits a bird with the plumage of cinereus, but with a bill very strongly notched, and suddenly bent down at the tip, after the manner of all dentirostral types. What the Todus cinereus of the old authors really is, can now hardly be ascertained, it having since been discovered that their description is applicable to four or five species now known.

Little further requires to be added to the specific character above given. The size is rather smaller than that of the green tody, especially in the head. The upper plumage is rery dark cinereous, with a few shades of olive on the back; the front of the head and lores are deep black, which blends on the crown and ears with the cinereous of the upper parts; the greater and lesser covers, and all the quills, are deep black, edged externally with yellow or yellowish-white; the tail is graduated and deep black, the lateral feathers being tipt with white : all the under parts are yellow. The toes differ from those of viridis ; the outer and middle are only connected as far as the first joint, and the inner has the 



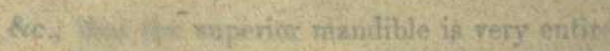

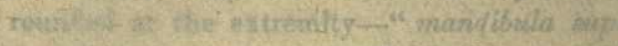

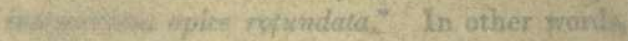

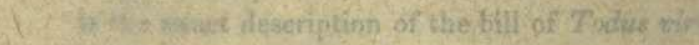
Whas lit exeny thives that regards asze and - cith

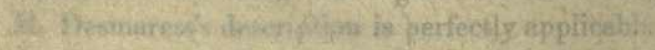

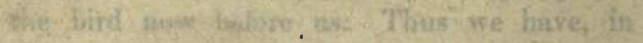

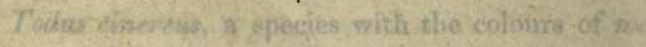
rocepuatue and the bill of viridis. Oite pre species carries ys one remarve fariher from the ty and exbibits a bird with the plumage of fiver bot with a bitt very strongly netched, and sudiges bont dowzl at the fip, after the mamen of at den

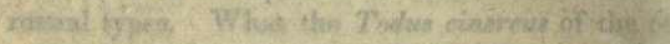

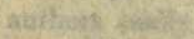

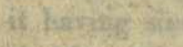

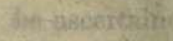
Thets despr:

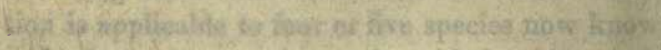

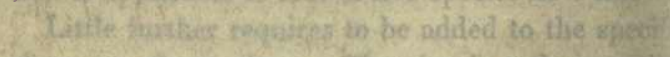

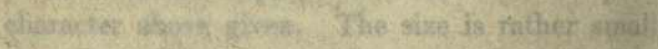

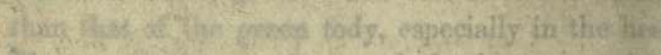

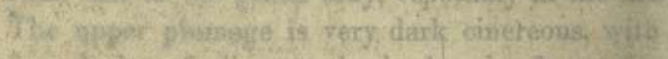

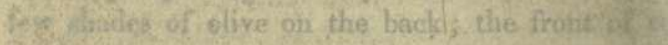
Thead anil lorus are deep black, which blencis ob crowh and ears with the cinereous of the ure yorth the Exenter and lessef coxers; and all caills, are cleeb black, odged externally with yoh or gellowish whites the tait is yroduated minde bhock, the lateral feachers boing wits with witste the iniler zorks are yellow. The wes diffur.

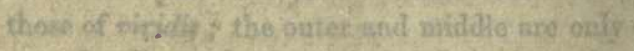

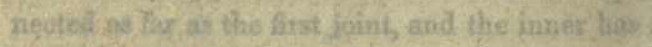




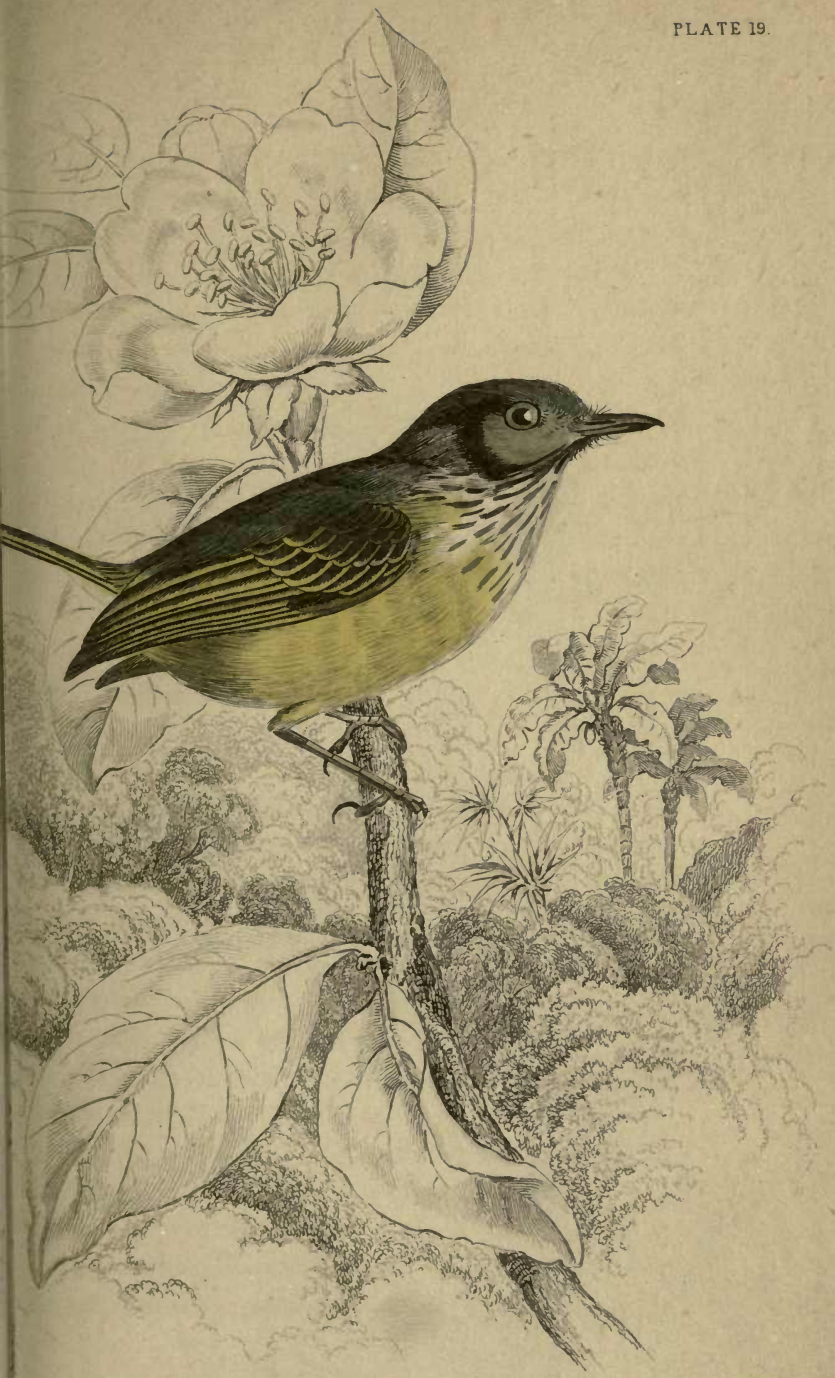


REESE LIBRAAY
OK THE
UNIVITRSITY
CALIFORNIA. 
first joint free; bill black, the base beneath being pale. Inhabits Brazil and Cayenne.

Total length, $3 \frac{3}{4}$ inches; bill, front, $1^{8} 0$; wings, $I^{7} ;$; tail, base, $1 \frac{1}{4}$, tarsus, $\mathrm{I}^{7}$.

GREAT-HEADED TODY.

Tudus Megacephalus, SWaINs.

PLATE XIX.

Alove olive-green; beneath yellow; neck above, and stripes un the throat, cinereous; sides of the head pale, with black crescent on the ears; bill short, triangular.

WE have here a genuine, although an aberrant Tody, disguised with the bill of a Lepturus, or that sub-genus which next succeeds in the chain of nature. Except in this particular organ, it has the general structure of the Todies. The feet, indeed, are particularly weak, and both the lateral toes are united to the middle one as far as the first joint ; the head, as the specific name expresses, is particularly large.

The natural size is represented in the figure; the general plumage above is olive-green, with a strong fulvous tinge in front of the head and on the crown. 
This colour is separated from the back by the uppe neck being entirely of the same cinereous as the sides, chin, and throat; but these two latter parts are striped with white: the rest of the under plumage is yellow, tinged with olive, and obsoletely striped with cinereous on the breast and flanks. Sides of the head and base of the ear-feathers whitish; the latter with a broad transverse black band on their terminal half; wings and tail brown; the feathers margined with yellowish ; tail-feathers even, but remarkably narrow, with their tips more pointed than in any of the Todies, but assimilating in this respect to Lepturus.

Total length, $3 \frac{1}{10}$ inches ; bill, front, 1 $^{\frac{4}{0}}$; wings, 1) ; tail, base, 1 ; tarsus hardly $\frac{6}{10}$.

Let us now proceed to the sub-genus 


\section{LEPTURUS,}

the rasorial type of the todies, and to which we are conducted by Todus megacephalus. So close indeed is this approximation, that the profile of the bills of the two are almost precisely the same; with this difference only, that in Lepturus the sides are more compressed, so that the outer half of the bill is as high as it is broad. This is a nice, but a very important distinction; because it shows that in Todus megacephalus we had the last remnant of the boatshaped bill of that sub-genus. At present we know but of one example of this type, which, as its name implies, has rather a long, but very slender tail. It resembles, in fact, a little Malurus, or Orthotomus, with the bill of a flycatcher. Its wings are even still shorter, for the size of the bird, than those of $T$. megacephalus, but here the similarity ceases: instead of possessing the short weak feet and small toes so characteristic of all the species of Todus we have just dwelt upon, those of the bird before us are long, and, for its size, even robust. The toes are all cleft to their base; the lateral ones are of equal length, and the middle one is much developed. This structure, added to its remarkably short wings and lengthened tail, points out this singular bird to be the rasorial sub-genus of 
Todus, having for its prototypes a host of representations in nearly all the families and genera of the perching birds, of which it is only necessary to mention Troglodytes, Orthotomus, Crateropus, Fluvicola, Synallaxis, \&c. to gire an accurate idea of the structure of the bird before us. We have no doubt that other species of Lepturus, and probably its types of form, will be detected, when the immense number of South American flycatchers, which we already know of from books and museum specimens, are properly examined, setting aside those which still remain undiscovered in that productive region, the central metropolis, as it were, of flycatching birds. The structure of the toes and claws in Lepturus ruficeps will detach it from the typical todies, while the length of the tarsi and the compression of the bill, removes it far away from the little tyrants (Tyrannula). 


\section{ron \\ 3.}
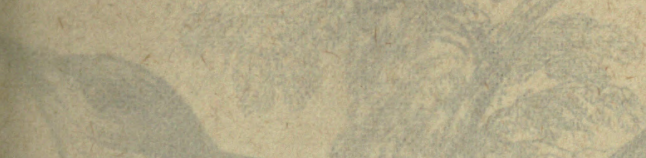

$$
44^{2}+2 x+2
$$
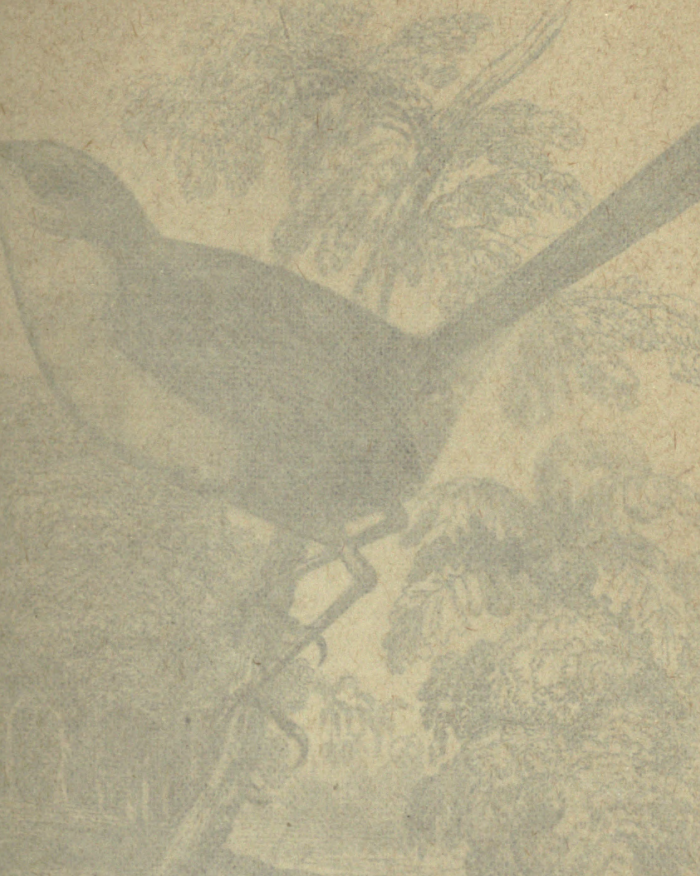

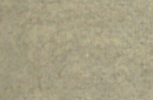

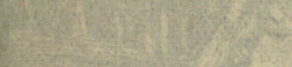

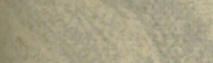

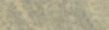

$\sqrt{203}$

a

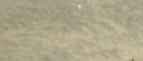

$x=$

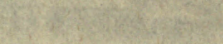
20.

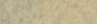




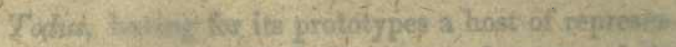

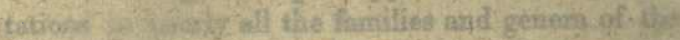

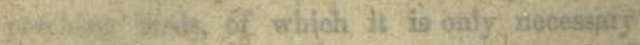

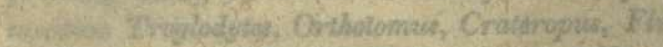

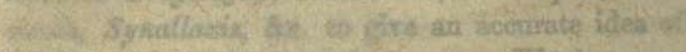

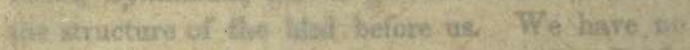

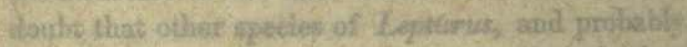
fics types of form, will be defected, whea the im meros number of Sonth A merican flycatchers, whing. we slroedy. know of finom boolcs and trusem oper Aneris, expe propoxiy examined, serting avide thror

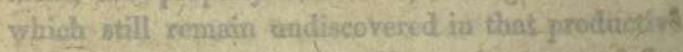

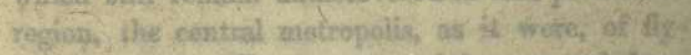

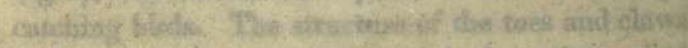

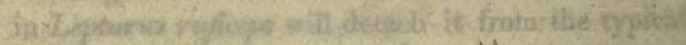

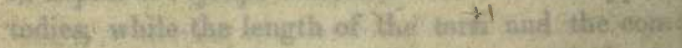

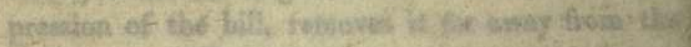

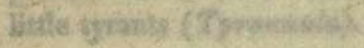

is 


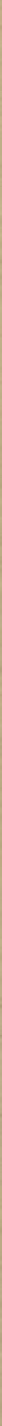




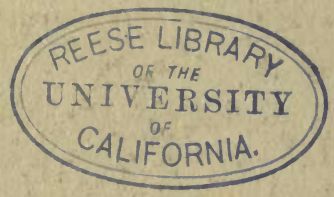




\section{1}

\section{RUFOUS-CROWNED TODY.}

Lepturus ruficeps, SWAINB.

\section{PLATE XX.}

Above brown; middle of the crown with a rufous stripe; chin and throat white; breast and body pale yellow; the sides ferruginous; lores whitish.

Is artificial systems this little bird would be placed in the genus Malurus, which has been made a common receptacle for all insessorial birds which have lengthened slender tails, short wings, and large feet, no matter what their other characters and affinities may be.

The upper plumage is of a light drab-drown, inclining to fulrous on the rump; the tail and wings are rather darker, with the edges of the wing-covers and quills dirty white. Over the eye, and on the lores, is a dirty white stripe; the middle of the crown is pale rufous, or ferrugineous; the under plumage is white, but straw-coloured from the breast, having the sides ferrugineous; the under mandible and the feet are pale; the upper dark horn colour. The figure is of the size of life.

Total length, $4 \frac{2}{10}$ inches; bill, gape, $\frac{6}{10}$; front, - $\frac{4}{\delta}$; wings, $1 \frac{1}{2}$; tail, beyond, $1 \frac{4}{10}$; base, 2 ; tarsus, $\frac{3}{3}$; middle toe and claw, $\frac{1}{2}$.

The next sub-genus is 


\section{PLATYSTERA (JARD. \& Selb.),}

composed alone of the African todies. Perfect as is the union of the two last divisions, that between Lepturus and the one we have now come to, if possible, is still more so. The first species of Platystera, in short, which meets us in our progress, has such a close resemblance to Lepturus, that had we not ascertained it to be an aberrant example, we should, without hesitation, have placed them together as species only. To the bird in question, we venture to impose the name of Platystera longipes, and it has been described and figured by Le Vaillant under the name of Lo Mignard*. He specially remarks, that this is the smallest flycatching bird that has been discovered in Africa, -and the very same may be said of the Lepturus ruficeps, with regard to those of America; both, in fact, have short feeble wings, small triangular bills, and long slender tails and feet. How then, it may be asked, can they be generically separated? The answer is not difficult. In the first place, the bill of the Platystera longipes

* Ois. d'Afrique, iv. pl. 154. The colouring of these figures, no less than that of many others in this otherwise valuable work, is very unnatural. Instead of the ground colour being light blue, it is of the darkest grey above, and cinereous beneath, the chin and middle of the breast being tinged with rove colour, as seen in our figure. 
is but slightly compressed towards the tip, and the under mandible, instead of being stout, is flat and thin; the wings are longer, which gives them a more pointed appearance; their structure is also different, the first quill being only half as long as the third; the toes are considerably smaller than those of the Lepturus, and the claws, instead of being slender and pointed, are broad, and much curved. Now, as theso peculiarities of the wings and feet are typical of Platystera, we can have no hesitation in placing Platystera longipes in this, rather than in the last sub-genus. Nevertheless, it is an aberrant species, just as is Todus megacephalus in the subgenus Todus; for independant of all other considerations, it has one distinguishing character,-the lateral toes are perfectly equal, whereas in all the other species of Platystera we yet know of, they are unequal. This latter structure, in fact, we see in the next modification of form, instanced by the Prit-prit of Le Vaillant, figured in the same work: here the bill is considerably broader, yet still gradually narrowed towards the end; the wings are longer, the tail shorter and even, and the feet differently formed; the inner toe is the shortest, and the outer connected to the base of the middle toe, as far as the first joint. This second modification brings us at once to the typical species of the group represented by the Platystera lobata, Sw. The bill now puts on the aspect of that of a genuine Tody; it is broad along its whole length, but with a sharp culmen; the rictus, or gape, is strongly 
bristled, the wings lengthened, and the tail-feathers broad and obtuse; but its two most remarkable characters are as follows: on the upper part of each eyelid is a semicircular, naked, and detached skin; completely analogous to what we see in Perspicilla, its corresponding type in the circle of the water-chats, (Fluricolinos): while, as if Nature determined that this peculiarity should not disturb the analogy of this group to the typical todies, she has given to this bird the feet of Todus viridis; the inner toe is connected to the middle as far as the first joint, while the connexion of the outer extends as far as the second joint. The syndactyle structure in both birds is the same, not only in sort, but in degree; and yet this is accompanied by so many differences in other respects, that no one would ever think of taking this relation for one of absolute affinity; that is of placing the two birds next to each other. 



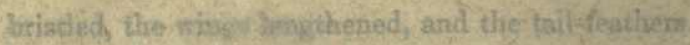
brosd tand olvartis thin ith two most rennarkabie

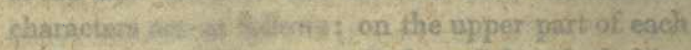

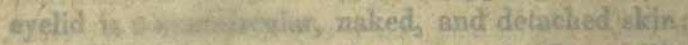

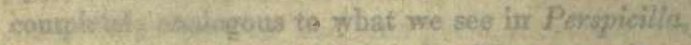
its costmosteding type in the eircle of the water-chals (X) undeotiva) s while, as if Nature dotermined that Ins e f culiarity shoula not disturb the anaiogy of this group to the typical todies, she has given to this bird the feet of Todus viridis; the inmer toe is connected to the middle as far as the first joing while the connexsion of the outer extends as far as the second joint. The sjudactyle structuxe in botb Binds is she numas not orit latwoth bat in degree,

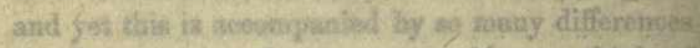

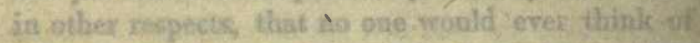
taking this xelation for one of alusolute affinity; thut

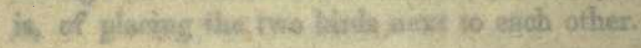





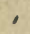

REESE LIBRARY UNIVERSITY

CALIFORNIA. 


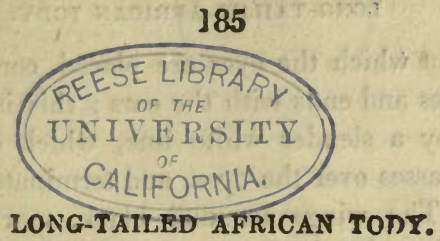

Platystera longipis, SWaINs.

PLATE XXI.

Cinereous above and beneath; chin and middle of the body beneath rose-colour; wings, tail, and sides of the head, black, varied with white; legs long; bill slender, triangular.

Le mignard, Le Vaill. Ois. d'Af. iv. Pl. 154.

TuIs pretty species has been very, well described by Le Vaillant, although the figures accompanying his account are too inaccurate to deserve the same commendation. He states it to have the manners of the true flycatchers, that is, of sitting in ambuscade, and darting upon passing insects, as well as searching for larva and apterous insects among foliage. This latter habit at once accounts for the superior size and strength of its legs over all its congeners; so true it is, that structure and economy go hand in hand.

Le Vaillant observes that this is the smallest flycatcher he had met with in Africa, and our figure represents it of the natural size: the upper plumage is dark cinereous, verging to grey, which becomes duil black on the wings. A broad and deep black 
stripe, in which the eyes are placed, commences at the lores and ends with the ears; this is margined above by a slender white line, which crosses the front, passes over the eyes, and terminates with the ears. The wings are dull black, marked in the middle by a longitudinal stripe of white, which tips in its course some of all the different ranges of feathers. The tail is deep black; the three outside lateral feathers are more or less white at the ends, the outermost being entirely so; while the rest, towards the middle, are entirely black, and nearly even : the under plumage is cinereous, but the chin and middle of the body are rose colour, and the belly and vent are white. Bill and legs black; the outer toe is slightly connected to the middle; the inner one nearly free.

Total length, $4 \frac{1}{2}$ inches; bill, gape, $\frac{1}{2}$; front, $\frac{7}{7}$; wings, 1s; tail, base, 2 ; tarsus, Ifo $^{2}$. 

186

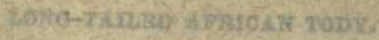

atripe, th which the egen are placed, cominienced at

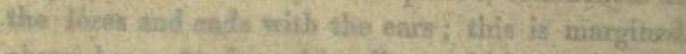

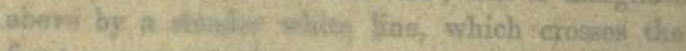

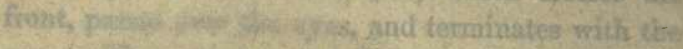

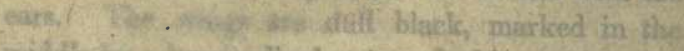

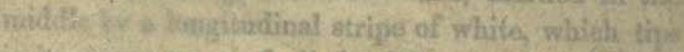
in ite thros some of all the different ranges of feat 16erin The tail is deep black; the thinee oveside fatemil feathers are more or less white at the endics. the pritermost being entirely oos while the rest, to. terads the toiddle, are extirely black, and vienith

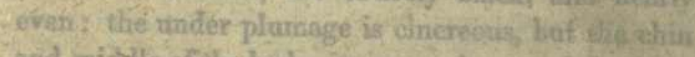

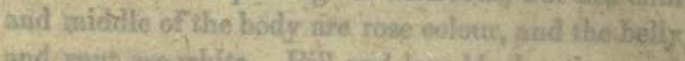

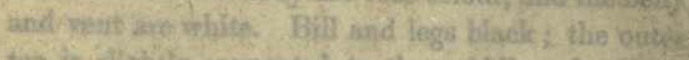
toe in sulightily cownoofed to the rividdle; the fonca ane mently tiee.

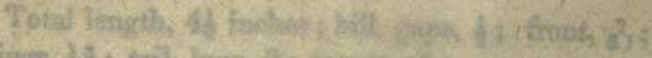

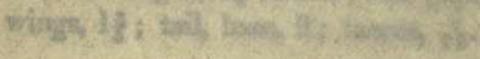




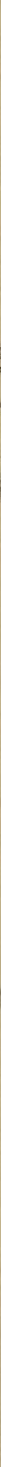




\section{CALIFORNIA.}




\section{SPECT ACLE TODY.}

Platystera lobata, Swains.

PLATE XXII.

Male.-Above glossy blue-black, with an angulated stripe of white on the wings; beneath white, with a black bar upon the breast; lobe of the eye red.

Female.-Above cinereous; chin white; throat chestnut.

Mus. melanoptera, Gmelin.-Platystera collaris et Desmaresti, Jardine and Selby, Ill. of Orn. i. Pl. 9.-Platys. lobata, Sw. West. Afr. ii. p. 49.

HAviNg already, in a former volume of this work, fully described those two birds, which we consiảer are the sexes of our $P$. lobata, it is scarcely necessary to repeat the same in this. It seems to be by no means uncommon in Western Africa, but does not extend to the southern part of that continent, at -east it is not among the other species of this genus figured by Le Vaillant. The feet are syndactyle.

The annexed figure represents what we consider as the female, a red or rufous breast being the distinguishing mark of this sex in the two species figured by Le Vaillant. See his Ois. $d^{\prime} A f r$. vol. iv. pl. $160,161$.

Total length about $4 \frac{1}{2}$ inches; bill from the gape, $\frac{13}{8}$; from the front, $x^{7}$; wings, $2 \frac{1}{2}$; tail from the base, 2.

We shall now offer some additional remarks upon 


\section{PLATYSTERA.}

Is proportion to the number of species which enter into a group, so do we invariably find a proportionate degree of variation. Applying this universal law to the assemblage of birds forming the genus Todus, we observe that as the typical subgenus contains the most in number, so does it exhibit the greatest variation of structure. Platystera, in like manner, ranks the next in extent, and we have thus been able to detect three distinct modifications of its typical characters. We have no doubt that several other species exist of this group; one is obviously the Môlenar of Le Vaillant, and we suspect the Capuchon blanc (Pl. 159.) may be arother, although the presence of a crest is much against the supposition. All these we have described from the birds before us, but no public or private collection, however large, can be supposed to contain every thing. We must, therefore, now have recourse to our notes, among which we find the following, made some years ago, in the early stages of this analysis. "Platystera is united either to Conopophaga or to Platyrhynchus by a bird in the British Museum which belongs to Platystera, but which has a very short tail; short, unequal, and syndactyle toe, formed for perching, and quite as much united as those of $T$. viridis." Here, then, is the fissirostral type of Platystera, approximating 
much closer than either of the three already pointed out to Conopophaga, and yet preserving the general characters of its own group. The importance of such a form is very great, for it not only gives us a repetition, even in a sub-genus, of the fissirostral type ; but it brings Platystera in immediate conjunction with Conopophaga, the first group in the circle we have been so long in tracing, and the last to which we again return. Whether this Platystera, which we had named provisionally breoicau$d a$, still exists in the National Museum, we know not; but at the time the above note was made upon it, that law of variation which renders Platyrhynchus the raptorial type of the genus Todus, had not been discovered; and this explains a part of the foregoing memorandum.

We will now compare the species representing the types of form in the sub-genera of Todus and Ilatystera, and ascertain in what way they resemble each other.

Species of Platystera reprementing types of form.

Species of Toder

ANALOGICAL CHARACTRRS. Tepresenting types of form.

$P$. longipes...........Legs and tail very long..........T. platycircus.

$P$. pectoralis.... $\left\{\begin{array}{c}\text { Bill much depressed, the } \\ \text { tip abruptly and strongly } \\ \text { hooked. }\end{array}\right\} T$. melanocepho$P$. perspicillata....All the toes syndactyle..........T. viridis.

$P$. brevicauda.......Tail remarkably short.............T. megacephalus.

We were perplexed, for many years, in endearouring to make out why it so frequently happened that in very small groups, like sub-genera, there aro 
species agreeing most perfectly in their structure, except in a single point, $i$. e. the tail of one being very long, and of the other very short. In a family, or a sub-family, such a variation may be expected, because every ornithologist knows that these two forms of tail are always to be seen in good sized groups; the flycatchers, for instance, and in the thrushes and warblers: but such a decided difference has always been considered sufficient to constitute a generic character, and in former years, we, no less than the generality of modern systematists, carried this belief so far as to make it often the only character of a new genus. In this we have all much erred, not, indeed, in making the distinctions, but in giving them a higher value than they really possess, - a value, in short, which analysis would have shewn they were not entitled to. Greater experience, however, has solved this difficulty. In the first place, the long-tailed or rasorial form, very generally passes into the short-tailed or natatorial; and this, not by graduating steps, but as it were abruptly; that is to say, the difference of the tail alone marks the passage. The crow and the magpie, the blue and the long-tailed tit, are among the most familiar instances of this sudden change; not more striking, indeed, than those we have here exhibited in the sub-genera Todus and Platystera. Now, there are two modes of accounting for this; the first is, that Nature preserves her distinction of types even in the series of the species comprising a sub-genus, when that sub-genus is full and circular; 
and secondly, the two extreme aberrant types, which are the rasorial and the natatorial, always shew such a strong tendency to unite, that in such small groups they reciprocally impart to each other some of their characters. We see this in the genera Rhipidura and Megalophus, in the Fluvicolince and the Saxicolino, and in Conopophaga and Lepturus. In these two latter, the legs of both are remarkably long, but in Conopophaga, as in natatorial types, they are syndactyle, while in Lepturus, as in the Rasores, they are free, and the lateral toes equal. In maintaining, therefore, the correctness of the foregoing table, wherein long and short tailed birds are placed together as mere species, we only follow that law which Nature has manifested in so many other instances.

No test can more fully substantiate the fact, that the species of todies described at pages 173-178 really follow each other in the order we have placed them, than a comparative table, wherein their analogy to the sub-genera of Todus are shewn. This we now subjoin.

Species representing types of form in the sub-genus

ANALOGICAL CHARACTERs. Sub-genera of Todus.

Todus.

Todus viridis.... $\left\{\begin{array}{c}\text { Typical representing the } \\ \text { sub-genus. }\end{array}\right\}$ Todus.

Melanocephalus $\left\{\begin{array}{c}\text { Sub-typical tip of the bill } \\ \text { distinctly bent. }\end{array}\right.$

Megacephalus.. $\left\{\begin{array}{l}\text { Head large, tail short, feet } \\ \text { syndactyle. }\end{array}\right\} \begin{gathered}\text { CHUS. } \\ \text { CoNOPOPHAQ1. }\end{gathered}$ Unknown Platystera. Platycircus....... $\left\{\begin{array}{c}\text { Tail long, graduated feet, } \\ \text { greatly lengthened. }\end{array}\right\}$ LEPTURua 
This comparison must speak for itself. Having already shewn that the sub-genera in the last column represent the genera of the sub-family Muscicapinoe, and that there, again, are representations of the primary divisions of all birds, we know not how demonstration can be carried further. We think the complaint, in this instance at least, formerly brought against us, of making assertions instead of demonstrations, will be thought somewhat premature: seeing that a proposition must be first made, before the drift of the evidence to be adduced in its support can be well understood. We shall, therefore, now close this analysis of the genus Todus, and com. mence a survey of the last and most typical grouv of these insectivorous birds.

The genus 


\section{3}

\section{MUSCICAPA}

is restricted, in this survey, to the genuine or typical flycatchers inhabiting the old world, and who never pursue their prey. From this habit we may term them the sedentary flycatchers, in contra-distinction to the hunting and the cursorial races, represented by the todies, the fantails, and the water-chats. Their distinguishing characters have already been intimated, but we shall now shortly recapitulate them : they are so few and simple, that if duly regarded, there will be no great danger of this genus being made, as it now stands in systems, a sort of general receptacle for all birds with flat bills, whose affinities cannot at the moment be made out. The sedentary flycatchers of the Uld World are to be known by the prominent and leading peculiarities derived from their wings, feet, and bill : and although there are a few instances of other types possessing one of these characters, and although one out of the three may be wanting in the aberrant divisions of this very group, yet the average of variation does not extend further*. When, there-

* Some species of Tyrannula have the syndactyle feet of Muscicapa, some the even tail, and others come very near is. their wings, but nothing more. Ptiliogonys and the Culicivoris wave the graduated wings, but none of the other characters. 
fore, we have a flycatcher possessing two out of the three characters here assigned to the genus Muscicapa, we may safely search for it in the aberrant genera; but if two out of the three are wanting, it may be concluded that the bird does not enter into this group. As to the wings, their formation has already been explained; the first quill-feather is invariably spurious, or very short, $-a$ character so absolute, that we know not a single exception : yet notwithstanding this diminution in the length of the primaries, the wings themselves are rather long than short, far exceeding those of Todus, and even the generality of the small Tyrannuloe, or tyrants of America. The feet are very peculiar, and are remarkable for their comparative shortness and feebleness of structure, when compared to the todies. Thus, although the toes are very small, and the hind one not unusually long; this latter is but little shorter than the tarsus, and this, again, is about equal with the length of the middle toe and claw*: the lateral toes are always unequal, and the outer, which is the longest, is attached to the middle as far as the first joint. This syndactyle structure of the toes, and the general shortness of the feet, is quite in unison with the sedentary nature of these birds, who scarcely use their feet for any other office than to support them on their perch. The scutalation, or form and disposition of the scales upon the tarsi, deserve attention ; because, although

- The exceptions occur in the two aberrant sub-genera Cryptolopha and Muscicapa. 
a minute character, it is a very constant one, and is quite different from that possessed by the tyrants. Among these birds the anterior scales only cover the front of the tarsus, and they are divided into four or five pieces, while the lateral scales, which protect the sides, are all of one piece : in Tyrannula, these side pieces, on the contrary, are entirely wanting; for the anterior scales completely envelope the tarsus, and the two edges meet behind. The bill of the present genus is here noticed the last, because it is the most variable of the characters here given, and cannot of itself be taken as an exclusive mark of distinction, unconnected with the wings and feet. Nevertheless the form of this member, in the present genus, has something so peculiar to the eye of the experienced ornithologist, that he will immediately detect, although he would find a difficulty in defining, its characters: It differs, of course, from that of the todies, in being much shorter and more triangular; that is, it begins to narrow towards the tip almost from its base; there is no danger, therefore, of a Muscicapa being mistaken for a Todus: the difficulty lies in distinguishing Muscicapa from $T y$ rannula, - the Old from the New World flycatchers. In the present genus, the bill, however, although equally broad, is more flattened on the sides, and the culmen or ridge is consequently more prominent, neither is the tip so much bent as in the tyrants. In its form, as just observed, there are considerable variations : in Muscipeta it is long, while in some of the Myiagra it is shorter and 
broader; but as these two divisions are the most typical, so have they the most depressed bills : in all the others, the sides towards the tips are compressed, and this is accompanied by a thickening of the under mandible, which is never seen in Muscipeta or Myïagra. The rictal bristles, or those at the base of the bill, vary in length, but they are always very stiff, and assume a decided character. Lastly, we may observe that the tail is never short or forked; its usual length is proportionate to the wings, but the termination is diversified, and is either even, rounded, or graduated. It deserves to be mentioned, that out of all the typical Muscipeto and Myïagrae not one has been discovered with a green or olive-coloured plumage; the general hue being different shades of rufous, brown, grey, blue, and sometimes black, the latter colours having always a steel-blue gloss: this is analogous to what we find among the swallows, the types of the Fissirostres, as these birds are the types of the fissirostral division of the Dentirostres. The geographic range of the flycatchers is very wide, but it extends more longitudinal than lateral. One of the abberrant forms extends to Europe, and the most northern species is probably our common Muscicapa grisola. As we approach the tropics of India and Africa the typical species abound, and they may be said to have their chief metropolis in those regions. The species with even or slightly rounded tails, placed in the sub-genus Myiagra, are chiefly from the large islands which constitute the Australian province, 
while those retained under the name of Muscipeta seem to be equally spread over Asia and Africa; although we have not yet seen any from New Holland. Having now prepared the reader to understand the general nature of the group before us, we shall at once proceed to its divisions or subgenera, distinguishing them by the following names : 1. Cryptolopha; 2. Muscipeta; 3. Myïagra; 4. Muscicapa; and, 5. Hyliota. The first, fourth, and fifth form the aberrant group, already distinguished from those two which are typical, by their more narrowed bill, by the superior length or strength of their feet, and by the terminal half of the bill being laterally compressed: a structure which carries with it a proportionate increase of strength and thickness in the under mandible, so that its ridge or gonyx is often curved upwards. In the typical sub-genera neither of these latter characters are seen; the whole of the bill is depressed, and the under mandible is very flat. 


\section{CRYPTOLOPHA}

is the rasorial sub-genus, and has hitherto remained undistinguished, the species having been counfounded with other groups. It seems to represent Rhipidura in the pointed ends of the tail-feathers, but it differs from its prototype in several particulars. The bill is larger and stronger; the anterior scales of the tarsi are entire, and not in four or five pieces; and the hind toe is so long as nearly to equal the middle toe. The two groups, however, differ so materially in their manners, that they cannot possibly be mistaken; for even their analogies are obscure. Cryptolopha, indeed, may be distinguished at first sight from all the Indian flycatchers we have yet seen; for this is the only group in which the plumage of all that we have yet seen is olive-green. This is the only exception to our former remarks upon the colouring of the Old World flycatchers, and was intended, as all such general descriptions usually are, to be applicable alone to the pre-eminent typical examples; that is, in the present instance, to the sub-genera Muscipeta and Myïagra. We have no doubt, indeed, that many of the green flycatchers of South America truly belong to the sub-genus Lepturus, 
the last of the divisions in Todus; and we may therefore naturally expect to find the same colour continued to the group which succeeds, although that group is in the next circle, namely, that of Muscicapa. We already possess three species of Cryptolopha, and are acquainted with two or three others. In all these the upper plumage is olivegreen, which, added to a prevalence of yellow on some part of their upper plumage, gives them all the appearance of being American Tyrannula. But this, in truth, is merely an analogous resemblance,-a disguise, as it were, in which nature has clothed them, while the structure of their wings and tarsi are in complete accordance with the rest of the Old World flycatchers. Such species as evince the nearest approximation to Lepturus have consequently the bill less broad, the tarsi longer, and the tail more narrowed and slender; while such, on the other hand, as advance towards the sub-genus Muscipeta, or rather, as we suspect, constitute the types of this sub-genus, have the bill broader, the rictal bristles long, thick set, and very stiff (as in Rhipidura), with the tarsi shorter, and the tail broader and even. There is nothing therefore to associate these oriental flycatchers with the little tyrants of America, beyond their olive plumage; for they may be immediately recognized by that primary character,-a short spurious quill-feather,which, without a single exception, distinguishes the Old World flycatchers from those of the New. There is a very interesting species of Cryptolopha 
in the Linn. Society's Museum, sent from India, having a similar concealed crest to our Lepturus ruficeps. And even in the Cryp. poiocephala, which we shall now describe, the crown, although of a uniform colour, nevertheless sanctions the name of Cryptslopha, which we now apply to this division.

\section{GREY-HEADED FLYCATCHER.}

Cryptolopha poicephala, SwaIss.

PLATE XXIII.

Olive-green; body beneath fine yellow; head, neck, throat, and breast, cinereous; eyelids white; head sub-crested striped with darker shades.

Platyrhynchus Ceylonensis, Zool, Ill. i. Pl. 13.

WE have no doubt that this is the bird imperfectly described by us nearly twenty years ago, under the name of Platyrhynchus Ceylonensis, at a time, indeed, when ornithology was but in its infancy, and when the geographic distribution of its groups had been totally neglected. It need hardly be said that the only reason of its being then placed in the genus Platyrhynchus was, that its bill is broader than those 




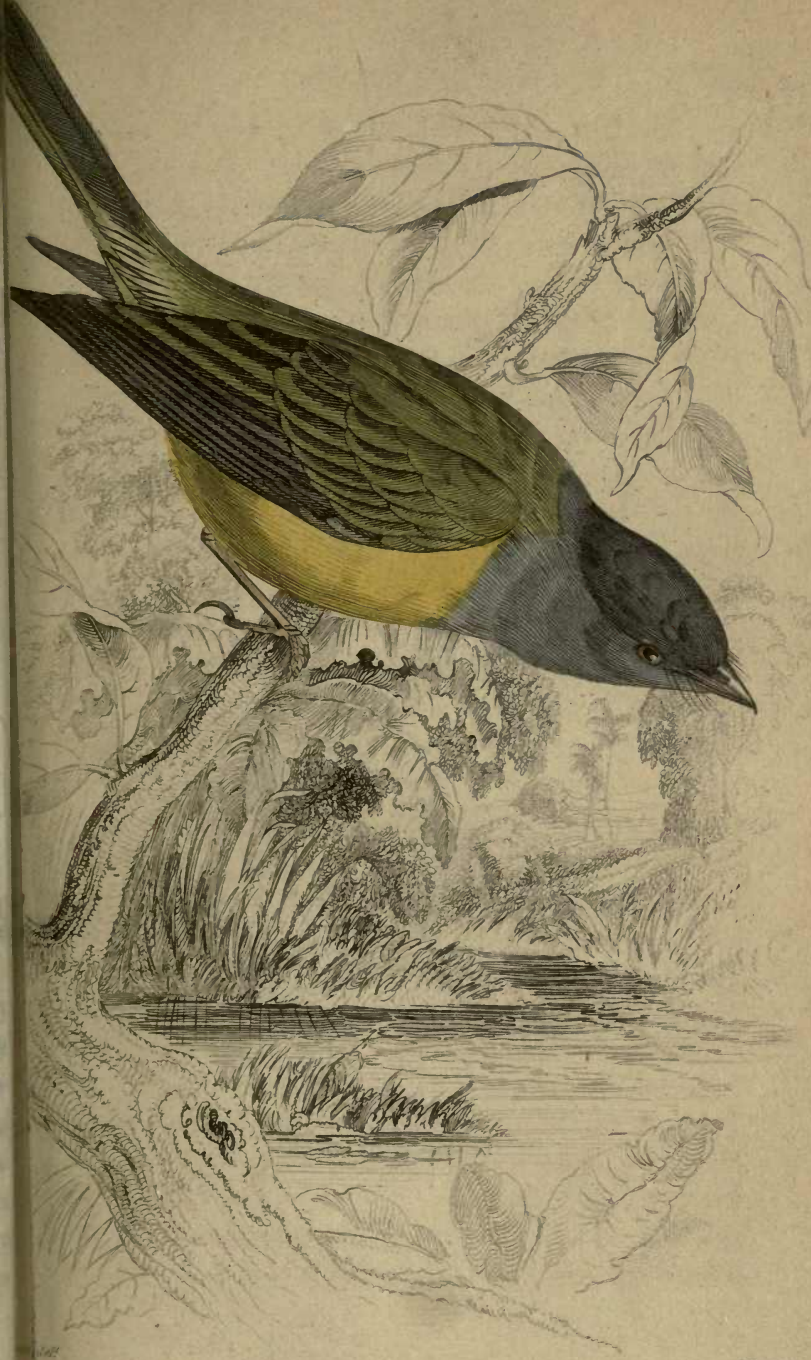




$$
\text { REESE LIBRA AP }
$$

UNIVERSITY

CALIFORNIA. 
of the common European flycatchers. The size is small, and the incumbent crest, when the feathers are raised, becomes very conspicuous, the feathers being broad, and nearly black in the middle. The whole of the head and neck above, as well as the chin, throat, and breast beneath, are uniform cinereous, palest beneath. This colour terminates abruptly on the breast beneath and on the neck above; the rest of the upper plumage is olive-yellow, which colour also margins the wing and tail-feathers, which are otherwise dark-brown: from the breast to the under tail-covers is pure and bright yellow, uniform in its colour, but paler and mixed with olive on the under wing-covers. The three first quills are graduated, the fourth being the longest; the tail is nearly even, and the feathers broader at their tips than is usual in this sub-genus; the legs are particularly slender and pale fulvous; the bristles of the rictus, which are thick-set, are nearly as long as the bill; the under mandible is almost white, and there is a white ring round the eyelids : feet as in Muscipeta.

Total length, $4 \frac{4}{1}$; bill, gape, $\frac{1}{2}$; front, ${ }_{10}^{3}$; wings, $2 \frac{1}{4}$; tail beyond, $\frac{3}{4}$; base, 2 ; tarsus, $\frac{1}{8}$.

The sub-genus 


\section{2}

\section{MUSCIPETA,}

of Cuvier, will be here restricted to the long-tailed flycatchers of Africa and India, distinguished, at the first glance, by the excessive length of their two middle tail-feathers, which are often longer than all the rest of the bird together. These beautiful plumes, however, are only to be found in the males during the season of breeding, for at other times they have the tail like that of the female, that is, simply graduated, or very much rounded. It is not to be supposed, however, that Nature passes abruptly from such birds as are in the last division to these long-tailed flycatchers; and we accordingly find, that one species, at least, is destitute of these feathers at all seasons. Le Vaillant describes the long-tailed species as very wild and quarrelsome; but his Gobe-mouches mantelé is such a tame and gentle bird, that a pair of them actually made a habit of frequenting the inside of his tent, where they took their station on the furniture to catch the flies, destitute of all fear on his approach. He particularly alludes to this species " having an advantage" over the others in the superior ornament of a moveable crest of pointed feathers, which extend some way beyond the occiput; a sort of 
crest which is very different from those of its congeners. Here, then, we have two rasorial characters. But this is not all-for this little species is the turkey-cock of its own group; it erects its crest, and spreads out its tail precisely as do the typical forts*. Our acquaintance with this remarkable bird unfortunately depends at present only upon the figure and description of Le Vaillant; we are therefore unprepared to say whether it really belongs to this sub-genus or to Rhipidura; the figures would lead to the former supposition, while the habits just mentioned would incline us to the latter. In either case, it is a most beautiful exemplification of the rasorial type. We have seen among the todies, that the variation of species is regulated by the same lan as the variation of groups. Nor is this bird the only instance in the little group before us. We have the aquatic type in Le Vaillant's Nebuleux, which he describes as thicker in the body, living only upon insects found near streams, and building its nest on boughs overhanging the water. This bird, moreover, is coloured black and white, and, but for its two long tailfeathers, might be mistaken for a species of Fluvicola. Next, we have the tenuirostral type in the Cordon noir of the same author, who describes the bill as altogether smaller and weaker than in any of the other species, and the tail as considerably

* - "Cette huppe lui forme un belle crête qu'il relève en même tems qu'el épanouit sa queue etagée, en lui faisant faire la rane comme le cog d'Inde, ou le grand tétras qui a la même faculte." Le Vaill." 
less rounded; the figures, in fact, represent the lateral feathers as nearly even. Nor is the colouring of the plumage of this species to be overlooked; it very much resembles that of the wagtail, and has that broad pectoral collar which is so remarkably prevalent among grallatorial and tenuirostral types. All these instances of species putting on some one or more of the characters seen in the primary forms of nature are most remarkable, for they occur in a sub-genus which does not at present exceed ten or a dozen species: so that whatever doubts we might have in regard to the nomenclature of other speoris: types, it would be thought the height of acsurdity to make each of these birds a sub-genus, because they are, in point of fact, types of form in the series of species. 


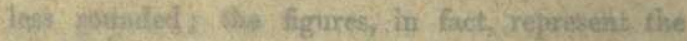

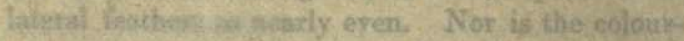

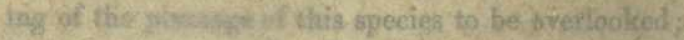

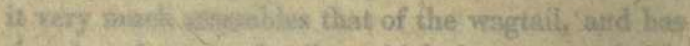

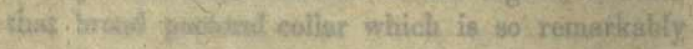

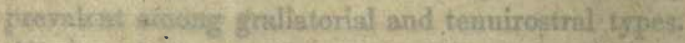

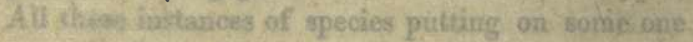
or thots of klic chansoters seen in the prinary formas of misture are megt remarimbles for they pocur in 8 sub-gersus which does not at present, excoed tem or a dozen ippocies: so that whatever doubth we might lave in regard to the nomendature of other apeorte trpes, If would be thoughit the height of acsurdity

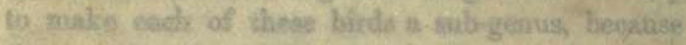

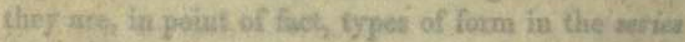
Q Aricelia. 


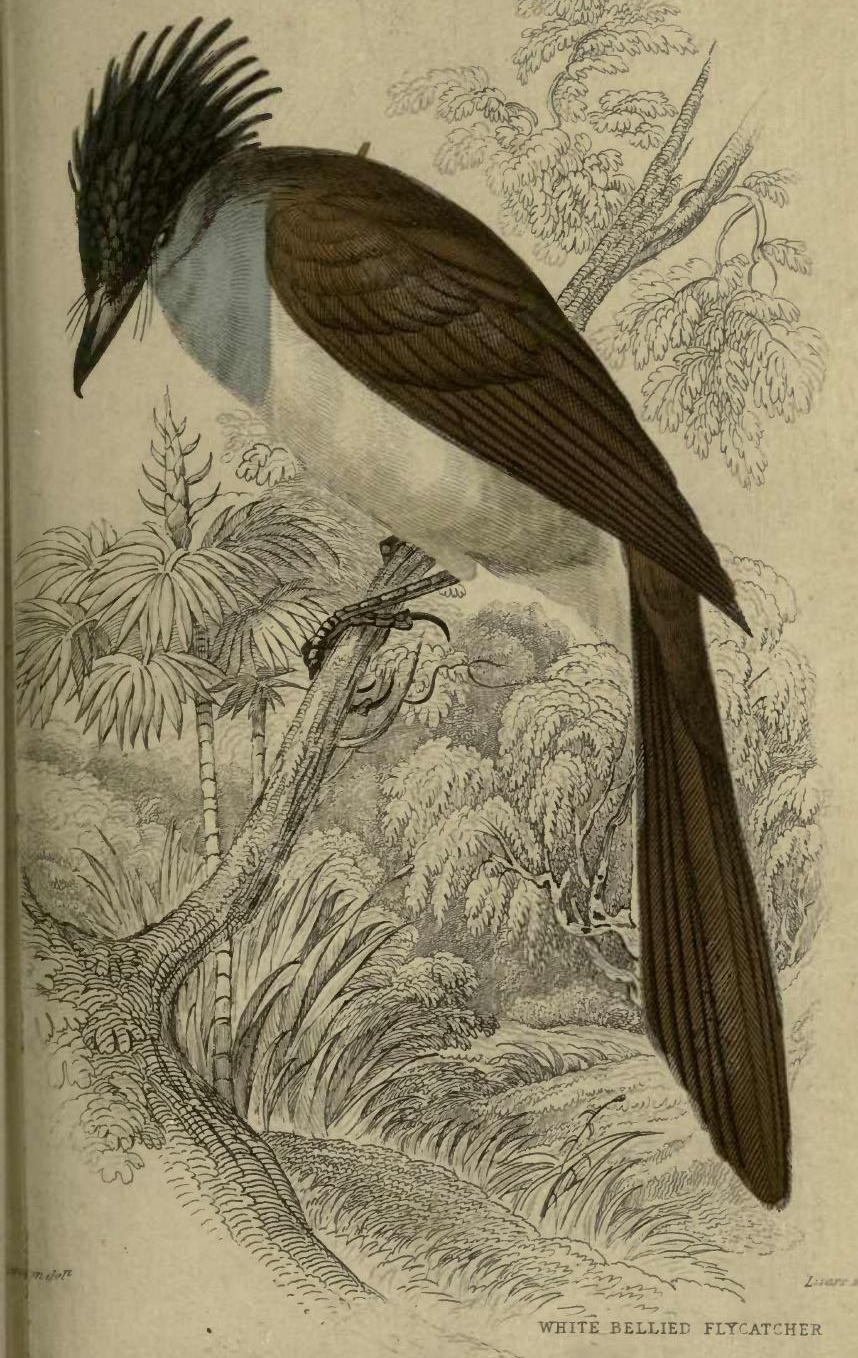




$$
\begin{aligned}
& \text { REESE LIBRA RY } \\
& \text { OF THE } \\
& \text { UNIVERSITY }
\end{aligned}
$$

CALIFORNIA. 


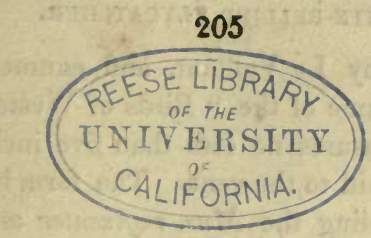

WHITE-BELLIED FLYCATCHER.

Muscipeta leucogaster, Swains.

PLATE XXIV.

Zat bemeath pure white; back, wings, and tail, rufous: -nrast end neck light grey; crown blue-black, furnished wrun a crest of lengthened, narrow, pointed feathers.

For an acquaintance of this, and several other interesting birds from India, our best acknowledgements are due to the Countess of Dalhousie, who, during her residence in India, paid much attention to the native birds, and has obligingly communicated to us many valuable notes upon their manners. From a memorandum attached to the only specimen in the collection, it appears to be a female; yet its superior size to any other of this group we have yet seen, together with the pure white of the under plumages, stamps it at once as a distinct and an unrecorded species. As our knowledge of these long-tailed Flycatchers increases, the more does it appear how much ornithologists have been mistaken in regarding them as varieties of our species. The size of this bird is considerably above any of 
those figured by Le Vaillant, and enumerated in the second volume of the "Birds of Western Africa;" for it measures no less than five inches fronı the tip of the bill to the vent. The form is strictly typical, resembling the Mus. rufiventer and its allies ; but the bill, in proportion, is much longer. The colouring, however, preserves the family likeness. The whole of the back, wings, and tail (the latter considerably graduated) are bright rufous. the neck and throat being light cinereous, and the top of the head dark steel-blue. The crest, as seen in the figure, differs from all the species hitherto known, in having the feathers very narrow and much lengthened, so as to have some analogv to that of Megalophus; the whole of the body, trom the throat, is white.

The exact measurements, unfortunately. zave been mislaid; and, as the specimen has been re turned, we cannot make them again.

The sub-genus 


\section{7}

\section{MYÏAGRA}

was defined some years ago by Messrs. Horsfield and Vigors as containing all those flycatchers which nad the tail more or less even, and a shorter and oroader bill.* This latter distinction, theoretically, appears to be very good; yet the difference is so very trifling between these and the latter, as hardly to be w orth naming. As the tail, however, is one of the cnief aistinctions, we may still look upon $M$. plumbia $(H$. and $V$.) as one of the typical forms. The otner cnaracter, which has been overlooked, is the superior length of the third quill-feather, which in this, and two or three other birds which are equally typical, is nearly, if not quite, as long as the fourth. In Muscipeta, on the contrary, the third quill is even shorter than the fourth and fifth. Now the passage between these two closely allied sub-genera may be thus traced. The first form which meets us on leaving the wedge-tailed Muscipetoe is seen in a bird from New Holland, now before us, and

* Three species are described as having the bill moderately short, and in which it differs from the bill of Muscipeta ; but in two of these, now before me, I can see no difference; while the third species, $M$. macraptera, judging from the description, I do not think belongs to the group. 
which we shall presently describe and figure, namely, the Myiagra longicauda. It is entirely blue, and has the graduated tail of Rhipidura and its prototypes; the bill, however, is unusually broad, and somewhat dilated at the base, while the bristles are so long as almost to reach-like those in the fantailed flycatchers - to the end of the bill. By this form we are prepared for the second, as seen in Myjagra latirostris, where the tail is shorter, and, although not graduated like the last, is yet decidedly rounded; while the bill is so short and broad, as inmediately to remind us of the genus Todus, or rather of its sub-genus Platyrhynchus. The breadth of the bill lessens, and its length increases, in the Myiagra coerulia and torquata; and in the same proportion does the tail loose its roundness, until we come to $M$. rubiculoides and Plumbea ( $H$. and $V$.), both of which have the tail-feathers completely even, and the wings, as already observed, more pointed. The fourth type of form is very remarkable; it is exhibited in a species from Africa in the Paris Museum. The head and bill is unusually large, while the crown is surmounted by a conspicuous pointed crest; the wings are lengthened, and the tail so short as hardly to project beyond them. Still more remarkable are the feet, which, although rather stout, are so excessively small, that the tarsus only measures four-tenths of an inch, being the exact sength of the hind toe and claws: contrary, also, to any example yet known in the whole of this subfamily, the feet are of a beautiful yellow, with the 
claws deep black, while the anterior scales are divided into irregular hexagons, analogous to what we see among the gallinaceous birds. The whole aspect of this bird suggests the idea of a swallow flycatcher; yet it obviously combines just as many characters of the rasorial as of the fissirostral type. Its thick compact form, large head, short feet and tail, long wings, and glossy plumage, remind us of a swallow; while the stout tarsi, their hexagonal scales, and the long pointed crest, are so many indications of the rasorial type: for reasons which will presently appear, we shall view it in the latter light*. The fifth type of form we have not yet seen; it should intervene between this bird and $M$. longicauda, and represent the tenuirostral form. Hitherto, out of the numerous species that have passed under our inspection, there has been no one which will completely answer our expectations on this head, or against which some objections cannot be raised. When the extreme delicacy, however, of the analysis we are now making is considered, it can excite no surprise, that in the present state of ornithological knowledge, we are unprepared to close the circle of a sub-genus, or that we should be ignorant of one part of the succession of its species. Before proceeding to generalize these ob. servations, we shall first describe one of the species above alluded to, namely, the Myïagra longicaisda.

* Myäagra Aavipes Nob. 
CARTULEAN, OR LONG-TAILED FLYCATCHER。

Mÿ̈agra longicauda, SwaINs.

\section{PLATE XXV.}

Jintirely cærulean blue, paler beneath; tail lengthered and considerably graduated; rictal bristles as long as the bill.

Tuere are so many Flycatchers, generally so called, whose plumage is entirely blue, although of different tints and shades, that it is quite impossible to determine this species from among those in our systems at present in use. It was formerly in Bullock's Museum, and stated to come from New Holland, a locality not at all improbable; for although we have never yet seen any species of Muscipeta from Australia, it affords several species of the present subgenus.

The general structure, as already observed, accords more with that of the typical Myiagra than with any other of the neighbouring groups; for the tail, although long, is graduated, and not fanshaped, as in Rhipidura, while the prolongation of the middle feathers, although but slight, induces the belief that this bird is an annectant species be- 


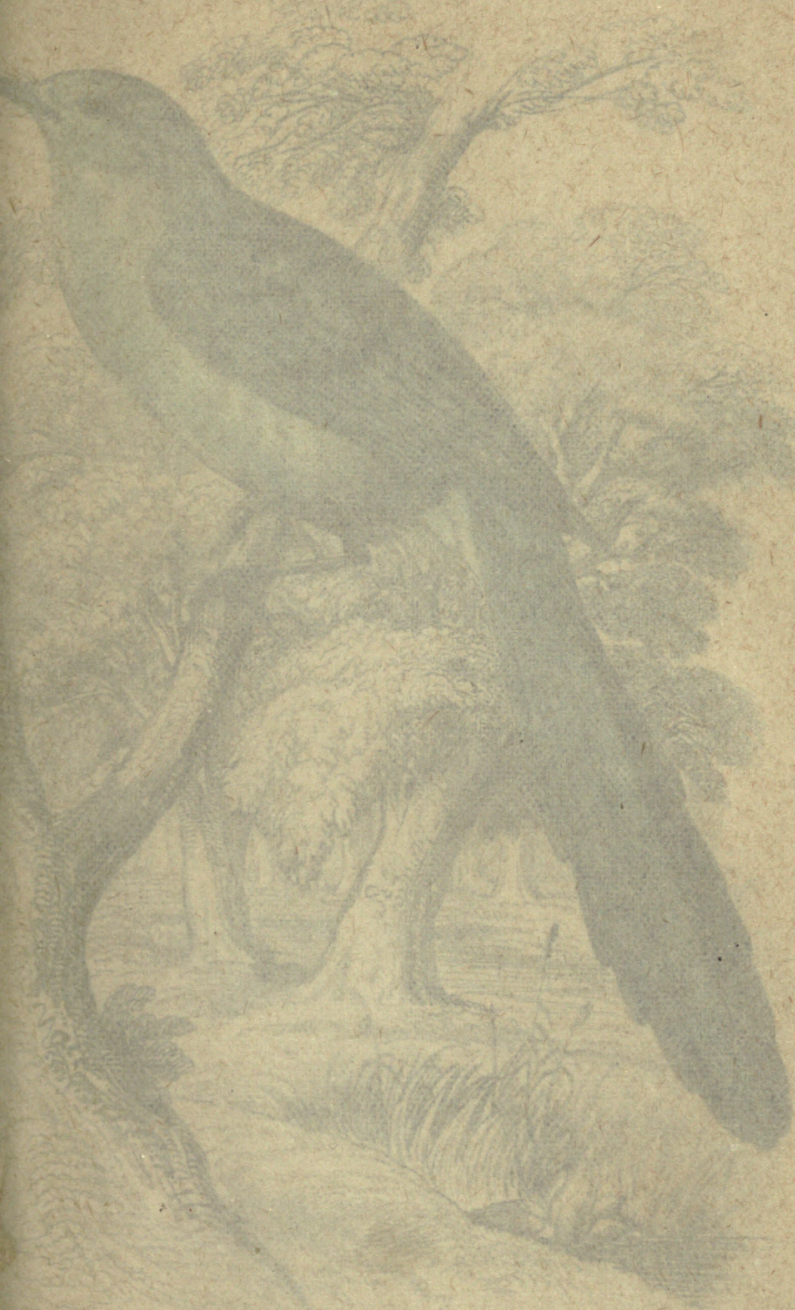


athes:

4. 210

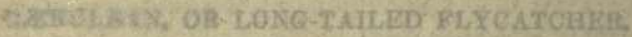

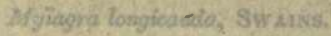

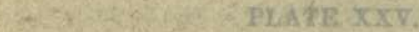

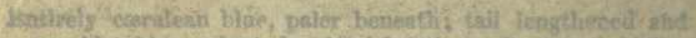

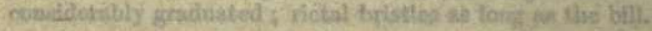

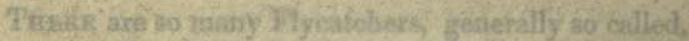

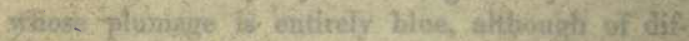

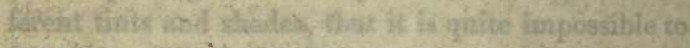

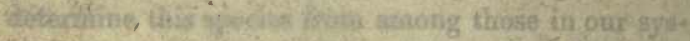

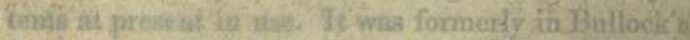
MLusearo, end stated to oome from Now Holland, a Woatity not at dil improbable; for sthough wethar: mever yot seen any species of Muccipata from Ause - Wratias it affords several species of the present sil: granasing $\rightarrow$

The general structure, as already observod, ys cartis more with that of the typical Diyzagna than gith any other of the neighbouriag froups ; fortive sat, aithough long, is graduated, and wot f furt whopois ag in Rhipiduro, while the prolongatien

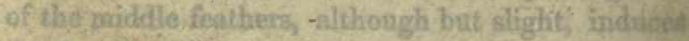
the belieflath this birut is an annectint specios bet 


\section{CALIFORNIA.}


CARULEAN, OR LONG-TAILED FLYCATCHER. 211

tween Myïagra and Muscipeta; possessing, in other respects, much more of the characters of the former than of the latter.

General colour of the upper plumage light cærulean-blue, which spreads uniformly over all the exposed parts of the wing and tail-feathers: the under parts are lighter and tinged witn grey, wnich becomes almost white on the belly and vent; the covered portions of the tail and quill-feathers are blackish; the bristles of the mouth are strong, and are two-thirds the length of the bill, which, with the feet, are blackish. Of this rare species we have never seen a second example.

Total length, 7 inches; bill, gape, $\frac{6}{10}$; front, $\frac{4}{10}$; wings, $2 \frac{7}{10}$; tail, base, $3 \frac{1}{2}$; tarsus, $\frac{6}{10}$.

That the foregoing outline of the circle of Myiagra is founded on some solid basis, will appear more probable when we compare the species, here named as constituting types of form, with those of the longtailed Muscipetoe and with the divisions of the entire genus.

\footnotetext{
Genera Types of form Sub-gen. Types of form i of the in the sub-gen. of in the sub-gen. Muscicapida. Myïagra. Muscicapa. Muscipeta. RHIPIDURA......M. longicauda...Cryptolopha......fuvicola. Le Vaill. Muscic4PA...... - latirostris......Muscipeta.........picata. ToDus.............. - plumbea........Myïagra...........paradisea. MrgalophUS. - flavipes..........Muscicapa........fabellifera. MONACHA........ - ? ..............Hylicta ..............pectoralis.
} 
It would be vain, in the present state of ornithology, to think of explaining the whole of these analogies; yet if a few are established, they will tend much to illustrate our preceding analogies. Rhipidura and Cryptolopha, as we have already seen, are representations of each other; and if Myïagra longicauda really belongs to that group, it becomes their representative also in the series of the species. Between the two typical series there are so many reciprocal analogies in structure, that nothing further need be said, seeing that we are in complete ignorance of the manners and habits of those birds, from which, no doubt, satisfactory evidence might be drawn; certain, however, it is, that nothing is yet known to invalidate the series in which they have been placed. On passing to the two other aberrant columns, we find all those with conspicuous crests coming parallel to each other, as $\mathrm{Me}$ galophus, Muscipeta flabellifera, and Myïagra flavipes; this latter bird, by its long pointed wings and short tail, being also the type of form of the sub-genus Muscicapa. Lastly, the most aberrant types in each of the three columns which are filled up, are Monacha, Hyliota, and Muscipeta pectoralis, the only birds among the whole which have the narrowest bills.

We retain the original name of 


\section{MUSCICAPA (LiNNEUS)}

to that sub-genus which immediately follows Myiagra. All the birds coming under this designation have, in comparison to the three last divisions, longer and more pointed wings, stronger and more equal lateral claws, and shorter and more even tails. The bill, also, is materially different from all the other sub-genera, and more resembles that of $\mathrm{Co}_{0}$ nopophaga : it is small, short, and rather strong, the sides being considerably compressed, although the base is still broad. These characters are more or less developed in different species; but they are sufficient, even in the most aberrant examples, to prevent any ornithologist, with proper attention, from confounding this group with any we have yet noticed in the family. The tarsi have also this peculiarity, that although they are often not longer than in Myiagra, or in Muscipeta, they are nevertheless stouter, and the scales which cover them in front, instead of being divided, are formed of an entire piece. This although a minute character, is yet the most constant, and therefore one of the most important. The compression of the bill is accompanied by a thickening of the under mandible, the gonys of which, instead of being straight, is curred upwards; the bristles at the base, although 
well defined, and pointing directly forward, so as to separate these birds from the stone-chats*, are yet short, and by no means so strong as in the preceding divisions. The wings, as already intimated, are the longest and the most pointed of all the flycatchers: they generally reach to half or threequarters the length of the tail, while their typical structure is no less peculiar: the first quill is completely spurious, -in other words, it is quite useless for any purposes of flight, and seems intended either to designate the natural situation of these birds in the scale of nature, or to serve as some protection to the base of the next or second quill, which very nearly reaches the end of the third, so that the second and third pen-feathers, - which in all the preceding sub-genera are short and graduated,become the longest of all. The tail is rather short, and the termination is not only quite even, but assumes in the middle an inclination to being slightly forked. Such are the typical characters as exhibited by our common Muscicapa grisola and the two other European species. But before we attempt to show in what manner these characters are modified in the extra-European species, we shall figure and describe the Muscicapa albicollis.

- See Observations on the two families, under the head of Petroica multicolor, Zool, IIl. 



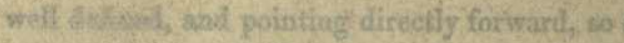

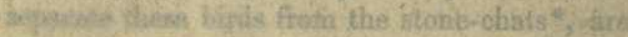

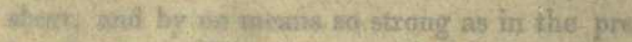

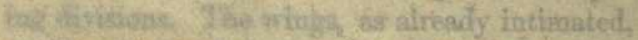

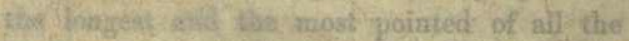

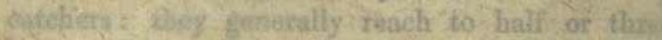

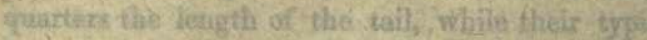
Grincture is no leos pectiar, the first guill is so pitebly spurious, in other worls, it is guite sogle for hay purposes of flight, and scems intended achese fo de fignate the natural sicuation-of thesd thirds in fho scale of matare, por to serve as somp' protectidu to the beas of the zext or second buill whieh vers

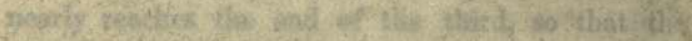

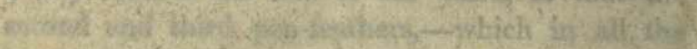

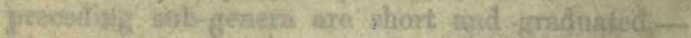

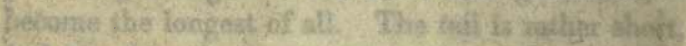

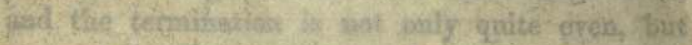
assumpeas in of Highy forked. Suob are the typioal chimaters os exhibised by one common Mrsacicdpes grisola nat the twe sther European species. But before kin. atcongt to show in what manner these charaotonn ans mot.

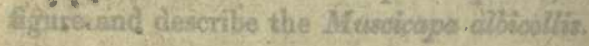

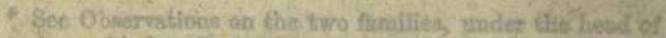
Restrotos atciticotor, Zool. ni. 


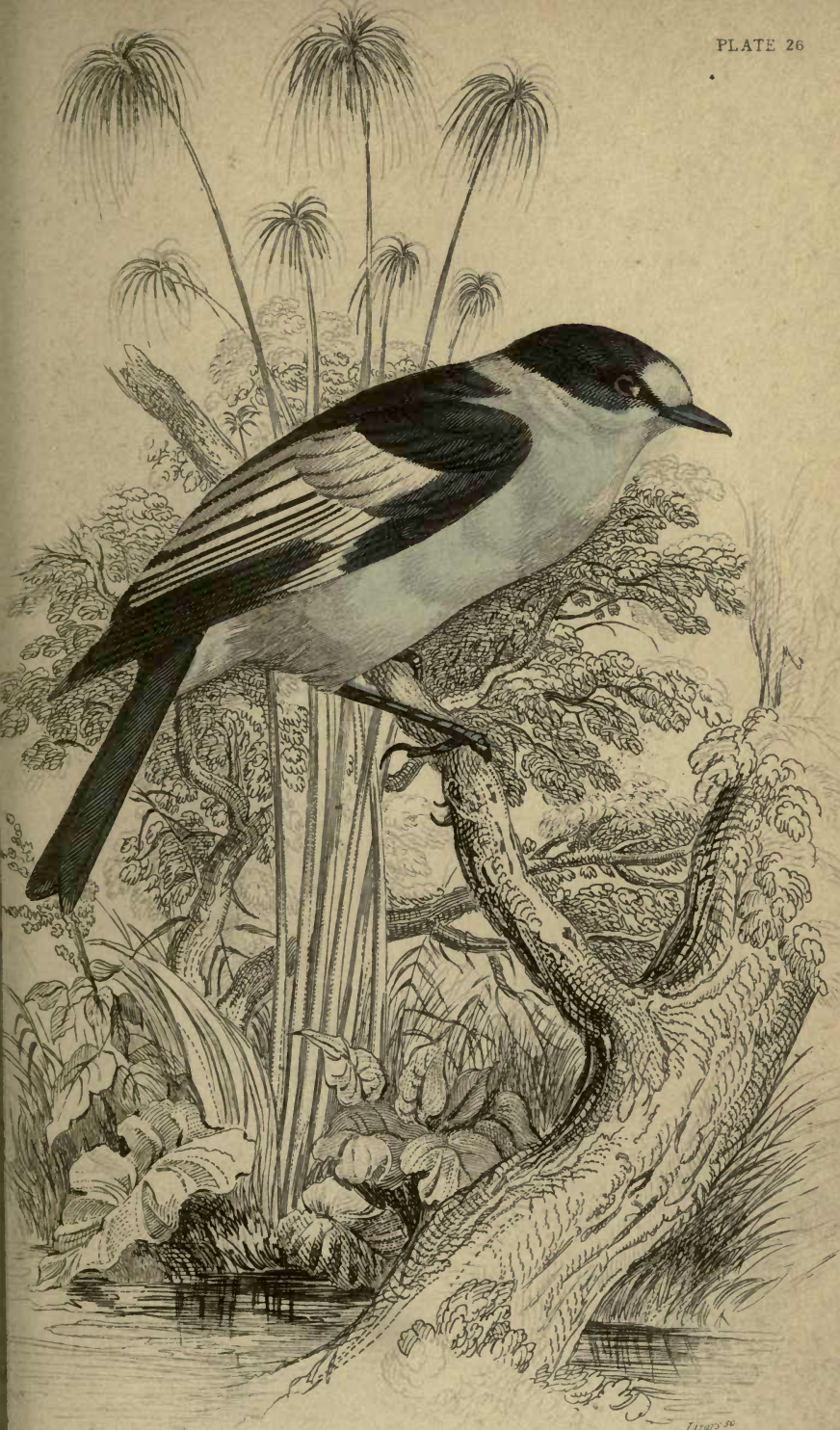




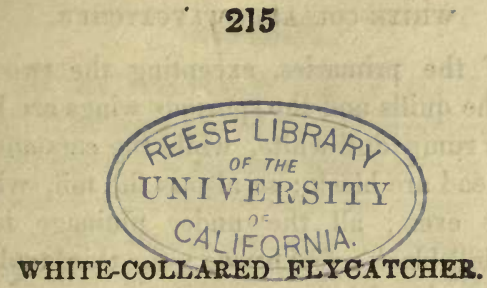

Muscicapa albicollis, TeMminck.

\section{PLATE XXVI.}

Above, black; front, collar round the neck, and a large patch upon the wings, white; quills brown, their base white; rump greyish-white ; tail-covers entirely black.

Muscicapa albicollis, Tem. Man. i. 153, Pl. Enl. 565, f. 2.Pied Flycatcher, var. b. Lath. Sy. iii. 325.

THE annexed figure accurately represents an individual of this species we shot in the island of $\mathrm{Si}$ cily, so far back as the year 1807 ; it is almost the only specimen remaining of a large collection of the birds of that island, formed in the subsequent five years, which has escaped destruction from moths.

The ground colour of the upper plumage is black, but varied with white in the following manner:-The front of the head, the collar round the nape, and a large spot on the wings, are all pure white; this latter spot is longitudinal, and spreads over the tertials and a portion of the larger wing-covers; there is a band of white at the base of the secondaries, and a much narrower one on 
those of the primaries, excepting the two outermost; the quills and the spurious wings are brownish ; the rump dull white, while the ears and sides of the head are black; so also is the tail, which is perfectly even; all the under plumage is pure white; bill black; feet brown; the third and fourth quill is equal and longest.

Total length, nearly 5 inches; bill, gape, $\frac{1}{2}$; front, $1^{7} \frac{7}{0}$; wings, $3 \frac{1}{10}$; tail beyond, ${ }_{1}^{7} \frac{7}{0}$; base, 2

Let us now compare the genuine flycatchers, as here characterized, with some other groups related to them by analogy, and with which they have been confounded by many of the best modern ornithologists. We think this comparison will be beneficial to the science, and not uninteresting to the amateur.

The European flycatchers very closely resemble both the stone-chats (Saxicola) and the robins (Erythaca), while they seem to approach very much to those little tyrants of America, which constitute the aberrant examples of Ptilogonys: the two last mentioned resemblances are strictly analogical, but nothing more. Muscicapa, however, in its own circle, represents the flycatching shrikes (Tyrannina) in theirs; and it likewise represents Ptilogonys in the circles of the Tyrannina: from both these, however, it is at once distinguished (independent of more obvious but variable charac- 
ters), by the very small size of the first quillfeather. The strongest of these resemblances, however, is between Muscicapa and Saxicola, for here the spurious quill-feather and the whole structure of the wings is almost precisely the same. Neither will the bill altogether "serve our turn;" for although that of Muscicapa is rather more depressed, such a distinction, founded merely upon a comparative quality, is vague and unsatisfactory. Nevertheless, as one family lives chiefly upon the ground, and the other is never seen but upon trees, this difference of habit necessarily carries with it a difference of structure, and this is immediately apparent in the feet,-those of Saxicola being nearly half as large again as those of Muscicapa. The one, in fact, is constructed for perching only, the latter for perching and walking; hence the great length of the tarsus, and the complete separation of the toes in all the different genera of the Saxicolince* ${ }^{*}, \mathrm{a}$ structure quite opposed to the shortness of the tarsus, and the union of the outer and inner toe, which pervades, more or less, through the whole of the Muscicapinae.

The variations in the foregoing characters of Muscicapa, so far as they have come before us, will now be stated. Let us first, however, call the attention of the ornithologist to the last bird which has been mentioned in our account of Myiagra, because its structure will assist us materially in

* One of these is composed of the robins, Erythaca, which Muscicapa, as now restricted, represents. 
tracing the chain of progression. The Myzagyra flavipes differs from all those in its own sub-generic circle, not only in the feet, but in the great length of the wings, and the shortness of the tail. Now this evidently points it out as an aberrant species, and gives an intimation, that in the group which is to come next, some species will be found having one or more of these characters, and yet partaking likewise of those mure properly belonging to Myïagra. And such a bird has fortunately been described. The Myiagra macroptera*, in short, realizes precisely what the law of variation would lead us to expect. It is a Myïagra, according to M. M. Horsfield and Vigors, in its bill, " but the comparative length of the wings, and the shortness of the tail, distinguish it from the other species of that group; the wings reach to the extremity of the latter member." Now as this structure is almost precisely what we see in M. flavipes, why not place both in one group? Here, however, the similarity ceases. M. favipes has a conspicuous crest, because it is the rasorial type, while its feet are particularly short. M. macroptera has no crest, and its feet are fully as long as those of Muscicapa grisolat. It retains, in short, according to the account of its describers, nothing of Myäagra but its bill; for its wings, tail, and feet, are those of our Muscicapos.

- Horsf. and Vigors. Linn. Trans. xv.

+ The tarsi of these three birds measure as follows :Myiagra flavipes four-tenths of an inch, Muscicapa grisola six tenths, Myiagra macroptera (H. and V.), thirteen-twentieths. 
It is seldom we can establish the connexion of two groups in so satisfactory a way: this sort of evidence, indeer, is more entitled to confidence when it can be drawn from the writings of those who become in this way unbiassed, and therefore trustworthy witnesses, than when it merely rests upon the inference of one who is advocating his own theory. The intelligent ornithologists who described this bird, seem to have had an idea of its being the connecting link between Myiagra and Muscicapa, although they have shown much judgment in discriminating it so well, that without having seen the bird, we feel fully persuaded it has been correctly described. According to these views, Myiagra macroptera, by its structure, comes in the circle of Muscicapa; and if any other proof was wanting, it will be found in the inference to be deducted from the following fact. Mr. Caley gives the following note upon the species:- "This bird has all the actions of the British robin red-breast, except coming inside houses: when a piece of ground was fresh dug it was always a constant attendant." We repeat that we have had no opportunity of examining this bird; but were it not that our two best ornithologists had referred it to Myïagra, we should, upon this simple statement alone, have been impressed with a conviction that it really was a robin, because this assertion of Mr. Caley's would seem to imply that it hopped like our red-breast upon the ground, a habit which no fissirostral bird is known to possess. But does this supposition militate against 
the probability of its being a true flycatcher? Something, it must be confessed, but not quite; for we shall now mention a bird as actually baving the typical feet of a flycatcher, but which, in size, colour, and appearance, is so like a robin, that no one, even a professed ornithologist, would be able to distinguish one from the other, unless the feet and the wings were carefully examined. It is, in fact, the most extraordinary instance of disguise, or rather of complete analogy, that has ever occurred to our observation in the whole animal kingdom. Let the reader suppose a robin before him, and he has an exact picture of our Muscicapa erythaca. A single specimen of this bird is in the Paris Museum ; nor were we perfectly satisfied it was not a deceptive preparation until we examined it most attentively, for the purpose of seeing that the feet were actually united by the skin to the body. It proved, however, in this respect, to be perfectly genuine; and we shall now figure and describe it. 


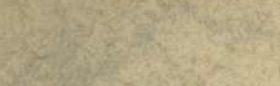

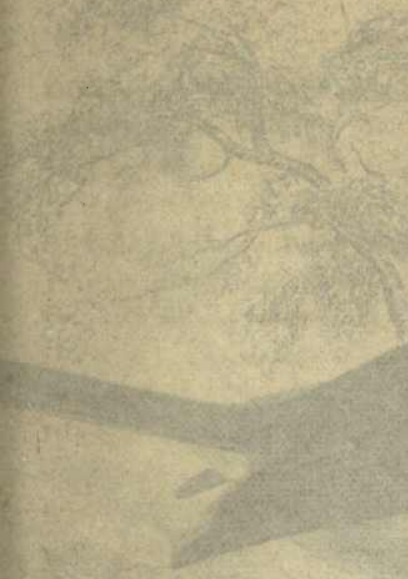

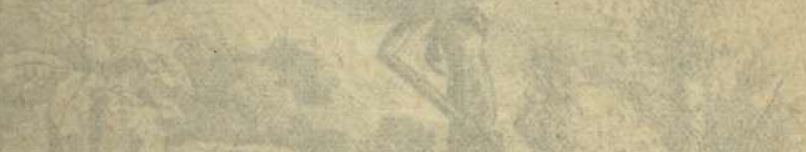

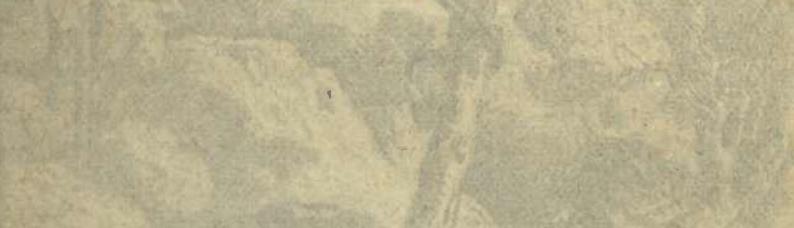

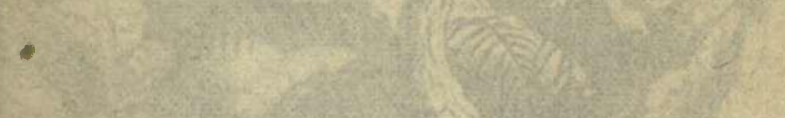

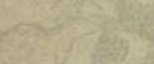

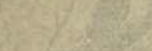

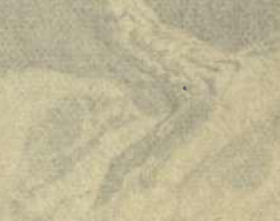

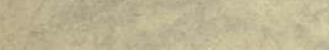




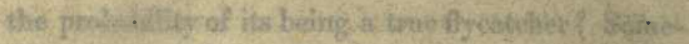

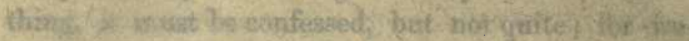

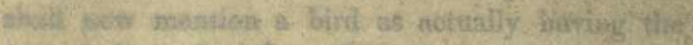

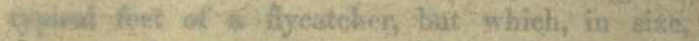

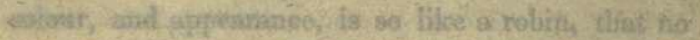

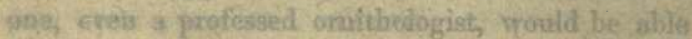
ta distingraikh ond from the othery unlese the foet ant the wings wope carefully examined. It is cia fanty the most exthordinary inatance of disgulse, of nid her iof complete analogns that has erer owvitred

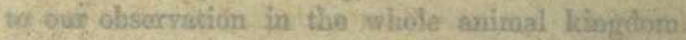
Let the reader surpolie is vobir, before him, and the

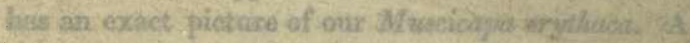

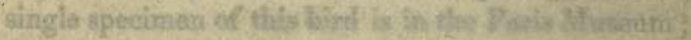

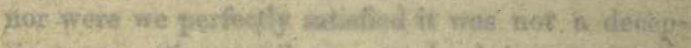

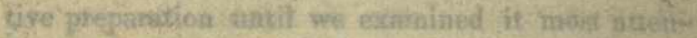

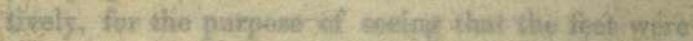

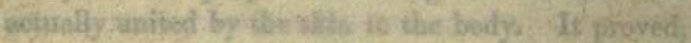

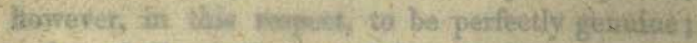

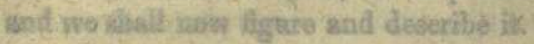





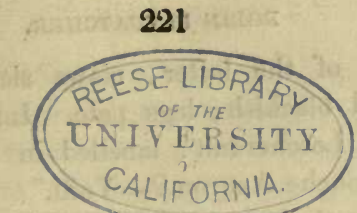

RORIN FLYGATCHER.

Mascicapa rubecola, Swains.

PLATE XXVII.

THE only specimen we have ever seen of this rery remarkable bird, is the one already alluded to as existing in the Royal Museum at Paris; and, as every particular respecting its structure must be highly interesting, we shall here transcribe our original description, verbatim, as written when the specimen was before us.

Size and colour of the robin, which it so closely resembles, that it might easily pass for that bird :oill rather larger, straight, but abruntly bent at the tip; the base broad, but not dilated; culmen elevated and straight; the sides compressed; gonys ascending; rictus as much bristled as in the European Flycatchers; wings moderate, reaching to half the length of the tail; the first quill very short, the second equal to the seventh, the fourth and fifth longest; tail moderate, slightly rounded; tarsi (for a Flycatcher) rather long, pale; anterior and lateral scales entire; outer and inner toes nearly equal; the inner slightly connected at the base, but the outer and middle toe are connected beyond the 
first joint of the latter; claws slender, arched, acute; bill blackish; legs pale. Inhabits Pondichery, M. Lescherault: labelled in the Museum, "Grobe Mouche Azuron.+ - Vaill."

Total length, in a straight line, about $5 \frac{1}{2}$ inches; bill, from the front, $\frac{4}{10}$; wings, $2 \frac{8}{1 \gamma}$; tail beyond, 1 ; tarsus, $\frac{6}{10}$; hind toe and claw, $\frac{5}{10}$.

It is necessary to add, that the name above quoted seems to us erroneous.

That the analogy of this singular bird to the robin should be illustrated more fully, we shall subjoin the circles of the two groups in which they respectively occur.

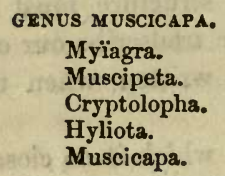

GENUS MUSCICAPA.

Myiagra.

Muscipeta.

Cryptolopha.

Muscicapa.
GENERA OF SAXICOLINE.

Saxicola.

Thamnobia.

Gryllivora.

Petroica.

Erythaca.

Without at present entering into all the details of these two circles, we would apply our preceding observations as strong proofs in support of our belief, not only in the analogy of Muscicapa and Erythaca, which here stand opposite to each other, but in the union of the Muscicapido, the Sylviado, and the Ampelidoe (the three aberrant divisions of the tribe Dentirostres) into a circular group of their own, quite independent of the other two, which, when united to this, constitutes the whole tribe. In whatever view, therefore, we may take of the Myz̃agra macroptera, whether as a genuine Myz̈a- 
gra or as a Muscicapa, our theory that these two sub-genera unite will not be affected. But we must not think that there are no variations from the structure of Muscicapa grisola in the other species associated in the same sub-genus: on the contrary, there are some very remarkable ones besides the one just instanced in $M$. erytraca, which, as we shall presently show, is evidently an extreme aberrant species. In our $M$. thalassina and ruficauda, two Indian species subsequently described, the wings are so much rounded as to resemble those of $\boldsymbol{M}$. erythaca, although the toes are not more united than in $M$. grisola, and in all these three the tail is rounded. Again, in our $M$. latirostris, another species from India, the plumage is almost precisely the same as that of grisola; but then the bill is so remarkably depressed as to give it the appearance, in this respect, of being a $M y z a-$ gra. From these we pass to the European albicollis, by means of such birds as $\boldsymbol{M}$. parvirostra and leucura, which begin to show the white and black colour so common on the tail of the stone-chats. Our $M$. parvirostra agrees so closely in point of colour with the description of the bird called by $\mathbf{M}$. Temminck the young male of his $M$. albicollis, that we question very much if it may not have been overlooked for that. However this may be, the two species, in our opinion, are sufficiently distinct. The bill of the adult albicollis, which we found in Sicily near twenty years ago, is broad at its base, while that of paroirostra, as the name implies, is 
the smallest of any species we have yet seer; and, for this genus, is remarkably narrow and compressed. We are, indeed, sceptical as to the birds described by Temminck as the female and young male of albicollis; the white edging of the lateral tailfeathers, said to exist in the adult male only, is opposed to every conclusion drawn from analogy, more particularly among the insectivorous birds. But to pursue our analysis of the Muscicapo further, will, however, be needless. All the variations that we can possibly speak of, from personal knowledge, have been enumerated, but several more no doubt exist. Throughout all these, the only characters in which no material variation can be detected are those of the feet: first, the middle toe is always long, and is of the same length as the tarsus; 2. the tarsus itself is always smooth, and is defended in front by one entire scale; and, 3 . the outer toe is in all united to the middle as far as the first joint. Now these three characters will of themselves enable any ornithologist to distinguish the group from all those which it resembles in other families. It may be further remarked, that we have not hitherto seen one species of an olive-green, that colour apparently belonging only to the subgenus Cryptolopha, where the wings; instead of being pointed, are rounded.

The last sub-genus is 


\section{HYLIOTA,}

which agrees with Muscicapa and Cryptoloplia in having the outer half of the bill compressed; but here this structure is carried to its extreme. Its length is sufficient to give to the bird an appearance of being a warbler: the base, indeed, is broad, but beyond the nostrils it suddenly contracts, and the remaining portion is so much compressed that its height (when viewed in profile) is much greater than its vertical breadth : the rictus, moreover, has merely a few setaceous hairs, and is destitute altogether of stiff bristles. Hyliota further differs from Muscicapa in having the claws broader, stronger, and more curved, and in the scales of the tarsi being divided into four pieces. And yet, notwithstanding these great deviations from the typical character of fly-catching birds, we feel fully persuaded that this is the tenuirostral type of the genus before us. The wings and tail are precisely those of M. albicollis. The outer toe is connected as far as the first joint; and the glossy blue-black plumage, white scapulars, and buff-coloured throat, is in complete unison with the family we are now treating of. The first aspect of the species now before us suggests the idea that it belongs to Platysterch 
while the breadth of the bill at its base indicates its insectivorous habits : its apparently anomalous structure, in other respects, is explained by the situation it holds as the tenuirostral type of its own genus. Hence its bill is the longest, and, like that of Monachus, it is considerably compressed; by the absence of bristles, and by the thick feathers on the rump, it preserves its analogy to the Cellepyrina, or caterpillar-catchers, without diminishing its affinity in other parts of its structure to Muscicapa, or its analogy in point of colour to Platystera. Such are the conclusions we have come to after some years reflection, and which we have elsewhere intimated*. At present we know but of one species; the sexes of which, unlike all the other types of Muscicapa, differ as remarkably in colour as do those of its prototype Platystera. And the student will remember, that the tenuirostral types are always those which have the most marked difference in the plumage of the sexes. The whole of the Ampelidoe, the order Grallatores, and the tribe of Tenuirostres, not to mention the Orioles, Psariano, and several others of minor note, are convincing proofs of this general law. It is well known, again, that nearly all tenuirostral types have the longest bills among their congeners : witness the humming-birds and the whole order of waders. We find this analogy, therefore, rreserved in the present family : for this is a peculiar characteristic in Psaris, Parspicilla, Monacha, and Hyliota, groups of dif-

* Classification of Birds, ii. 
ferent ranks, yet representing each other in their own circles. An exception to this rule would seem to appear in Platystera, but length of bill is here the typical distinction of the genus: and if it is longer in the tenuirostral than either in the fissirostral or rasorial types of that genus, the analogy is still preserved; and such, in regard to Platystera, is actually the case. We have thought it necessary to illustrate Hyliota by these varied comparisons, because it stands at present as a single species, and there is consequently a want of that gradation to Cryptolopha which we find between such types as are fuller of examples. This species we shail now describe as the 


\section{8}

\section{BUFF-BODIED FLYCATCHER.}

Hyliota favigaster, SwaINs.

\section{PLATE XXVIII.}

Piumage, in the male, glossy blue-black ; in the female, cinereous; beneath, in both, ochraceous yellow; wing-covers and rump with a band of white.

Hyliota flavigaster, West. Afr. Birds, ii.

As we have given a full description of this species in the work above quoted, a shorter one will here suffice. The male has the upper plumage deep and glossy blue-black, where that of the female is deep grey, inclining to cinereous; the quills are paler and browner, but their outer edges are glossy; the sides of the head and ears are like the back; the feathers of the rump are long, soft, and pure white; but the tail-covers are small and glossy black. The female has the quills, and some of the lateral tailfeathers, with a narrow whitish margin. In both sexes, the greater and lesser wing-covers are pure white, continued, in the female, in a stripe along one or two of the tertials ; the under parts are buffyellow, deepest on the breast, and lightest in the female; bill and feet black.

Total length, 5 inches; bill, gape, ${ }^{7}$; front, not quite $\frac{1}{2}$; wings, $2 \frac{7}{10}$; tail beyond, $\frac{6}{10}$; base, $\frac{3}{4}$; tarsus, $I^{7}$. 

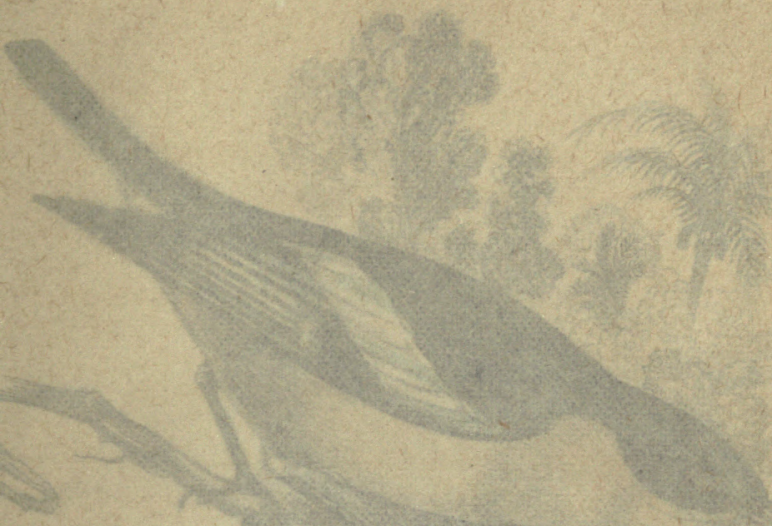


\section{8}

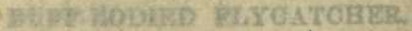

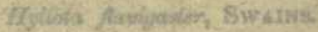

\section{PLATE XXVII.}

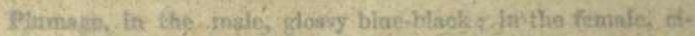

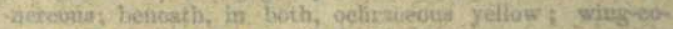
vesa and turoip with a bond of white.

X5. 3i Eyllota flavigasten; Wai, Afr. Birds, II

As we have given a fill description of kis eppecits.

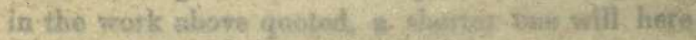

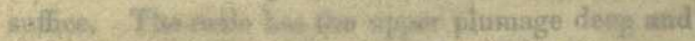

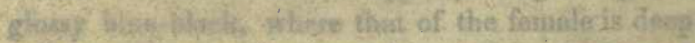

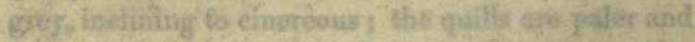

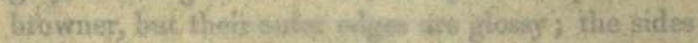

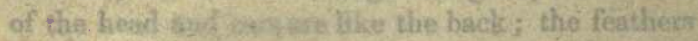
of the rump are loigg, soft, and pure whites but the lail corers are small and gloseg black. The female has the quills; and some of the lateral tailteachers, Viciti a narrow whitish margin. In beth secres, the greater and lesser wing-covers ane pure: White, continued, in the female, in a stripe stong othe on two of the tertials; the under parts are buffyellogh decpest on the bireast, and lightest in the foungey ? bill and feet black.

Total Jerngth, 5 inches ; bill, gaps, 7 : ; front,

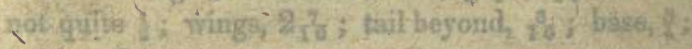
serails, 27. 


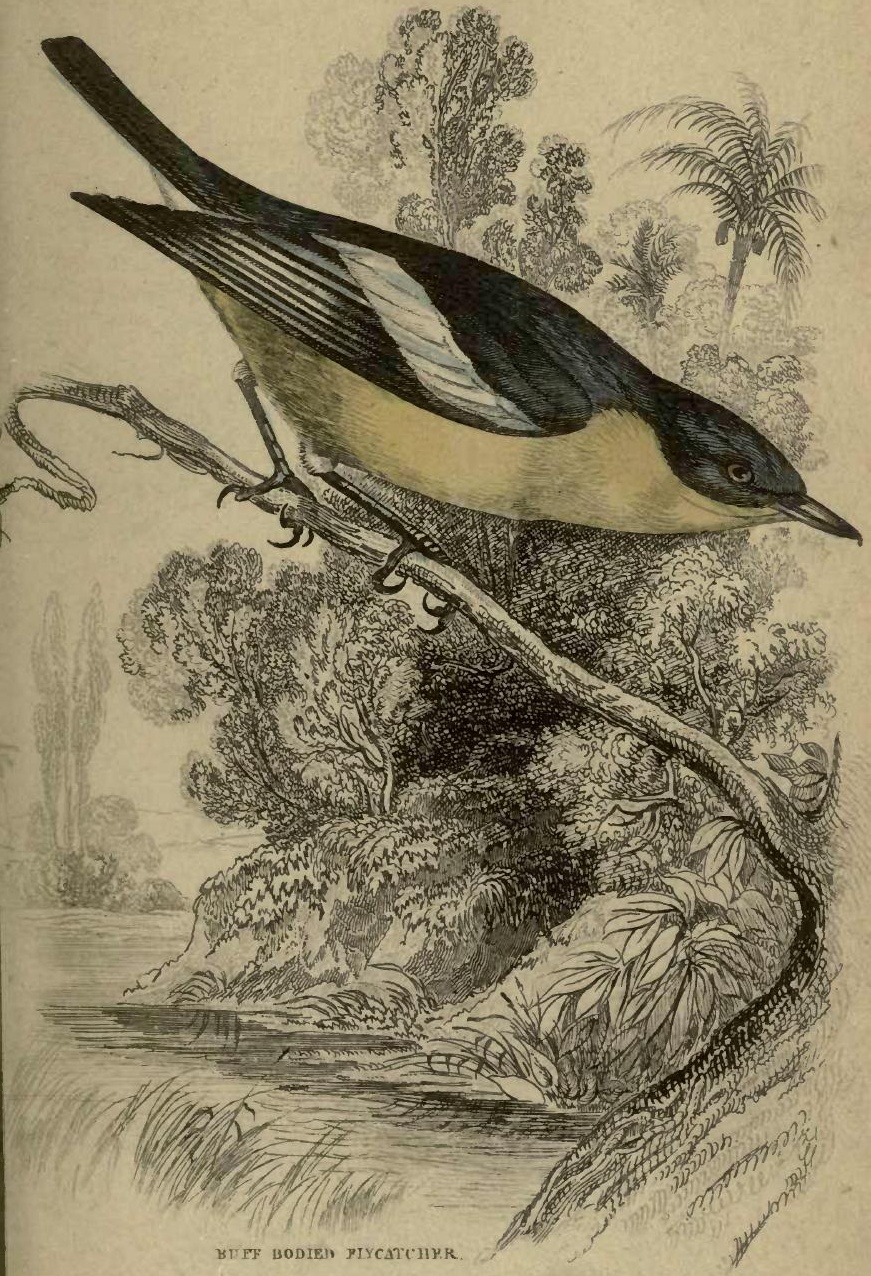



We have now traversed the whole of that great circle which is composed of the sub-family Muscicapince. We commenced with the genus Rhipidura, and then proceeded successively through those of Monacha, Megalophus, Todus, and Muscicapa, dwelling upon all the minor circles they contained, and pointing out the graduated chain of connexion between each. We have endeavoured to demonstrate the truth of our propositions at every step by as refined a species of analysis as we possibly could make. But our task in regard to this great circle is not yet done; for we have not yet shown in what manner the Muscicapina, as a whole, actually form a circle. We entered it at one point, which was Rhipidura, and having traced it as far as Muscicapa, it yet remains to be proved that these two groups unite, so that the circle is actually formed, and that the series returns into itself. We are, in other words, to return by a different route to the point from whence we started : this point was the genus Rhipidura. The question then is, in what manner is this genus united to Muscicapa? How is the junction made, and the circle closed? We will leave this to the observation of the reader with little or no comment. Let him turn to the description and figure of our Myadestes genibarbis, then look upon that of Muscicapa erythaca, and he will at once perceive no two birds of two connecting genera can be more closely allied : their very aspr.et alone bespeaks their connexion. The only doubt that remains on our mind is, whether the latter is not in reality a second species of Myadestes! rather 
than a Muscicapa; while, but for its tail, M. genibarbis might be classed as a flycatcher. In either case the affinity is too palpable to require comment.-And thus do we think that the great circle of the Muscicapina is closed.

Concentrating the results of that analysis we have now gone through of the two typical circles of the Muscicapidoe, we shall find that their contents mutually represent each other in the following manner :

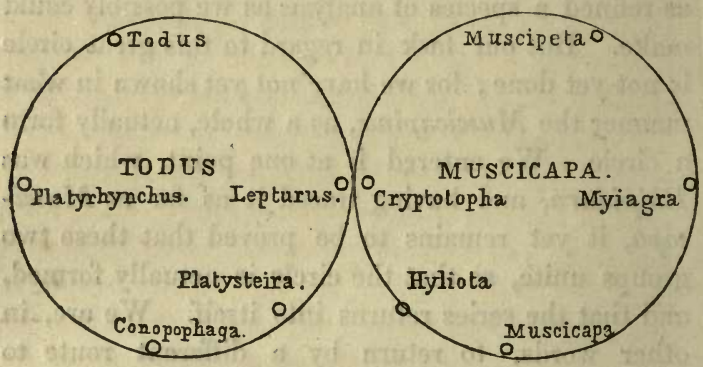

While the analogies of the sub-genera may be thus briefly recapitulated.-

Genus Todus, . Sub-genera.

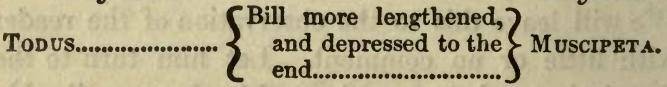

Platyraynchus.........Bill shorter, very broad.... Mrïagra.

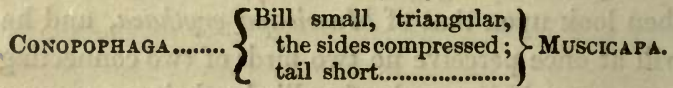

Pratrsteira .......... $\left\{\begin{array}{c}\text { Bill lengthened; tail } \\ \text { short, broad, even.... }\end{array}\right\}$ Hyliota.

LETPTUR US................... $\left\{\begin{array}{c}\text { Bill triangular, the sides } \\ \text { compressed; tail slen- } \\ \text { der, the tips pointed. }\end{array}\right\}$ CRYPTOLOPHA. 
Let us, in conclusion, offer a few remarks on the more general results which the preceding investigation tends to establish, while the facts are as yet fresh on the memory. 1. We perceive that all natural sub-genera, as such, imitate, as it were, or represent one or other of the primary forms of nature, and that their variation is regulated by the same order of succession. The rasorial forms, for instance, is followed by the tenuirostral; and this, again, by the fissirostral. 2. That this law of variation is the same, also, which regulates the variation of the species: one example of this we have already given in a sub-genus of quadrupeds, and in the sub-genus of Todus we have a second example in the class of birds. Lastly, we perceive that the rank of any one of these types can only be known by analysis; and then only when our materials are very ample. Hence arises the uncertainty respecting the rank of every type; because, without the most refined analysis, it is impossible to determine whether a bird is a specific or a sub-generic type of form. Let us now proceed to the fifth and last group of this family. The

\section{EURYLAMIN死, OR BROADBILLS,}

as before observed, constitute one of the primary divisions of this family. They are a most remarkable group of birds, whether we regard their appearance, or the extreme interest which attaches to 
their scientific elucidation. The different groups of flycatchers we have hitherto noticed have been small, delicate-shaped birds, seldom equalling the size of the robin, and generally smaller than a wren; but those we are now come to are of a very different character. Their average size is nearly that of a starling or small thrush. Their shape is thick and robust, and their head and bill enormously large; their whole aspect, in short, at the first glance, is so different from any other group, that the most unpractised eye would detect, without at first comprehending, their striking difference from all other birds. So far, therefore, we shall find this peculiarity of character a circumstance highly favourable for the investigation of their affinities, because it removes those difficulties which impeded the complete illustration of the intricate groups just noticed. And yet, notwithstanding this great dissimilarity in general appearance between the ordinary flycatchers and these birds, a more attentive examination of their structure proves them to be but a race of the same family, essentially possessing the same general structure, yet with some parts enlarged and others reduced; modifications, in short, which obviously indicate peculiar manners, and which tend to exhibit, at the same tıme, a higher developement of the fissirostral type than any we have yet noticed. All the species jet discovered have been found in Tropical Asia, where they represent, in the same latitudes, the todies of the New World. Linnæus and his followers, indeed, placed both in the same 
genus; but Dr. Horsficld, who discovered one species in Java, since distinguished by his name, charasterized it as belonging to a distinct group. Unfortunately he was not able to give any account of its manners, further than that it was found in "one of the most distant and inaccessible parts of Java, covered with extensive forests, and abounding with rivers and marshes." But Sir Stamford Raffles, speaking of another species, observes, "it frequents the banks of rivers and lakes, feeding on insects and worms. It builds its nest pendant from the branches of a tree or bush which overhangs the water." We have thus two witnesses to the fact of two species of these birds habitually living in the vicinity of water.

The preceding observations renders it almost unnecessary to state the more minute peculiarities in which these remarkable birds differ from all the other flycatchers; yet some of them deserve particular attention, as establishing their collateral affinities. The bill, notwithstanding its excessive breadth, is by no means so very much flattened as what we see in Muscicapa; for the culmen is sufficiently elevated to form a regular curve, while the tip is almost as abruptly hooked as that of a raptorial type, although the notch is very smali; the lateral margins of the upper mandible are very much curved, and so much dilated as to fold over and completely hide those of the lower mandible, more especially at the angle of the mouth. The rictal bristles are comparatively very short, and do 
not protect the nostrils, whose situation and form is various in the subordinate types. The feet cannot be termed small or delicate, yet they are obviously of a weak construction, and adapted only for sedentary habits; their colour is always pale, and their structure completely syndactyle; the hind toe is proportionably very long, and equals the length of the tarsus, which latter is often without any posterior or lateral scales. Now there is no example of a foot, so constructed, in all the other genera of this family, except Megalophus, which, in like manner, has a large portion of the tarsus equally naked; while the proportionate length of all the claws is the same in both. Megalophus, in short, is the connecting link between the Eurylaimince and the Muscicapina; and we may now proceed to consider the former more in detail.

That natural groups, of the same rank, are very ofren vastly disproportionate in their extent, has been frequently observed; and upon another occasion we have attempted to show, that such numerical disproportion is absolutely essential to the harmony and consistency of the creation*. Now the group before us is another striking example of this inequality. Were it an imperfect circle, and were we unacquainted with those forms which connect it on both sides to other types, strong doubts might be reasonably entertained if a group, containing so few species, really represented a sub-family, and deserved to be placed in the same rank with the * Classification of Animals, p. 247. 
Muscicapince and the Fluvicolinoe. But this diffculty we are now about to remove. It has happened. most fortunately for our present purpose, that the industry of modern naturalists have transmitted to Europe, from different and remote localities, every one of those which we consider the primary types of the Eurylamidae; so that we shall now venture, after patiently waiting several years for this event, to submit to the public our elucidation of the whole group. All the species yet discovered of this subfamily we accordingly arrange under one or other of the following divisions, which we shall distinguish as Cymbirhynchus, Eurylaimus, Serilophus, Psarisoma, and Platystoma. It will subsequently appear that these are types of genera, and we shall now give the distinguishing characters of each in detail. The genus, named by Mr. Vigors,

\section{CYMBIRHYNCHUS,}

is represented by the Todus nasutus of the old ornithologists, and it differs in several remarkable particulars from all its congeners. The bill is not only broad but high, so that when viewed in profile it seems to belong to a conirostral bird; the under mandible is consequently strong, and almost as 
deep as the upper, the gonyx taking an angulated ascending curve; the rictus is defended by three or four long bristles; the bill is not only powerful in its general character, but it has, something like that of the toucans, a thickened margin. Another peculiarity is to be found in the nostrils, which are perfectly naked, and situated towards the middle of the bill; the aperture is oval, and without any rim or membrane; the tail, although graduated, is of the average length of ordinary birds ; but, in other respects, the structure accords with the remaining species. 


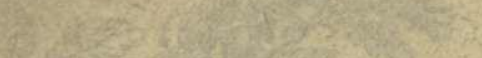

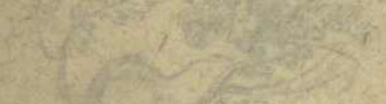


236

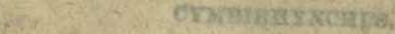

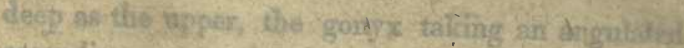
escending curve : the rictus is defonded by slive $x$

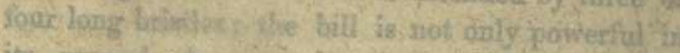

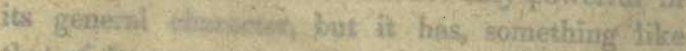

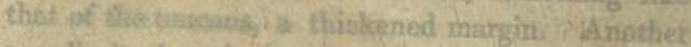
pevaluarty if to be foumd in the nostrilo, which aro perfect.y saked, and sifuated townrits the middle of the bill; the aperture is ovsh, and without ainyonvin or puerabrave; the tail, although graduated is of the average length of ordthary birds; but im edtiet respects, the structure pocourds with the romaining apeciens: 
REESE LIBRA PP

UNIVERSITY

CALIFORNIA. 


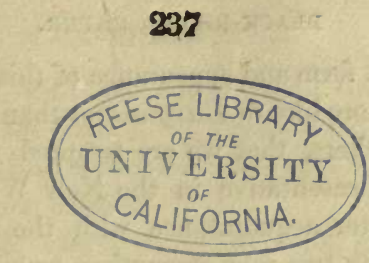

B! $\triangle A C K-B I L I, E D$ GAPER,

Cymbirhynchus nasusus, Vyorescic.

PLATE XXIX.

Upper parts, with the chin and pectoral collar, black; boneath, dark red; scapuiars narrow and white.

Todus nasutus, Latham, Index Orn. i. p. 268 ; Gmelin, i. p. 446.-Great-billed Tody, Lath. Gen. Syn. ii. 664, jl. 30. (fig. pass.); Gen. Hist. iv. 94, pl. 45, (fir. med.)-Cymbirhynchus nasutus, Vigors.-Eurylaimus nasutus, Tem. Pl. Col. 154.-Erolla nasica, Lesson. Tr. d'Orr. 260.

Under the name of Todus nasutus, this remarkable bird, although by no means frequent in our collections, was well known to the old ornithologists, as will appear from the various synonymes we can, in this instance at least, quote with safety. As it is at present the only representative of its genus, there is no occasion to go into a particular account of its structure. We may observe, however, that the deep red feathers of the throat and breast, like those of some of this group, are precisely of the same rigid and glossy structure as those on the throat of Querula rubricollis: and 
the general form and appearance of this latter bird is so much more like to Eurylaimus than to the rest of the Flycatchers, that we are tempted to believe it is their representative in the New World. Whether a better acquaintance with the natural economy of the two may strengthen or annul this opinion, must at present remain uncertain; but the experienced ornithologist cannot fail to remark the near approach of the Eurylaimina, in general, to the American bird, which, in our estimation, is as nearly connected, on the one hand, to this group, as it is, on the other, to Psaris. In this manner do we consider that the great circle of the entire family of Muscicapidae is closed, and returns into itself.

Our specific character, aided by the annexed figure, precludes the necessity of a lengthened description. The pure white upon the scapulars forms a long, slender, and well defined stripe, the feathers themselves being lanceolate; with this exception, and the crimson rump and tail-covers, all the upper plumage is a deep black, glossed with obscure green; the wings, tail, chin, and band just above the breast, are likewise of this colour; the latter patches of black leaves a transverse band of dark crimson on the throat, which also covers the ears, and the whole of the under plumage, from the breast downwards; the edge of the shoulders, or carpus, is orange ; the three shortest tail-feathers have an oblong white spot, placed obliquely, near the tip of the inner webs; the bill 
is blue-black, with the edges pale; the feet are also pale. The female, or young bird, is distinguished by having a fulvous-white spot at the tip of each of the wing-covers.

Total length, exactly 9 inches; bill, gape, $1 \frac{1}{10}$; front, $\frac{2}{10}$; wings, 4 ; tail beyond, $2 \frac{2}{10}$; base, 4 ; tarsus, $\frac{3}{4}$.

The next form is that to which we retain $\mathrm{Dr}$. Horsfield's original name of

\section{EURYLAIMUS.}

Here we have the bill more flattened, particularly the under mandible, the gonys of which is nearly straight; the nostrils are placed close to the front of the head, and are surrounded with a narrow membrane. The rictal bristles, which are so conspicuous in the last genus, are here very short and weak, and the dilated base of the under mandible very remarkable. The Eurylaimus Horsfieldii and Sumatranus* belong to this genus, and there are probably other species. In the last named bird, the dilation of the bill is so great that it actually

* The new names which M. Temminck, and some other Continental writers, have attempted to affix to the species originally lescribed by Sir Stamford Raffles, we cannot, in Justice, adopt. 
exceeds the breadth of the head, broad as it is ; and in the Paris specimen, the margin has an appearance of being obscurely and irregularly crenated. In this bird, also, the rictus is quite smooth; so that it is more typical than Horsfieldii. . The tail in this group is rather short; although this, of course, is variable.

\section{HORSFIELD'S GAPER.}

\section{Eurylaimus Horsfieldii, TEMмINCK.}

\section{PLATE XXX.}

Body above black; the scapulars and middle of the back striped with bright yellow; under plumage vinaceous, tinged with cinereous on the throat; above the breast a narrow brown bar; head cinereous-brown, with an incumbent erest.

Eurylaimus Javanicus, Horsf. Lin. Tr.: Kesearches in Java.E. Horsfieldii, Ten. Pl. Col. 130, 131.

Dr. Horsfield was the first zoologist who defined the present genus; and this species, which he proposed to call Javanicus, has since been justly distinguished by his name. It retains much of the character of Cymbirlynchus in its general structure, in the glossy nature of its feathers, and even in its colours ; but the tail is much shorter, and the bill,' although equally large and broad, is much nore 

excende whe brearlth of the head, broad as it is in the Posie fospoiaxen, the margin has atr ap

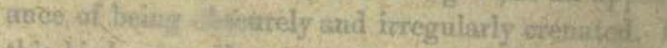

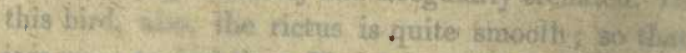

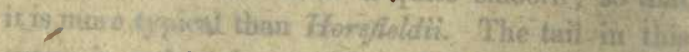

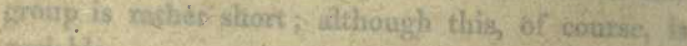
mistabit.

MgRsFitú's GAPRK.

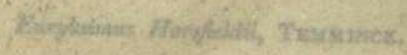
29.

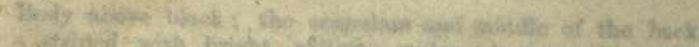

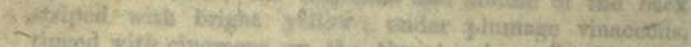

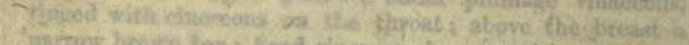

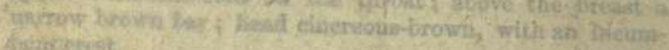
Sighrickist.

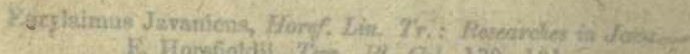

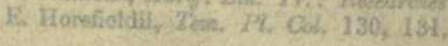

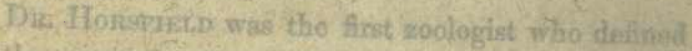
the present gerus $y$, and this opecies, which he proposed to call Jowanicing, thas sinoe been Jnstly distrignaished by bis name. It rotains tanch of the

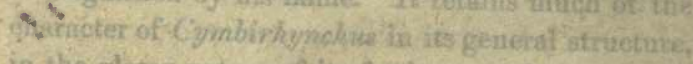
in the glossy nature of its feathers, and oven his its colours; but the taik is mnch shorter, and the bill,

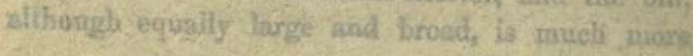




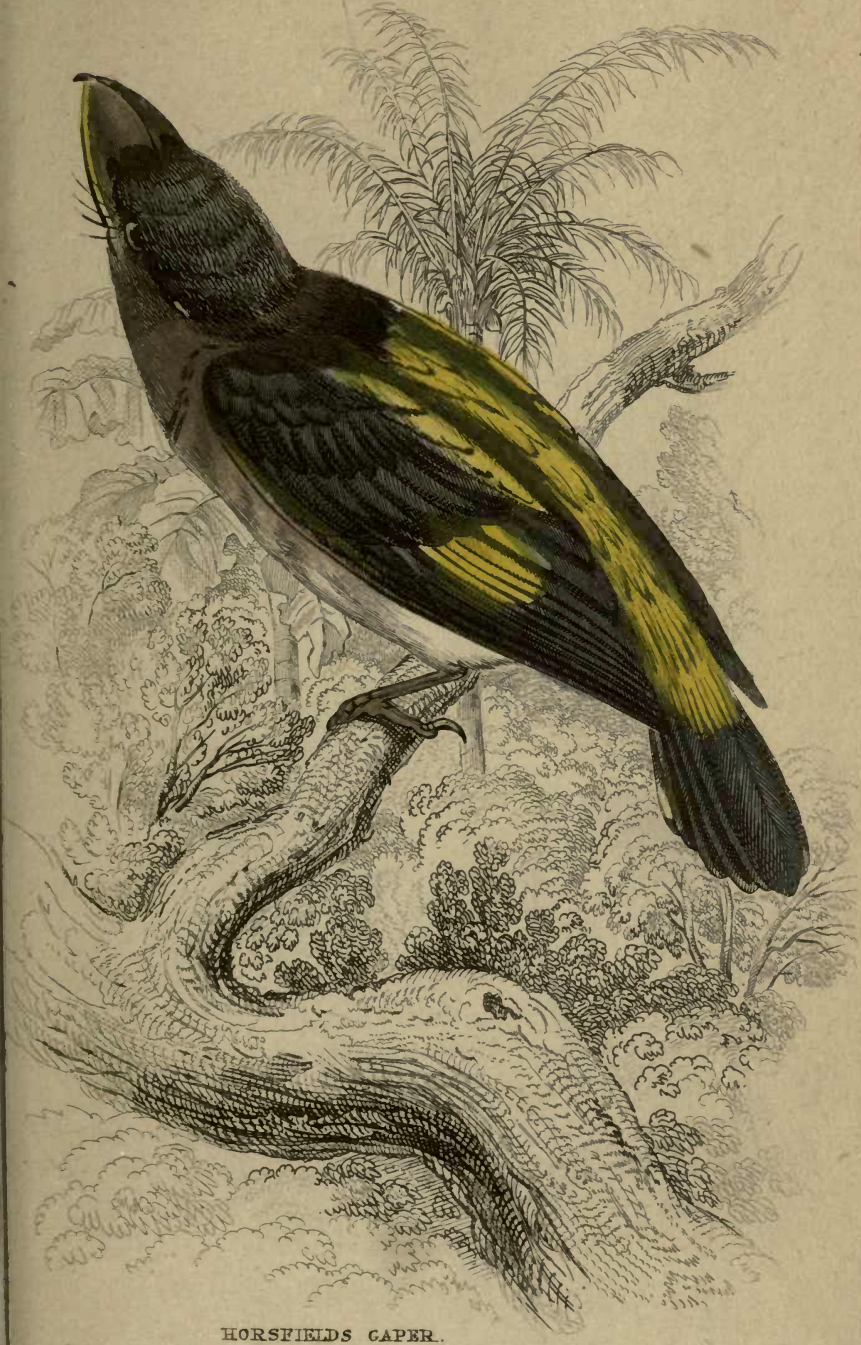




$$
\text { REESE LIBRARY }
$$

$$
\text { UNIVERSITY }
$$

CALIFORNIA. 
flattened, as well as dilated at the gape; the colouring of the head and neck is very peculiar. and is so mixed and blended as not to admit of an easy definition. The top and sides of the head are of a chestnut-black, graduating into a shade of cinereous on the nape, and of vinaceous-red on the ears and sides of the throat; this changes to dark brown on the lower part of the neck above, and then into deep black, which is the ground colour of the remaining upper plumage; on the scapulars, and down the middle of the back, is a broad stripe of bright and pure yellow; the base of the feathers, and edges of the same, being black; a band of yellow is also on the middle of the lesser quills, and a very small one, much paler, at the base of the primaries; the edges of the wings, and the under wing-covers, are also pale yellow; the under parts are dull vinaceousred, becoming nearly cinereous on the chin and throat, which are like the ears; across this, and just above the breast, is a narrow band of dark brown; the under tail-covers are dingy yellow, and the thighs brown. The tail is black; all the feathers, except the middle pair, having a transverse white band before their tips; bill vinaceous brown, part of the culmen and the margins being yellow; the legs are pale, and probably flesh-coloured.

Total length, 8 inches; bill, gape, $1 \frac{4}{10}$; front. $\mathrm{I}^{7}$; wings, 4 ; tail beyond, $1 \frac{1}{10}$; base, $2 \frac{1}{2}$; tarsus, $\frac{\delta}{10}$.

The next type* we have named

- Eurylaimus lunatus. Gould. Zool. Trans. i. 75, pl. 25. 


\section{SERILOPHUS;}

it is represented by that beautiful and interesting bird, the Serilophus lunatus, recently discovered near Rangoon, where several of them were shot by Major Godfrey. Here, again, although the information on its manners and habits is very concise, it is peculiarly applicable to our purpose. Major Godfrey observes, "that it inhabits the thickest jungles, and that its food was found, upor minute investigation, to consist entirely of berries and fruits*." The generic and typical peculiarities of this bird are peculiarly interesting. The first aspect, notwithstanding many dissimilarities, reminds the ornithologist of the true chatterers (Bombycilla), the plumage having the same silky gloss, and the head being surmounted, as in those birds, with a conspicuous, pointed, and pendant crest. The wings are very remarkable, uniting the two chief characters of the rasorial and of the fissirostral structure the first is manifested in the suddenly attenuated and pointed ends of the primary quills, almost precisely similar to those of some species of Fluvicola;

- Zool. Trans. i. 177. 
while the secondary quills, by their broad, truncated, and indented termination, give us the fissirostral character, so eminently developed in the Meropido and many other types. These peculiarities leave us in no doubt where to look for the analogies of Serilophus, and induces us to view it, by the preponderance of these characters, as the rasorial type.

The next in the natural series is our genus

\section{PSARISOMUS*,}

represented at present by a single species, and of which we can only speak from the figure and description published by Dr. Roylet.

We now come to the genus

* Class. of Birds, vol. ii. 261.

+ Since the above was written, and the Classification of Birds was published, a beautiful figure of this remarkable type has appeared in the Icones Avium of Mr. Gould, while the additional characters he mentions fully confirms the views we had taken of its relations. The bill, as Mr. Gould observes, is not only narrower than in the other types, but is even a little compressed; thus representing that form we should expect in the tenuirostral type, which is to represent Pachyrhynchus, Hyliota, Monacha, \&c. It seems impossible to look at this bird without being immediately reminded of Pachyceph. Cuvieri, and even of the Ptilonopus melanocephalus, Sw. (Pl. Enl. 214.) which is also a tenuirostral type. The Classification of Birds was published in May 1837, the Icones Avium, as stated on the covers, in the following August. We are at a loss, therefore, to discover why the new name of Crossodera was proposed, unless we suppose that Mr. Gould was ignorant of our prior denomination. 


\section{1}

\section{PLATYSTOMUS,}

which represents the fissirostral type of this most natural group; the only species yet known being the Eurylaimus Blainvilli of M.M. Garnot and Lesson. The unique specimen brought home by these naturalists was met with in New Guinea, and is now deposited in the Paris Museum, where we had the satisfaction of drawing and examining it some years ago. The ground colour of the whole plumage is a deep and glossy raven-black, with the rump and belly vermillion, and two conspicuous white spots, one on the ears and another on the nape; the wings are lengthened, the tail forked, and the feet small and feeble. It assumes, in fact, as much of the structure of a swallow as it can weii do, consistent with the preservation of its reai arinities. 

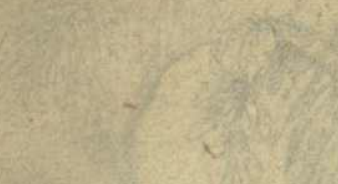

As.

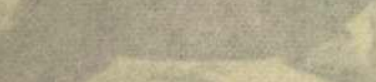
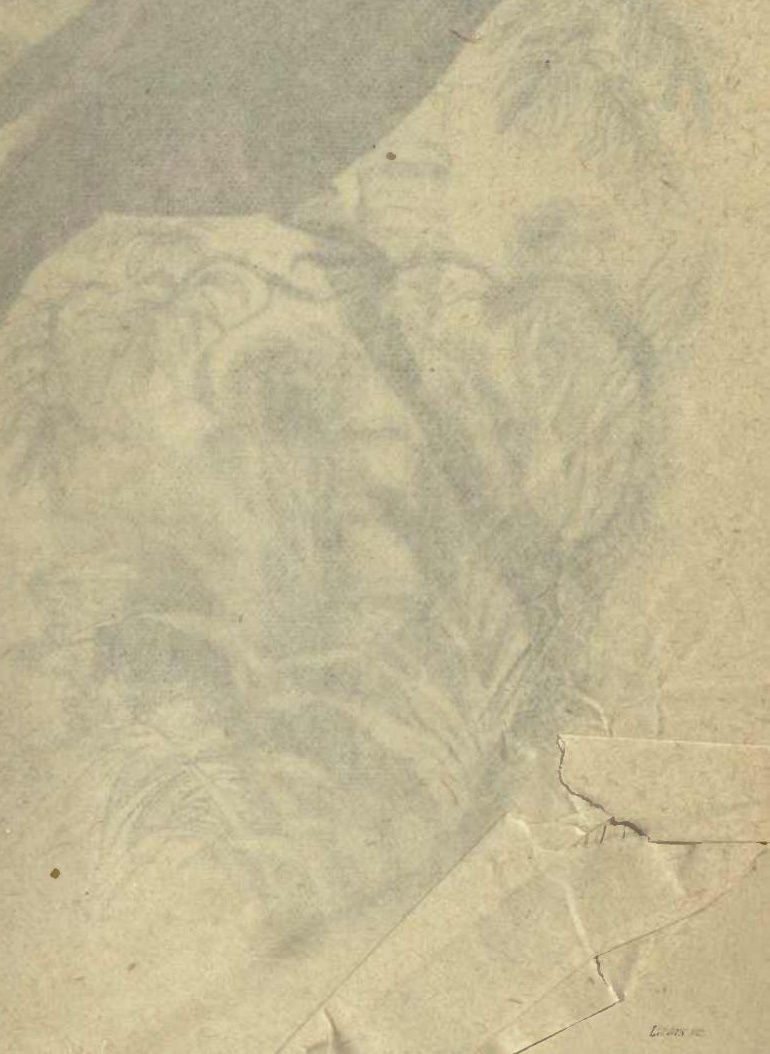


\section{8}

\section{PIATXSTOMU:}

which represents the fissirositral tyje of this most Whaturah group it the only species yet kibow being the Eurylaimue Blainpills of M.M. Garnots and Tesson. The unlinue specimen brought home by these nafuralists was met with in New. Guines, gad is now deposited is the Porsh Massank, wbere we had the hotisficotios of drankag and examinang is some years apo. The grousd colone of the y bitg

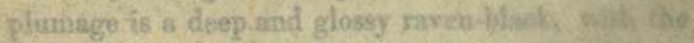
rump and befly renvalion, sat twe conspictooss White opobsy ptse us this ears and another on the napes sho wings sits lengthened, the tail forkes; and the feet smail and feeble. It assumes, la fich, as zarich of the structure of a swallow as it can treil do. corpistent with the preserration of ita realvisaives.

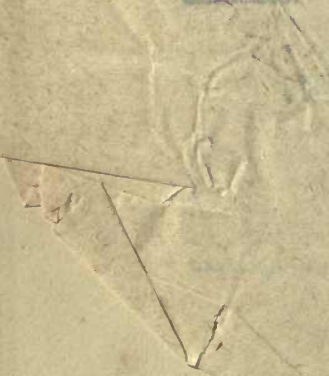




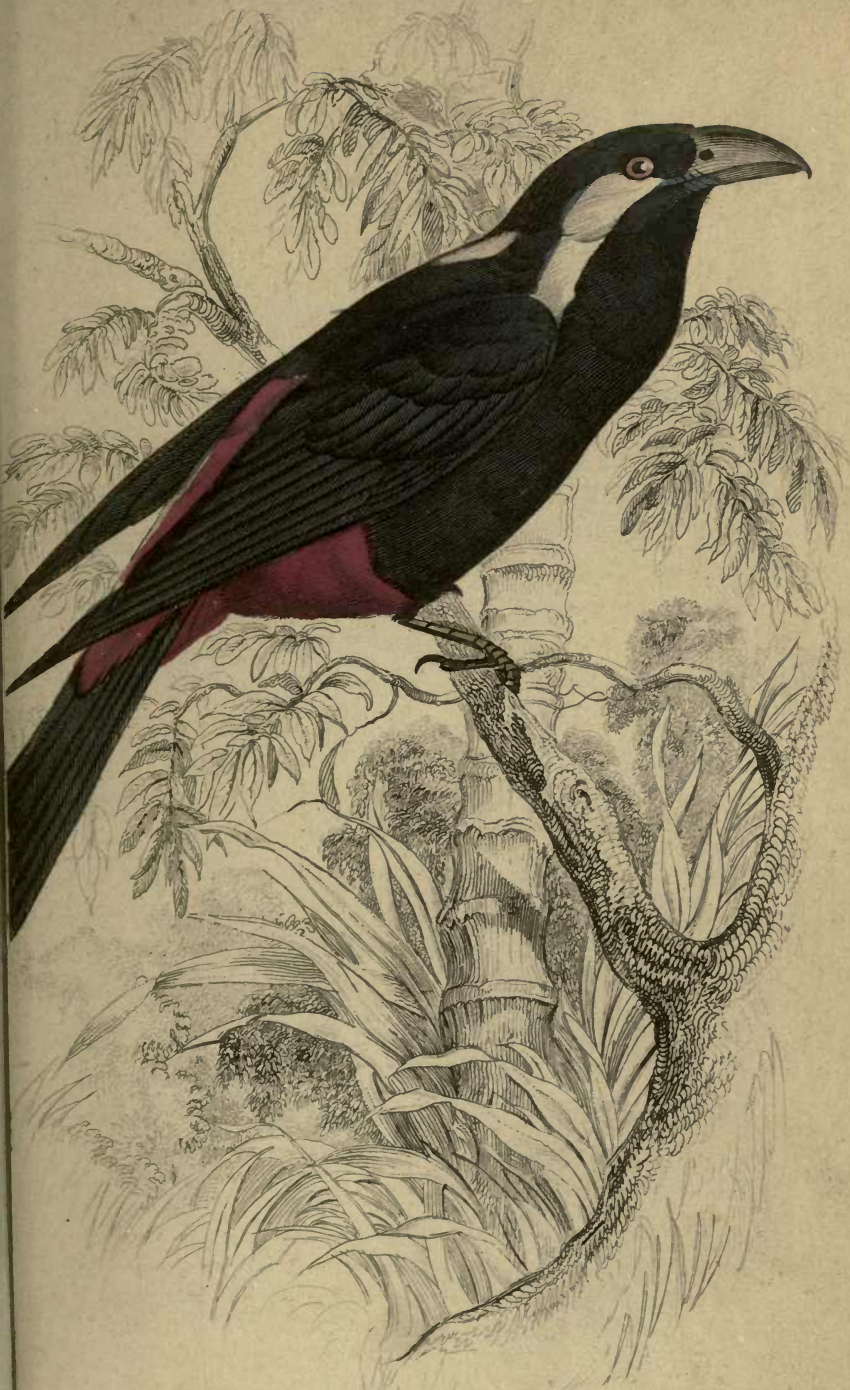




$$
\begin{aligned}
& \text { REESE LIBRAAP } \\
& \text { UN THE } \\
& \text { UNIVERITY ORIT } \\
& \text { CALIFORNIA. }
\end{aligned}
$$




\section{FORK-TAILED GAPER.}

Platystumus Blainvillii, Swarns.

PLATE XXXI.

Glosey blue-black ; stripe on the ears, and spot on the nape, white; runp, vent, and tail-covers, crimson; tail forked.

Furylaimus Blainvillii, Garnot, Zool. Coquille, P1. 19.-Erolla Blainvillii, Lesson. Trait. d'Orn. 260.-Platystomus Blainvillii, Sw. Class. of Birds, ii. p. 261.

THE structure of this exceedingly rare bird has already been fully explained in another place*, and its affinities and analogies have just been glanced at. The annexed figure and description are both taken from the only specimen as yet known, now in the Paris Museum, and discovered by M. Garnot in the Island of New Guinea.

The general ground colour of the entire plumaze. both above and beneath, is deep and uniform black, glossed with blue, particularly on the head and breast. A broad white stripe begins at the gape, covers the ears, and terminates beyond, on each side of the neck; a similar patch, but smaller, is between the nape and the interscapulars; from the lower part of the back to the upper tail-covers, the

* Class. of Birds, ii. p. 261. 
colour is bright but dark crimson, while the belly and under tail-covers are the same; the wings are lengthened and reach to half the length of the tail, the latter being slightly forked; the thighs are black, and the bill and feet blackish-brown.

Total length, about 7 inches; bill, gape, 1 ; front, $1^{7} \frac{7}{0}$; wings, $3 \frac{1}{2}$; tail beyond, $1 \frac{1}{10}$; depth of the fork, $\frac{3}{10}$; tarsus, $\frac{1}{2}$.

We have now described the last type of form, which, to establish the circularity of the Eurylaiminoe, should not only represent one of the primary types of Nature, but also show a disposition to unite with Cymbirhynchus, which was our first type. Now this is a demonstration which can very rarely be made good where the species, as in the present instance, are very few. But here, again, we hope to determine not only the primary types of the Eurylaimina, but of proving their circularity. The genus $C y m b i r h y n c h u s$, it will be remembered, differs from all the others we have noticed in one very peculiar character,-the base of the bill being marked by a thickened rim. Now this is precisely one of the characters of the type before us; and these two birds are the only instances in the group of the rictus being strongly bristled. If any other evidence was necessary to show this union, it may be drawn from the fact of M. Lesson having actually brought Cymbirkynchus and Platystomus into one genus, distinct from the other Eurylaimina, which he names 
Erolla. The circle is thus closed ; the series follow each other in the usual order; and we have the foliowing beautiful illustration of the primary types of the ornithological circle.

BURYLAIMIN F, THE BROAD-BILLS.

Genera.

Primary Types of Nature.

EURruaimus...........Bill excessively dilated........TYPICAL.

CYMBIR HYNCHUS...Bill more conical .....................SUB-TYPICAL.

Platystom Us....... Wings long, tail forked........Fissirostral. Psarisomus............Mouth or bill very small.....TenUirostral. SRRILOPHUS............ Head crested, quills pointed.RASORIAL.

If we consider the Eurylaiminae as constituting the sub-typical division of the family of Muscicapida, it will of course follow that Eurylaimus, as cxhibiting the most depressed and the strongest hooked bill, is the type of its own circle. This is further proved by Platystomus, which is the fissirostral type, evincing such an immediate connexion to Cymbirhynchus, which must consequently be the subtypical form, these two types always following each other. We find, in confirmation of this law, that the Dentirostres follow the Fissirostres in the tribes of the Insessores, and the Raptores follow the $\mathrm{Na}$ tatores in the orders of the whole class. Eurylaimus being therefore the type, represents the insessores, and Cymbirhynchus is the sub-typical; the other genera speak for themselves. For although we know little of Psarisoma, and therefore cannot establish its direct analogies to the Tenuirostres, it 
has confessedly the smallest mouth and bill of the whole group.

If, again, we compare the above five genera with the primary divisions of the family, another harmonious series of relations come to light.

Sub-families of the Muscicapida. CHARACTERS.

Genera of

ANALOGICAL Eurylaimina.

Typical.........Muscicapinæ.... $\left\{\begin{array}{l}\text { Bill exces- } \\ \text { sively broad } \\ \text { and flat........ }\end{array}\right\}$ Eurylaimus.

Sub-typical..Eurylaiminæ.... $\left\{\begin{array}{c}\text { Bill more con- } \\ \text { vex................ }\end{array}\right\}$ Cymbirhynchus. Aberrant..... $\left\{\begin{array}{l}\text { Querulinæ..... }\left\{\begin{array}{l}\text { Wingslength- } \\ \text { ened, feet } \\ \text { small ........... }\end{array}\right\} \text { Platystomus. } \\ \text { Psarianæ....... }\left\{\begin{array}{l}\text { Sides of the } \\ \text { bill slightly } \\ \text { compressed.. }\end{array}\right. \\ \text { Fluvicolinæ... }\left\{\begin{array}{l}\text { Wings with } \\ \text { abruptly } \\ \text { pointed quills }\end{array}\right.\end{array}\right\}$ Serilophus.

In order to understand why the genus Cymbirhynchus stands opposite the Eurylaimino, we must remember that it is Eurylaimus which is the preeminent type of its own particular circle ; and that, consequently, Cymbirhynchus becomes the subtypical genus. Platystomus and Querula agree, not only in the general cast of their plumage, but actually in the structure of their lengthened wings, the proportion of their quill-feathers, and in their unusually small feet. It is, in short, by the approximation of these two forms, that the circle of the entire family becomes manifest. Psarisomus is an evident representation of the Psarianos, and 
seems to have put on the very plumage of Pachyrhynchus Cuvierii; while Serilophus, in like manner, appears to have borrowed the pointed quills and broad secondaries of the Fluvicolinos. Thus the great dissimilarity between the types of the Eurylaimina, which, under a confined view, appears altogether anomalous, may be accounted for on the most simple principles ; namely, that besides being bound together by some prominent and general characters, they are also intended to teach us what are their immediate allies, and the nature of the five great divisions of the whole family.

Lastly, by comparing the two typical divisions of the whole family with each other, we shall not only have a clearer exposition of each, but we shall see at a glance the relations which each circle, in its genere, bears to the other.

SUB-FAMILY MUSCICAPINA.

Todus.

Megalophus.

Muscicapa.

Monacha.

Rhipidura.
SUB-FAMILY KURYLAIMINE.

Eurylaimus.

Serilophus.

Cymbirhynchus.

Psarisomus.

Platystomus.

Todus and Eurylaimus agree in having the rictus but slightly, or not at all, bristled; while in Muscicapa and Cymbirinynchus these bristles are rery long. Megalophus and Serilophus are the rasorial types of their respective circles, and both are remarkable for their beautiful crests. Monacha and Psarisomus represent each other through the medium of the Psariana; while the tail is conspicuously developed, although in different ways, both in 
Rhipidura and Platystomus. In this manner we might test these two circles through the whole class of ornithology, and gain the same results; for as every natural group is but a representation, under different modifications, of the five primary types of Nature, it follows, that if they agree with one, they will agree with all. In regard to the aberrant subfamilies, represented by the genus Querula, Psaris, and Fluvicola, the circles, though imperfect, are proved to be natural, for they have their representations in the two we have been comparing; and, therefore, if they belong to this family at all,- and this cannot admit of a doubt,-they will follow each other in the order we have placed them : and this point, also, has been established by the preceding analysis. Before the discovery of Platystomus, the affinity of Queru'a to the Eurylaimina might have been doubtful; but it seems to be no longer so. And, setting aside all other considerations, these two birds alone agree in the curved form of the commissure; while the Pachyrhynchus pectoralis connects Querula, on the other side, to the great series of the Muscicapidoe, through Psariance and Fluvicolinoe. Future discoveries will no doubt fill up the smaller links, and probably alter some of the location of the types; but, until that period arrives, we know not any fact or argument sufficiently strong to induce us to suspect the general principles of the arrangement of the family to which this volume of the Naturalist's Library has been devoted. 


\section{APPENDIX.}

Synopsis of Species, apparently new, alluded and referrea ro in this Volume.

\section{Muscicapa ruficauda.}

Grey-brown above; cinereous-white beneath ; eyes encircled with a white ring; tail rounded, fulvous-browu.

Inhabits India. Total length, 6 inches; bill, gape, $1^{7} \frac{7}{0}$; front, $\frac{1}{2}$; wings, $2 \frac{3}{4}$; tail beyond, $1 \frac{1}{2}$; base, $2 \frac{1}{2}$; tarsus hardly $\frac{6}{10}$. The colouring of this specimen is obscure and somewhat peculiar, so as to excite the suspicion of its being a young bird, or female; but its general structure does not agree with any other we have hitherto seen. The head is cinereous grey, brighter on the sides, and graduating from the neck into a fulvous-brown, which deepens, again, into ferrugineous on the tail ; the wings are like the back; the fore parts of the throat and breast are pale cinereous, which becomes white on the middle of the belly; under tail-covers pale fulvous; the tail is slightly rounded; 
the tarsi are very short, but the toes large and strong. The form of the bill, its stoutness, and compressed sides, accords with that of the Mus. rubecola; and both offer a miniature resemblance to the genus Tephrodornis among the Laniadoe; the bill, in fact, is shrike-like; the first joint of the outer toe is free, and the inner one is slightly ; shorter.

\section{Muscicapa thalassina.}

Entirely greenish-blue; beneath paler; lores grey; fourth quill the longest; tail even; wings three inches long.

Inhabits India. Total length, 6 inches; bill, gape, $\frac{6}{10}$; front, $\frac{3}{10}$; wings, 3 ; tail beyond, $1 \frac{1}{2}$; base, $2 \frac{1}{2}$; tarsus, $\frac{6}{10}$. General size and structure of the last, except in the bill, which, although small, has the short and dilated form, typical of Myïagra, to which it obviously leads, although it retains the short and stout feet of $M$. ruficauda. This species closely resembles the Mus. melanops of Nepaul in its size, and much in its colour; but it has not the same changeable tints : the lores are not velvetblack, and the wings only measure 3 , instead of $3 \frac{3}{10}$. This difference of colour, slight as it may appear, is very observable when the two species are compared; the fourth quill is the longest. 


\section{Muscicapa latirostris.}

Grey above; white beneath; head not striped; bill short and broad; wings two inches and three-quarters long; the third and fourth quills equal and longest.

Inhabits India. Mus. Nost. Total length, 5 inches; bill, gape, $\frac{1}{2} \frac{3}{0}$; front, $\frac{4}{10}$; wings, $2 \frac{3}{4}$; tail beyond, $\frac{3}{4}$; base, 2 ; tarsus, $\frac{1}{2}$. Colour almost exactly the same as $M$. grisola, but smaller, and without any distinct stripes on the crown or under plumage, nor are the inner wing-covers tinged with fulvous; the bill is much shorter and considerably broader, and the second quill-feather is only as long as the sixth.

\section{Muscicapa lencura.}

Above fulvous-brown, immaculate; beneath whitish; tail rounded, black; the lateral feathers white at their basal half.

Inhabits India. Total length, $4 \frac{8}{4}$ inches; bill, gape, $1 \frac{1}{2}$; front, $\frac{4}{10}$; wings, $2 \frac{6}{10}$; tail beyond, $\frac{3}{4}$; base, 2 ; tarsus, $\frac{1}{2} \frac{5}{0}$. Smaller than latirostris, but of the same general structure, except in the bill, which is shaped like that of $M$. grisola, although its size is much smaller. The drab-brown of the back is very uniform, and equally spreads over the wings, the third, fourth, and fifth feathers of which are longest and nearly equal; lores whitish; und parts white, tinged with brown on the sides and 
breast, and with fulvous on the flanks; the under tail-covers and basal half of the lateral tail-feathers, are pure white; the outer half of the rest, and the whole of the middle feathers, are deep black; the middle and the outermost pair are rather shorter than the others. Bill and feet blackish.

\section{Muscicapa picata.}

Above grey; beneath white; wings and tail deep black ; the former with a white band at the base of the quills and on the margin of the tertials; second quill not much longer than the sixth.

Inhabits Western Africa. Total length, $5 \frac{1}{4}$ inches; bill, front, $\frac{7}{2}$; wings, 3 ; tail, beyond, 1 ; base, $2 \frac{1}{2}$; tarsus, $\frac{13}{2} \frac{3}{0}$. General structure, except in the wings, of $M$. albicollis, but the size is larger, and the bill rather narrower. The front has a very slender black line, and a whiter shade above it. The wings and covers are deep black, excepting those feathers nearest the body, which are grey; the white band which passes along the tertials extends to the edges of some of the greater wingcovers, while that which is at the base of the quills does not traverse the three outermost; the upper covers and the tail are deep black, the latter being very slightly forked; the under parts are white, tinged with grey on the breast. 


\section{Myiagra latirostris.}

Above, entirely dark glossy cinereous; ears and sides of the head the same; chin and throat rufous-orange; the rest of the under plumage white; bill short and very broad; tail rounded.

Todus rubicula? Lath. Supp. ii. 147.-Moucherette à gorge rousse, Paris Mus.

BiLL and legs brown; outer and middle toe connected as far as the first joint ; inner toe much the shortest; two outer tail-feathers very slightly tipt with white; plumage glossy slate colour; the throat, from the chin to the upper part of the breast, is coloured like that of the robin, beyond which the under plumage is pure white.

Total length, about $6 \frac{1}{4}$; bill, gape, $1_{1}^{7}$; front, $\frac{7}{8} 0$; wings, $2 \frac{6}{10}$; tail beyond, $2 \frac{2}{10}$; base, $2 \frac{\pi}{10}$.

\section{Myżagra flavipes.}

First very short, bright yellow ; plumage above, and on the throat and breast, deep black, glossed with greenish; body heneath white; head with a lengthened pointed crest.

Inhabits Senegal? Mus. Paris. Total length, 6 inches; bill, gape, 1 ; front, ${ }_{17}^{7}$; wings, $33_{10}^{\circ}$; tail beyond, $\frac{3}{10}$; tarsus, $\frac{4}{10}$. The general structure of this curious bird, as already intimated, is very peculiar; but, upon the whole, I am disposed to consider it the crested species of the sub-genus Myiagra, 
with which it agrees in its even tail : its bill, however, is that of Muscipeta, its long wings those of Muscicapa, while its excessively short feet are without parallel in this family. The upper plumage is of the darkest black, glossed with sea-green, and this colour extends in front of the throat so far as to cover the breast; the rest of the under plumage is white, varied with black on the flanks; the bill is unusually long and very flat; the tip abruptly hooked; the crown has a lengthened procumbent crest which ends in a point, and the tail is so short as hardly to exceed the wings. At the base of the primaries is a conspicuous white spot; bill and thighs black; feet bright yellow, stout; the claws strong, compressed, and deep black; anterior scales of the tarsi divided into irregular hexagons.

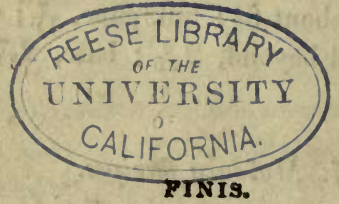






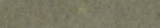

W.

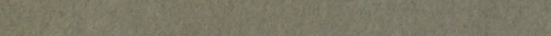

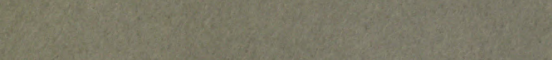
6.

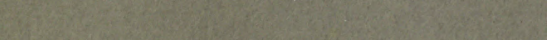

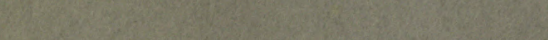
E

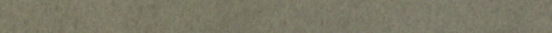

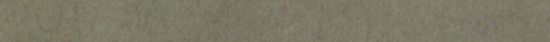

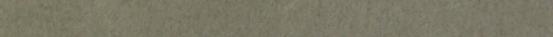
Whor

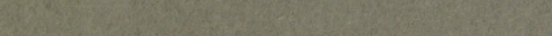
W.

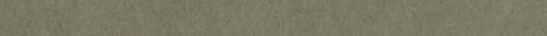
y.

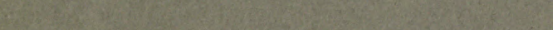
Nete E.

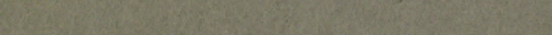

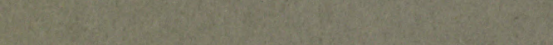
oth Wh w (2) Wentar. 6)

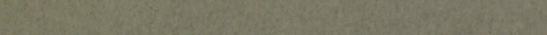
Ho.

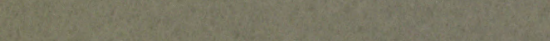

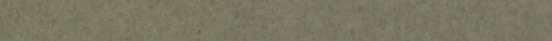

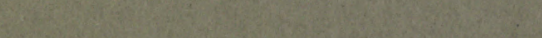

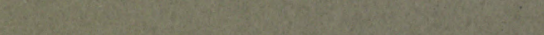
Ath W.

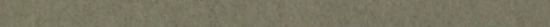

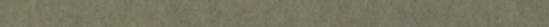

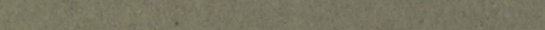

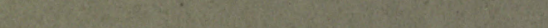

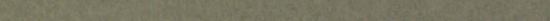

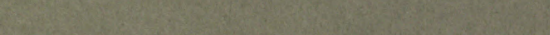
U. 3.5. 5 .

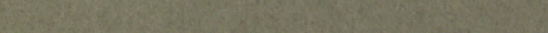

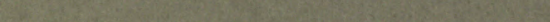




\section{Return to desk from which borr}

is book is DUE on the last date star

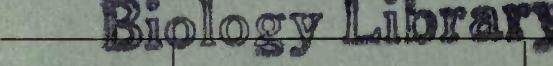

Y 291965

81971

TURNED TO 


$$
28663
$$


